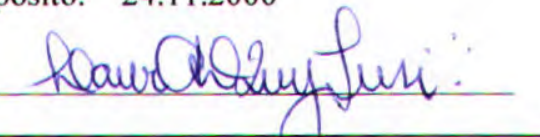

\title{
Dimensionamento de Lotes em Máquinas Paralelas com Restrições de Capacidade em Sistemas Multiestágios
}

\author{
Maristela Oliveira dos Santos \\ Orientador: Prof. Dr. Marcos Nereu Arenales \\ Co-orientador: Prof. Dr. Vinícius Amaral Armentano
}

Tese apresentada ao Instituto de Ciências Matemáticas e de Computação - ICMC-USP, como parte dos requisitos para obtenção do título de Doutor em Ciências de Computação e Matemática Computacional.

USP - São Carlos

Novembro de 2000 
A Deus.

A minha familia

e aos amigos sempre presentes. 


\section{Agradecimentos}

- A Marcos Nereu Arenales e Vinícius Amaral Armentano pela orientação, apoio e amizade durante o desenvolvimento deste trabalho.

- A Regina Esther Berretta pela amizade e ao grande apoio ao desenvolvimento desta pesquisa.

- Ao Prof. Dr. Jatinder Gupta pelo apoio durante o estágio na Ball State University, Muncie, Indiana, USA.

- Ao Prof. João Vitor Moccellin pelo estímulo a pesquisa.

- A Lilian, Luiz Fernando e Silvio pelo interesse, amizade e ajuda durante este trabalho.

- A Patrícia Teixeira pela presença e incentivo durante os momentos que mais precisei.

- A Fred Borges, Mary Shiraishi e Ana Paula Shiroma (amigos de longos anos).

- A Tatiana Sugeta e Marisa Back pela grande amizade.

- A Arzu Brumendi pelos momentos felizes em Muncie.

- Ao Mario Oleskovicz, Sadao, Ricardo Silveira e Cidinho pela presença em todos os momentos.

- Aos meus amigos Araxá, Lu de Maringá, Valéria (Maringá), Lu Martinez, Lu Grossi, Elisangela Meza, Heloisa, Thiago, Wellington, Maju, Cris Cris, Rubia, Juliana, Ro Ballini, Janaina \& Zé, Valéria, Robinson, Claudia Satake, Nildinha, Chandler, Will, Enzo, Cláudia \& Walter, Renato, Gedson, Kattiana, Fábio Melfi, Ju, Gisele, Selma, Claudinha, Rudi, Dani e Taboca por todos os momentos de descontração e conversas nada a ver com trabalho.

- A turminha da elétrica: Edmárcio, João Bosco \& Meire, Arthur, Marcelo Cléo, Guilherme e Sereno pelo companheirismo.

- As secretárias Beth, Laura e Marília pela atenção, a todos professores do ICMC, as bibliotecárias pela disponibilidade e a todos funcionários de maneira geral.

- A FAPESP pelo suporte financeiro fundamental para a realização deste trabalho.

- Finalmente, agradeço a todos que ajudaram na elaboração deste trabalho. 


\section{Índice}

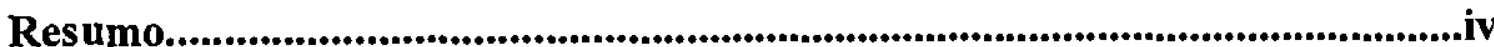

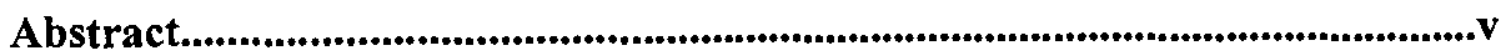

Capítulo $\hat{1}_{j}^{\prime}-$ Introdução......................................................................................1

Capítulo 2 - Revisão Bibliográfica................................................................5

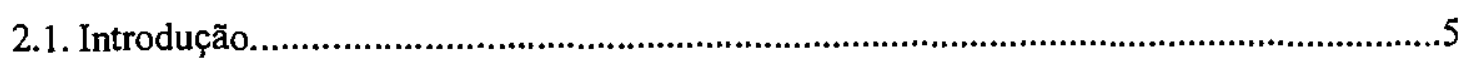

2.2. O Problema de Dimensionamento de lotes ................................................................

2.2.1. O Problema de Dimensionamento de Lotes Monoestágio....................................7

2.2.2. O Problema de Dimensionamento de Lotes Multiestágio..................................11

2.3. O Problema de Dimensionamento e Sequenciamento de Lotes..................................2 I

2.3.1. O Problema de Dimensionamento e Sequenciamento de Lotes

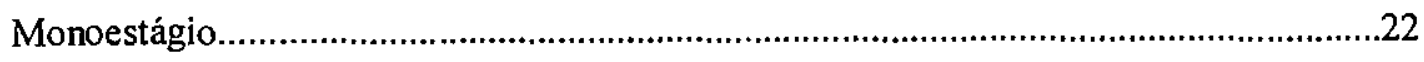

2.3.2. O Problema de Dimensionamento e Sequenciamento de Lotes Multiestágio........25

2.3.3. O Problema de Dimensionamento e Sequenciamento de Lotes (Macro Períodos)..26

Capítulo 3-- Dimensionamento de Lotes em Ambiente de Produção Multiestágio com Limitações de Capacidade e Máquinas Paralelas

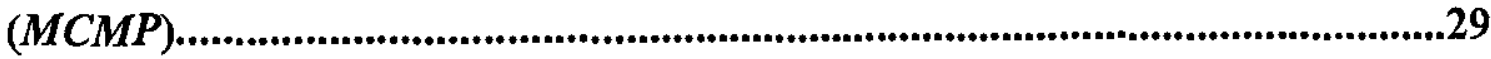

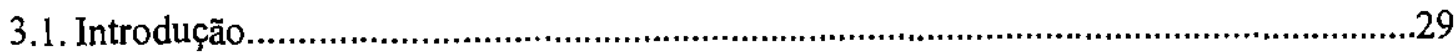

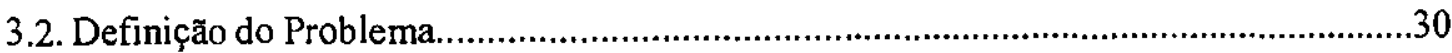

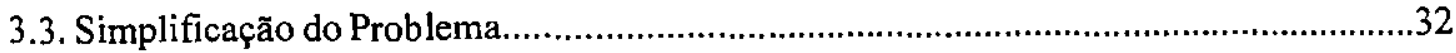


Capítulo 4 - Um Procedimento Heurístico para a Resolução do Problema

MCMP.............................................................................................................34

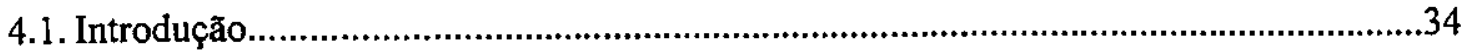

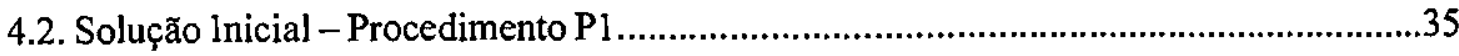

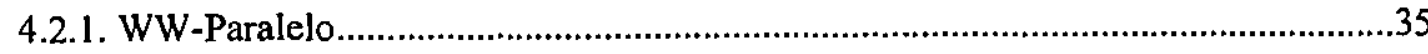

4.2.2. WW-Paralelo Penalizado ....................................................................................39

4.3. Heurística de Factibilização................................................................................45

4.3.1. Procedimento de Factibilização - Procedimento P2 .................................................51

4.3.1.1. Procedimento Auxiliar ao Processo de Factibilização.........................................52

4.3.1.2. Conceitos Básicos de Busca Tabu..............................................................61

4.3.2. Procedimento para Reconfiguração da Solução - Procedimento P4 ........................64

4.4. Heurística de Melhoria - Procedimento P3 .................................................................66

4.5. Limitante Inferior..........................................................................................67

Capítulo 5 - Resultados Computacionais (MCMP)...........................................72

5.1. Geração dos Dados..............................................................................................72

5.2. Medidas de Auxílio à Análise....................................................................................76

5.3. Heuristicas em Análise.............................................................................................78

5.4. Análise dos Resultados para os Exemplos do Grupo G1 ............................................80

5.4.1. Análise dos Resultados em Relação à Porcentagem de Soluç̃es Factiveis Obtidas...80

5.4.2. Análise dos Resultados em Relação à Qualidade das Soluções Obtidas..................83

5.4.3. Análise dos Resultados Relacionados ao Consumo de Capacidade Gerada............86

5.5. Análise dos Resultados para os Exemplos do Grupo G2 ..............................................89

5.5.1. Análise dos Resultados em Relação à Porcentagem de Soluções Factíveis Obtidas....89

5.5.2. Análise dos Resultados Relacionados ao Uso da Capacidade Gerada....................108

5.5.3. Análise dos Resultados com Relação as Infactibilidades......................................119

5.5.4. Análise dos Resultados em Relação à Qualidade das Soluções Obtidas................128 
5.5.4.2. Qualidade das Soluções Fornecidas pela Heurística HT2 ............................137

5.5.4.3. Comparação das Soluções Fornecidas pelas Heurísticas. .143

Capítulo 6 - Um Problema de Dimensionamento e Sequenciamento de Lotes e um Procedimento de Resolução............................................................................154

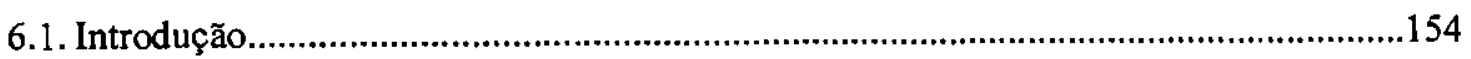

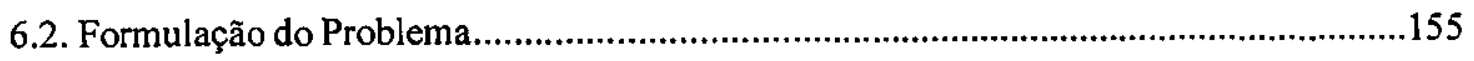

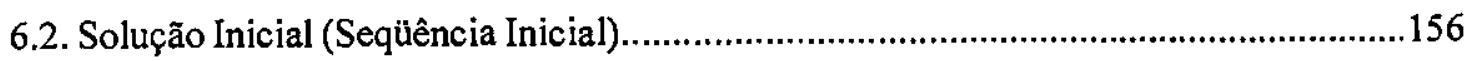

6.3. Procurando uma Solução Factível...........................................................................157

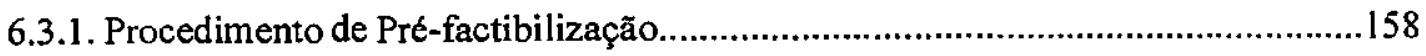

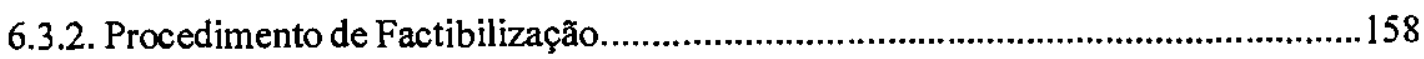

Capítulo 7 - Conclusões e Perspectivas Futuras.............................................164

Bibliografia.......................................................................................................168

Apêndice A - Notação Matricial e Formulações Equivalentes do Problema de Dimensionamento de Lotes Multiestágio: Estoque Convencional versus Estoque

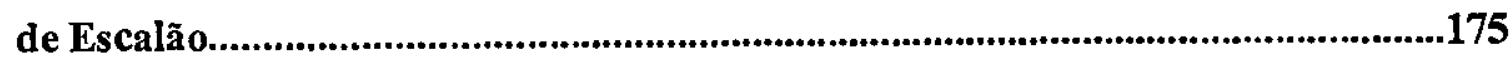

Apêndice B - Abordagens Equivalentes: Relaxação Lagrangiana Baseada na Formulação em Termos de Estoque Convencional versus Relaxação Lagrangiana Baseada na Formulação em Termos de Estoques de Escalão.................................185 


\section{RESUMO}

Este trabalho considera o problema de dimensionamento de lotes em um sistema de produção multiestágio, onde cada estágio é composto por máquinas paralelas com capacidades limitadas. O problema consiste em determinar um plano de produção que atenda a demanda dos itens finais e de seus componentes em cada período de um horizonte finito de planejamento. Um tempo de preparação é considerado para começar a produção em qualquer máquina e perfodo. O objetivo é determinar um plano de produção que minimize os custos de produção, preparação e de estoque. O problema é formulado como um programa inteiro misto e um método heurístico básico é proposto. A partir deste método básico, algumas heurísticas variantes foram desenvolvidas sendo que, algumas incorporam estratégias de Busca Tabu. A análise computacional foi feita com milhares de exemplos gerados aleatoriamente. Para os exemplos de dimensões pequenas, as soluções heurísticas foram comparadas com as soluções ótimas obtidas pelo pacote CPLEX 4.0. Para os exemplos maiores, os resultados obtidos foram analisados considerando o limitante inferior obtido através da técnica da Relaxação Lagrangiana e do método do subgradiente.

Uma proposta de resolução para um problema de dimensionamento e sequenciamento de lotes também é apresentado nesta tese. Este problema é uma extensão do problema de dimensionamento de lotes, pois integra o dimensionamento de lotes e o sequenciamento de itens nas máquinas e períodos. O objetivo consiste em determinar o quanto produzir dos itens, em cada período e máquina e, em que ordem estes itens devem ser produzidos. $O$ procedimento de resolução é baseado no método básico proposto para o problema de dimensionamento de lotes. As seqüências de produção em cada máquina e período podem ser interpretadas como rotas do caixeiro viajante. No apêndice, uma notação matricial é introduzida, permitindo mostrar facilmente a equivalência entre formulações alternativas para o problema de dimensionamento de lotes multiestágio, bem como entre abordagens de solução.

Palavras-chaves: Planejamento da Produção, Otimização Linear Inteira, Dimensionamento de Lotes, Multiestágio, Sequenciamento, Heurística. 


\section{ABSTRACT}

This work addresses the lot-sizing problem in a multistage production system, each stage consisting of parallel machines with finite capacity. This problem lies in the determination of a production plan for the end items and their components in order to satisfy the demand in each period of a finite horizon. A setup time is considered to start production on any machine in a given period. The solution should minimize production, setup and inventory costs. The problem is formulated as a mixed integer programming model and a basic heuristic method is proposed. From this basic method, a few heuristic approaches were developed, and some of them encompass a short-term memory tabu search. The computational analysis was done with thousands of examples randomly generated. For small instances, the heuristic solutions are compared with optimal solutions obtained by CPLEX 4.0. For larger instances, the quality of the solution is evaluated using a lower bound provided by Lagrangean relaxation.

This work also presents an approach to lot sizing and scheduling. This problem is an extension of the lot sizing problem, since it integrates the lot sizing and scheduling of items on machines and periods. The goal is to determine the production plan for all items in each period and machine and in what order these items should be produced. The resolution procedure is based on the basic method for the lot sizing problem. The production sequences in each machine and period can be interpreted as a tour of the traveling salesman. In the appendix, a matrix notation is introduced, allowing to show the equivalence among alternative formulations for the multistage lot sizing problem easily, as well as among different approaches for this problem.

Keywords. Production Planning, Mixed Integer Programming, Lot Sizing, Multistage Systems, Heuristics. 


\section{CAPÍTULO 1}

\section{Introdução}

Em termos gerais, a produção pode ser definida como o processo de conversão de matérias primas em produto final. Este processo deve ser gerenciado efetivamente para poder entregar o produto final com alta qualidade, dentro do tempo e com custos apropriados. Em uma empresa, o sistema responsável pelo gerenciamento da produção é denominado de planejamento e controle da produção (PCP), sendo este composto por um grande número de componentes que devem ser gerenciados. O PCP é responsável pela aquisição das matériasprimas até a entrega dos produtos finais. Este sistema também é responsável pelo gerenciamento dos recursos disponíveis à produção, disponibilidade de mão-de-obra, controle dos níveis de estoques, entre outros. A estrutura hierárquica de um sistema PCP pode ser dividida em três níveis de planejamento distintos: estratégico, tático e operacional (Anthony, 1965).

O planejamento estratégico envolve a definição de objetivos de longo prazo, e esta sob responsabilidade da alta direção da empresa. As decisões tomadas nesse nível, geralmente estão relacionadas a metas globais da empresa e ao estabelecimento de políticas para o cumprimento dessas metas.

O planejamento tático, de alcance de médio prazo, está relacionado com a utilização efetiva de recursos existentes, com o objetivo de cumprir os objetivos determinados no planejamento estratégico. Decisões típicas deste nível incluem a utilização do trabalho regular 
e de horas extras, planejamento da produção, níveis de estoques, definição dos meios de distribuição e seleção dos transportes alternativos.

O planejamento operacional envolve ações de curto prazo, ou seja, está relacionado ao dia-a-dia da produção. Tem como objetivo definir e executar os planos detalhados de produção. Decisões deste nível incluem o sequenciamento da produção nos centros de trabalho, controle de materiais, a compra dos componentes, entre outros.

$O$ interesse maior desta tese está relacionado com as decisões de médio prazo especificamente com o problema de dimensionamento de lotes em um sistema multiestágio. $O$ dimensionamento de lotes é um problema de planejamento que envolve a determinação de quanto produzir em cada período, de forma a atender a demanda dos produtos (itens). Os produtos em um sistema multiestágio são constituídos de componentes que também devem ser produzidos ou comprados.

Um sistema utilizado neste problema de planejamento da produção é o sistema MRP (Material Requirements Planning ou Planejamento de Necessidades de Materiais) que surgiu na década 60. Um sistema MRP é uma coleção de procedimentos lógicos que tem sido amplamente utilizado para o planejamento da produção em sistema multiestágio, cujo objetivo é determinar um plano de produção dos produtos finais (itens finais) e dos seus componentes, sendo que estes podem ser comprados ou fabricados.

Para o funcionamento de um sistema MRP são essenciais as informações fornecidas pelo programa mestre da produção (master production schedule), que descreve um plano de produção para os produtos finais ao longo do horizonte de planejamento; pela lista de materiais (bill of material), que especifica os componentes para cada item final, sendo definida pela estrutura de produtos; pelos níveis de estoque; e pelas previsões de demanda para cada produto final em cada periodo de tempo (Baker, 1993 e Resende e Sacomano, 1997). Com estas informações, o MRP fornece um planejamento sincronizado da produção dos itens finais e de seus componentes, informando a quantidade específica a ser produzida (ou comprada) em cada período, de forma a atender a demanda prevista em cada perfodo (Berretta, 1997).

No entanto, segundo Baker (1993), existem limitações na abordagem tradicional de um sistema MRP. Estas limitações estão relacionadas com a utilização da capacidade e nos custos envolvidos. Um sistema MRP pode utilizar módulos para verificar se um plano de produção está satisfazendo as capacidades disponíveis. Porém, estes módulos somente informam que os recursos disponíveis estão excedidos e que devem fazer um remanejamento de parte da produção ou adicionar mais capacidade para ajustar este plano. Além disto, os 
planos de produção fornecidos pelos sistemas MRP não são projetados com o objetivo de alocar os recursos eficientemente no sentido de obter um plano com o menor custo possivel, ou seja, não são considerados os custos envolvidos na produção, no estoque e na preparação das máquinas (Beker, 1993, Shapiro, 1993 e Berretta, 1997).

O problema de dimensionamento de lotes (lot sizing) com limitações de capacidade tenta superar as limitações de um sistema MRP, ou seja, seu objetivo é determinar um plano de produção de forma a minimizar os custos envolvidos, sujeito a um conjunto de restrições que incluem as limitações dos recursos disponíveis. Os custos envolvidos podem ser os custos de produção, estoque e de preparação das máquinas (setup cost). O custo de preparação é um custo fixo que deve ser cobrado quando houver a decisão de produzir um determinado lote de um item, em uma determinada máquina, num determinado período. Para levar em conta os recursos, supõe-se que estes são consumidos na produção e preparações (setup time) das máquinas.

A consideração dos custos e tempos de preparação faz com que o problema seja formulado matematicamente como um programa de programação inteira mista, de difícil resolução. $\mathrm{Na}$ literatura foi mostrado que somente o trabalho de determinar um plano de produção factível para este problema é muito difícil. Assim, devido à complexidade introduzida pelos tempos e custos de preparação, os métodos desenvolvidos para resolver otimamente este problema consideram casos particulares e exemplos de pequenas dimensões. Com o objetivo de resolver exemplos de dimensões médias e grandes, vários métodos heurísticos foram propostos.

Nesta tese são propostos procedimentos heurísticos para a resolução do problema de dimensionamento de lotes multiestágio, no qual cada estágio é composto de máquinas paralelas distintas com capacidade limitada. Os itens podem ser processados em cada uma das máquinas e para iniciar a produção ocorre um tempo de preparação da máquina. Os custos considerados são os custos de produção, estoque e de preparação (setup cost). Estes métodos heurísticos são extensões dos trabalhos de Berretta (1997) e Toledo (1998). No trabalho de Berretta (1997) é considerado o problema de dimensionamento de lotes multiestágio, no entanto, não considera máquinas paralelas. Já no trabalho de Toledo (1998) foi desenvolvida uma heurística para o problema de dimensionamento de lotes considerando máquinas paralelas, mas para o problema monoestágio. Assim, o problema estudado nesta tese difere destes dois trabalhos por considerar o problema multiestágio onde cada estágio é composto por máquinas paralelas. 
Um outro problema abordado nesta tese é o problema de dimensionamento e sequenciamento de lotes (lot sizing and scheduling problem), o qual está integrando decisões de médio e curto prazo. Neste problema, além de tomar as decisões do quanto produzir para atender as demandas em cada período, deve-se determinar qual será a sequiência de produção dos itens para cada período de tempo, a qual interfere no cálculo dos custos (os custos e tempos de preparações dependem da seqüência de produção). As pesquisas sobre este problema ainda são escassas, sendo que a maioria dos trabalhos existente considera algumas condições especais. Uma boa revisão bibliográfica para este problema pode ser encontrada em Drexel e Kimms (1997).

Este trabalho está dividido em outros seis capítulos e dois apêndices. No Capítulo 2 é apresentada uma revisão bibliográfica dos trabalhos da área de dimensionamento de lotes e dimensionamento e sequenciamento de lotes. No Capítulo 3 é definido e modelado o problema de dimensionamento de lotes enfocado nesta tese.

Um procedimento heuristico básico é proposto para o problema de dimensionamento de lotes multiestágio no Capítulo 4 e, os resultados computacionais obtidos são descritos no Capítulo 5, bem como as variantes do procedimento básico.

No Capítulo 6 é descrito o problema de dimensionamento e sequenciamento de lotes, e um método é proposto. Finalmente, as conclusões e as propostas futuras são apresentadas no Capítulo 7.

No Apêndice A é introduzida uma notação matricial e é mostrada a equivalência entre a formulação do problema de dimensionamento de lotes multiestágio em termos de estoque de convencional e estoque de escalão. Finalmente, no Apêndice B são apresentadas as relaxações Lagrangiana do problema formulado em termos de estoque convencional e em termos de estoque de escalão e mostrada sua equivalência. 


\section{CAPÍTULO 2}

\section{REVISÃo BIBLIOGRÁFICA}

\subsection{Introdução}

Neste capítulo são apresentados problemas de dimensionamento de lotes (lot sizing) e alguns trabalhos relacionados. O problema de dimensionamento de lotes trata da determinação de um plano de produção dos itens sobre um horizonte de planejamento de modo a atender uma demanda preestabelecida. Também são apresentados problemas, onde o sequenciamento é integrado ao problema de dimensionamento de lotes (lot sizing and scheduling) e alguns procedimentos de resolução são discutidos.

\subsection{O Problema de Dimensionamento de Lotes}

O problema de dimensionamento de lotes determina um plano de produção para vários itens com o objetivo de atender uma demanda conhecida (ou estimada) sem atrasos. Os itens a serem produzidos podem dividir recursos comuns, sendo estes recursos, na maioria das vezes escassos (capacidade limitada). Para este problema existem boas revisões na literatura, como as apresentadas em Billington et al. (1983), Bahl et al. (1987), Kuik et al. (1994) e Drexel e Kimms (1997). 
Bahl et al. (1987) classificam os problemas de dimensionamento de lotes de acordo com a representação mostrada na Figura 2.1. Neste capítulo, considera-se esta classificação para apresentação destes problemas.

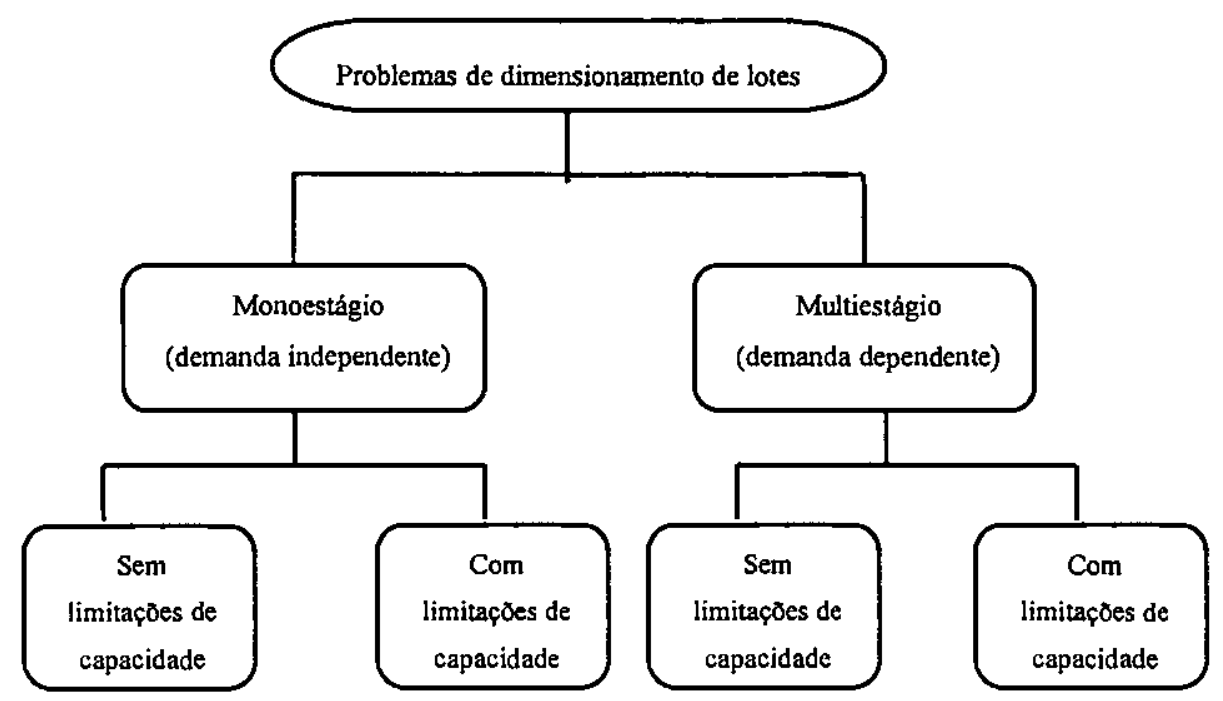

Figura 2.1 Classificação dos problemas de dimensionamento de lotes(Bahl et al., 1987).

Esta classificação é simplista, enfatizando apenas dois aspectos dos problemas de dimensionamento de lotes: o número de estágios e a existência de limitações de capacidades. Um outro aspecto importante, que é desconsiderado, é a relevância das preparações de máquinas (setup).

Nesta tese é estudado o problema de dimensionamento de lotes multiestágio em um ambiente com máquinas paralelas distintas. Os itens podem ser produzidos em qualquer máquina e a decisão de produção em uma determinada máquina acarreta um tempo gasto para a preparação desta máquina. O objetivo do problema é determinar um plano de produção que minimize os custos de produção, estoque e preparação e que satisfaça as restrições do atendimento das demandas e as limitações das capacidades.

Considerar tempo e custo de preparação torna o problema difícil de resolver (Florian et al., 1980 e Maes et al., 1991). Na literatura, encontram-se trabalhos que discutem o fato de considerar ou não o tempo de preparação na formulação do problema, sendo que alguns autores dizem que os tempos de preparação já estão inclusos nos custos de preparação, portanto, os tempos gastos para as preparações podem ser desconsiderados (Maes et al. 1991). No entanto, Kuik et al. (1994) discutem a importância de considerar tempo de preparação na formulação do problema, para poder revelar o consumo real dos recursos e não apenas 
considerar os tempos de preparação através dos custos. No trabalho de Tempelmeier (1997) mostram que, para o problema de dimensionamento de lotes multiestágio com limitações de capacidade, procedimentos que levam a planos que representam um real consumo de recursos, são aqueles desenvolvidos para os problemas que consideram tempos de preparação na formulação.

A seguir é apresentada uma breve revisão bibliográfica para o problema de dimensionamento de lotes.

\subsubsection{O Problema de Dimensionamento de Lotes Monoestágio}

O sistema de produção monoestágio ocorre quando os itens a serem produzidos são independentes, isto é, nenhum item depende da produção de outro item. O problema com um único item surge como um subproblema de problemas mais complexos, como os problemas estudados em Tempelmeier e Derstroff (1996) e França et al. (1997).

\section{O Problema de Dimensionamento de Lotes Monoestágio sem Limitações de Capacidade}

As primeiras pesquisas relacionadas com o problema de dimensionamento de lotes foram iniciadas considerando o modelo clássico EOQ (Economic Order Quantity), o qual foi proposto por F.W. Harris (Harris, 1915 e Harris, 1990). O modelo EOQ considera o processo de produção monoestágio e capacidade ilimitada, ou seja, considera o problema com um único item, sendo a demanda deste item estacionária, isto é, a demanda ocorre continuamente no tempo com uma taxa constante. O horizonte de planejamento para o modelo EOQ é infinito. Uma solução ótima para o modelo pode ser determinada facilmente.

Já o modelo de Wagner-Whitin (Wagner e Whitin, 1958), assume que o horizonte de planejamento é finito, sendo este dividido em vários períodos discretos. A demanda é determinística e dinâmica. $\mathrm{O}$ modelo de Wagner-Whitin considera o problema monoestágio com um único item sem limitações de capacidade. Este problema pode ser visto como o problema do caminho mínimo em um grafo direcionado, o que leva a conclusão que uma solução ótima existe e, é polinomialmente limitada. Algoritmos ótimos para este problema podem ser encontrados em Wagner e Whitin (1958), Ferdergruem e Tzur (1991), Walgelmans et al. (1992). Evans (1985) propôs uma implementação eficiente do algoritmo de Wagner e 
Whitin (1958). Armentano e Toledo (1997) propuseram uma extensão do algoritmo proposto por Wagner e Whitin (1958) para a resolução do problema monoestágio com um único item e máquinas paralelas. $O$ problema com máquinas paralelas ocorre quando, para cada período, deve-se tomar a decisão de onde produzir, ou seja, em qual máquina deve-se produzir. Este algoritmo (Armentano e Toledo, 1997) é utilizado no procedimento de resolução dos problemas propostos nesta tese. Uma breve revisão sobre o problema de dimensionamento monoestágio sem limitações de capacidade pode ser encontrada em Wolsey (1995).

\section{O Problema de Dimensionamento de Lotes Monoestágio com Limitações de Capacidade}

O problema de dimensionamento de lotes com limitaçōes de capacidade (CLSPCapacitated Lot Sizing Problem) pode ser visto como uma extensão do problema de WagnerWhitin (Wagner e Whitin, 1958) considerando restrições de capacidade. O problema CLSP é um problema monoestágio com múltiplos itens com o horizonte de planejamento finito e, demanda dinâmica.

O modelo apresentado a seguir para o problema CLSP, encontra-se em Trigeiro et al. (1989), onde foi considerado a demanda conhecida sobre os $T$ períodos do horizonte de planejamento, a capacidade disponível limitada e a existência de tempo e custo de preparação das máquinas (setup time e setup cost). O objetivo do modelo é determinar um plano de produção que minimize os custos, sujeito a um conjunto de restrições que inclui o atendimento de uma demanda preestabelecida.

Considere as seguintes variáveis de decisão para o problema CLSP:

$1_{\text {it }}$ Estoque do item i no final do período $t$.

$\mathrm{X}_{\mathrm{it}} \quad$ Produção do item i no período $\mathrm{t}$.

$Y_{i t}=\left\{\begin{array}{ll}1 & \text { se o item i é preparado no periodo } t \\ 0 & \text { caso contrário }\end{array}\right.$.

E os seguintes parâmetros:

Cap, Capacidade disponível da máquina no período $t$.

$\mathrm{d}_{\mathrm{it}} \quad$ Demanda para o item i no período $t$.

$\mathrm{c}_{\mathrm{it}} \quad$ Custo de produzir uma unidade do item i no periodo $t$.

$h_{i t} \quad$ Custo de estocar uma unidade do item i no período t. 
$b_{i} \quad$ Tempo necessário para produzir uma unidade do item i.

$\mathrm{cs}_{\mathrm{it}} \quad$ Custo de preparação para o item i no período $t$.

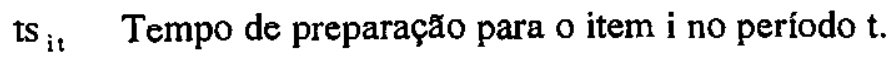

M Número grande.

$\mathrm{i}=1, \ldots, \mathrm{N} \quad$ itens.

$\mathrm{t}=1, \ldots, \mathrm{T} \quad$ períodos.

O problema CLSP pode ser formulado como um modelo de programação linear misto:

(CLSP)

$$
\operatorname{minimize} \sum_{\mathrm{i}=1}^{N} \sum_{\mathrm{i}=1}^{\mathrm{T}}\left(\mathrm{h}_{\mathrm{it}} \mathrm{I}_{\mathrm{it}}+\mathrm{c}_{\mathrm{it}} \mathrm{X}_{\mathrm{it}}+\mathrm{cs}_{\mathrm{it}} \mathrm{Y}_{\mathrm{it}}\right)
$$

Sujeito a:

$$
\begin{aligned}
& I_{i, t-1}+X_{i t}-I_{i t}=d_{1 t} \quad i=1, \ldots, N \quad t=1, \ldots, T \\
& \sum_{i=1}^{N}\left(b_{i} X_{i t}+t_{i t} Y_{i t}\right) \leq C_{1} P_{t} \quad t=1, \ldots, T \\
& X_{t}-M Y_{i t} \leq 0 \quad i=1, \ldots, N \quad t=1, \ldots, T \\
& X_{i t} \geq 0 \text { e } I_{i t} \geq 0 \quad Y_{i t}=0 \text { ou } 1 \quad i=1, \ldots, N \quad t=1, \ldots, T
\end{aligned}
$$

A função objetivo (2.1) a ser minimizada representa os custos de produção, estoque e preparação dos $\mathrm{N}$ itens ao longo dos $\mathrm{T}$ períodos. As restrições (2.2) representam o balanceamento de estoque de cada item no final de cada período. As inequações (2.3) indicam as limitações de capacidade em cada período e (2.4) são restrições lógicas que indicam a necessidade de preparação quando há produção. As variáveis de preparação são garantidas a serem binárias por (2.5) que garantem também as condições de não-negatividade das variáveis de estoque e produção.

O problema CLSP é chamado de "large bucket problem" (Drexel e Kimms, 1997), porque vários itens podem ser produzidos por período. Um período usualmente representa uma quantidade de tempo, como por exemplo, uma semana no mundo real, assim, o horizonte de planejamento geralmente é menor do que seis meses.

Do ponto de vista computacional, quando os recursos são limitados, a consideração de custos das preparações das máquinas (setup cost) faz com que o problema com um único item seja NP-dificil (Florian et al., 1980). Isto acontece mesmo para os casos especiais, nos quais todas as demandas são iguais e todos custos de estoques são nulos, logo o problema monoestágio com múltiplos itens também é considerado NP-dificil. Maes et al. (1991) 
mostraram que o problema de identificar a existência de uma solução factível é NP.Completo quando se considera consumo de recursos para preparações das máquinas (setup time). No trabalho de Chen e Thuzy (1990) é discutido o modelo (2.1)-(2.5), a complexidade e ainda vários procedimentos de solução do problema.

Encontram-se na literatura métodos ótimos, quase ótimos e heurísticos para resolver o problema considerando algumas variações, principalmente em relação aos custos e tempos de preparação.

Dentre os que desenvolveram métodos heurísticos destacam-se: Trigeiro et al. (1989), Lozano et al. (1991) e Toledo (1998).

Trigeiro et al. (1989) desenvolveram um método heurístico que consiste em relaxar as restrições de capacidade (2.3) aplicando a técnica da relaxação Lagrangiana, obtendo deste modo $\mathrm{N}$ subproblemas sem limitações de capacidade, os quais foram resolvidos utilizando um algoritmo de programação dinâmica. Em seguida, se a solução for infactível, aplica-se um método de factibilização que transfere produção entre períodos, na tentativa de factibilizar a solução e, finalmente atualiza os multiplicadores duais utilizando o método do subgradiente (Held et al., 1974).

Lozano et al. (1991) desenvolveram um algoritmo similar ao de Trigeiro et al. (1989), sendo que as diferenças estão no algoritmo do subgradiente e no procedimento utilizado para restaurar a factibilidade. Em Toledo (1998) propõe-se uma heurística Lagrangiana, baseada na relaxação das restrições de capacidade do problema e em otimização do subgradiente, para resolução do problema considerando máquinas paralelas. Primeiramente o problema Lagrangiano é resolvido e caso a solução obtida for infactível, aplica-se um procedimento de factibilização baseada nas transferências de produção entre máquinas e períodos. Se a solução obtida for factível, aplica-se um procedimento de melhoria visando a obtenção de uma solução de melhor qualidade. Observa-se aqui que o procedimento de factibilização é aplicado a cada $\mathrm{k}$ passos do método do subgradiente, sendo assim, a heurística é executada partindo de várias soluções diferentes.

No trabalho de Haase (1998) considera-se o problema (2.1)-(2.5) mas, foram introduzidas certas condições no modelo, para reduzir os custos de preparação entre períodos adjacentes, mas não consideraram os tempos gastos com preparações. Neste trabalho foi proposto um procedimento heurístico, onde as decisões sobre o tamanho do lote e das semisequências (pelo fato de estar considerando os períodos adjacentes) são baseadas numa regra de prioridade que consiste em uma combinação convexa dos custos de estoque e de preparação. Os resultados computacionais mostraram que o método proposto resolveu este 
novo modelo de uma maneira mais eficiente do que aplicar primeiro ao problema sem considerar as ligações entre períodos, e num passo posterior considerá-las.

Dentre os que desenvolveram métodos ótimos e quase ótimos destacam-se: Diaby et al. (1992) e Armentano et al. (1999). Diaby et al. (1992) desenvolveram métodos ótimos/quase ótimos utilizando branch-and-bound no qual, os limitantes (bounds) foram gerados por relaxação Lagrangiana e os custos duais atualizados pelo método do subgradiente. Eles consideraram custo e tempo de preparação e também horas extras na formulação do problema. Armentano et al. (1999) como em Trigeiro et al. (1989) consideram o problema com custos e tempos de preparação, e representaram o problema como uma rede generalizada e desenvolveram um método ótimo. $\mathrm{O}$ método é um algoritmo branch-and-bound especializado, onde em cada nó é resolvido um problema de custo mínimo em uma rede generalizada.

\subsubsection{O Problema de Dimensionamento de Lotes Multiestágio}

O problema de dimensionamento de lotes multiestágio ocorre quando um item final possui itens predecessores (componentes), que também devem ser programados para produção ou compra. Os itens finais possuem suas próprias demandas, chamadas demandas independentes, enquanto que, os itens componentes podem possuir demanda dependente (utilizados para o consumo interno) e demanda independente.

A estrutura do processo de produção multiestágio, chamada de estrutura de produtos, pode ser representada por um grafo orientado acíclico $G(V, E)$, onde os elementos de $V$ (nós) representam o conjunto de itens e os elementos de $E$ (arcos) representam as relações entre eles. $O$ arco $(i, j)$ existe somente se, o item $j$ depende da produção do item $i$, ou seja, $j$ é um sucessor imediato do item $i, i>j$ (por convenção, na estrutura do produto os itens são numerados de 1 até $\mathrm{N}$ ) (Afentakis e Gavish, 1986). Assim, as relações de precedência entre os itens definem a estrutura de produto que pode ser: geral, serial e montagem. Na Figura 2.2 estão representados exemplos de estruturas de produtos definidas a seguir.

- Serial: cada item, com exceção do primeiro e do último, tem exatamente um sucessor e um predecessor.

- Montagem: cada item pode ter vários predecessores, mas com a restrição de um único sucessor. 
- Geral: não há restrição quanto ao número de sucessores e predecessores de um item, exceto os itens finais que não possuem sucessores.

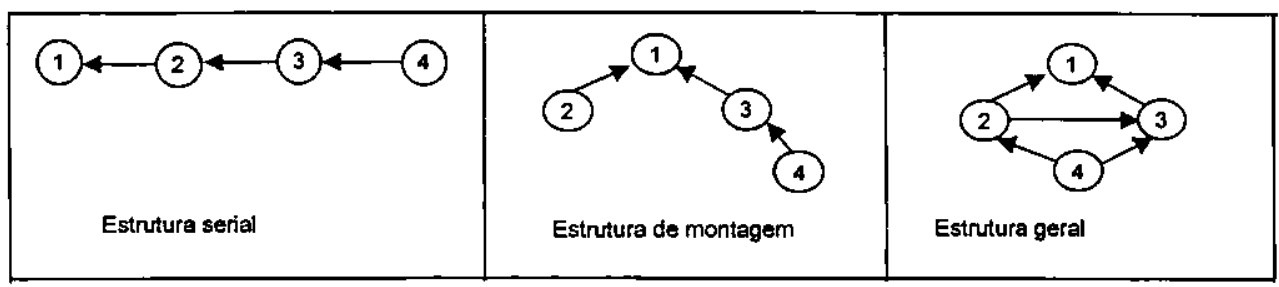

Figura 2.2. Exemplos de três estruturas de produtos.

Este problema pode ser encontrado em situações industriais, o qual é usualmente, resolvido utilizando um sistema do tipo MRP (Material Requirements Planning). Sistemas do tipo MRP definem os tamanhos de lotes de produção dos itens finais e seus componentes com objetivo de atender a demanda. Entretanto, os sistemas MRP, em sua maioria, não incluem restriçōes de recursos para produção dos lotes, nem consideram os custós envolvidos nesta fase. Se este plano inicial é infactível, um procedimento (Capacity Requirements Planning Procedure-CRP) é aplicado para ajustá-lo (Tempelmeier, 1997 e Maes e Wassenhove, 1991). Geralmente, depois da aplicação destes procedimentos, ajustes manuais são necessários.

O modelo para o problema de dimensionamento de lotes multiestágios, apresentado a seguir, é uma simplificação do encontrado em Billington et al. (1983). Eles consideraram o problema de dimensionamento de lotes multiestágio com restrições de capacidade, lead time diferente de zero, tempo e custo de preparação. Lead time é o tempo decorrido entre o instante em que se formaliza uma solicitação e o instante em que o que foi solicitado se torna disponível, (Femandes, 1991). Os seguintes dados adicionais devem ser considerados:

$\mathrm{L}_{\mathrm{i}} \quad$ Minimo lead time para o item $i$, (O mínimo é enfatizado porque $\mathrm{L}_{\mathrm{i}}$ não deve incluir uma estimativa da demora devido os limites de capacidade.)

$a_{i j} \quad$ Quantidade do item $i$ requerida para a produção de uma unidade do item $j$.

$\mathrm{ts}_{\mathrm{ik}} \quad$ Tempo de preparação para produzir o item i na máquina $\mathrm{k}$.

$\mathrm{b}_{\mathrm{ik}} \quad$ Tempo necessário para produzir uma unidade do item i na máquina $\mathrm{k}$.

$\mathrm{CAP}_{\mathrm{tk}}$ Capacidade disponível (em unidades de tempo) no período t na máquina $\mathrm{k}$. $\mathrm{k}=1, \ldots, \mathrm{K} \quad$ Máquinas.

S(i) - Conjunto dos sucessores imediatos do item i.

$\mathrm{P}(\mathrm{i})$ - Conjunto dos predecessores imediatos do item $\mathrm{i}$. 
Para exemplificar como é determinado estes conjuntos, considere estrutura de produtos dada pela Figura 2.3. Esta figura exemplifica também a relação $\mathrm{a}_{\mathrm{ij}}$.
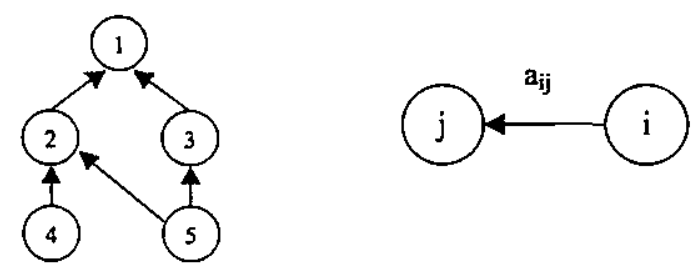

Figura 2.3. Estrutura de produtos exemplo e relação entre os itens.

$S(1)=\{\}, S(2)=\{1\}, S(3)=\{1\}, S(4)=\{2\}$ e $S(5)=\{2,3\}$.

$P(1)=\{2,3\}, P(2)=\{4,5\}, P(3)=\{5\}, P(4)=\{\}, P(5)=\{\}$.

Modelo Matemático

$$
\mathrm{z}=\min \sum_{\mathrm{i}=1}^{\mathrm{N}} \sum_{\mathrm{t}=1}^{\mathrm{T}}\left(\mathrm{h}_{\mathrm{it}} \mathrm{I}_{\mathrm{it}}+\mathrm{cs}_{\mathrm{it}} \mathrm{Y}_{\mathrm{it}}\right)
$$

Sujeito a:

$$
\begin{array}{lr}
I_{i, t-1}+X_{i, t-L,}-I_{i t}-\sum_{j \in S(i)} a_{i j} X_{j t}=d_{i t}, & i=1, \ldots, N, t=I, \ldots, T \\
\sum_{i=1}^{N}\left(b_{i k} X_{i t}+t s_{i k} Y_{i t}\right) \leq C A P_{t k}, & k=1, \ldots, K, t=1, \ldots, T \\
X_{i t}-M Y_{i t} \leq 0, & i=1, \ldots, N, t=I, \ldots, T \\
Y_{i t} \in\{0,1\}, X_{i t} \geq 0, I_{i t} \geq 0 . & i=1, \ldots, N, t=1, \ldots, T
\end{array}
$$

A função objetivo (2.6) visa à minimização do custo total, que é formado por custos de estoque e preparação. As restrições (2.7) são restrições de balanço de estoque. O estoque final para cada item em cada período t é igual ao estoque inicial mais a produção líquida do item no período $t-L_{i}$ menos as demandas internas (demanda dependente é dada por: $\sum_{j \in S(i)} a_{i j} X_{j t}$ ) e externa $\left(d_{i t}\right)$ para o item nesse período. As restrições de capacidade e preparação são dadas pelas restrições (2.8) e (2.9). Observa-se que a diferença de um sistema de produção 
monoestágio e multiestágio está na dependência entre os itens $\left(\sum_{\mathrm{j} \in S(\mathrm{i})} \mathrm{a}_{\mathrm{ij}} \mathrm{X}_{\mathrm{j}}\right)$ nas restrições (2.7).

\section{O Problema de Dimensionamento de Lotes Multiestágio Sem Limitaçōes de Capacidade}

Muitos autores consideram o problema de dimensionamento de lotes multiestágio sem limitações de capacidade, ou seja, as restrições (2.8) não são consideradas.

Alguns algoritmos ótimos para obter soluções ótimas para o problema, quando consideram capacidade ilimitada, são baseados em programação dinâmica como em Veinott (1969). Zangwill (1969) utilizaram a formulação em redes e consideraram os problemas com estrutura serial. Crowston e Wagner (1973) desenvolveram um algoritmo baseado em programação dinâmica e outro do tipo branch-and-bound para os problemas com estrutura do tipo montagem. Nos trabalhos de Veinott (1969), Zangwill (1969) e Crowston e Wagner (1973) não foram considerados custos de preparações, ou seja, trataram com um problema de programação linear. Já nos trabalhos de Afentakis et al. (1984) e Afentakis e Gavish (1986), os quais apresentaram métodos ótimos para o problema sem limitações de capacidade, consideraram os custos de preparações não nulos.

Em Afentakis et al. (1984) o problema de dimensionamento de lotes sem limitações de capacidade é reformulado em termos de estoque de escalão, o que simplificou sua decomposição por itens. O conceito de estoque de escalão foi introduzido por Clark e Scarf (1960), sendo definido como a quantidade total do item presente no sistema, incluindo a quantidade do item em estoque mais a quantidade do item contida no estoque de seus sucessores. Neste trabalho foi considerada a estrutura de produtos de montagem e foi desenvolvido um algoritmo branch-and-bound onde os limitantes são gerados pela resolução do problema Lagrangiano. Afentakis e Gavish (1986) converteram a formulação do problema sem limitações de capacidade com estrutura geral de produto para uma estrutura de montagem com restrições adicionais, mas, esta transformação aumentou significativamente o número de variáveis. Resolveram o problema transformado utilizando o algoritmo apresentado em Afentakis et al. (1984).

Outros trabalhos que tratam o problema sem limitaçōes de capacidade podem ser encontrados em Blackburn e Millen (1982), Afentakis (1987), Chiu e Lin (1989), Kuik e 
Salomon (1990) e Dellaert e Jeunet (2000), os quais desenvolveram métodos heurísticos para a resolução do problema.

Blackburn e Millen (1982) desenvolveram um método de decomposição que considera implicitamente a inter-relação dos itens na estrutura de produtos através da modificação dos custos de preparação e de estoque. Eles consideram os problemas com estrutura de produtos tipo montagem, horizonte de planejamento infinito, e resolvem estes problemas utilizando um algoritmo para o problema monoestágio. Chiu e Lin (1989) desenvolveram uma heurística que obtém uma solução inicial utilizando um algoritmo de programação dinâmica. Consideram regras que utilizam a topologia da estrutura para incorporar as interdependências entre os itens, desconsideradas no momento da obtenção da solução inicial.

Kuik e Salomon (1990) propuseram uma heurística utilizando Simulated Annealing, onde primeiramente é utilizado o algoritmo proposto por McClain et al. (1989) para resolver o problema de programação linear obtido quando se ignora a condição de integralidade das variáveis de preparações. Depois de resolvido este problema linear, são definidas distintas vizinhanças (seis) envolvendo as variáveis binárias, para a aplicação do Simulated Annealing.

Dellaert e Jeunet (2000) desenvolveram um algoritmo genético híbrido que combina qualidades de algumas heurísticas e princípios de algoritmo genético para resolução do problema sem limitações de capacidade, onde foi considerado custo de preparação não nulo. Os resultados obtidos para exemplos de pequena dimensão foram comparados com as soluções ótimas obtidas pelo pacote GAMS. Os resultados mostram que a melhor versão do algoritmo genético obteve soluçôes com desvio do ótimo de $0.26 \%$. Foram considerados exemplos de médio e grande porte, sendo que, os resultados obtidos pelo genético foram comparados com resultados obtidos por outras heurísticas desenvolvidas para resolução deste problema. Os resultados mostraram que o desempenho das versões do algoritmo genético foi superior aos obtidos pelas heurísticas consideradas.

\section{O Problema de Dimensionamento de lotes Multiestágio Com Limitações de Capacidade}

Muitos autores que consideram o problema com limitações de capacidade fazem algumas restrições, seja na variação das estruturas de produto e/ou na consideração dos custos e tempo de preparação para facilitar a resolução. O trabalho de Billington et al. (1983) apresenta uma boa revisão bibliográfica para o problema multiestágios e com limitaçסes de 
capacidade. Apresentam também uma técnica para a redução das estruturas de produtos, mas, não fornecem nenhum procedimento de resolução.

O trabalho de McClain et al. (1989) aborda o problema sem considerar tempos e custos de preparação, mas consideraram horas extras e vários recursos com capacidade limitada. O procedimento de resolução é um método de decomposição que explora a estrutura especial do programa linear quando os estoques são nulos. $O$ problema Lagrangiano obtido com a dualização das restrições de capacidade possui uma estrutura especial, a estrutura de Leontief e, pode ser resolvido utilizando um algoritmo muito rápido, denominado algoritmo de "dois passos". As propriedades e solução para o sistema de Leontief são discutidos em Dantzig (1955) e Veinott (1969).

Billington et al. (1986) propuseram um método heurístico para resolução do problema com apenas um estágio com limitações de capacidade e com custo e tempo de preparação, ou seja, consideram um único centro gargalo (um gargalo é um centro de trabalho que limita a taxa de produção da fábrica). O método proposto é um branch-and-bound com heurísticas. Em qualquer nó na árvore de ramificação um problema é definido com valores fixos para algumas variáveis $\mathrm{X}_{\mathrm{it}}$. Uma heurística Lagrangiana resolve o problema de dimensionamento de lotes em cada nó item a item. Um procedimento de factibilização ajusta a produção dentro da capacidade disponível, se possível, produzindo uma solução provisória. A seguir, os multiplicadores de Lagrange são atualizados de modo a desestimular a produção no centro de trabalho gargalo em período super utilizados. Os testes computacionais envolvem exemplos com capacidade ilimitada e limitada. No caso limitado foram consideradas estruturas seriais e de montagem com 5 itens. Os resultados obtidos com estes exemplos foram comparados com os valores ótimos. Para os exemplos com capacidade limitada foram consideradas estruturas paralelas (estruturas seriais em paralelo) com 1, 3 ou 5 itens finais, sendo que as limitações de capacidade ocorrem somente em um nível (um nível $L$ dos itens em série). No caso de 1 item final e 5 niveis ( 5 itens em série) os resultados mostram $27 \%$ a $62 \%$ de gap comparando a solução heurística com o limitante inferior obtido pela relaxação Lagrangiana e, variando o nível que ocorre as limitações de capacidade. Convém observar aqui, que os piores valores de gap foram determinados quando as limitações encontravam-se nos níveis mais baixos, ou seja, mais próximos das matérias-primas (últimos itens componentes). Também é relatado que em 8 exemplos, onde a solução ótima foi obtida, a heurística obtém soluções a menos de $1 \%$ do ótimo, sendo que o gap comparado com o limitante inferior garantia $25 \%$. Isto leva a crer o grande gap de dualidade existente. 
Maes e Van Wassenhove (1991) consideraram o problema multiestágio com estrutura serial de produtos, custo de preparação não nulo e capacidade limitada. Investigam o desempenho de heurísticas que trabalham considerando cada nível na estrutura de produtos e, propõem uma extensão de uma heurística para o problema monoestágio para a resolução do problema multiestágio. Utilizaram para esta extensão, o método dos custos modificado proposto por Blackburn e Millen (1982) e Blackburn e Millen (1984) que consideram as interdependências entre os itens, sendo que em Blackburn e Millen (1984) são introduzidas, além das informaçб̃es das interdependências entre os itens, informaçб̃es sobre limitaçð̃es das capacidades. Os resultados obtidos considerando exemplos de pequenas dimensőes (com até 3 níveis) mostram que o desvio do ótimo é inferior a $7.50 \%$.

Em Roll e Karni (1991) também é somente considerada uma máquina gargalo como em Billington et al. (1986), mas não consideram tempo de preparação. Na heurística proposta uma solução inicial é obtida através da aplicação do algoritmo de Wagner e Whitin (Wagner e Whitin, 1958) item a item sem considerar as restrições de capacidade e, uma heurística baseada nas transferencias de produção entre períodos também é aplicada para obter um plano de produção factível. Os experimentos computacionais consideraram as dimensões dos exemplos gerados de $(N=2, T=5)$ até $(N=4, T=8)$, para os quais o desvio, em relação às soluções ótimas obtidas utilizando o LINDO, foi inferior a $6 \%$.

O trabalho de Billington et al. (1995) compara um conjunto de heurísticas desenvolvidas para o problema monoestágio ao problema multiestágio com limitações de capacidade, mas, considera apenas estruturas seriais de produto e não considera tempo de preparação, como feito em Maes e Van Wassenhove (1991). Com a utilização do método dos custos modificado proposto por Blackburn e Millen (1982) e Blackburn e Millen (1984) estenderam estas heurísticas para a aplicação ao problema multiestágio. Para os testes computacionais, consideram os exemplos com 3 e 12 itens e, 10 e 12 períodos. Os resultados foram comparados com os valores ótimos obtidos pelo LINDO para os exemplos de pequena dimensão ( 3 itens), e também foi feita uma comparação entre as heurísticas. Os resultados mostram um desvio do ótimo inferior a $3 \%$.

Tempelmeier e Helber (1994) estendem a formulação desenvolvida por Eppen e Martin (1987) para o problema monoestágio com limitações de capacidade, para o problema multiestágios com limitações de capacidade. Nesta formulação são considerados custos de preparação e estrutura geral de produtos, no entanto, desconsideram os tempos gastos com as preparações. Eles usam esta formulação para obter soluções ótimas para alguns exemplos e também para obtenção de limitantes inferiores. Eles comentam que ao considerar esta 
reformulação obtém-se melhores limitantes inferiores, reduzindo assim o gap dualidade. $O$ procedimento heurístico desenvolvido consiste em resolver vários problemas monoestágios com limitações de capacidade utilizando o algoritmo de Dixer e Silver (Dixon e Silver, 1981), e em um estágio final, uma heurística de factibilização é considerada para restaurar a factibilidade. O desempenho da heurística foi testado utilizando soluções ótimas de quatro conjuntos de exemplos de pequena dimensão (10 itens, 3 máquinas e 4 períodos), e os desvios destes quatro conjuntos foram de $4.87 \%, 3.79 \%, 2.21 \%$ e $2.44 \%$, mostrando assim o bom desempenho da heurística. As soluções para exemplos de dimensões maiores foram comparadas com o limitante inferior calculado utilizando o problema reformulado (Eppen e Martin, 1987), com as soluções apresentando desvios de $2 \%$ até $26 \%$.

Maes et al. (1991) apresentaram uma heurística baseada na programação linear para resolver o problema com múltiplos recursos com limitações de capacidade, com custo de preparação positivo e tempo de preparação nulo. Ignoraram as variáveis inteiras, resolveram o problema linear e em seguida testaram três heurísticas para "arredondar" as variáveis inteiras. O desempenho da heurística é testado utilizando exemplos de pequena dimensão ( 3 estruturas paralelas e 10 periodos), sendo que estas apresentaram um desempenho bom. Os resultados obtidos para os exemplos com até três níveis, mostram um desvio do ótimo inferior a 3\%.

Em Kuik et al. (1993) é considerado o problema com restrições de capacidade em apenas um estágio como em Billington et al. (1986). Não consideraram tempo de preparação e nem estrutura geral. Compararam o desempenho das três heurísticas baseadas em programação linear de Maes et al. (1991) e as outras duas, baseadas em técnicas de busca heuristica (Simulated Annealing e Busca Tabu). O desempenho das heurísticas com Busca Tabu e Simulated Annealing foi melhor do que as heurísticas somente com programação linear, no entanto, os desempenhos destas heuristicas foram melhorados quando considerados alguns elementos de Busca Tabu e Simulated Annealing.

A maioria dos trabalhos mencionada acima considera o problema sem tempo de preparação, somente em Billington et al. (1986) foi considerado o tempo de preparação positivo. Pesquisas desenvolvidas considerando custos e tempos de preparação são poucos. Além de Billington et al. (1986), os seguintes trabalhos consideram custo e tempo de preparação: Clark e Armentano (1995), Tempelmeier e Derstroff (1996), França et al. (1997), Berretta (1997), Tempelmeier (1997), Katok et al. (1998).

No trabalho de Clark e Armentano (1993) é apresentado um modelo utilizando o conceito de estoque de escalão, onde foram considerados os lead times não nulos e custos das preparações. Neste modelo as restrições de capacidade não foram consideradas. Em Clark e 
Armentano (1995) é apresentado uma heurística para a resolução do problema em Clark e Armentano (1993), considerando a capacidade para produção e preparação limitada e os lead times não nulos. A heurística consiste na aplicação seqüencial do algoritmo de Wagner e Whitin (Wagner e Whitin, 1958) ao problema sem restrições de capacidade e, a seguir executa-se transferências de uma certa quantidade de produção entre períodos com o objetivo de obter a factibilidade. Nos testes computacionais foram considerados dois grupos de exemplos. No primeiro grupo foram gerados exemplos com 5 itens, estrutura geral de produtos, 12 períodos e 2 recursos limitados. Os resultados obtidos para estes exemplos foram comparados com o valor ótimo obtido pelo OSL (Optimization Subrotines Library) e com o valor do limitante inferior obtido pela relaxação Lagrangiana. Os resultados mostram que o desvio médio das soluções heurísticas com o ótimo foi de $4.92 \%$, enquanto que, o desvio médio das soluções heurísticas com o limitante inferior, foi de $25.08 \%$, indicando a existência de um gap dualidade de $20 \%$. O outro grupo de exemplos foi gerado com $\mathrm{N}=40, \mathrm{~T}=12$ e $\mathrm{K}=2$, e os resultados foram comparados utilizando o valor do limitante inferior.

Em França et al. (1997) é desenvolvida uma heurística baseada na apresentada em Clark e Armentano (1995), para o problema com os lead times nulos. A heurística é composta por quatro procedimentos, solução inicial, factibilização, alteração e melhoria. Os testes executados mostraram que os resultados obtidos em Clark e Armentano (1995) foram melhorados. Berretta (1997) desenvolveu uma heurística baseada no trabalho de França et al. (1997), mas consideram o lead time diferente de zero. Nesta heurística são consideradas técnicas meta-heurísticas para obtenção de soluções de melhores qualidades.

Tempelmeier e Derstroff (1996) apresentam um procedimento baseado na relaxação Lagrangiana das restrições de capacidade e de balanço de estoque. O problema considerado neste trabalho difere de Billington et al. (1986), pois, consideraram restrições de capacidade em todas operações. Com a relaxação destas restrições, se obtém um problema decomponível por item, o qual pode ser resolvido eficientemente por um algoritmo de programação dinâmica (Ferdergruem e Tzur, 1991), para obtenção de um limitante inferior para o problema. O procedimento para obtenção de uma solução factível parte de uma solução inicial, a qual é factivel para as restrições de balanço de estoques, executando transferencias de produção dos recursos com sobrecarga em determinados periodos. $O$ procedimento heurístico é testado usando exemplos de dimensões pequenas e grandes, considerando os exemplos com e sem tempo de preparação. As soluções dos exemplos de dimensões pequenas (10 itens, 4 periodos e 3 máquinas) estão, em média, próximas das ótimas, sendo que estas apresentam um desvio (gap) de $1.47 \%$ para os exemplos sem tempos de preparação e, $1.35 \%$ 
para os exemplos com custo de preparação. Os resultados para os exemplos com dimensões maiores (40 itens, 16 períodos, 6 máquinas) são comparados com os valores dos limitantes inferiores obtidos através da relaxação Lagrangiana. Para estes exemplos, o desvio em relação ao limitante inferior, para os exemplos sem custo de preparação foi, em média, $17 \%$ e de $16.5 \%$ para os exemplos com custo de preparação. Eles também consideraram exemplos com 100 itens, 16 períodos e 10 máquinas e tempo de preparação nulos. Para estes exemplos, o desvio médio foi de $17.76 \%$, comparados com o limitante inferior, sendo este resultado, semelhante aos dos problemas com 40 itens sem tempo de preparação.

Neste mesmo trabalho de Tempelmeier e Derstroff (1996), cuja formulação matemática é equivalente à estudada por Berretta (1997), existe o seguinte comentário: “...de nosso conhecimento, não existem procedimentos (exatos ou heuristicos) disponiveis que usem uma verdadeira relaxação Lagrangiana para o problema, que apliquem uma heurística sofisticada e que tenha feito testes computacionais considerando estrutura geral de produtos com vários recursos, utilizados por itens de diferentes niveis da estrutura de produto". Devese observar que, a heurística desenvolvida por Berretta (1997) é aplicada ao problema considerando os lead times não nulos e, considera-se todas as particularidades comentadas no trabalho de Tempelmeier e Derstroff (1996). Também convém comentar que, o procedimento proposto para a resolução do problema desta tese considera todas as particularidades comentadas no trabalho de Tempelmeier e Derstroff (1996), além de considerar o problema em um ambiente de produção com máquinas paralelas.

Tempelmeier (1997) considera o planejamento de dimensionamento de lotes para a estrutura geral de produtos e discute sobre as principais deficiências dos sistemas MRP. Neste trabalho, utilizou vários problemas de dimensionamento de lotes para mostrar que o dimensionamento de lotes item por item deve ser substituído pela solução do problema de dimensionamento de lotes multiestágio com limitações de capacidade com tempo de preparação.

Katok et al. (1998) introduzem um procedimento heurístico para determinar boas soluções factíveis para problemas com estrutura de montagem. O desempenho da heurística é avaliado comparando as soluções ótimas obtidas para exemplos de pequena dimensão $(8,10$, 12 e 14 itens e 4, 5 e 6 períodos), usando OSL versão 1.2 (Optimization Subroutine Library, IBM, 1991). Neste caso, a heurística obteve soluções, em média, $4 \%$ piores do que as soluções ótimas. Para os exemplos com dimensão média (entre 37 a 108 itens e períodos gerados aleatoriamente entre 13 e 26), os resultados obtidos pela heurística foram comparados utilizando os valores das soluções factíveis obtidas pelo pacote OSL, o qual foi executado 
durante um tempo determinado. A heurística determinou neste caso, soluções, em média, $26 \%$ melhores do que as determinadas pelo OSL. Convém observar que o tempo utilizado para 0 OSL resolver os exemplos de dimensão média foi de 10.000 segundos de processamento, enquanto que, a heurística gastou $10 \%$ deste tempo para encontrar as soluções .

Este trabalho de doutorado aborda o problema de dimensionamento de lotes em ambiente mutiestágio de produção, onde cada estágio é composto por máquinas paralelas com capacidade limitada. Os custos considerados são de produção, estoque e preparação, sendo este último um custo fixo caso ocorra produção. É suposto que os recursos são gastos com produção e preparação. Os seguintes trabalhos também consideram múltiplas máquinas, Stadler (1996), Tempelmeier e Derstroff (1996) e Tempelmeier e Helber (1994), França et al. (1997), Berretta (1997), Katok et al. (1998). No entanto, as decisões em qual máquina produzir um determinado item em um determinado período não são tomadas, dadas pelas variáveis $X_{\text {itk }}$ (produção do item i na máquina $k$ no período t) e $Y_{i t k}$, (variáveis binárias que indicam a necessidade das preparações das máquinas caso ocorra produção). Na literatura, são encontrados poucos trabalhos que consideram o ambiente de produção com máquinas paralelas. Dentre os trabalhos que abordam o problema, podemos citar: Lasdon e Terjung (1971), Sabbag (1993), Toledo (1998) e Kang et al. (1999). Mas, tais trabalhos não consideram ambiente multiestágio de produção.

No Capítulo 3 é apresentado o modelo para o problema de dimensionamento de lotes multiestágio e máquinas paralelas para o qual é proposto um método de solução.

A seguir é apresentada uma breve revisão bibliográfica do problema de dimensionamento e sequenciamento de lotes.

\subsection{O Problema de Dimensionamento e Sequenciamento de Lotes}

Como pode ser visto nos modelos apresentados anteriormente, as decisões de sequenciamento não são tomadas. Uma abordagem usual no tratamento do problema de dimensionamento e sequenciamento de lotes consiste na determinação dos lotes e a seguir, na resolução do problema de sequenciamento em cada período separadamente (Sikonora et al. 1996)

Os trabalhos sobre o problema de dimensionamento e sequenciamento de lotes são escassos, sendo que a maioria encontrada na literatura considera o problema monoestágio com algumas condições especiais. Nesta breve revisão são consideradas somente abordagens que consideram o problema de dimensionamento e sequenciamento de lotes integrado. Como feito 
para o problema de dimensionamento de lotes, descreve-se primeiramente o problema monoestágio e a seguir, o multiestágio. Uma boa revisão bibliográfica sobre os problemas de dimensionamento e sequenciamento de lotes pode ser encontrada em Drexel e Kimms (1997), onde são apresentados vários modelos, dos quais, alguns são descritos nas próximas seções.

\subsubsection{O Problema de Dimensionamento e Sequenciamento de Lotes Monoestágio}

Com a subdivisão dos (macro) períodos do problema (2.1)-(2.5) em vários (micro) períodos leva ao problema de dimensionamento e sequenciamento de lotes discreto (DLSP). A principal suposição do problema DLSP é a produção "tudo-ou-nada", ou seja, somente um item pode ser produzido por período e, se houver produção, a produção deste item usa toda a capacidade (Drexel e Kimms, 1997). Cada período no modelo DLSP corresponde a horas ou transferências, ao contrário do problema (2.1)-(2.5) onde o período pode corresponder a semanas. O DLSP é chamado a small bucket problem (Fleischmann, 1990), porque não há mais de um item sendo produzido por período. Neste modelo, a produção de um lote pode levar vários períodos e deverá ocorrer o custo de preparação somente se iniciar a produção de um novo item, e as preparações devem ocorrer somente no inicio dos períodos. Observe que no modelo (2.1)-(2.5) ocorre um custo de preparação em cada período que houve produção (restrições 2.4). Para que não ocorra preparação se o item continua sendo produzido entre períodos consecutivos, faz-se necessário introduzir uma nova variável de decisão que representará a preparação em um certo período. A nova variável de decisão a ser considerada é:

$$
Z_{\text {it }}=\left\{\begin{array}{ll}
1 & \text { se a máquina é preparada para o item i no período } t \\
0 & \text { caso contrário }
\end{array} .\right.
$$

O novo dado para o problema DLSP é:

$$
\mathrm{Z}_{\mathrm{i} 0}=\left\{\begin{array}{ll}
1 & \text { se a máquina é preparada para o item } \mathrm{i} \text { no inicio do período } 1 \\
0 & \text { caso contrário }
\end{array} .\right.
$$

É considerado que a restrição $\sum_{\mathrm{i}=1}^{\mathrm{N}} \mathrm{Z}_{\mathrm{i} 0} \leq 1$ é válida.

Matematicamente o DLSP pode ser formulado como um problema de programação linear mista (Drexel e Kimms, 1997), o qual foi formulado por Fleischmann (1990): 


$$
\operatorname{minimize} \sum_{\mathrm{i}=1}^{N} \sum_{\mathrm{i}=1}^{T}\left(\mathrm{~h}_{\mathrm{it}} \mathrm{I}_{\mathrm{it}}+\mathrm{c}_{\mathrm{it}} \mathrm{X}_{\mathrm{it}}+\mathrm{cs}_{\mathrm{it}} \mathrm{Y}_{\mathrm{it}}\right)
$$

Sujeito a:

$$
\begin{array}{lc}
I_{i, t-1}+X_{i t}-I_{i t}=d_{i t} & i=1, \cdots, N, t=1, \cdots, T \\
b_{i} X_{i t}=C_{t} Z_{i t} & i=1, \cdots, N, t=1, \cdots, T \\
\sum_{i=1}^{N} Z_{i t} \leq 1 & t=1, \cdots, T \\
Y_{i t} \geq Z_{i t}-Z_{i(t-1)} & i=1, \cdots, N, t=1, \cdots, T \\
Z_{i t} \in\{0,1\} & i=1, \cdots, N, t=1, \cdots, T \\
I_{i t}, Y_{i t}, X_{i t} \geq 0 & i=1, \cdots, N, t=1, \cdots, T
\end{array}
$$

A função objetivo e algumas restrições são iguais as do problema (2.1)-(2.5). A suposição da produção "tudo-ou-nada" é representada na restrição (2.13), onde ao contrário da restrição (2.4) do problema CLSP, o lado direito e esquerdo devem ser iguais. As restrições (2.14) asseguram que somente um item pode ser produzido por período. As limitações de capacidade estão representadas pelas restrições (2.13) e (2.14) combinadas. O início de um novo lote a ser produzido é representado pela restrição (2.15). As restrições (2.16) garantem que as variáveis de preparação são binárias. Note também que ao contrário do problema CLSP, a não-negatividade das variáveis $\mathrm{Y}_{\mathrm{it}}$ é suficiente. Isto é devido à combinação das restrições (2.15) e (2.16) com a função objetivo (2.11).

Trabalhos que tratam o problema DLSP podem sem encontrados em Fleischmann (1990), que propõe um algoritmo do tipo branch-and-bound usando a técnica da relaxação Lagrangiana para determinar limitantes inferiores e soluções factíveis; Fleischmann (1994) que considerou o problema com custo de preparação dependente da seqüência como em Fleischmann (1990), no entanto, reformulou o problema como um problema do caixeiro viajante com janelas de tempo e apresentou uma heurística de melhoria, porém são resolvidos somente exemplos de dimensão média (máximo 10 itens e 150 períodos); Salomon et al. (1997) considera tempo e custo de preparação na formulação do problema e, generaliza a reformulação apresentada em Fleischmann (1994). O novo problema é resolvido pelo método proposto por Dumas et at. (1995); e Brüggemann e Jahnke (2000) que apresenta um estudo sobre a complexidade do problema e um procedimento de solução baseado na meta-heurística Simulated Annealing. 
Num outro problema, o problema de dimensionamento e sequenciamento de lotes contínuo, a suposição do "tudo-ou-nada" é abandonada, mas, somente um item pode ser produzido por período (Drexel e Kimms, 1997). A única diferença entre os modelos para o problema de dimensionamento de lotes e sequenciamento discreto e contínuo se encontra na restrição (2.13). Para o problema contínuo esta restrição torna-se:

$$
\mathrm{b}_{\mathrm{i}} \mathrm{X}_{\mathrm{it}} \leq \mathrm{C}_{\mathrm{t}} \mathrm{Z}_{\mathrm{it}} \quad \mathrm{i}=1, \cdots, \mathrm{N}, \mathrm{t}=1, \cdots, \mathrm{T}
$$

Assim, o problema de dimensionamento e sequenciamento de lote contínuo é formado pelas restrições (2.11)-(2.12), (2.14)-(2.18). Observa-se que a preparação para um item é mantida entre periodos de folga, ou seja, se não houve produção deste item no período $t^{\prime}$, e a máquina estava preparada para este item em t'-1 então, se a produção deste item ocorrer no período $t^{\prime}+1$, não haverá custo de preparação adicional $e$, isto não ocorre no problema anterior.

Considerando a suposição de que somente um item é produzido por período e pela restrição (2.18) observe que, se a capacidade por período não for usada completamente, o restante da capacidade ficará ociosa. Uma tentativa de evitar isto é considerar o problema de dimensionamento e sequenciamento de lotes proporcional (PLSP), estudado por Drexel e Haase (1995). A idéia básica deste problema é usar a capacidade restante na máquina para produzir um segundo item num determinado periodo. Assim, no problema PLSP pode ocorrer produção de até dois itens no período, o que não ocorre nos dois problemas anteriores. Se dois itens são produzidos em um período, deve-se saber qual é a ordem de produção. Assim é necessário a introdução de uma nova variável, a variável de preparação $Z_{\mathfrak{i t}}$, definida da seguinte maneira:

$Z_{i t}=\left\{\begin{array}{ll}1 & \text { se a máquina é preparada para o item i no final periodo } t \\ 0 & \text { caso contrário }\end{array}\right.$.

Observe que neste problema, a variável de preparação pode ser mudada no máximo uma vez por período. Assim, produção no periodo depende da preparação da máquina no início ou no final deste período. A seguir é dada a formulação matemática para o problema PLSP.

$$
\operatorname{minimize} \sum_{\mathrm{i}=1}^{\mathrm{N}} \sum_{\mathrm{t}=1}^{\mathrm{T}}\left(\mathrm{h}_{\mathrm{it}} \mathrm{I}_{\mathrm{it}}+\mathrm{c}_{\mathrm{it}} \mathrm{X}_{\mathrm{it}}+\mathrm{cs}_{\mathrm{it}} \mathrm{Y}_{\mathrm{it}}\right)
$$

Sujeito a:

$$
\begin{array}{ll}
\mathrm{l}_{\mathrm{i}, \mathrm{t}-1}+\mathrm{X}_{\mathrm{it}}-\mathrm{I}_{\mathrm{it}}=\mathrm{d}_{\mathrm{it}} & \mathrm{i}=1, \cdots, \mathrm{N}, \mathrm{t}=1, \cdots, \mathrm{T} \\
\mathrm{b}_{\mathrm{i}} \mathrm{X}_{\mathrm{it}} \leq \mathrm{C}_{\mathrm{t}}\left(\mathrm{Z}_{\mathrm{i}(\mathrm{t}-1)}+\mathrm{Z}_{\mathrm{it}}\right) & \mathrm{i}=1, \cdots, \mathrm{N}, \mathrm{t}=1, \cdots, \mathrm{T}
\end{array}
$$




$$
\begin{array}{lc}
\sum_{i=1}^{N} b_{i} X_{i t} \leq C, & t=1, \cdots, T \\
\sum_{i=1}^{N} Z_{i t} \leq 1 & t=1, \cdots, T \\
Y_{i t} \geq Z_{i t}-Z_{i(t-1)} & i=1, \cdots, N, t=1, \cdots, T \\
Z_{i t} \in\{0,1\} & i=1, \cdots, N, t=1, \cdots, T \\
I_{i t}, Y_{i t}, X_{i t} \geq 0 & i=1, \cdots, N, t=1, \cdots, T
\end{array}
$$

As restrições (2.21) asseguram que a produção de um item em um certo período pode ocorrer somente se a máquina é preparada no inicio do período ou no final do período. As restrições (2.22) combinadas com (2.23) garantem as limitações de capacidade por período. Observe que se não houver produção em um determinado período, a preparação é preservada para a produção em um período para frente do horizonte de planejamento.

Nos trabalhos de Kimms (1996a), Kimms (1996b), Kimms (1997), Kimms e Drexel (1998a) e Kimms e Drexel (1998b), o problema proporcional é considerado, no entanto, consideram o sistema de produção multiestágio.

\subsubsection{O Problema de Dimensionamento e Sequenciamento de Lotes Multiestágio}

Trabalhos sobre o problema de dimensionamento e sequenciamento de lotes multiestágio são escassos. Os trabalhos em que o dimensionamento e sequenciamento de lotes são feitos simultaneamente são os apresentados em Kimms (1996a), Kimms (1996b), Kimms (1997), Kimms e Drexel (1998a) e Kimms e Drexkl (1998b), os quais consideram o problema de dimensionamento e sequenciamento de lotes proporcional. A mudança para a formulação do problema multiestágios consta de considerar a restrição (2.7), no lugar da restrição (2.20) e, assim a formulação é formada pelo grupo de restrições (2.19), (2.7), (2.21)-(2.26), onde a restrição 2.7 é dada por:

$$
I_{i, t-1}+X_{i, t-L_{i}}-I_{i t}-\sum_{j \in S(i)} a_{i j} X_{j t}=d_{i t}, \quad i=1, \ldots, N, \quad t=1, \ldots, T,
$$

No trabalho de Kimms (1996a) duas heurísticas são apresentadas, uma baseada em estratégias de Busca Tabu e a outra em perdas aleatórias (randomized regret), as quais apresentam bom desempenho na obtenção de soluções de boa qualidade. Em Kimms (1996b) 
é considerado o problema anterior com estoques iniciais não-nulos, e utiliza-se a heurística baseada em perdas aleatórias para resolver o problema. Kimms (1997) propõe um método que combina estrutura de dados, que afeta a construção de planos de produção, e transferências de demandas baseadas nesta estrutura de dados, cujo método é chamado de demanda shuffle. Em Kimms e Drexel (1998a) são consideradas algumas extensões do problema, como por exemplo, o problema com máquinas paralelas e apresentam um método genérico para construção de planos de produção. Refinando este esquema genérico de construção, um método baseado em perdas aleatórias é introduzido. O trabalho de Kimms e Drexel (1998b) fornece alguns insights sobre o problema, os quais podem ser úteis ao desenvolvimento de heurísticas ou de procedimentos exatos. No mesmo trabalho é apresentada uma formulação matemática para o problema e este modelo é relacionado com outros encontrados na literatura, discutindo as características que fazem a tarefa de resolver exemplos deste problema difícil.

\subsubsection{O Problema de Dimensionamento e Sequenciamento de Lotes (Macro Períodos)}

$\mathrm{Na}$ literatura, existem poucos trabalhos que consideram o problema de dimensionamento e sequenciamento de lotes com vários itens sendo produzidos num período. A maioria trata dos problemas de dimensionamento e sequenciamento de lotes discreto ou proporcional. Os trabalhos de Laguna (1999), Kang et al. (1999), Meyr (2000), Haase e Kimms (2000), Clark e Clark (2000), Clark (2000a) e Clark (2000b) consideram o problema com vários itens sendo produzidos por período, ou seja, consideram macro períodos. Dentre todos estes trabalhos, somente Clark (2000b) considera o problema multiestágio. Nestes trabalhos são apresentados formulações matemáticas e procedimentos de resolução, mas, estes não consideram exemplos de grandes dimensões.

Em Laguna (1999) o problema de dimensionamento e sequenciamento de lotes monoestágio, única máquina é formulado como um problema inteiro misto, onde restriçōes de eliminação de subtour são necessárias para garantir que as seqüências de produção em cada período formam um tour. Com a relaxação das restrições de subtour pode-se resolver o problema resultante para determinar um limitante inferior. $O$ método heurístico proposto é baseado em um método de decomposição. O problema original é decomposto em dois subproblemas, um para determinar as produções e estoques e um problema do caixeiro viajante que trata com as sequêencias de produção. A heurística usa estratégias baseadas na 
memória de curto prazo do método de Busca Tabu para coordenar o problema de programação linear (produção e estoques) e o caixeiro viajante na busca de soluções factíveis.

Kang et al. (1999) consideram um modelo não convencional para o problema de dimensionamento e sequenciamento de lotes monoestágio com máquinas paralelas, onde uma sequêencia de produtos produzidos em uma máquina ao longo do horizonte de planejamento é modelada como uma coleção de subsequiências. $O$ procedimento de resolução baseado em geração de colunas e na metodologia branch-and-bound é desenvolvido, o qual foi heuristicamente adaptado para resolver exemplos reais.

No trabalho de Meyr (2000), a formulação apresentada em Fleischmann e Meyr (1997) do problema geral de dimensionamento e sequenciamento de lotes é estendida para tratar o problema com tempo de preparação dependente da seqüência de produção. Os lotes de produção devem ser determinados e sequenciados em uma única máquina com o objetivo de minimizar os custos de estoque e das preparações (dependentes da seqüência). Um método para resolução do problema é apresentado, o qual combina técnicas de busca local (Simulated Annealing e Threshold Accepting) com um algoritmo de reotimização dual.

Haase e Kimms (2000) apresentam um modelo de programação inteira mista com custos e tempos das preparações não nulos, onde são consideradas somente sequiências eficientes. A determinação das seqüências eficientes é feita resolvendo-se um problema de caixeiro viajante. Para este problema é proposto um algoritmo do tipo branch-and-bound ótimo que inicia o procedimento do periodo $\mathrm{T}$ escolhendo a melhor seqüência de produção para este período. Para os experimentos com putacionais, são considerados exemplos de 2 até 10 itens com um número de períodos de 3 até 10, e ainda 15 e 20 períodos. Os resultados computacionais mostraram que o tempo de processamento cresce mais rápido com o número de itens do que com o número de períodos, sendo que o tempo limite foi de 3600 segundos e no pior caso, ou seja, o tempo máximo gasto para resolução de um exemplo foi de 3501 segundos.

Clark e Clark (2000) apresentaram um modelo para o problema monoestágio, onde permitem níveis de estoques negativos, ou sejam, admitem que as demandas podem ser atendidas com atrasos. $\mathrm{Na}$ formulação são considerados os tempos gastos com as preparaç⿸̃es, no entanto, os custos das preparações são desconsiderados. O método desenvolvido considera o problema em um horizonte de tempo rolante e tem como objetivo determinar seqüências eficientes para um conjunto de máquinas paralelas. Clark (2000a) apresenta um modelo para o problema monoestágio, onde considera tempo de preparação não nulo, no entanto, como em Clark e Clark (2000), os custos das preparações são desconsiderados e permitem níveis de 
estoques negativos. O método heurístico proposto para resolução é semelhante ao desenvolvido por Laguna (1999), ou seja, resolve-se um problema de programação linear que determina os tamanhos do lotes e um problema do caixeiro viajante assimétrico que fornece as seqüências eficientes.

Em Clark (2000b) é apresentada uma formulação matemática para o problema de dimensionamento de lotes multiestágio, onde cada estágio é composto por máquinas paralelas não idênticas. Na formulação matemática os tempos gastos com as preparações são considerados não nulos e os níveis de estoques podem ser negativos. Foi utilizado o CPLEX para resolver otimamente exemplos de pequenas dimensões. Um exemplo com 5 itens, 2 máquinas e 5 períodos foi gerado e depois de 8 horas de execução do CPLEX, não foi confirmada a otimalidade, o que indica o grau de dificuldade na obtenção de soluções ótimas para o problema.

Nesta tese é considerado o problema de dimensionamento e sequenciamento de lotes multiestágio, onde os tempos e custos das preparaçōes são seqüências dependentes. Considera-se também que vários itens podem ser produzidos em um determinado período, ou seja, considera o problema com macro períodos. Para este problema é proposto um método de solução ("primeiros passos"), no entanto, os resultados computacionais não serão apresentados, por serem muito preliminares.

A seguir, no Capítulo 3, um modelo para o problema de dimensionamento de lotes multiestágio será apresentado. 


\section{CAPÍTULO 3}

\section{Dimensionamento de Lotes em Ambiente de Produção Multiestágio com Limitações de Capacidade e Máquinas Paralelas (MCMP)}

\subsection{Introdução}

Neste capftulo é apresentada uma formulação matemática para um problema de dimensionamento de lotes considerando diversas características. Uma formulação simplificada foi considerada, porém, ainda bastante geral, para qual não foram encontrados estudos realizados.

Os trabalhos que consideram o ambiente de produção com máquinas paralelas distintas, ou tratam com o problema monoestágio (Lasdon e Terjung, 1971, Sabbag, 1993, Toledo, 1998 e Kang et al., 1999) ou consideram decisões de sequenciamento no problema multiestágio (Kimms e Drexф1, 1998a).

O trabalho de Kang et al. (1999) é um dos poucos trabalhos encontrados na literatura que considera máquinas paralelas e, adicionalmente uma variável venda, que é relacionada com a demanda a ser atendida em cada periodo. No entanto, o modelo apresentado não é um modelo convencional como é o apresentado neste capítulo.

Assim, nesta tese é considerado o problema de dimensionamento de lotes em ambiente mutiestágio de produção, onde cada estágio é composto por máquinas paralelas com capacidade limitada. $\mathrm{Na}$ formulação matemática são considerados tempos e custos de 
preparação, o que torna o problema da otimalidade NP-dificil (Florian et al., 1980) e o problema da factibilidade NP-Completo (Maes et al., 1991).

O problema com máquinas paralelas pode ser encontrado em muitos ambientes de produção, tais como indústrias de freios de automóveis, indústrias farmacêuticas, na produção de placas de plástico, engarrafamento de líquidos, instalação de computadores, indústria química, na indústria têxtil, entre outros (Graves, 1981, Akink, 1993 e Toledo, 1998).

\subsection{Definição do Problema}

O objetivo do problema consiste em determinar um plano de produção ótimo que maximize o lucro líquido composto por: preço de venda dos itens, custos de estoque, produção, preparação e de capacidade alocada em cada máquina. As capacidades das máquinas são variáveis de decisão (dependem, por exemplo, do número de pessoas alocadas) e a demanda ocorre dentro de um intervalo, isto é, ao invés de um valor determinado, há uma tolerância para o atendimento da demanda. Estas características surgiram de uma aplicação prática, embora tenha sido implementada uma versão simplificada, devido às dificuldades encontradas na coleta dos dados e resolução do problema.

Para a formulação do modelo original, foram observadas algumas particularidades do problema em questão. Durante esta fase, foi possível observar que a capacidade disponível em uma determinada máquina, em cada período de tempo, dependia do número de pessoas designadas para trabalhar nesta máquina. Uma máquina é considerada como sendo um centro de trabalho formado por vários equipamentos, onde itens são trabalhados e montados, para o qual podem ser alocadas várias pessoas. Foi estimado o valor da capacidade de uma máquina $k$, para cada pessoa alocada, dada por $m_{k}$. A capacidade total para cada máquina foi aproximada linearmente e dada por $\mathrm{H}_{\mathrm{tk}}=\mathrm{H}_{\mathrm{tk}}\left(\mathrm{N}_{\mathrm{tk}}\right)=\mathrm{m}_{\mathrm{k}} \mathrm{N}_{\mathrm{tk}}$, onde $\mathrm{N}_{\mathrm{tk}}$ é o número de pessoas a ser alocadas para trabalhar na máquina $\mathrm{k}$ no período $\mathrm{t}$. $\mathrm{O}$ aumento do número de pessoas alocadas para trabalhar numa máquina tende a saturar-se de modo a decair a produtividade. $O$ ponto de saturação é suposto conhecido e modelado pela restrição $\mathrm{N}_{\mathrm{tk}} \leq \eta_{\mathrm{tk}}$, para cada máquina $\mathrm{k}$ e período $\mathrm{t}$, onde $\eta_{\mathrm{tk}}$ é o número máximo de pessoas alocáveis na máquina $\mathrm{k}$ no período t. Portanto, $\mathrm{MO}_{\mathrm{tk}}=\mathrm{m}_{\mathrm{k}} \eta_{\mathrm{tk}}$ é a capacidade máxima alocável à máquina $\mathrm{k}$ no período t. Os seguintes dados adicionais são considerados para a apresentação do modelo. 
Dados:

$\underline{\mathrm{d}}_{\mathrm{i}} \quad$ Demanda mínima prevista do item i no período $\mathrm{t}$.

$\overline{\mathrm{d}}_{\mathrm{i}_{1}} \quad$ Demanda máxima prevista do item i no período $\mathrm{t}$.

$\alpha_{i t} \quad$ Preço de venda de uma unidade do item i no período t.

$\omega_{\mathrm{tk}}$ Custo por unidade de capacidade alocada na máquina $\mathrm{k}$ no período $\mathrm{t}$

Total $l_{\mathrm{t}}$ Quantidade total de unidades de capacidade disponível no período $t$.

$\mathrm{MO}_{\mathrm{k}}$ Quantidade máxima de capacidade alocável na máquina $\mathrm{k}$ no período $\mathrm{t}$.

$\mathrm{c}_{\mathrm{itk}} \quad$ Custo unitário de produção do item i no período t na máquina $\mathrm{k}$.

$\mathrm{cs}_{\mathrm{ik}} \quad$ Custo de preparação do item i na máquina $\mathrm{k}$.

Variáveis:

$v_{i t} \quad$ Quantidade do item i a ser vendida no periodo $t$.

$\mathrm{H}_{\mathrm{tk}} \quad$ Capacidade alocada no periodo t na máquina $\mathrm{k}$.

$\mathrm{X}_{\mathrm{itk}} \quad$ Quantidade do item $\mathrm{i}$ a ser produzida no período $\mathrm{t}$ na máquina $\mathrm{k}$

$\mathrm{Y}_{\mathrm{itk}}=\left\{\begin{array}{ll}1, & \text { se } \mathrm{i} \text { é produzido no período t na máquina } \mathrm{k} \\ 0, & \text { caso contrário }\end{array}\right.$.

$\operatorname{Max} Z=\sum_{\mathrm{t}=1}^{T} \sum_{\mathrm{i}=1}^{N} \alpha_{i t} \mathrm{v}_{\mathrm{it}}-\left(\sum_{\mathrm{t}=1}^{\mathrm{T}} \sum_{\mathrm{i}=1}^{\mathrm{N}} \sum_{\mathrm{k}=1}^{\mathrm{K}} \mathrm{c}_{\mathrm{itk}} \mathrm{X}_{\mathrm{itk}}+\sum_{\mathrm{i}=1}^{\mathrm{N}} \sum_{\mathrm{t}=1}^{\mathrm{T}} \mathrm{h}_{\mathrm{it}} \mathrm{I}_{\mathrm{it}}+\sum_{\mathrm{t}=1}^{\mathrm{T}} \sum_{\mathrm{k}=1}^{\mathrm{K}}\left(\omega_{\mathrm{tk}} \mathrm{H}_{\mathrm{tk}}+\sum_{\mathrm{i}=1}^{\mathrm{N}} \mathrm{cs}_{\mathrm{ik}} \mathrm{Y}_{\mathrm{itk}}\right)\right)$

Sujeito a:

$$
\begin{aligned}
& \sum_{k=1}^{K} X_{i t k}+I_{i(t-1)}=v_{i t}+\sum_{j \in S(i)} a_{i j} \sum_{k=1}^{K} x_{j t k}+I_{i t} \quad i=1, \ldots, N t=1, \ldots T \\
& \sum_{i=1}^{N}\left(b_{i k} X_{i t k}+t_{i k} Y_{i t k}\right) \leq H_{t k} \quad k=1, \ldots K t=1, \ldots, T \\
& \sum_{\mathrm{k}=1}^{\mathrm{K}} \mathrm{H}_{\mathrm{tk}} \leq \text { Total }_{\mathrm{t}} \quad \mathrm{t}=1, \ldots, \mathrm{T} \\
& \mathrm{H}_{\mathrm{tk}} \leq \mathrm{MO}_{\mathrm{tk}} \quad \mathrm{k}=\mathrm{I}, \ldots \mathrm{K} \mathrm{t}=\mathrm{I}, \ldots, \mathrm{T} \\
& \underline{\mathrm{d}}_{\mathrm{it}} \leq \mathrm{v}_{\mathrm{it}} \leq \overline{\mathrm{d}}_{\mathrm{it}} \\
& \mathrm{i}=1, \ldots, \mathrm{N} \mathrm{t}=1, \ldots, \mathrm{T} \\
& \mathrm{X}_{\mathrm{itk}}-\mathrm{q} \mathrm{Y}_{\mathrm{itk}} \leq 0 \\
& \mathrm{i}=1, \ldots, \mathrm{Nk}=1, \ldots \mathrm{K} \mathrm{t}=1, \ldots, \mathrm{T} \\
& \mathrm{I}_{\mathrm{it}} \geq 0, \mathrm{X}_{\mathrm{itk}} \geq 0, \mathrm{H}_{\mathrm{tk}} \geq 0 \mathrm{Y}_{\text {itk }}=0 \text { ou } \mathrm{l} \quad \mathrm{i}=1, \ldots, \mathrm{N} \mathrm{k}=1, \ldots \mathrm{K} \mathrm{t}=1, \ldots, \mathrm{T}
\end{aligned}
$$


A função objetivo (3.1) representa o lucro que deve ser maximizado, sendo este formado pelo preço de venda dos itens menos os custos com produção, estocagem, preparação e por unidade de capacidade alocada em cada máquina. As restrições (3.2) são restrições de balanço de estoque e de produção. Em (3.3) estão as restrições que garantem que a quantidade utilizada para produção dos itens deve ser limitada pela capacidade a ser alocada em cada máquina $\mathrm{k}$ e em cada período t. As restrições (3.4) garantem que as quantidades de capacidades alocadas às máquinas em um determinado período $t$, não excedam a quantidade total disponivel no período (representando, por exemplo, o corpo de funcionários). A disponibilidade máxima de capacidade a ser alocada em cada máquina $\mathrm{k}$ é dada por (3.5). As restrições (3.6) garantem as limitações de mercado. Em (3.7) é indicada a necessidade de preparação das máquinas, caso ocorra produção e (3.8) são as restrições de não-negatividade das variáveis.

\subsection{Simplificação do Problema}

Com todas as características juntas, torna-se muito complicado determinar um procedimento de resolução para o modelo (3.1)-(3.8). Assim, é proposto um modelo simplificado e, numa fase posterior a esta tese, considerar as dificuldades gradativamente. A simplificação consiste em considerar fixas as capacidades e as demandas, com isso, eliminando-se um certo número de restrições e variáveis (variáveis $\mathrm{v}_{\mathrm{it}}$ e $\mathrm{H}_{\mathrm{tk}}$, e restrições 3.4, 3.5 e 3.6). Denomina-se a capacidade fixada para cada máquina $\mathrm{k}$ no período t por $\mathrm{CAP}_{\mathrm{tk}}$ e a demanda por $d_{1 t}$. Esta simplificação do problema resulta ainda num problema para o qual, não foram encontrados métodos de solução na literatura.

O problema simplificado consiste em determinar o tamanho do lote de produção de cada item em cada período em um horizonte de tempo finito de modo a atender uma demanda fixa e satisfazer restrições de balanceamento de estoques e de capacidade. Os custos considerados são de produção, estoque e preparação, sendo este último um custo fixo caso ocorra produção. É suposto que os recursos são gastos com produção e preparação.

O modelo matemático do problema simplificado pode ser escrito como

$$
\operatorname{Min} \mathrm{Z}=\sum_{\mathrm{i}=1}^{\mathrm{N}} \sum_{\mathrm{t}=1}^{\mathrm{T}}\left(\mathrm{h}_{\mathrm{it}} \mathrm{I}_{\mathrm{it}}+\sum_{\mathrm{k}=1}^{\mathrm{K}}\left(\mathrm{c}_{\mathrm{itk}} \mathrm{X}_{\text {itk }}+\mathrm{cs} \mathrm{s}_{\mathrm{ik}} \mathrm{Y}_{\text {itk }}\right)\right)
$$


Sujeito a:

$$
\begin{array}{ll}
\sum_{k=1}^{K} X_{i t k}+I_{i(t-1)}-I_{i t}=d_{i t}+\sum_{j \in S(i)} a_{i j} \sum_{k=1}^{K} X_{j t k}, & \forall i, t
\end{array}
$$

A função objetivo (3.9) minimiza os custos de produção, estoque e preparação. A restrições (3.10) representam as equações de balanço de estoque. As restrições (3.11) são as restrições de limitação de capacidade e, (3.12) assegura que $\mathrm{X}_{\mathrm{itk}}=0$, se $\mathrm{Y}_{\mathrm{itk}}=0$. Os estoques inicias $\left(\mathrm{I}_{\mathrm{i} 0}, \forall \mathrm{i}\right)$ e finais $\left(\mathrm{I}_{\mathrm{iT}}, \forall \mathrm{i}\right)$ de todos os itens são considerados nulos.

Observe que o problema inteiro misto (3.9)-(3.13) tem $\left(\mathrm{NxT}+\mathrm{Nx}_{x \mathrm{~K}}\right)$ variáveis reais e $\mathrm{N}_{x} \mathrm{~T}_{x \mathrm{~K}}$ variáveis binárias, e $\left(\mathrm{N}_{x} \mathrm{~T}+\mathrm{T}_{x K} \mathrm{~K}+\mathrm{N}_{x} \mathrm{~T}_{x} \mathrm{~K}\right)$ restrições. Considerando, por exemplo, $\mathrm{N}=40, \mathrm{~T}=18$ e $\mathrm{K}=4$, obtém-se um problema com 3600 variáveis reais e 2880 variáveis binárias, sujeito ao atendimento de 3640 restrições. Dificilmente um software que resolva o problema otimamente conseguiria determinar uma solução ótima para um exemplo desta dimensão em um tempo razoável.

No Capítulo 4 é apresentando um método heurístico básico para resolução do problema (3.9)-(3.13), sendo que, os resultados computacionais são apresentados no Capítulo 5 , juntamente com as variantes do método. 


\section{CAPÍTULO 4}

\section{UM PROCEDIMENTO HEURÍSTICO PARA A RESOLUÇÃo do PRoblema MCMP}

\subsection{INTRODUÇĀO}

Neste capítulo é descrito um método heurístico para o problema de dimensionamento de lotes multiestágio com máquinas paralelas, as quais possuem limitações de capacidade, definido no Capítulo 3. O método proposto pode ser representado pelos seguintes procedimentos no fluxograma dado pela Figura 4.1.

A heurística proposta utiliza, primeiramente, um procedimento $\mathrm{P} 1$, que constrói uma solução inicial que, geralmente, é infactível (infac). A seguir, caso a solução inicial seja infactível, um procedimento P2 tenta encontrar uma solução factível (fac), a partir dessa inicial. Se uma solução factível for encontrada, um procedimento P3 procura obter uma solução factivel de melhor custo. No entanto, o procedimento de factibilização P2 pode falhar, ou seja, após um certo número de iterações nenhuma solução factível é encontrada. Se ocorrer a falha do procedimento $\mathrm{P} 2$, aplica-se um procedimento $\mathrm{P} 4$, o qual reconfigura a solução infactível dada pelo procedimento $\mathrm{P} 2$, obtendo um novo ponto de partida para o procedimento de factibilização (P2). O procedimento P2 será reaplicado a esta nova solução durante um certo número de iterações preestabelecido. Se após a reaplicação do procedimento P2 ainda não for obtida uma solução factível, então o método é interrompido com duas possibilidades: 
1) o problema é infactível ou, 2) o método heurístico falha em determinar uma solução factível.

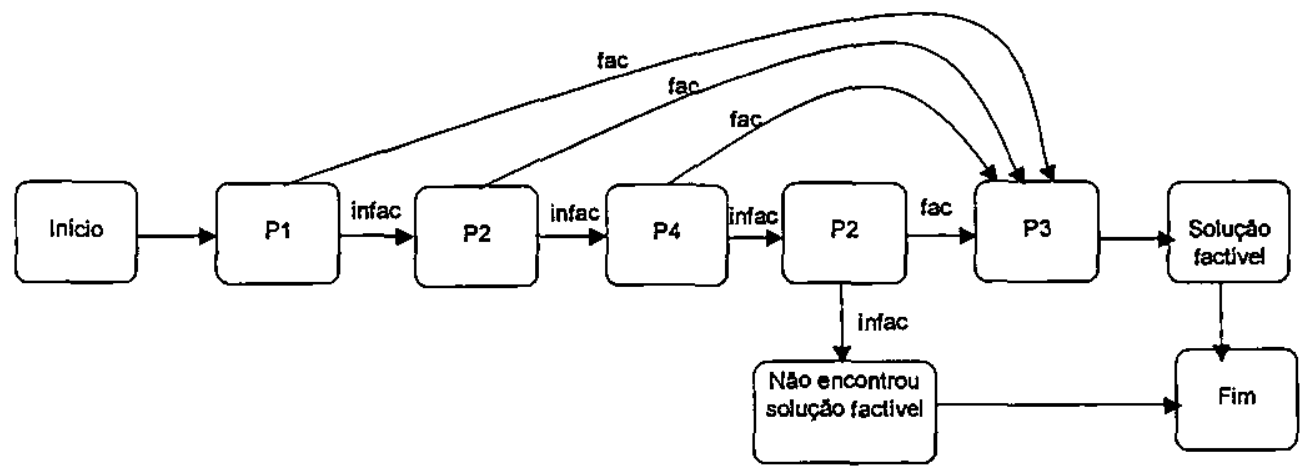

Figura 4.1. Fluxograma do procedimento heuristico para resolução do problema (3.9)-(3.13).

No próximo capítulo é apresentado o que ocorre com a heurística com relação ao número de soluções factíveis obtidas e também é feita uma análise das soluções, para as quais, o procedimento de factibilização P2 falhou em obter a factibilidade. Para estas soluções é verificado se são "recomendáveis", apesar da infactibilidade.

\subsection{SoluÇão Inicial - Procedimento P1}

Neste trabalho são desenvolvidos dois procedimentos para determinar soluções iniciais. Tais procedimentos são baseados no trabalho de Armentano e Toledo (1997).

\subsubsection{WW-PARALELO}

O algoritmo de Wagner e Whitin (1958) resolve o problema de dimensionamento de lotes com um único item, sem restrições de capacidade para uma única máquina. Armentano e Toledo (1997) estenderam este algoritmo para máquinas paralelas que pode ser facilmente estendido ao problema estudado neste trabalho para cada item separadamente, para a obtenção de uma solução inicial, possivelmente infactível.

Inicialmente as restrições de capacidade (3.11) são relaxadas (simplesmente abandonadas), obtendo-se um problema multiestágio com máquinas paralelas sem limitações de capacidade. A seguir, o algoritmo de Armentano e Toledo (1997) é utilizado para produzir 
uma solução factível para problema multiestágio em relação às restrições de balanço de estoque da seguinte forma.

Para cada item $\mathrm{i}, \mathrm{i}=1, \ldots, \mathrm{N}$, resolve-se o seguinte problema, a partir dos itens finais, pois tais itens não possuem sucessores $(S(i)=\varnothing)$, de modo que o lado direito da equação (4.2) reduz-se a $d_{\mathrm{it}}$. Descendo a estrutura do produto, o termo do lado direito de (4.2) fica sempre determinado, porque as quantidades $\sum_{\mathrm{j} \in \mathrm{S}(\mathrm{i})} \mathrm{a}_{\mathrm{ij}} \sum_{\mathrm{k}=1}^{\mathrm{K}} \mathrm{X}_{\mathrm{jtk}} \mathrm{já}$ foram determinadas para todos os itens sucessores do item i. Desta forma, obtém-se uma solução heurística para o problema (4.1)-(4.4).

$$
\text { Minimize } Z_{i}=\sum_{i=1}^{T} \sum_{k=1}^{K} c_{i t k} X_{i t k}+\sum_{i=1}^{T} h_{i t} I_{i t}+\sum_{i=1}^{T} \sum_{k=1}^{K} c s_{i k} Y_{i t k}
$$

Sujeito a:

$$
\begin{array}{ll}
\sum_{k=1}^{K} X_{i t k}+I_{i(t-1)}-I_{i t}=d_{i t}+\sum_{j \in S(i)} a_{i j} \sum_{k=1}^{K} X_{j t k} & t=1, \ldots T \\
X_{i t k}-M Y_{i t k} \leq 0 & k=1, \ldots K ; t=1, \ldots, T \\
I_{i t} \geq 0, X_{i t k} \geq 0, Y_{i t k}=0 \text { ou } 1 & k=1, \ldots K ; t=1, \ldots, T
\end{array}
$$

A função objetivo (4.I) pode ser rescrita, definindo-se:

$$
g_{i l k}\left(X_{i t k}\right)= \begin{cases}c s_{i k}+c_{i t k} X_{i t k} & \text { se } X_{i l k}>0 \\ 0 & \text { se } X_{i t k}=0\end{cases}
$$

e, portanto,

$$
\mathrm{Z}_{\mathrm{i}}=\sum_{\mathrm{i}=1}^{\mathrm{T}}\left(\mathrm{h}_{\mathrm{it}} \mathrm{I}_{\mathrm{it}}+\sum_{\mathrm{k}=1}^{\mathrm{K}} \mathrm{g}_{\mathrm{itk}}\left(\mathrm{X}_{\mathrm{itk}}\right)\right)
$$

que consiste em uma função côncava.

Assim, pode-se rescrever o problema (4. I)-(4.4) do seguinte modo:

$$
\text { Minimize } Z_{\mathrm{i}}=\sum_{\mathrm{t}=1}^{\mathrm{T}}\left(\mathrm{h}_{\mathrm{it}} \mathrm{I}_{\mathrm{it}}+\sum_{\mathrm{k}=1}^{\mathrm{K}} \mathrm{g}_{\mathrm{itk}}\left(\mathrm{X}_{\mathrm{itk}}\right)\right)
$$

Sujeito a:

$$
\begin{array}{ll}
\sum_{k=1}^{K} X_{i t k}+I_{i(t-1)}-I_{i t}=D_{i t}^{\prime} & t=I, \ldots T \\
I_{i t} \geq 0, \quad X_{i t k} \geq 0 & k=I, \ldots K t=I, \ldots, T
\end{array}
$$

onde: $D_{i t}^{\prime}=d_{i t}+\sum_{j \in S(i)} a_{i j} \sum_{k=1}^{K} X_{j t k}$ 
Portanto, o problema (4.6)-(4.8) consiste em minimizar uma função objetiva côncava sobre um conjunto de restrições convexas, de modo que a solução deste problema ocorre em um dos pontos extremos da região definida por (4.6)-(4.8) (Luenberger, 1984). Conseqüentemente, a solução do problema (4.6)-(4.8) é composta por no máximo T variáveis não nulas (variáveis básicas, já que as restrições são lineares).

Armentano e Toledo (1997) observaram que se $D_{i t}{ }^{\prime}>0$, i fixo, para $t=1, \ldots, T$, então, ou $\mathrm{I}_{\mathrm{i}(\mathrm{t}-1)}>0$ ou $\mathrm{X}_{\mathrm{itk}}>0$ para um ou mais $\mathrm{k} \in\{\mathrm{l}, \cdots, \mathrm{K}\}$. Isto significa que, ou a demanda no período $t$ é atendida pela produção no próprio período $t$ em uma ou mais máquinas e/ou pelo estoque proveniente do período $\mathrm{t}-1$. Dado que existem somente T restrições, portanto existem no máximo $\mathrm{T}$ variáveis não nulas em um ponto extremo, ou seja, exatamente uma das variáveis $\mathrm{I}_{\mathrm{i}(\mathrm{t}-1)}>0$ ou $\mathrm{X}_{\mathrm{itk}}>0$ para um único $\mathrm{k} \in\{1, \cdots, \mathrm{K}\}$ poderá ser positiva. Então, para um $\mathrm{i}$ fixo, todo ponto extremo satisfaz a seguinte propriedade: $1_{\mathrm{i}(\mathrm{t}-1)} \mathrm{X}_{\mathrm{itk}}=0$ para todo $\mathrm{k} \in\{1, \cdots, \mathrm{K}\}$ e $\mathrm{t}=1, \ldots, \mathrm{T}$.

A seguir, é descrito o algoritmo proposto por Armentano e Toledo (1997), para o problema de dimensionamento de lotes de um único item produzido em máquinas paralelas (4.6)-(4.8), que deverá ser aplicado seqüencialmente, iniciando de $\mathrm{i}=1$.

\section{O Algoritmo de WW para Máquinas Paralelas}

Seja $M_{i k \uparrow}$, o custo de produção do item $i$, na máquina $k$, no período $\tau+1$, para atender as demandas do período $\tau+1$ até $o$ período $t$, isto é, o custo de $D_{i t t}^{\prime}$, onde $D_{i \tau t}^{\prime}=D_{i(\tau+1)}^{\prime}+\cdots+D_{i t}^{\prime}$. Assim, $M_{i k \tau t}$ é o custo de preparação $\mathrm{cs}_{i \mathrm{k}}$, mais o custo de produção $c_{i(\tau+1) k} D_{i \tau t}^{\prime}$, mais os custos de estoque $h_{i(\tau+1)} D_{i(\tau+1) t}^{\prime}+h_{i(\tau+2)} D_{i(\tau+2) t}^{\prime}+\ldots$

Então $M_{i k \tau t}= \begin{cases}c s_{i k}+c_{i(\tau+l) k} D_{i \tau t}^{\prime}+\sum_{\gamma=\tau+1}^{t-1} h_{i \gamma} D_{i \gamma t}^{\prime} & \text { se } D_{i \tau t}^{\prime}>0 \\ 0 & \text { se } D_{i \tau t}^{\prime}=0\end{cases}$

Seja $F_{i l}$, o custo mínimo de produção do item $i$, no período 1 até o período t, dado que $I_{i t}=0$. Então $F_{i t}$ pode ser determinado recursivamente como:

$$
\begin{aligned}
& \mathrm{F}_{\mathrm{it}}=\min \left\{\mathrm{F}_{\mathrm{i \tau}}+\mathrm{M}_{\mathrm{ikt} t}, 0 \leq \tau \leq \mathrm{t}, 1 \leq \mathrm{k} \leq \mathrm{K}\right\} \text {, para } \mathrm{t}=1, \cdots, \mathrm{T} \text {, e algum } \mathrm{j} \text { fixo. } \\
& \mathrm{F}_{\mathrm{j} 0}=0 .
\end{aligned}
$$

A fórmula de programação dinâmica progressiva no tempo é equivalente ao problema de encontrar o caminho de custo mínimo em uma rede. Nesta rede, cada nó corresponde a um 
período de tempo e ao item para o qual está sendo determinado o plano de produção, e um $\operatorname{arco}(\tau, \mathrm{t})$ está associado à produção de $D_{i+1}^{\prime}$ com custo $M_{i k+t}$. Um exemplo com 3 períodos e 2 máquinas, para um item i qualquer, é ilustrado na Figura 4.2. Foi implementado uma modificação proposta em Evans (1985), que consiste em escrever os custos $M_{i k \tau \text {, }}$ da seguinte forma:

$$
\begin{array}{lc}
M_{i k \tau(\tau+1)}=c s_{i k}+c_{i(\tau+1) k} D_{i(\tau+1)} & k=1, \cdots, K, l=1, \cdots, T-1 \\
M_{i k \tau t}=M_{i k \tau(t-1)}+D_{i t}\left(c_{i k}+C E_{i \tau t}\right) & t>\tau+1
\end{array}
$$

onde:

$$
C E_{i(\tau+1)(t-1)}=\sum_{\gamma=\tau+1}^{t-1} h_{i \gamma}
$$

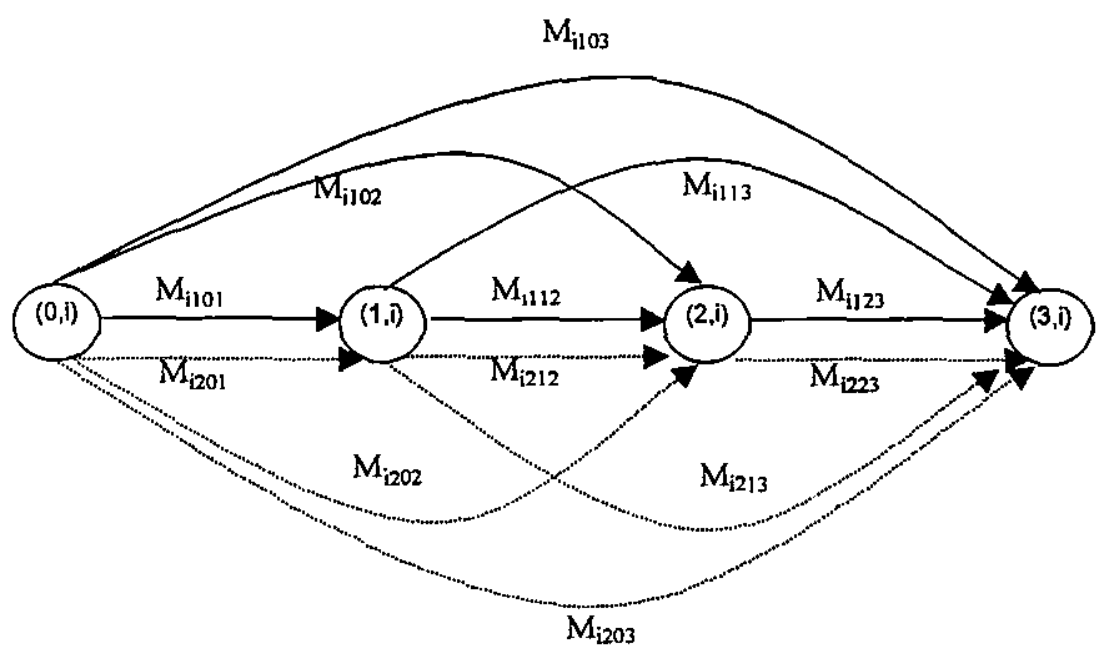

Figura 4.2. Rede represenıando o algoritmo para máquinas paralelas.

\section{RESUMO Do Algoritmo}

\section{Para $i=1 . . . N$ faça}

\section{Início}

Se $S(i) \neq \varnothing$ (i.e., i é um item componente) então faça $D^{\prime}{ }_{i t}=d_{i t}+\sum_{j \in S(i)} a_{i j} \sum_{k=1}^{K} X_{j t k}$

Determine $\mathrm{M}_{\mathrm{i} \times \tau(\tau+1)}=\mathrm{cs}_{\mathrm{ik}}+\mathrm{c}_{\mathrm{i}(\tau+1) \mathrm{k}} \mathrm{D}_{\mathrm{i}(\tau+1)}^{\prime} \quad \mathrm{k}=1, \cdots, \mathrm{K}, \tau=1, \cdots, \mathrm{T}-\mathrm{le}$,

$$
\mathrm{M}_{\mathrm{ik \tau t}}=\mathrm{M}_{\mathrm{ik \tau (t-1)}}+\mathrm{D}_{\mathrm{it}}^{\prime}\left(\mathrm{c}_{\mathrm{i} 1 \mathrm{k}}+\mathrm{CE}_{\mathrm{it} t}\right) \quad \mathrm{t}>\tau+1 \text {; }
$$

Determine $F_{i t}=\operatorname{minimo}\left\{F_{i \tau}+M_{i k \tau t}, 0 \leq \tau \leq t, 1 \leq k \leq K\right\}$ para $t=1, \cdots, T$ e $F_{i 0}=0$. Fim. 
O algoritmo acima é aplicado item a item iniciando com $\mathrm{i}=1$ (um item final, $\mathrm{S}(\mathrm{i})=\varnothing$ ) até $\mathrm{i}=\mathrm{N}$.

Assim, as soluções dos $\mathrm{N}$ problemas formam uma solução para o problema original. Tal solução pode ser infactível em relação às restrições de capacidade (3.11) e, portanto, infactivel para o problema original. Se este for o caso, uma heurística de factibilização, descrita a seguir, é aplicada. Caso a solução seja factível, a heuristica de melhoria, descrita na seção 4.4., é aplicada.

O procedimento para obtenção da solução inicial baseada no trabalho de Armentano e Toledo (1997) é denominado de WW-Parelelo.

\subsubsection{WW-Paralelo Penalizado}

O procedimento WW-Parelelo Penalizado consistiu numa simples extensão do trabalho de Armentano e Toledo (1997) considerando a estrutura do problema. Entretanto, o procedimento de Armentano e Toledo (1997) (como também o algoritmo de Wagner e Whitin original) ignora restrições de capacidade. Nesta seção é proposta uma modificação na definição dos pesos dos arcos, de modo que máquinas sobrecarregadas sejam inibidas de produção, objetivando atenuar as violaçōes. Considere novamente, $M_{i k \tau t}$ dado por (4.9)/ou (4.12)-(4.14).

Este custo, $\mathrm{M}_{\mathrm{i}_{\mathrm{k} \tau \mathrm{t}}}(\operatorname{arco})$, é multiplicado por um valor penalidade $\mathrm{k}_{\mathrm{it}}$ que incentiva a produção nos períodos e máquinas com menor utilização da capacidade para produção e preparação. $O$ valor desta penalidade é dado por:

penalidade $_{k \tau t}=\frac{\text { utilização }_{k(\tau+1)}}{\operatorname{cap}_{(\tau+1) k}}$

sendo que:

utilização $_{\mathbf{k}(\tau+1)}=$ utilização_anterior $_{\mathbf{k}(\tau+1)}+$ utilização_agora $_{\mathbf{k}(\tau+1)}$

utilização_anterior $_{k(\tau+1)}=\sum_{j<i}\left(b_{j k} X_{j(\tau+1)}+t_{j k} Y_{j(\tau+1) k}\right)$

utilização_agora $_{k(\tau+1)}=\mathrm{b}_{\mathrm{ik}} \mathrm{d}_{\mathrm{i}(\tau+1)}^{\prime}+\mathrm{ts}_{\mathrm{ik}}$

onde: $d_{i(\tau+1)}^{\prime}=D_{i \tau t}^{\prime}$, sendo que, $d_{i(\tau+1)}^{\prime}$ é a demanda acumulada do período $\tau+1$ até o período $t$, como dada na definição de $D_{i \tau t}^{\prime}\left(D_{i \tau 1}^{\prime}=D_{i(\tau+1)}^{\prime}+\cdots+D_{i t}^{\prime}\right)$. 
A utilização $o_{k(\tau+1)}$ contabiliza a quantidade de recursos gasto para produção e para as preparações de todos os itens produzidos anteriormente a i (sucessores, pois o algoritmo é aplicado seqüencialmente), incluindo o tempo gasto para produção e preparação do item i, na máquina $\mathrm{k}$ e período $(\tau+\mathrm{l})$. Observe que este valor é diferente para todos os pares $(\mathrm{k}, \mathrm{t})$ considerados. Este procedimento será denominado, daqui para frente, de WW-Paralelo Penalizado.

Observe também que, se penalidade $\mathrm{k}_{\tau t}>1$, indica que tal decisão produzirá uma violação da capacidade da máquina $\mathrm{k}$, no período $(\tau+1)$.

No capítulo de resultados computacionais são apresentadas experiências comparando as duas soluções iniciais. Porém, um exemplo é aqui apresentado para ilustrar os dois procedimentos na obtenção das soluções iniciais. A estrutura de produtos considerada é do tipo serial com dois itens. O horizonte de planejamento é de três períodos e duas máquinas e os parâmetros são descritos na Tabela 4.1. A resolução deste exemplo, para o item i=l, é apresentada na Tabela 4.2.

Tabela 4.1. Dados do Exemplo.

\begin{tabular}{|c|c|c|c|}
\hline & $t=1$ & $t=2$ & $\mathrm{t}=3$ \\
\hline$d_{1 t}$ & 165 & 38 & 19 \\
\hline$d_{2 t}$ & 9 & 2 & 4 \\
\hline$\overline{h_{1 t}}$ & 0.53 & $\overline{0.53}$ & 0.53 \\
\hline$h_{21}$ & 0.22 & 0.22 & 0.22 \\
\hline $\mathrm{cap}_{11}$ & 656 & 435 & 435 \\
\hline \multirow[t]{2}{*}{ capt2 $_{2}$} & 654 & 435 & 435 \\
\hline & $\mathrm{k}=1$ & $\mathrm{k}=2$ & \\
\hline$c_{l \mathrm{lk}}:=c_{l k}$ & 1.55 & 1.54 & \\
\hline$c_{2 t k}=c_{2 k}$ & 1.71 & 1.71 & \\
\hline $\mathrm{cs}_{\mathrm{Ik}}$ & 11.27 & 76.9 & \\
\hline $\operatorname{cs}_{2 k}$ & 39.89 & 49.78 & \\
\hline$b_{l_{k}}$ & 2.41 & 2.5 & \\
\hline$b_{2 k}$ & 2.57 & 2.37 & \\
\hline$t_{1 k}$ & 227.11 & 241.03 & \\
\hline $\mathrm{ts}_{2 \mathrm{k}}$ & 208.73 & 164.34 & \\
\hline
\end{tabular}

Primeiramente, o exemplo é resolvido utilizando o algoritmo de WW-Paralelo e depois, é aplicado o algoritmo WW-Paralelo Penalizado. 
Tabela 4.2. Aplicação do algoritmo de WW-Paralelo para o item I (item final).

\begin{tabular}{|c|c|}
\hline $\mathrm{M}_{1101}$ & $c s_{11}+c_{11} d_{11}=267.02$ \\
\hline $\mathbf{M}_{1201}$ & $\mathrm{cs}_{12}+\mathrm{c}_{12} \mathrm{~d}_{11}=331$ \\
\hline $\mathrm{M}_{1112}$ & $c s_{11}+c_{11} d_{12}=70,2$ \\
\hline$M_{1212}$ & $c s_{12}+c_{12} d_{12}=135.42$ \\
\hline $\mathrm{M}_{1,23}$ & $\mathrm{cs}_{11}+\mathrm{c}_{11} \mathrm{~d}_{13}=40.72$ \\
\hline $\mathrm{M}_{1223}$ & $c s_{12}+c_{12} d_{13}=106.16$ \\
\hline $\mathrm{M}_{1102}$ & $c s_{11}+c_{11}\left(d_{11}+d_{12}\right)+h_{11} d_{12}=346.06$ \\
\hline $\mathrm{M}_{1202}$ & $c s_{12}+c_{12}\left(d_{11}+d_{12}\right)+h_{11} d_{12}=409.66$ \\
\hline $\mathrm{M}_{1103}$ & $c s_{11}+c_{11}\left(d_{11}+d_{12}+d_{13}\right)+h_{11}\left(d_{12}+d_{13}\right)+h_{12} d_{13}=395.65$ \\
\hline $\mathrm{M}_{1203}$ & $c s_{12}+c_{12}\left(d_{11}+d_{12}+d_{13}\right)+h_{11}\left(d_{12}+d_{13}\right)+h_{11} d_{13}=459.06$ \\
\hline $\mathrm{M}_{1113}$ & $c s_{11}+c_{11}\left(d_{12}+d_{13}\right)+h_{12} d_{13}=109.69$ \\
\hline $\mathrm{M}_{1213}$ & $c s_{12}+c_{12}\left(d_{12}+d_{13}\right)+h_{12} d_{13}=174.75$ \\
\hline$F_{10}$ & 0 \\
\hline$F_{11}$ & $\min \left\{\mathrm{F}_{10}+\mathrm{M}_{1101}, \mathrm{~F}_{10}+\mathrm{M}_{1201}\right\}=\mathrm{F}_{10}+\mathrm{M}_{1101}=267.02$ \\
\hline $\mathrm{F}_{12}$ & $\min \left\{F_{10}+M_{1102}, F_{10}+M_{1202}, F_{11}+M_{1112}, F_{11}+M_{1212}\right\}=F_{11}+M_{1112}=337.19$ \\
\hline$F_{13}$ & $\min \left\{F_{10}+M_{1103}, F_{10}+M_{1203}, F_{11}+M_{1113}, F_{11}+M_{1213}, F_{12}+M_{1123}, F_{12}+M_{1223}\right\}=F_{11}+M_{1113}=376.71$ \\
\hline Produção & $\mathrm{X}_{111}=165, \quad \mathrm{X}_{121}=57, \quad \mathrm{X}_{131}=0$ \\
\hline & $X_{112}=0, \quad X_{122}=0, \quad X_{132}=0$ \\
\hline Estoques & $h_{11}=0, \quad h_{12}=19, \quad h_{13}=0$ \\
\hline
\end{tabular}

Como o algoritmo é aplicado seqüencialmente, determina-se agora, o plano de produção para o item 2 . As demandas deste item são mudadas levando em consideração o plano de produção do item 1 .

Definido a demanda do item $\mathrm{i}=2$, em cada $\mathrm{t}$ por: $\mathrm{D}^{\prime}$ it, tem-se:

$\mathrm{D}_{21}^{\prime}=\mathrm{d}_{21}+\mathrm{X}_{111}+\mathrm{X}_{112}=9+165=174$

$\mathrm{D}_{22}^{\prime}=\mathrm{d}_{22}+\mathrm{X}_{121}+\mathrm{X}_{122}=2+57=59$

$D^{\prime}{ }_{23}=d_{23}+X_{131}+X_{132}=4+0=4$

A aplicação do algoritmo para este item é dada na tabela seguinte. 
Tabela 4.3. Aplicação do algoritmo de WW-Paralelo para o item 2 (item componente).

\begin{tabular}{|c|c|}
\hline $\mathrm{M}_{2101}$ & $\mathrm{cs}_{21}+\mathrm{c}_{21} \mathrm{D}_{21}^{\prime}=337.4$ \\
\hline $\mathrm{M}_{2201}$ & $\mathrm{cs}_{22}+\mathrm{c}_{22} \mathrm{D}^{\prime}{ }_{21}=347.3$ \\
\hline $\mathrm{M}_{2112}$ & $\mathrm{cs}_{21}+\mathrm{c}_{21} \mathrm{D}_{22}^{\prime}=140.8$ \\
\hline $\mathrm{M}_{2212}$ & $\mathrm{Cs}_{22}+\mathrm{c}_{22} \mathrm{D}^{\prime}{ }_{12}=150.7$ \\
\hline $\mathrm{M}_{2123}$ & $\mathrm{cs}_{21}+\mathrm{c}_{21} \mathrm{D}_{23}^{\prime}=46.7$ \\
\hline $\mathrm{M}_{2223}$ & $\mathrm{cs}_{22}+\mathrm{c}_{22} \mathrm{D}_{23}^{\prime}=56.6$ \\
\hline $\mathrm{M}_{2102}$ & $\mathrm{Cs}_{21}+\mathrm{c}_{21}\left(\mathrm{D}_{21}^{\prime}+\mathrm{D}_{22}^{\prime}\right)+\mathrm{h}_{21} \mathrm{D}_{12}=451.3$ \\
\hline $\mathrm{M}_{2202}$ & $\mathrm{cs}_{22}+\mathrm{c}_{22}\left(\mathrm{D}_{21}^{\prime}+\mathrm{D}_{22}^{\prime}\right)+\mathrm{h}_{21} \mathrm{D}_{22}^{\prime}=461.2$ \\
\hline $\mathrm{M}_{2103}$ & $\mathrm{Cs}_{21}+\mathrm{c}_{21}\left(\mathrm{D}_{21}^{\prime}+\mathrm{D}_{22}^{\prime}+\mathrm{D}_{23}^{\prime}\right)+\mathrm{h}_{21}\left(\mathrm{D}_{22}^{\prime}+\mathrm{D}_{23}^{\prime}\right)+\mathrm{h}_{22} \mathrm{D}_{23}^{\prime}=459.9$ \\
\hline $\mathrm{M}_{2203}$ & $\mathrm{Cs}_{22}+\mathrm{c}_{22}\left(\mathrm{D}_{21}^{\prime}+\mathrm{D}_{22}^{\prime}+\mathrm{D}_{23}^{\prime}\right)+\mathrm{h}_{21}\left(\mathrm{D}^{\prime}{ }_{22}+\mathrm{D}^{\prime}{ }_{23}\right)+\mathrm{h}_{21} \mathrm{D}_{23}^{\prime}=469.8$ \\
\hline$M_{2113}$ & $c s_{21}+c_{21}\left(D^{\prime}{ }_{22}+D^{\prime}{ }_{23}\right)+h_{22} D^{\prime}{ }_{23}=148.5$ \\
\hline $\mathrm{M}_{2213}$ & $\mathrm{cs}_{22}+\mathrm{c}_{22}\left(\mathrm{D}_{22}^{\prime}+\mathrm{D}_{23}^{\prime}\right)+\mathrm{h}_{22} \mathrm{D}_{23}^{\prime}=158.4$ \\
\hline$F_{20}$ & 0 \\
\hline $\mathrm{F}_{21}$ & $\min \left\{\mathrm{F}_{20}+\mathrm{M}_{2101}, \mathrm{~F}_{20}+\mathrm{M}_{2201}\right\}=\mathrm{F}_{20}+\mathrm{M}_{2101}=337.4$ \\
\hline$F_{22}$ & $\min \left\{\mathrm{F}_{20}+\mathrm{M}_{2102}, \mathrm{~F}_{20}+\mathrm{M}_{2202}, \mathrm{~F}_{21}+\mathrm{M}_{2112}, \mathrm{~F}_{21}+\mathrm{M}_{2212}\right\}=\mathrm{F}_{20}+\mathrm{M}_{2102}=451.3$ \\
\hline$F_{23}$ & $\min \left\{\mathrm{F}_{20}+\mathrm{M}_{2103}, \mathrm{~F}_{20}+\mathrm{M}_{2203}, \mathrm{~F}_{21}+\mathrm{M}_{2113}, \mathrm{~F}_{21}+\mathrm{M}_{2213}, \mathrm{~F}_{22}+\mathrm{M}_{2123}, \mathrm{~F}_{22}+\mathrm{M}_{1223}\right\}=\mathrm{F}_{20}+\mathrm{M}_{2103}=459.9$ \\
\hline Produção & $X_{211}=237, \quad X_{221}=0, \quad X_{231}=0$ \\
\hline & $X_{212}=0, \quad X_{222}=0, \quad X_{232}=0$ \\
\hline Estoques & $h_{11}=0, \quad h_{12}=0, \quad h_{13}=0$ \\
\hline
\end{tabular}

As tabelas seguintes mostram a aplicação do algoritmo WW-Paralelo Penalizado para o exemplo dado na Tabela 4.1. 
Tabela 4.4. Aplicação do algoritmo WW-Paralelo Penalizado para o item l (item final).

\begin{tabular}{|c|c|}
\hline$M_{\{10\}}$ & $\begin{array}{l}\text { utilização_anterior } 11=0, \text { utilização_agora }{ }_{11}=b_{11} d_{11}+t s_{11}=624.76, \quad \text { Penalidade } \\
0.95\left(c_{11}+c_{11}=(624.76 / 656)=0.95\right. \\
\left.d_{11}\right)=0.95(267.02)=254.3\end{array}$ \\
\hline $\mathrm{M}_{1201}$ & $\begin{array}{l}\text { utilização_antcrior }{ }_{21}=0, \quad \text { utilização_agora } a_{21}=b_{12} d_{11}+t_{12}=653.53, \quad \text { Penalidade } 201=0.9993 \\
0.9993\left(\mathrm{cs}_{12}+c_{12} d_{11}\right)=0.9993(331)=330.76\end{array}$ \\
\hline$M_{1112}$ & $\begin{array}{l}\text { utilização_anterior }{ }_{12}=0 \text {, utilização__agora } a_{12}=b_{11} d_{12}+t_{11}=318.69, \quad \text { Penalidade } 112=0.73 \\
0.73\left(\operatorname{cs}_{11}+c_{11} d_{12}\right)=0.73(70.2)=51.25\end{array}$ \\
\hline$M_{1212}$ & $\begin{array}{l}\text { utilização_anterior } 22=0, \quad \text { utilização_agora } 22=b_{12} d_{12}+t_{12}=336.03, \quad \text { Penalidade } 212=0.77 \\
0.77\left(\operatorname{cs}_{12}+c_{12} d_{12}\right)=0.77(135.42)=104.3\end{array}$ \\
\hline $\mathrm{M}_{1123}$ & $\begin{array}{l}\text { utilização_anterior } r_{13}=0, \quad \text { utilização_agora } a_{13}=b_{11} d_{13}+t s_{11}=272.9, \quad \text { Penalidade } 123=0.63 \\
0.63\left(\operatorname{cs}_{11}+c_{11} d_{13}\right)=0.63(40.72)=25.7\end{array}$ \\
\hline $\mathrm{M}_{1223}$ & $\begin{array}{l}\text { utilizaçảo_anterior }{ }_{23}=0, \text { utilização_agora } a_{23}=b_{12} d_{13}+t s_{12}=288.53, \quad \text { Penalidade } 233=0.66 \\
0.66\left(\operatorname{cs}_{12}+c_{12} d_{13}\right)=0.66(106.16)=70.1\end{array}$ \\
\hline$M_{1102}$ & $\begin{array}{l}\text { utilização_anterior } r_{12}=0, \quad \text { utilização_agora }{ }_{12}=b_{11}\left(d_{11}+d_{12}\right)+t_{11}=716.34, \quad \text { Penalidade }{ }_{102}=1.092 \\
1.092\left(c_{11}+c_{11}\left(d_{11}+d_{12}\right)+h_{11} d_{12}\right)=1.092(346.06)=377.9\end{array}$ \\
\hline$M_{1202}$ & $\begin{array}{l}\text { utilização_anterior }{ }_{22}=0 \text {, utilização_agora }{ }_{22}=b_{12}\left(d_{11}+d_{12}\right)+t_{12}=748.53, \quad \text { Penalidade } 202=1.145 \\
1.145\left(\operatorname{cs}_{12}+c_{12}\left(d_{11}+d_{12}\right)+h_{11} d_{12}\right)=1.145(409.66)=469.06\end{array}$ \\
\hline $\mathrm{M}_{1103}$ & $\begin{array}{l}\text { utilização_anterior }{ }_{13}=0, \text { utilização_agora }{ }_{13}=b_{11}\left(d_{11}+d_{12}+d_{13}\right)+t s_{11}=762.13, \\
1.162\left(c_{11}+c_{11}\left(d_{11}+d_{12}+d_{13}\right)+h_{11}\left(d_{12}+d_{13}\right)+h_{12} d_{13}\right)=1.162(395.65)=459.75\end{array}$ \\
\hline$M_{1203}$ & $\begin{array}{l}\text { utilização_anterior }{ }_{23}=0, \text { utilização_agora }{ }_{23}=b_{12}\left(d_{11}+d_{12}+d_{13}\right)+t s_{12}=796.03, \\
1.217\left(\operatorname{cs}_{12}+c_{12}\left(d_{11}+d_{12}+d_{13}\right)+h_{11}\left(d_{12}+d_{13}\right)+h_{11} d_{13}\right)=1.217(459.06)=558.68\end{array}$ \\
\hline $\mathrm{M}_{1113}$ & $\begin{array}{l}\text { utilização_anterior } r_{13}=0, \quad \text { utilização_agora }{ }_{13}=b_{11}\left(d_{12}+d_{13}\right)+t s_{11}=364.48, \\
0.838\left(\operatorname{cs}_{11}+c_{11}\left(d_{12}+d_{13}\right)+h_{12} d_{13}\right)=0.838(109.69)=91.92\end{array}$ \\
\hline$M_{1213}$ & $\begin{array}{l}\text { utilizaçâo_anterior }{ }_{23}=0, \text { utilização_agora } a_{23}=b_{12}\left(d_{12}+d_{13}\right)+t_{12}=383.53 \\
0.882\left(c_{12}+c_{12}\left(d_{12}+d_{13}\right)+h_{12} d_{13}\right)=0.882(174.75)=151.13\end{array}$ \\
\hline $\begin{array}{l}F_{10} \\
F_{11} \\
F_{12} \\
F_{13}\end{array}$ & $\begin{array}{l}\min \left\{F_{10}+M_{1101}, F_{10}+M_{1201}\right\}=F_{10}+M_{1101}=254.3 \\
\min \left\{F_{10}+M_{1102}, F_{10}+M_{1202}, F_{11}+M_{1112}, F_{11}+M_{1212}\right\}=F_{11}+M_{1112}=305.55 \\
\min \left\{F_{10}+M_{1103}, F_{10}+M_{1203}, F_{11}+M_{1113}, F_{11}+M_{1213}, F_{12}+M_{1123}, F_{12}+M_{1223}\right\}=F_{12}+M_{1123}=331.25\end{array}$ \\
\hline Produção & $\begin{array}{lll}X_{111}=165, & X_{121}=38, & X_{131}=19 \\
X_{112}=0, & X_{122}=0, & X_{132}=0\end{array}$ \\
\hline es & $\mathrm{h}_{12}=0, \quad \mathrm{~h}_{13}=0$ \\
\hline
\end{tabular}

Como se pode notar, o plano de produção para o item $\mathrm{i}=1$ considerando o algoritmo WW-Paralelo Penalizado é diferente do fornecido pelo procedimento WW-Paralelo. Na tabela seguinte é apresentada a aplicação do algoritmo para o item 2 e, a seguir, mostra-se o consumo da capacidade das soluções fornecidas pelo dois procedimentos.

As demandas atualizadas para o item 2 são:

$D^{\prime}{ }_{21}=d_{21}+X_{111}+X_{112}=9+165=174$

$D_{22}^{\prime}=d_{22}+X_{121}+X_{122}=2+38=40$ 
$\mathrm{D}_{23}^{\prime}=\mathrm{d}_{23}+\mathrm{X}_{131}+\mathrm{X}_{132}=4+19=23$

Tabela 4.5. Aplicação do algoritmo WW-Paralelo Paralelo para o item 2 (item componente).

\begin{tabular}{|c|c|}
\hline $\mathrm{M}_{2101}$ & $\begin{array}{l}\text { utilização_anterior }{ }_{11}=b_{11} X_{11}+t s_{11}=624.76, \text { utilização_agora }{ }_{11}=b_{21} D_{21}^{\prime}+t s_{21}=655.9, \\
\text { Penalidade }{ }_{101}=((624.76+655.9) / 656)=1.952 \\
1.952\left(\mathrm{cs}_{21}+c_{21} D_{21}^{\prime}\right)=1.952(337.43)=658.66\end{array}$ \\
\hline $\mathrm{M}_{2201}$ & $\begin{array}{l}\text { utilizaçâo_anterior }{ }_{21}=0, \quad \text { utilização_agora }{ }_{21}=\mathrm{b}_{22} \mathrm{D}_{21}^{\prime}+\mathrm{ts}_{22}=576.72, \quad \text { Penalidade }{ }_{201}=0.882 \\
0.882\left(\mathrm{cs}_{22}+\mathrm{c}_{22} \mathrm{D}_{21}^{\prime}\right)=0.882(347.32)=306.34\end{array}$ \\
\hline $\mathrm{M}_{21: 2}$ & $\begin{array}{l}\text { utilização_anterior }{ }_{12}=b_{11} X_{121}+t_{11}=318.69 \text {, utilização_agora }{ }_{12}=b_{21} D_{22}^{\prime}+t_{21}=311.53 \text {, } \\
\text { Penalidade } e_{12}=1.449 \\
1.449\left(c_{21}+c_{21} D_{22}^{\prime}\right)=1.449(107.29)=155.46\end{array}$ \\
\hline $\mathrm{M}_{2212}$ & $\begin{array}{l}\text { utilização_anterior } r_{22}=0, \text { utilização_agora }{ }_{22}=\mathrm{b}_{22} \mathrm{D}_{22}^{\prime}+\mathrm{ts}_{22}=259.14, \quad \text { Penalidade }{ }_{212}=0.596 \\
0.596\left(\mathrm{cs}_{22}+\mathrm{c}_{22} \mathrm{D}_{22}^{\prime}\right)=0.596(118.18)=70.40\end{array}$ \\
\hline $\mathrm{M}_{2123}$ & $\begin{array}{l}\text { utilização_anterior }{ }_{13}=\mathrm{b}_{11} \mathrm{X}_{131}+\mathrm{ts}_{11}=272.19 \text {, utilização_agora } \mathrm{a}_{13}=\mathrm{b}_{21} \mathrm{D}_{23}^{\prime}+\mathrm{ts}_{21}=267.84, \\
\text { Penalidade }{ }_{123}=1.241 \\
1.241\left(\mathrm{cs}_{21}+\mathrm{c}_{21} \mathrm{D}_{23}^{\prime}\right)=1.241(79.22)=98.31\end{array}$ \\
\hline$M_{2223}$ & $\begin{array}{l}\text { utilizaçāo_anterior }{ }_{23}=0, \text { utilização_agora } a_{23}=\mathrm{b}_{22} \mathrm{D}_{23}^{\prime}+\mathrm{ts}_{22}=218.85, \quad \text { Penalidade } \mathrm{e}_{233}=0.503 \\
0.503\left(\mathrm{cs}_{22}+\mathrm{c}_{22} \mathrm{D}_{23}^{\prime}\right)=0.503(89.11)=44.82\end{array}$ \\
\hline $\mathrm{M}_{2102}$ & $\begin{array}{l}\text { utilização_anterior }{ }_{12}=\mathrm{b}_{11} \mathrm{X}_{111}+\mathrm{ts}_{11}=624.76 \text {, utilização_agora }{ }_{12}=\mathrm{b}_{21}\left(\mathrm{D}_{21}^{\prime}+\mathrm{D}_{22}^{\prime}\right)+\mathrm{ts}_{21}=758.71 \text {, } \\
\text { Penalidade }{ }_{102}=2.109 \\
2.109\left(\mathrm{cs}_{21}+\mathrm{c}_{21}\left(\mathrm{D}_{21}^{\prime}+\mathrm{D}_{22}^{\prime}\right)+\mathrm{h}_{21} \mathrm{D}_{22}^{\prime}\right)=2.109(414.63)=874.46\end{array}$ \\
\hline $\mathrm{M}_{2202}$ & $\begin{array}{l}\text { utilização_anterior }{ }_{22}=0, \quad \text { utilização_agora }{ }_{22}=\mathrm{b}_{22}\left(\mathrm{D}_{21}^{\prime}+\mathrm{D}_{22}^{\prime}\right)+\mathrm{ts}_{22}=6 \overline{671.52,} \\
1.027\left(\mathrm{cs}_{22}+\mathrm{c}_{22}\left(\mathrm{D}_{21}^{\prime}+\mathrm{D}_{22}^{\prime}\right)+\mathrm{h}_{21} \mathrm{D}_{22}^{\prime}\right)=1.027(424.52)=435.98\end{array}$ \\
\hline $\mathrm{M}_{2103}$ & $\begin{array}{l}\text { utilização_anterior }{ }_{13}=b_{11} X_{11}+t_{11}=624.76, \text { utilização_agora } a_{13}=b_{21}\left(D_{21}^{\prime}+D_{22}^{\prime}+D_{23}^{\prime}\right)+s_{21}=817.82, \\
\text { Penalidade }{ }_{103}=2.199 \\
2.199\left(\operatorname{cs}_{21}+c_{21}\left(D_{21}^{\prime}+D_{22}^{\prime}+D_{23}^{\prime}\right)+h_{21}\left(D_{22}^{\prime}+D_{23}^{\prime}\right)+h_{22} D_{23}^{\prime}\right)=2.199(497.3)=1093.56\end{array}$ \\
\hline $\mathrm{M}_{2203}$ & $\begin{array}{l}\text { Utilização_anterior }{ }_{23}=0, \quad \text { utilização_agora }{ }_{23}=\mathrm{b}_{22}\left(\mathrm{D}_{11}^{\prime}+\mathrm{D}_{22}^{\prime}+\mathrm{D}_{23}^{\prime}\right)+\mathrm{ts}_{22}=726.03, \quad \text { Penalidade } 203=1.11 \\
1.11\left(\mathrm{cs}_{22}+\mathrm{c}_{22}\left(\mathrm{D}_{21}^{\prime}+\mathrm{D}_{22}^{\prime}+\mathrm{D}_{23}^{\prime}\right)+\mathrm{h}_{21}\left(\mathrm{D}_{22}^{\prime}+\mathrm{D}_{23}^{\prime}\right)+\mathrm{h}_{21} \mathrm{D}_{23}^{\prime}\right)=1.11(514.3)=570.94\end{array}$ \\
\hline $\mathrm{M}_{2113}$ & $\begin{array}{l}\text { Utilização_anterior }{ }_{13}=b_{11} X_{121}+t_{11}=318.69, \text { utilização_agora }{ }_{13}=b_{21}\left(D_{22}^{\prime}+D_{23}^{\prime}\right)+t_{21}=370.64, \\
\text { Penalidade }{ }_{13}=1.585 \\
1.585\left(c_{21}+c_{21}\left(D_{22}^{\prime}+D_{23}^{\prime}\right)+h_{22} D_{23}^{\prime}\right)=1.585(152.68)=242.0\end{array}$ \\
\hline $\mathrm{M}_{2213}$ & $\begin{array}{l}\text { utilização_anterior }{ }_{23}=0, \text { utilizaçâo_agora }{ }_{23}=\mathrm{b}_{22}\left(\mathrm{D}_{22}^{\prime}{ }_{22}+\mathrm{D}_{23}^{\prime}\right)+\mathrm{ts}_{22}=313.65, \quad \text { Penalidade } \mathrm{C}_{213}=0.721 \\
0.721\left(\mathrm{cs}_{22}+\mathrm{c}_{22}\left(\mathrm{D}_{22}^{\prime}+\mathrm{D}_{23}^{\prime}\right)+\mathrm{h}_{22} \mathrm{D}_{23}^{\prime}\right)=0.721(162.57)=117.21\end{array}$ \\
\hline $\begin{array}{l}F_{20} \\
F_{21} \\
F_{22} \\
F_{23}\end{array}$ & $\begin{array}{l}\min \left\{\mathrm{F}_{20}+\mathrm{M}_{2101}, \mathrm{~F}_{20}+\mathrm{M}_{2201}\right\}=\mathrm{F}_{20}+\mathrm{M}_{2201}=306.34 \\
\min \left\{\mathrm{F}_{20}+\mathrm{M}_{2102}, \mathrm{~F}_{20}+\mathrm{M}_{2202}, \mathrm{~F}_{21}+\mathrm{M}_{2112}, \mathrm{~F}_{21}+\mathrm{M}_{2212}\right\}=\mathrm{F}_{21}+\mathrm{M}_{2212}=376.74 \\
\min \left\{\mathrm{F}_{20}+\mathrm{M}_{2103}, \mathrm{~F}_{20}+\mathrm{M}_{2203}, \mathrm{~F}_{21}+\mathrm{M}_{2113}, \mathrm{~F}_{21}+\mathrm{M}_{2213}, \mathrm{~F}_{22}+\mathrm{M}_{2123}, \mathrm{~F}_{22}+\mathrm{M}_{2223}\right\}=\mathrm{F}_{22}+\mathrm{M}_{2223}=421.56\end{array}$ \\
\hline Produção & $\begin{array}{l}X_{211}=0, \quad X_{221}=0, \quad X_{231}=0 \\
X_{212}=174, \quad X_{222}=40, \quad X_{232}=23\end{array}$ \\
\hline Estoques & $h_{22}=0, \quad h_{23}=0$ \\
\hline
\end{tabular}


Os consumos da capacidade em cada período máquina considerando as duas soluções iniciais são apresentados nas tabelas seguintes. Na Tabela 4.6 é apresentado o consumo da capacidade para a solução inicial obtida através da aplicação do algoritmo de WW-Paralelo. Na Tabela 4.7 é apresentado o consumo da capacidade da solução inicial obtida com o algoritmo WW-Paralelo Penalizado.

Tabela 4.6. Consumo da capacidade da solução inicial de WW-Paralelo

\begin{tabular}{|c|c|c|c|}
\hline $\mathrm{CAP}_{\mathbf{i k}}$ & $t=1$ & $t=2$ & $t=3$ \\
\hline $\mathrm{CAP}_{11}$ & 656 & 435 & 435 \\
\hline Consumo $_{\mathbf{t}}$ & $\overline{1442.56}$ & 364.48 & 0.0 \\
\hline $\mathrm{CAP}_{\mathrm{t} 2}$ & 654 & 435 & 435 \\
\hline consumo $_{12}$ & 0.0 & 0.0 & 0.0 \\
\hline
\end{tabular}

Tabela 4.7. Consumo da capacidade da solução obtida pelo algoritmo WW-Paralelo Penalizado.

\begin{tabular}{|c|c|c|c|}
\hline $\mathrm{CAP}_{\mathrm{tk}}$ & $t=1$ & $t=2$ & $t=3$ \\
\hline $\mathrm{CAP}_{\mathrm{tl}}$ & 656 & 435 & 435 \\
\hline Consumo $_{\mathfrak{l}}$ & 624.78 & 318.69 & $28 \overline{86.82}$ \\
\hline $\mathrm{CAP}_{\mathrm{L} 2}$ & 654 & 435 & 435 \\
\hline consumo ${ }_{t 2}$ & 576.72 & 259.14 & 218.89 \\
\hline
\end{tabular}

As tabelas 4.6 e 4.7 mostram que o procedimento para determinação da solução inicial WW-Paralelo Penalizado, obtém uma solução inicial factível, enquanto que, para a solução obtida utilizando o algoritmo WW-Paralelo, será necessário aplicar o procedimento de factibilização, detalhado a seguir.

\subsection{Heurística de FactibilizaÇão}

Nesta seção é descrito um procedimento baseado em transferências de produção entre periodos e entre máquinas na tentativa de factibilizar soluções infactíveis, como por exemplo, uma solução infactível obtida por um dos procedimentos da seção 4.2.

O procedimento de factibilização é semelhante aos de França et al. (1997), Tempelmeier e Derstroff (1996), Sabbag (1993) e Toledo, (1998), sendo composto de dois passos principais: regressivo e progressivo no tempo.

Seja $\Delta_{k t}=\sum_{i=1}^{N}\left(b_{i k} X_{i k k}+t_{i k} Y_{i k k}\right)-C A P_{k k}$ a variável de folga da restrição de capacidade (3.11). O excedente de recursos utilizado na máquina $k$ no período $t$ é dado por 
excesso(k, $\mathrm{t})=\max \left\{0, \Delta_{\mathbf{k}}\right\}$. Para eliminar o excedente (excesso $(\mathrm{k}, \mathrm{t})>0$ ), realiza-se a transferência de uma quantidade $q$ de algum item i produzido no par $(k, t)$ (máquina $k$, período t) para $\left(k^{\prime}, t^{\prime}\right)$ com $k \neq k^{\prime}$ ou $t \neq t^{\prime}$. A quantidade $q$ a ser transferida pode ser escolhida como:

$$
\mathrm{q}=\min \left\{Z_{\mathrm{itk}}^{\mathrm{t}^{\prime} \cdot \mathrm{k}}, \mathrm{Q}_{\mathrm{itk}}\right\}
$$

onde:

$Z_{i t k}^{\prime \prime k}$ é quantidade máxima do item i produzida na máquina $\mathrm{k}$ que pode ser transferida do período t para o período t' e para máquina k' sem violar as restrições de balanço de estoque.

$\mathrm{Q}_{\mathrm{itk}}=\frac{\text { excesso }(\mathrm{k}, \mathrm{t})}{\mathrm{b}_{\mathrm{ik}}}$ é quantidade exata do item $i$ que elimina o excesso da máquina $\mathrm{k}$ e período $\mathrm{t}$.

A seguir será descrito como obter os valores de $Z_{\mathrm{itk}}^{\mathrm{t}^{\prime} \mathbf{k}^{\cdot}}$ nos passos progressivo e regressivo do procedimento de factibilização.

\section{Passo Regressivo no TeMPo}

No passo regressivo, são analisados os períodos $T, \ldots, 2$ e as máquinas $k=1, \ldots, \mathrm{K}$, nessa ordem. O período destino pode ser escolhido dentre $\tau \leq t^{\prime} \leq t$ onde $\tau=$ máximo $\{1$, último período em que há produção de $i$ antes do período $t\}$. Ou seja, se $X_{i t} k=0$ para todo $t^{\prime}<t$, considera-se $\tau=1$.

Mostra-se a seguir que ao transferir-se uma quantidade q de produção do item i para 0 período $t^{\prime}, t^{\prime}<t$, segue das equações de balanço de estoque (exemplificado a seguir), que os estoques dos itens predecessores imediatos do item i são reduzidos entre os períodos $t^{\prime}$ e $t$-1, enquanto que os estoques do item i são acrescidos de q unidades entre estes períodos. Assim, a quantidade máxima que pode ser transferida do item $\mathrm{i}$ do período $\mathrm{t}$ e máquina $\mathrm{k}$ para $\mathrm{o}$ período $\mathrm{t}^{\prime}$ e máquina $\mathrm{k}^{\prime}$ é dada por:

$$
Z_{i t k}^{i^{\prime} k^{\prime}}=\min \left\{X_{i t k}, \min _{\substack{j \in P_{i} \\ t^{\prime} \leq t \leq i-1}}\left\{\frac{I_{j \tau}}{a_{j i}}\right\}\right\} \text { para } t^{\prime}<t
$$

Considere a estrutura de itens na Figura 4.3, e suponha que uma certa quantidade $\delta$ do item $\mathrm{i}$ seja transferida do período $\mathrm{t}$ e máquina $\mathrm{k}\left(\mathrm{X}_{\mathrm{i} \mathrm{k}}-\delta\right)$ para o período $\mathrm{t}^{\prime}, \mathrm{t}^{\prime}<\mathrm{t}$ e máquina $\mathrm{k}^{\prime}\left(\mathrm{X}_{\mathrm{i}:^{\prime} \mathrm{k}^{\prime}}+\delta\right)$. 


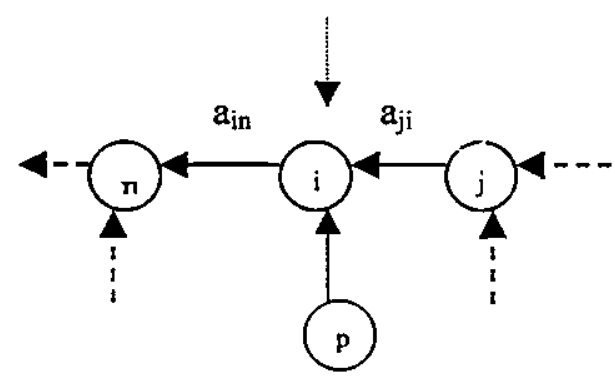

Figura 4.3. Estrutura de itens exemplo.

As restrições de balanço de estoque (3.10) do item i são satisfeitas pelas seguintes alterações nas variáveis de estoque e produção:

$\vdots$

$\mathrm{X}_{\mathrm{it1}}+\cdots+\left(\mathrm{X}_{\mathrm{i} t \mathrm{k}}-\delta\right)+\mathrm{X}_{\mathrm{it}(\mathrm{k}+1)}+\cdots+\left(\mathrm{I}_{\mathrm{i}(\mathrm{t}-1)}+\delta\right)=\mathrm{d}_{\mathrm{it}}+\mathrm{I}_{\mathrm{it}}+\mathrm{a}_{\mathrm{in}} \sum_{\mathrm{b}} \mathrm{X}_{\mathrm{n} t \mathrm{~h}}$

$\mathrm{X}_{\mathrm{i}(t-1) t}+\cdots+\mathrm{X}_{\mathrm{i}(\mathrm{t}-1) \mathrm{k}}+\mathrm{X}_{\mathrm{i}(\mathrm{t}-1)(\mathrm{k}+1)}+\cdots+\left(\mathrm{I}_{\mathrm{i}(t-2)}+\delta\right)=\mathrm{d}_{\mathrm{i}(\mathrm{t}-1)}+\left(\mathrm{I}_{\mathrm{i}(t-1)}+\delta\right)+\mathrm{a}_{\mathrm{in}} \sum_{\mathrm{h}} \mathrm{X}_{\mathrm{n(t-1)h}}$

$\mathrm{X}_{\mathrm{i}\left(\mathrm{t}^{\prime}+1\right) 1}+\cdots+\mathrm{X}_{\mathrm{i}\left(\mathrm{t}^{+}+1\right) k}+\mathrm{X}_{\mathrm{i}\left(\mathrm{t}^{\prime}+1\right)(\mathrm{k}+1)}+\cdots+\left(\mathrm{I}_{\mathrm{it}}+\delta\right)=\mathrm{d}_{\mathrm{i}\left(\mathrm{t}^{\prime}+1\right)}+\left(\mathrm{I}_{\mathrm{i}\left(\mathrm{l}^{\prime}+1\right)}+\delta\right)+\mathrm{a}_{\mathrm{in}} \sum_{\mathrm{h}} \mathrm{X}_{\mathrm{n}\left(\mathrm{t}^{\prime}+1\right) \mathrm{h}}$

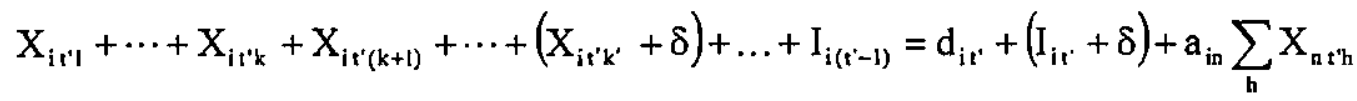

Ou seja, os estoques do item i são acrescidos de $\delta$ e não impõem limites sobre as transferências de $\delta$, no entanto tem que garantir que $\left(\mathrm{X}_{\mathrm{i} \text {, }}-\delta\right) \geq 0 \Rightarrow \delta \leq \mathrm{X}_{\mathrm{i} \text { । }}$.

Estas transferências $\left(\mathrm{X}_{\mathrm{i} t \mathrm{k}}-\delta\right)$ e $\left(\mathrm{X}_{\mathrm{i} \mathrm{t}^{\prime} \mathrm{k}^{\prime}}+\delta\right)$ introduzem também alterações nos itens predecessores do item i. As restrições de balanço de estoque para o item $j \in P(i)$ são satisfeitas da seguinte forma:

$$
\begin{aligned}
& X_{j t 1}+\ldots+X_{j t k}+\ldots+\left(I_{j(t-1)}-a_{j i} \delta\right)=d_{j t}+I_{j t}+a_{j i}\left(X_{i t k}-\delta\right)+a_{j i} \sum_{s \neq k} X_{i t s}+\sum_{0 \in S(j) .0 \neq i} \sum_{m} a_{j 0} X_{0 t m} \\
& X_{j(t-1) 1}+\cdots+X_{j(t-1) k}+\cdots+\left(I_{j(t-2)}-a_{j i} \delta\right)=d_{j(t-1)}+\left(I_{j(t-1)}-a_{j i} \delta\right)+\sum_{o \in S(j)} \sum_{m} a_{j o} X_{o(t-1) m} \\
& X_{j\left(t^{\prime}+1\right) 1}+\cdots+X_{j\left(i^{\prime}+1\right) k}+\cdots+\left(I_{j t^{\prime}}-a_{j i} \delta\right)=d_{j\left(t^{\prime}+1\right)}+\left(I_{j\left(t^{\prime}+1\right)}-a_{j i} \delta\right)+\sum_{0 \in S(j)} \sum_{m} a_{j 0} X_{o\left(l^{\prime}+1\right) m}
\end{aligned}
$$




$$
X_{j r^{\prime} 1}+\cdots+X_{j r^{\prime} K}+I_{j\left(r^{\prime}-1\right)}=d_{j r^{\prime}}+\left(I_{j r^{\prime}}-a_{j i} \delta\right)_{+} a_{j i}\left(X_{i r^{\prime} k^{\prime}}+\delta\right)+\sum_{m \neq k^{\prime}} X_{i r^{\prime} m}+\sum_{o \in S(j), 0 \neq i} \sum_{m} a_{j o} X_{o r^{\prime} m}
$$

A transferência não pode causar estoques negativos para o item $j \in P(i)$, então:

$$
\left(I_{j(t-1)}-a_{j i} \delta\right) \geq 0 \Rightarrow \delta \leq \frac{I_{j(t-1)}}{a_{j i}}, \cdots,\left(I_{j r^{\prime}}-a_{j i} \delta\right) \geq 0 \Rightarrow \delta \leq \frac{I_{j r}}{a_{j i}}
$$

A desigualdade acima é válida para todo $\mathrm{j} \in \mathrm{P}(\mathrm{i})$. Assim, a quantidade máxima do item i a ser transferida é dada por:

$$
z_{i t k}^{c^{\prime} k^{\prime}}=\min \left\{X_{i t k}, \min \left(\frac{I_{j i}}{a_{j i}}, \cdots, \frac{I_{j(t-1)}}{a_{j i}}, \frac{I_{p i^{\prime}}}{a_{p i}}, \cdots, \frac{I_{p(t-1)}}{a_{p i}}, \cdots\right)\right\}
$$

Se $t=t^{\prime}$, executa-se somente transferência entre máquinas, então $Z_{i t k}^{t^{\prime} k^{\prime}}=X_{i k k}$. Isto é válido também no passo progressivo.

\section{Passo Progressivo No TEMPO}

Neste passo, as transferências de produção são analisadas do período $t=1$ até $T-1$ e as máquinas de $k=1$ até $K$. Os períodos destino a serem analisados estão no intervalo $t \leq t^{\prime} \leq \tau$, onde $\tau=\min \{T$, primeiro período em que existe produção do item $\mathrm{i}$ após o período $t\}$. Neste caso a transferência de uma quantidade q de produção do item i acarreta uma diminuição do estoque deste item de $q$ unidades do período $t$ até o período $t$ ' -1 , enquanto que, o estoque dos itens predecessores imediatos terá um aumento neste mesmo intervalo. Dessa forma, a quantidade máxima a ser transferida do item $\mathrm{i}$ do período $\mathrm{t}$ e máquina $\mathrm{k}$ para o período $\mathrm{t}^{\prime} \mathrm{e}$ máquina $\mathrm{k}^{\prime}$ é dada por:

$$
Z_{i t k}^{i k^{\prime}}=\min \left\{X_{\text {itk }}, \min _{t \leq t \leq t^{\prime}-1}\left\{I_{i r}\right\}\right\} \text { para } t^{\prime}>t
$$

Considere novamente a estrutura de itens apresentada na Figura 4.3 e suponha que uma certa quantidade $\delta$ do item $\mathrm{i}$ é transferida do período t e máquina $\mathrm{k}\left(\mathrm{X}_{\mathrm{itk}}-\delta\right)$ para o período $t^{\prime}\left(t^{\prime}>t\right)$ e máquina $k^{\prime}\left(X_{i, k^{\prime}}+\delta\right)$. Suponha também que o horizonte de planejamento seja de $\mathrm{T}$ períodos e que existam $\mathrm{K}$ máquinas. 
As restrições de balanço de estoque (3.10) para o item i são então satisfeitas com as seguintes alterações nas variáveis de estoque e de produção:

$\mathrm{X}_{i t 1}+\cdots+\left(\mathrm{X}_{\mathrm{itk}}-\delta\right)+\cdots \mathrm{X}_{\mathrm{itK}}+\mathrm{I}_{\mathrm{i}(\mathrm{t}-1)}=\mathrm{d}_{\mathrm{it}}+\left(\mathrm{I}_{\mathrm{it}}-\delta\right)+\sum_{\mathrm{o \in S}(\mathrm{i})} \mathrm{a}_{\mathrm{io}} \sum_{\mathrm{m}} \mathrm{X}_{\mathrm{otm}}$

$\mathrm{X}_{\mathrm{i}(t+1) !}+\cdots+\mathrm{X}_{\mathrm{j}(\mathrm{t}+1) \mathrm{k}}+\cdots \mathrm{X}_{\mathrm{j}(t+1) \mathrm{k}}+\left(\mathrm{I}_{\mathrm{jt}}-\delta\right)=\mathrm{d}_{\mathrm{i}(\mathrm{t}+1)}+\left(\mathrm{I}_{\mathrm{i}(t+1)}-\delta\right)+\sum_{\mathrm{o} \in \mathrm{S}(\mathrm{i})} \mathrm{a}_{\mathrm{i} 。} \sum_{\mathrm{m}} \mathrm{X}_{\mathrm{otm}}$

$X_{i\left(t^{\prime}-1\right) 1}+\cdots+X_{i\left(t^{\prime}-1\right) k}+\cdots X_{i\left(i^{\prime}-1\right) K}+\left(I_{i\left(i^{\prime}-2\right)}-\delta\right)=d_{i\left(t^{\prime}-1\right)}+\left(I_{i\left(i^{\prime}-1\right)}-\delta\right)+\sum_{o \in S(i)} a_{i \circ} \sum_{m} X_{o\left(t^{\prime}-1\right) m}$

$X_{i t^{\prime} l^{\prime}}+\cdots+\left(X_{i t^{\prime} k^{\prime}}+\delta\right)+\cdots X_{i t^{\prime} K}+\left(I_{i\left(t^{\prime}-1\right)}-\delta\right)=d_{i t^{\prime}}+I_{1 t^{\prime}}+\sum_{o \in S(i)} a_{i o} \sum_{m} X_{o t^{\prime} m}$ $\vdots$

Os níveis de estoque dos itens predecessores imediatos são alterados para ajuste nas restrições de balanço, da seguinte maneira. Seja $j \in P(i)$ :

$X_{j t l}+\cdots+X_{j t k}+\cdots+I_{j(t-1)}=d_{j t}+\left(I_{j t}+a_{j i} \delta\right)+a_{j i}\left(X_{i t k}-\delta\right)+a_{j i} \sum_{m \neq k} X_{i t m}+\sum_{o \in S(j), 0 \neq i} a_{j 0} \sum_{m} X_{o t m}$

$X_{j(t+1) 1}+\cdots+X_{j(t+1) k}+\cdots+\left(I_{j t}+a_{j i} \delta\right)=d_{j(t+1)}+\left(I_{j(t+1)}+a_{j i} \delta\right)+\sum_{o \in S(j)} a_{j 0} \sum_{m} X_{o t m}$

$X_{j\left(t^{\prime}-1\right) 1}+\cdots+X_{j\left(t^{\prime}-1\right) k}+\cdots+\left(I_{j\left(t^{\prime}-2\right)}+a_{j i} \delta\right)=d_{j\left(t^{\prime}-1\right)}+\left(I_{j\left(t^{\prime}-1\right)}+a_{j i} \delta\right)+\sum_{o \in S(j)} a_{j o} \sum_{m} X_{o t m}$

$X_{j t^{\prime} l}+\cdots+X_{j t^{\prime} k}+\cdots+\left(I_{j\left(l^{\prime}-1\right)}+a_{j i} \delta\right)=d_{j t^{\prime}}+I_{j t^{\prime}}+a_{j i}\left(X_{i l^{\prime} k^{\prime}}+\delta\right)+a_{j i} \sum_{m \neq k^{\prime}} X_{i t^{\prime} m}+\sum_{o \in S(j), o \neq i} a_{j o} \sum_{m} X_{o t^{\prime} m}$

Analogamente para todos os itens predecessores imediatos do item i. Note que agora os níveis de estoque dos itens predecessores não impõem limites aos valores de $\delta$. Assim, a quantidade máxima do item i a ser transferida é:

$$
Z_{i t k}^{t^{\prime} k^{\prime}}=\min \left[X_{i t k}, \min \left(I_{i t}, I_{i(t+1)}, \cdots, I_{i\left(t^{\prime}-1\right)}\right)\right]
$$


Para avaliar as quádruplas (i,q, k', $\left.\mathrm{t}^{\prime}\right)$ de possíveis transferências do par $(\mathrm{k}, \mathrm{t})$ violado, utiliza-se um valor chamado de razão. Este valor é calculado baseado na alteração dos custos que a transferência causa, e no excesso de utilização de recursos nos pares envolvidos. Assim, para cada par (k,t), a quádrupla (i,q, k', t') escolhida é aquela que minimiza a seguinte razão (Toledo, 1998):

$$
\text { razão }=\frac{\Delta \text { custo }+ \text { FP.Penalidade }}{\Delta \text { redução }}
$$

A variação dos custos ( $\Delta$ custo ) causada pela transferência da quantidade q do item i de $(k, t)$ para $\left(k^{\prime}, t^{\prime}\right)$ pode ser expressa como

$$
\Delta \text { custo }=\frac{q\left(\left(c_{i t^{\prime} k^{\prime}}-c_{i t k}\right)+\text { passo } \sum_{\tau} \hat{h}_{i \tau}\right)+s u 1-s u 2}{\text { custo da solução corrente }}
$$

onde,

$$
\hat{\mathrm{h}}_{\mathrm{i} \tau}=\mathrm{h}_{\mathrm{i} \tau}-\sum_{\mathrm{j} \in \mathrm{P}(\mathrm{i})} \mathrm{a}_{\mathrm{ji}} \mathrm{h}_{\mathrm{j} \tau}
$$

$\tau=\left\{\begin{array}{l}\mathrm{t}^{\prime}, \ldots, \mathrm{t}-1 \text { se passo regressivo no tempo } \\ \mathrm{t}, \ldots, \mathrm{t}^{\prime}-1 \text { se passo progressivo no tempo }\end{array}\right.$

passo $=\left\{\begin{aligned}-1 & \text { se } t^{\prime}>t \quad(\text { progressivo) } \\ 0 & \text { se } t^{\prime}=t \\ 1 & \text { se } t^{\prime}<t \quad \text { (regressivo) }\end{aligned}\right.$

sul $= \begin{cases}\operatorname{cs}_{i, k^{\prime}} & \text { se } X_{i, t^{\prime}, k^{\prime}}=0 \\ 0 & \text { se } X_{i, t^{\prime}, k^{\prime}}>0\end{cases}$

su2 $= \begin{cases}\operatorname{cs}_{\text {ik }} & \text { se } q=X_{\text {itk }} \\ 0 & \text { se } q<X_{\text {itk }}\end{cases}$

A penalidade é um termo não-negativo que pode ser interpretado como um custo pelo excesso em $(k, t)$ e $\left(k^{\prime}, t^{\prime}\right)$, que é dado por:

$$
\text { Penalidade }=\frac{\text { excesso_depois }(\mathrm{k}, \mathrm{t})}{\mathrm{CAP}_{\mathrm{kt}}}+\frac{\text { excesso_depois }\left(\mathrm{k}^{\prime}, \mathrm{t}^{\prime}\right)-\text { excesso_antes }\left(\mathrm{k}^{\prime}, \mathrm{t}^{\prime}\right)}{\mathrm{CAP}_{\mathrm{k}^{\prime} \mathrm{t}^{\prime}}}
$$

onde, 


$$
\begin{aligned}
& \text { excesso_depois }(\mathrm{k}, \mathrm{t})=\max \left\{0,\left(\Delta_{\mathrm{kt}}-\left(\mathrm{q} \mathrm{b}_{\mathrm{ik}}+\mathrm{ts}_{\mathrm{ik}} v_{1}\right)\right)\right\} \\
& \text { excesso_depois }\left(\mathrm{k}^{\prime}, \mathrm{t}^{\prime}\right)=\max \left\{0,\left(\Delta_{\mathrm{k}^{\prime}}+\left(\mathrm{qb}_{\mathrm{ik}}+\mathrm{ts}_{\mathrm{ik}} v_{2}\right)\right\}\right. \\
& v_{1}= \begin{cases}1 & \text { se } \mathrm{q}=\mathrm{X}_{\mathrm{itk}} \\
0 & \text { se } \mathrm{q}<\mathrm{X}_{\mathrm{itk}}\end{cases} \\
& v_{2}= \begin{cases}1 & \text { se } \mathrm{X}_{\mathrm{it} \mathrm{t}^{\prime}}=0 \\
0 & \text { se } X_{\mathrm{i} \mathrm{t}^{\prime} \mathrm{k}^{\prime}}>0\end{cases}
\end{aligned}
$$

O fator FP em (4.18) representa um peso dado à penalidade, que pode ser aumentado de acordo com a dificuldade de obter uma solução factível. Nos primeiros passos regressivo e progressivo $F P=1$, e $F P=n$, no n-ésimo passo regressivo e progressivo.

A variação da redução ( $\Delta$ redução) representa a diferença entre 0 Excesso_depois $(k, t)$, ou seja, o excesso após executar a transferência de $q$ unidades do item i e, o excesso antes de executar a transferência, representado por Excesso_antes( $k, t)$. Assim, $\Delta$ redução $=\frac{\mathrm{qb}_{\mathrm{ik}}+\mathrm{ts}_{\mathrm{ik}} v_{1}}{\mathrm{CAP}_{\mathrm{tk}}}$

\subsubsection{Procedimento de factibilizaÇão - Procedimento P2}

Os passos regressivos e progressivos no tempo, descritos anteriormente, são aplicados sucessivamente até que uma solução factivel seja obtida ou um número limite de iterações seja atingido. Uma iteração do procedimento de factibilização é contada quando se executa um passo regressivo e progressivo da heurística.

Note que podem existir pares $(k, t)$ infactíveis onde não é possivel efetuar transferências, pelo fato de $Z_{\mathrm{itk}}^{\mathfrak{t}^{\prime} \mathrm{k}^{\prime}}=0$, para todos os itens produzidos na máquina $\mathrm{k}$ e periodo t. Este fato pode ocorrer em qualquer um dos passos de factibilização. Com o propósito de superar este obstáculo, foi proposto um procedimento para tentar tornar $Z_{i t k}^{t^{\prime} k^{\prime}}$ não nulo. 


\subsubsection{Procedimento AuXiliar ao Processo de FactibilizaÇão}

Suponha que para um determinado par máquina-período $(\mathrm{k}, \mathrm{t})$ com excesso de produção, as quantidades $Z_{\mathrm{i} t \mathrm{k}}^{\mathrm{t}^{\prime}} \mathrm{k}^{\prime}=0$ para todos os itens i que tenham produção no par $(\mathrm{k}, \mathrm{t})$, ou seja, não há nenhuma possibilidade de transferência de produção de um único item i do par $(k, t)$ (expressão (4.15)). Observando que o cálculo de $Z_{\mathrm{i}^{\prime} \mathrm{k}^{\prime}}^{\mathrm{k}^{\prime}}$ se faz a partir dos níveis de estoque dos itens e da produção, (expressões (4.16) e (4.17)) então, para se obter um valor positivo de $Z_{\mathrm{itk}}^{\mathrm{t}^{\prime} \mathbf{k}^{\prime}}$, tenta-se aumentar os níveis de estoque e de produção dos itens e, conseqüentemente alterar o valor de $Z_{\mathrm{i} t \mathrm{k}}^{\mathrm{t}^{\prime} \mathrm{k}^{\prime}}$. Como $Z_{\mathrm{i} \mathrm{k}_{\mathrm{k}}}^{\mathrm{t}^{\prime}}$ é determinado de maneira distinta para transferências realizadas progressivamente e regressivamente no tempo, o procedimento para auxiliar o processo de factibilização é dividido do mesmo modo. Esse procedimento, denominado cria_transferência, foi baseado nos trabalhos de Berretta (1997) e Tempelmeier e Derstroff (1996), os quais não consideraram máquinas paralelas. Convém salientar aqui que o procedimento que será discutido a seguir é válido somente para $\mathrm{K} \geq 2$.

O procedimento auxiliar ao processo de factibilização é composto de duas partes denominadas: procedimento cria_transferência progressivo no tempo e regressivo no tempo. Estes procedimentos são descritos detalhadamente a seguir.

\section{PROCEDIMENTO CRIA_TRANSFERÊNCIA PROGRESSIVO NO TEMPO}

Para explicar o procedimento cria_transferência progressivo no tempo, é considerado um exemplo. Suponha um problema do planejamento da produção de 3 itens em 3 periodos, sendo a estrutura de itens do tipo serial, (Figura 4.4), $\mathrm{a}_{\mathrm{ij}}=1$, para todo $\mathrm{i}, \mathrm{j}$ e, demanda sendo 10 para o item final 1 e zero para os demais itens e $\mathrm{K}=2$ máquinas.

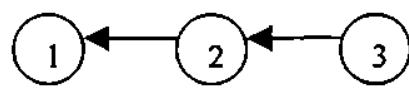

Figura 4.4. Estrutura de itens serial com 3 itens

Suponha que o plano de produção seja o representado pela Figura 4.5. 


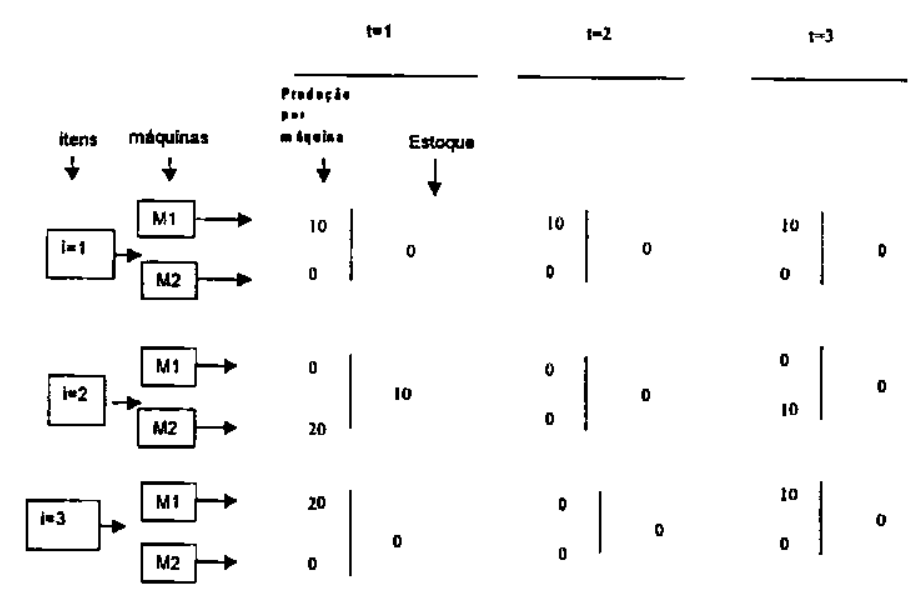

Figura 4.5. Plano de produção para exemplificar o procedimento cria_transferência progressivo no tempo.

Suponha ainda que o par (máquina, periodo) $=(1,1)$ esteja com excesso de produção e deseja-se reduzir este excesso com a transferência do item 3 para o período seguinte. Suponha também que esteja sendo feita a tentativa de transferir 10 unidades do item 3 do período 1 para o periodo 2, da máquina 1 para máquina 2. Note que é impossível fazer a transferência pois, $\mathrm{X}_{311}$ é a quantidade exata para suprir a demanda do item 2 . No entanto, se for feita uma transferência de 10 unidades do item 2 do período 1 da máquina 2 para o período 2 , então $\mathrm{X}_{311}$ pode ser reduzida de 10 unidades.

Como pode-se ver, a transferência de um item i para frente no tempo é impossível quando a produção deste item não for suficiente para atender a demanda dos seus itens sucessores imediatos (itens $\mathrm{j} \in \mathrm{S}(\mathrm{i})$ ) após a transferência. Assim, analisa-se uma possível transferência progressiva de algum item $j \in S(i)$. Quando a transferência progressiva do item $j$ é impossível pelos mesmos motivos, o raciocínio se repete recursivamente.

Convém salientar aqui que o procedimento cria_transferência só executa transferência de produção entre dois períodos adjacentes, ou seja, se o período $t=3$ está sendo considerado, o período destino é o período $t=4$, caso esteja executando o procedimento cria_transferência progressivo. O mesmo procedimento é utilizado para o procedimento cria_transferência regressivo no tempo.

Suponha agora que $\mathrm{X}_{\mathrm{i} 1 \mathrm{k}}>0,1_{\mathrm{it}}=0, \mathrm{t}^{\prime}=\mathrm{t}+1$ e que o par $(\mathrm{k}, \mathrm{t})$ esteja com excesso de produção. Suponha ainda, que exista algum $\mathrm{j} \in \mathrm{S}(\mathrm{i})$ tal que $\mathrm{X}_{\mathrm{j} t \mathrm{~m}}>0$, para algum 
$\mathrm{m}=1, \ldots, \mathrm{K}, \mathrm{m} \neq \mathrm{k}$, e que $\mathrm{I}_{\mathrm{jt}} \neq 0$. Então, neste caso é possível criar uma transferência para $\mathrm{o}$ item $i$, com a transferência de uma certa quantidade de produção do item $j$, denominada $q_{j}$. Observa-se aqui que a máquina destino $\mathrm{k}^{*}$, máquina que receberá a produção de $\mathrm{j}$, deverá ser determinada baseado nos custos de transferência.

Quando a restrição de balanço de estoque do item i no período $t$ com violação é considerada, restrição (4.20), observa-se que o estoque do item i é aumentado de $a_{i j} q_{j}$, permitindo assim, a transferência de uma certa quantidade de produção do item i. A quantidade $q_{j}$ no procedimento cria_transferência corresponde a $Z_{j \mathrm{tm}}^{t^{\prime} k^{\prime}}$ e, independe da máquina que está produzindo o item i, no caso, foi considerado que m é a máquina da qual é transferida uma certa quantidade de produção do item $\mathrm{j}$ no período $t$.

$$
X_{i t k}+\sum_{n \neq k} X_{i t n}+I_{i t-1}=d_{i t}+a_{i j}\left(X_{j t m}-q_{j}\right)+a_{i j} \sum_{s \neq m} X_{j t s}+\sum_{o \in S(i)-f j\}} \sum_{p} a_{i o} X_{o t p}+\left(I_{i t}+a_{i j} q_{j}\right)
$$

Como demonstrado no início da seção 4.3 , a quantidade $q_{j}$ a ser transferida do item $j$ é determinada como segue:

$$
q_{j}=Z_{j t m}^{(t+1) k}=\min \left\{X_{j t m}, I_{j t}\right\}
$$

Note que podem existir outras máquinas $(m \neq k)$ que estão produzindo o item $j \in S(i)$ no periodo t. Neste caso, deve-se adotar uma estratégia para determinar qual é a máquina origem. A estratégia adotada foi escolher a máquina com maior produção do item $\mathrm{j}$. Foram pesquisadas outras estratégias e esta apresentou melhor desempenho. Assim a quantidade $q_{j}$ é determinada do seguinte modo:

$$
\mathrm{q}_{\mathrm{j}}=Z_{\mathrm{jtm}}^{\mathrm{t}^{\prime} \mathrm{k}^{\prime}}=\min \left\{\max _{\mathrm{s}=1, \cdots, \mathrm{K}}\left\{\mathrm{X}_{\mathrm{jts}}\right\} \mathrm{I}_{\mathrm{jt}}\right\}
$$

O índice $\mathrm{k}^{\prime}$ (máquina destino) deve ser escolhido de tal maneira que o custo seguinte seja mínimo. O custo causado pela transferência da quantidade $Z_{\mathrm{jtk}}^{\mathbf{\prime}^{\prime}}$ do item j de $(\mathrm{m}, \mathrm{t})$ para $\left(k^{\prime}, t^{\prime}\right)$ pode ser expressa como: 


$$
\text { Custo }=Z_{j t m}^{r^{\prime} k^{\prime}}\left[\left(c_{j, t^{\prime}, k^{\prime}}-c_{j, t, m}\right)-\left(h_{j t}-\sum_{r \in P(j)} a_{r j} h_{r t}\right)\right]+s u 1-s u 2
$$

onde:

$$
\begin{aligned}
& \text { sul }= \begin{cases}c_{j, t^{\prime}, k^{\prime}} & \text { se } X_{j, t^{\prime}, k^{\prime}}=0 \\
0 & \text { se } X_{j, t^{\prime}, k^{\prime}}>0\end{cases} \\
& \text { su2 }= \begin{cases}c_{j, t, m} & \text { se } Z_{j, m}^{t^{\prime} k^{\prime}}=X_{j, t, m} \\
0 & \text { se } Z_{j t m}^{t^{\prime} k^{\prime}}<X_{j, t, m}\end{cases}
\end{aligned}
$$

\section{PROCEDIMENTO CRIA_TRANSFERÊNCIA REgRESSIVO NO TEMPO}

Considere o problema de planejamento apresentado para o procedimento auxiliar de factibilização progressivo no tempo e suponha o plano de produção apresentado pela Figura 4.6.

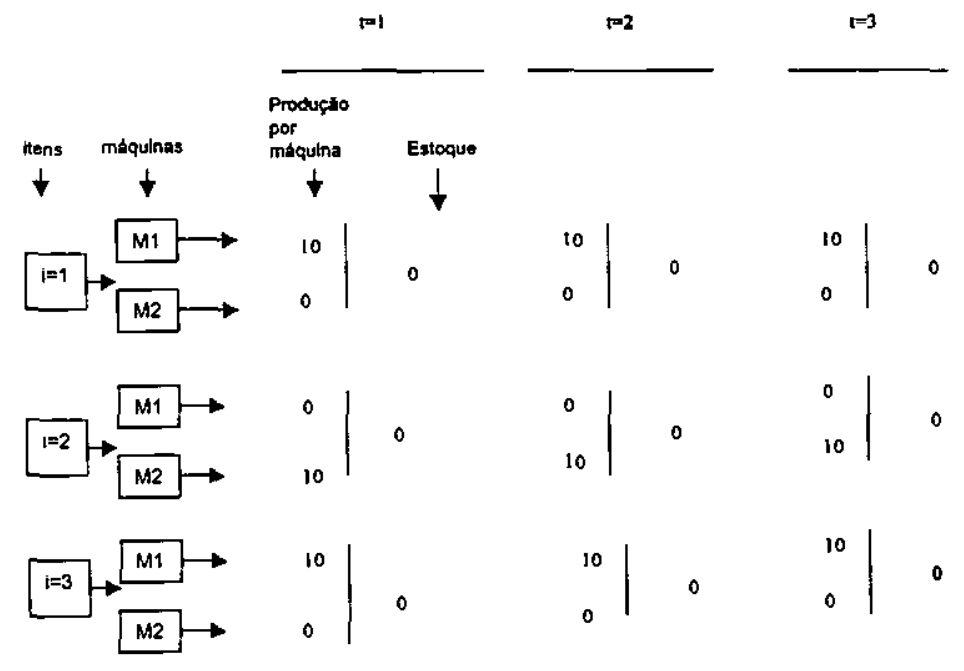

Figura 4.6. Plano de produção para exemplificar o procedimento de cria transferência regressivo no tempo.

Suponha que o par máquina-periodo $(2,3)$ esteja com excesso de produção. Suponha ainda que, durante a execução do procedimento de factibilização, esteja sendo feita uma tentativa de transferir regressivamente no tempo 5 unidades do item 2 , do período 3 para 0 período $2 \mathrm{e}$, que $\mathrm{a}_{\mathrm{ij}}=\mathrm{l}$ para todo $\mathrm{i}, \mathrm{j}$. Como $\mathrm{I}_{32}=0$, esta transferência é impossível (veja 
expressão (4.16)). Mas, se 5 unidades do item 3 forem transferidas do período 3 e da máquina 1, para o período 2, então $I_{32}$ irá aumentar de 5 unidades, quantidade suficiente para tornar possível a transferência do item 2 do período 3 para o período 2 .

Através do exemplo, pode-se observar que quando a transferência de um item i regressivamente no tempo de um par $(k, t)$ com excesso de produção for impossível devido a produção dos seus itens predecessores imediatos (itens $j \in P(i)$ ) não serem capazes de suprir um aumento da demanda do item $i$, tenta-se aumentar a produção do item $j(j \in P(i))$. Se a transferência do item $\mathrm{j}$ não for possível, utiliza-se o mesmo raciocínio, analisando os itens predecessores imediatos deste e assim, recursivamente.

Para exemplificar como são feitas as transferências, considere uma tentativa de transferir uma quantidade de produção de um item i que está sendo produzida num par $(k, t)$ com excesso de produção. Suponha então que $X_{i t k}>0$ e $I_{j t}=0$, para todo $j$ predecessor imediato de $i(j \in P(i)), t^{\prime}=t-1$. Suponha ainda que existe algum $j \in P(i)$ tal que $X_{j t m}>0$, para algum $m=1, \ldots, K, m \neq k$ e que $I_{n t} \neq 0, n$ predecessor imediato do item $j(n \in P(j))$. Então, neste caso é possível criar uma transferência para o item i, com a transferência de uma certa quantidade de produção do item $\mathrm{j}$. Observa-se que a produção do item $\mathrm{j}$ é aumentada de $\mathrm{q}_{\mathrm{j}}$ unidades. Esta quantidade é determinada como segue:

$$
q_{j}=Z_{j t m}^{t^{\prime} k^{\prime}}=\min \left\{\max _{s=1, \cdots, K}\left\{X_{j t s}\right\} \min _{n \in P(j)}\left\{\frac{I_{n t^{\prime}}}{a_{n j}}\right\}\right\}
$$

A máquina destino $\mathrm{k}^{\prime}$ deve ser escolhida baseado nos custos de transferência. $O$ índice $\mathrm{k}^{\prime}$ deve ser escolhido de tal maneira que o custo seguinte seja mínimo. $\mathrm{O}$ custo causado pela transferência da quantidade $q_{j}=Z_{j ı m}^{t^{\prime} k^{\prime}}$ do item $j$ de $(m, t)$ para $\left(k^{\prime}, t^{\prime}\right)$ pode ser expresso como:

$$
\text { Custo }=Z_{j t m}^{t^{\prime} k^{\prime}}\left[\left(c_{j, r, k^{\prime}}-c_{j, t, m}\right)+\left(h_{j t}-\sum_{n \in P(j)} a_{n j} h_{n t}\right)\right]+s u l-s u 2
$$

onde: 


$$
\begin{aligned}
& \text { sul }= \begin{cases}c_{j, r^{\prime}, k^{\prime}} & \text { se } X_{j, t^{\prime}, k^{\prime}}=0 \\
0 & \text { se } X_{j, t^{\prime}, k^{\prime}}>0\end{cases} \\
& \text { su2 }= \begin{cases}c_{j, t, m} & \text { se } Z_{j t m}^{t^{\prime} k^{\prime}}=X_{j, m} \\
0 & \text { se } Z_{j t m}^{t^{\prime} k^{\prime}}<X_{j, t, k}\end{cases}
\end{aligned}
$$

Observe que os procedimentos regressivo e progressivo no tempo descritos acima, consideram a transferência de múltiplos itens. Estes procedimentos são interrompidos assim que se consegue transferir o primeiro item sucessor imediato ou não, do item $i$, no caso progressivo, ou quando se transfere o primeiro item predecessor, imediato ou não, do item $i$, no caso regressivo no tempo.

\section{Ciclagem}

Um problema detectado durante o procedimento de factibilização foi à ciclagem de transferência entre máquinas num mesmo período e, entre os passos progressivos e regressivos no tempo. A ciclagem de transferências entre duas máquinas ocorre quando uma mesma quantidade $q$ de um dado item é transferida indefinidamente entre duas máquinas. $A$ ciclagem entre os passos regressivos e progressivos ocorre quando um passo regressivo desfaz as transferências executadas por um passo progressivo e vice-versa. Para evitar estas ciclagens foram implementadas duas estratégias:

1- Para evitar ciclagem de transferência entre máquinas num mesmo período, foi implementado um contador de ciclos que proíbe que se volte a executar uma transferência efetuada em um determinado período.

2- Para impedir que ocorra ciclagem entre os passos regressivos e progressivos foi necessário utilizar estratégias da metaheurística Busca Tabu baseadas na memória de curto prazo.

Estas duas estratégias foram testadas separadamente e os resultados relatados no Capítulo 5.

A Figura 4.7 ilustra as ciclagens entre máquinas. Na Figura 4.7, $\mathrm{k}$ e m representam duas máquinas e $T_{m k n}$ representa a $n$-ésima transferência da máquina $m$ para a máquina $k$. Para exemplificar as ciclagens entre máquina suponha que: 


$$
\begin{array}{ll}
T_{121} & q=6 ; \\
T_{122} & q=3 ; \\
T_{211} & q=3 ; \\
T_{212} & q=3
\end{array}
$$

Note que 6 unidades foram transferidas da máquina 1 para a máquina 2 na primeira transferência $\left(T_{121}\right)$ e, apenas 3 unidades permaneceram na máquina 2 pois, na primeira transferência da máquina 2 para máquina 1,3 unidades voltaram para máquina $1\left(T_{211}\right)$. Na segunda transferência da máquina 1 para máquina 2, as 3 unidades que acabaram de ser transferidas na transferência $T_{211}$, são transferidas novamente (transferência $T_{122}$ ). A segunda transferência da máquina 2 para máquina $I\left(T_{212}\right)$ é proibida através do contador de ciclos.

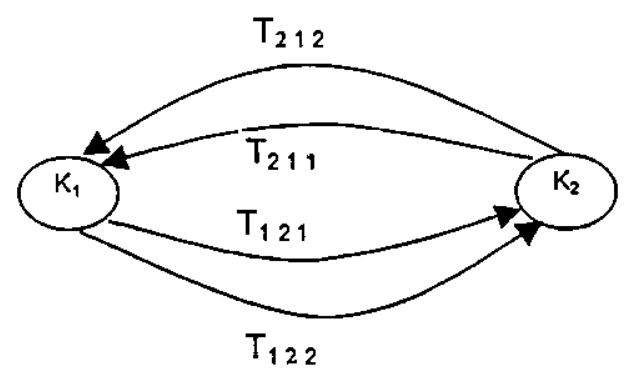

Figura 4.7. Transferências entre duas máquinas.

Se o limite de iterações é alcançado sem a obtenção de uma solução factível, aplica-se um procedimento $\mathrm{P} 4$ que visa obter uma nova configuração da solução infactível obtida. Esta solução servirá como um novo ponto de partida para o procedimento heurístico de factibilização P2. O procedimento de factibilização P2 é aplicado durante um certo número de iterações preestabelecido. Se após esta nova tentativa de factibilização, uma solução factível não for determinada, o método falha ou não existe uma solução factível.

A seguir, os pseudocódigos dos passos regressivo e progressivo da heurística de factibilização P2 são apresentados. 


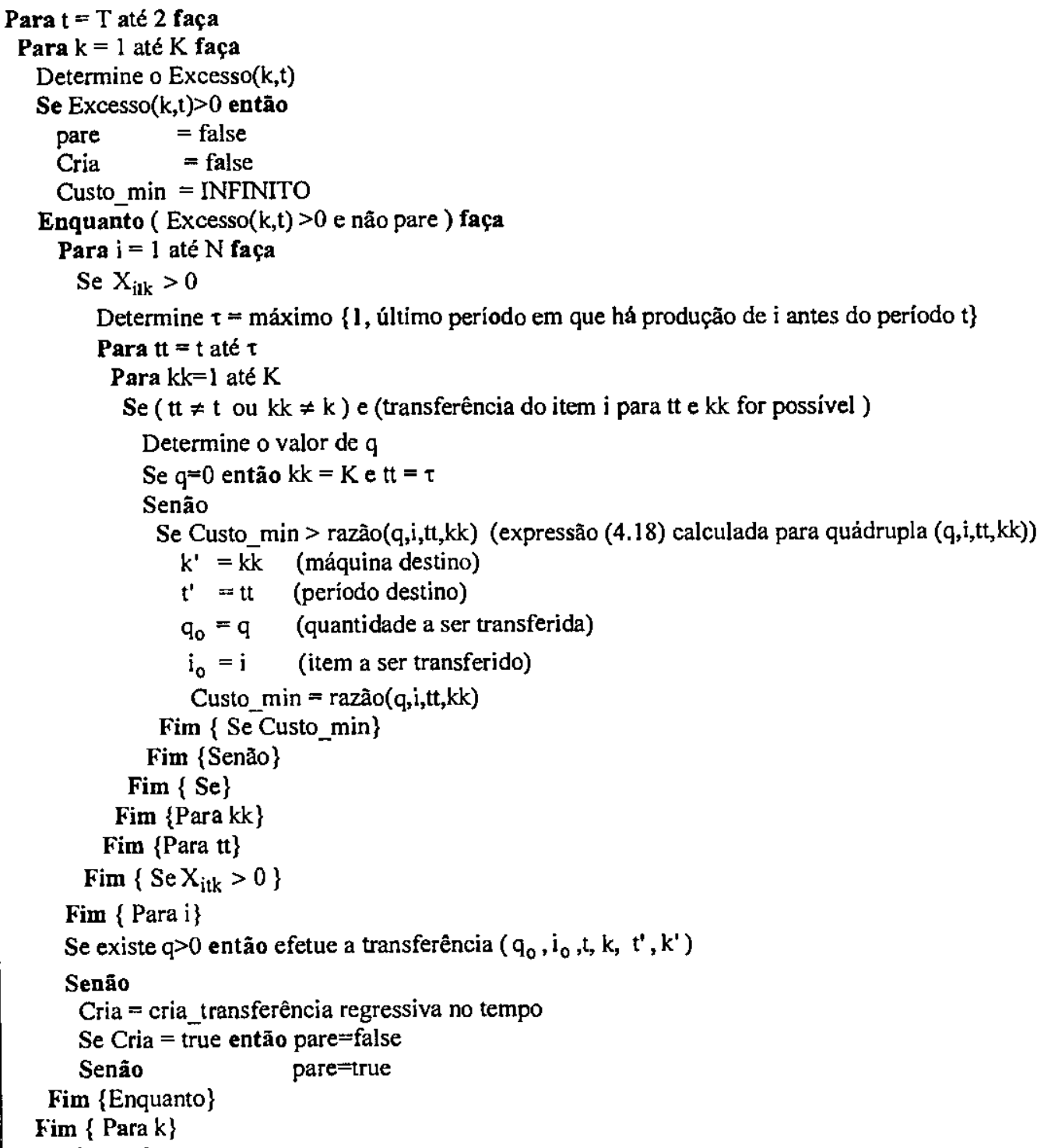

onde:

pare é uma variável lógica que indica a possibilidade de transferência no par (máquina,período) cuja capacidade está violada.

$\left(q_{0}, i_{0}, t, k, t^{\prime}, k^{\prime}\right)$ é a transferência que obteve a menor razão(expressão 4.18), sendo que custo_min é o valor da menor razão. Se uma solução factível não é obtida, o passo progressivo é aplicado. 


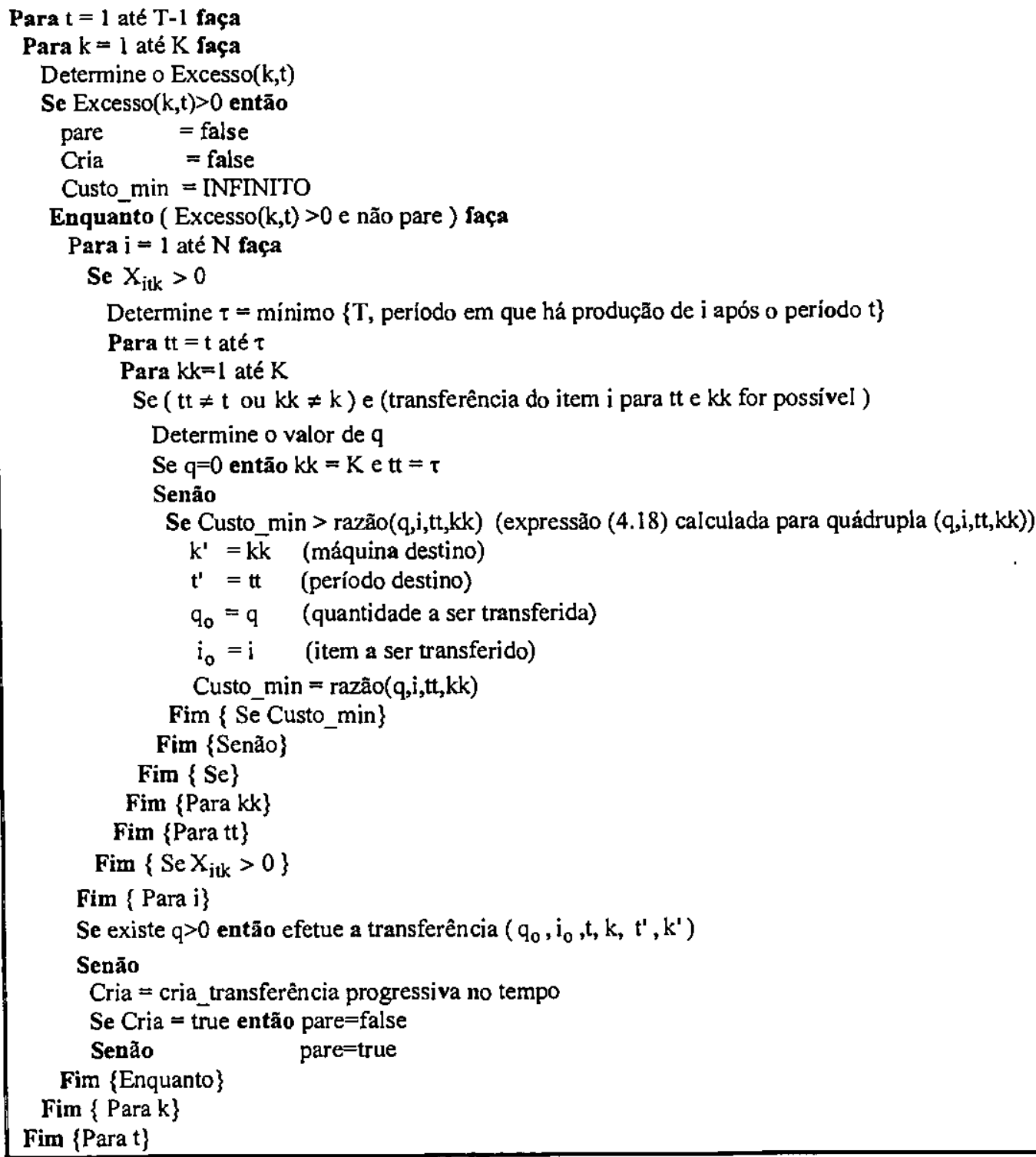

Se ao final do passo progressivo, não for obtida uma solução factível, o passo regressivo é aplicado novamente. Os dois passos são aplicados sucessivamente, até que uma solução factível seja obtida, ou um número máximo de iterações seja alcançado. 


\subsubsection{CONCEITOS BÁSICOS DE BUSCA TABU}

A busca tabu, introduzida por Fred Glover (Glover, 1989 e Glover, 1990), é uma metaheurística que guia um procedimento de busca local a explorar o espaço de soluções além do ótimo local. Um procedimento de busca local é uma busca que usa uma operação chamada movimento para definir uma vizinhança de uma dada solução (Laguna, 1995). Como um método de busca local, a busca tabu seleciona o melhor dos movimentos possíveis em cada passo porém, permite mover-se até uma solução da vizinhança não tão boa quanto a solução atual para escapar dos ótimos locais e continuar estrategicamente a busca de soluções ainda melhores.

A característica principal da busca tabu é a exploração de mecanismos flexíveis de memória adaptativa para orientar a busca, a qual pode ser de curto ou longo prazo. $O$ principio básico nas estratégias que utilizam a memória de curto prazo é de restringir a busca, prevenindo que certas soluções de um passado recente sejam novamente visitadas. Seus elementos básicos são os "atributos", "regra de ativação tabu", "tempo de permanência tabu" e "critério de aspiração".

Atributos são elementos que caracterizam soluções ou movimentos. A partir de sua definição, os atributos presentes em soluções (ou movimentos) recentemente visitadas são classificados como tabu e as soluçōes (ou movimentos) que contém os atributos tabus, ou uma combinação destes, ficam proibidos. Isto previne que certas soluções de um passado recentes sejam visitadas. A maneira de classificar quais movimentos estão proibidos a partir de um certo atributo marcado como tabu é a regra de ativação tabu.

Depois de um certo número de iterações, os atributos são liberados de sua condição tabu, sendo que o tempo de permanência tabu pode ser um número fixo ou algum valor associado com os dados do problema estudado. Após liberar os atributos de sua condição tabu, os movimentos (ou soluções) que possuem estes atributos podem ser executados.

Um movimento que contém atributos considerados tabus pode ser liberado de sua condição tabu a qualquer momento após uma avaliação chamada de critério de aspiração. Esse critério pode avaliar o quanto um movimento tabu pode ser atrativo, ou seja, se executar este movimento quanto o valor da solução pode ser melhorado ou algum outro critério previamente estabelecido for garantido. 
IMPlementaÇÃo da Búsca Tabu para o Problema de dimensionamento DE LOTES

Como dito anteriormente, as transferências executadas pelos passos regressivos e progressivos do procedimento de factibilização P2 tendem a ciclar, ou seja, uma transferência pode ser desfeita para o passo seguinte. Para evitar estas ciclagens e as ciclagens entre máquinas em um determinado período, foi feita uma implementação da busca tabu baseada na memória de curto prazo.

Um movimento é uma transferência de uma quantidade de produção de um item i de uma máquina $\mathrm{k}$ num período $\mathrm{t}$ para uma máquina $\mathrm{k}$ ' e período t', como mostra a Figura 4.8.

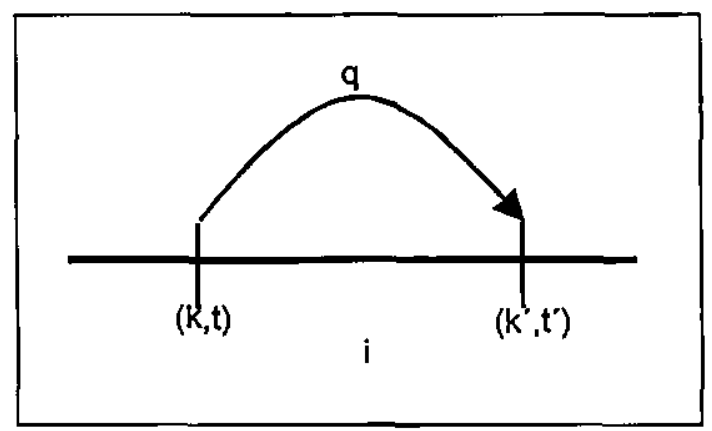

Figura 4.8. Representação de um movimento executado pela heurística.

Os atributos considerados para caracterizar este movimento são formados pelos elementos $i, t, k, t^{\prime}$ e $k^{\prime}$. Foi considerada uma matriz tridimensional para classificar os atributos como tabu. Cada posição $(\mathrm{i}, \mathrm{t}, \mathrm{k})$ dessa matriz representa um atributo e o valor armazenado nela indica se o atributo está classificado como tabu ou não. Inicia-se com zero todos os valores da matriz e a cada movimento realizado, a posição referente ao atributo deste movimento recebe um valor. Este valor é o tempo que este movimento vai ficar proibido, ou seja, o tempo de permanência tabu.

A regra de ativação tabu adotada foi proibir a produção do item i sair de $\left(k^{\prime}, t^{\prime}\right)$ e voltar para $(k, t)$, uma vez que este movimento já foi efetuado em um passado recente ou, qualquer quantidade de produção do item i sair de qualquer outro par $\left(k^{\prime \prime}, t^{\prime \prime}\right)$ para $(k, t)$ ou para $\left(k^{\prime}, t^{\prime}\right)$. Dentre todas as regras de ativação testadas, a heurística apresentou melhor desempenho com esta, apesar de ser muito restritiva

Para um melhor entendimento desta regra, suponha que esta sendo feita uma transferência $\left(q, i, t, k, t^{\prime}, k^{\prime}\right)=(10,2,2, I, 3,3)$, ou seja, está sendo executada uma transferência progressiva no tempo. Esta transferência é ilustrada na Figura 4.9. 


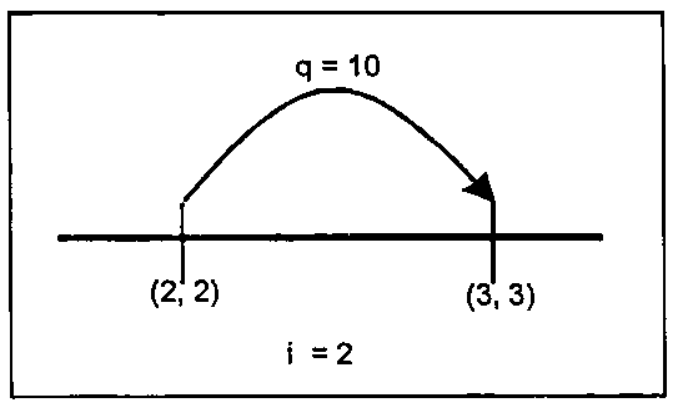

Figura 4.9. Representação de uma transferência executada pela heurística.

Suponha também, que o procedimento de factibilização já tenha executado 10 iterações e que, o tempo de permanência tabu seja de 5 iterações. Após realizar esta transferência têm-se as posições $(i, t, k)=(2,2,1)$ e $\left(i, t^{\prime}, k^{\prime}\right)=(2,3,3)$ da matriz tridimensional atualizados com o valor $15(10+5)$. Assim, até que o procedimento de factibilização atinja 16 iterações, os movimentos relacionados às posições $(2,2,1)$ e $(2,3,3)$ estão proibidos. Ou seja, ao executar um passo progressivo e regressivo no tempo, os movimentos relacionados a estas posiçôes (atributos) estão proibidos durante um certo número de iterações (veja a ilustração dos movimentos considerados tabus na Figura 4.10).

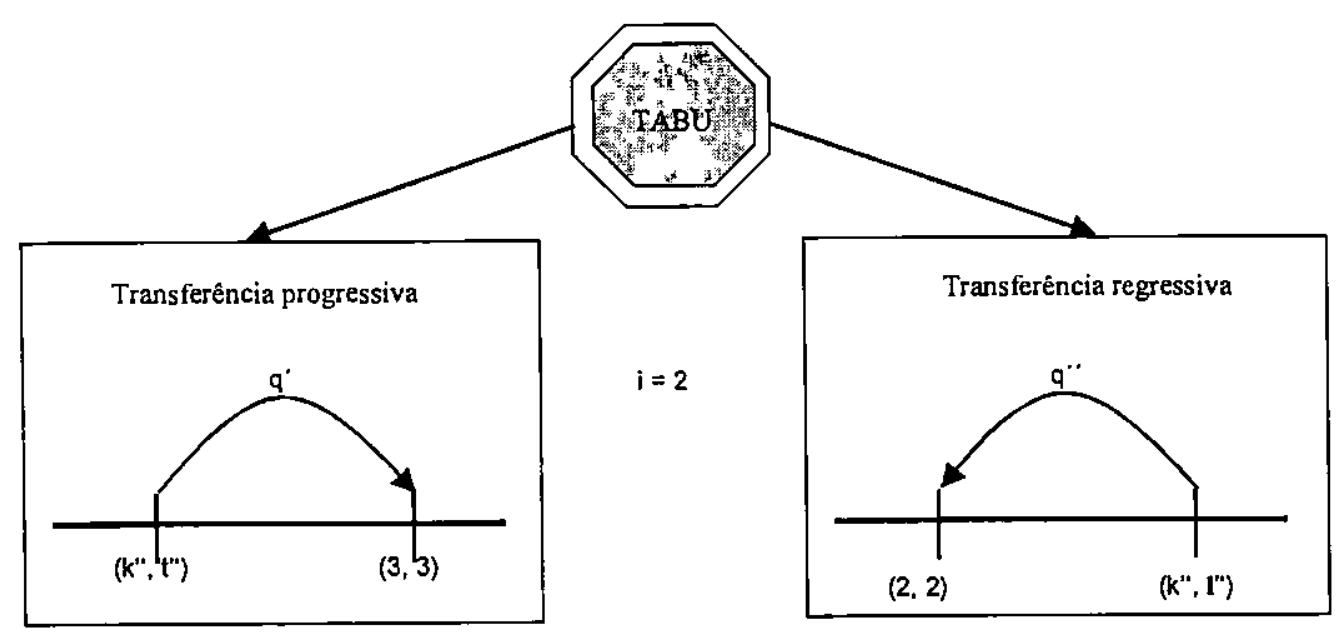

Figura 4.10. Movimentos considerados tabus durante um certo número de iterações.

Convém salientar aqui que, se não existe nenhum item i com produção no par $(k, t)$ com excesso de produção tal que $Z_{i \text { t } k^{\prime}}^{\prime^{\prime}}>0$, então pode ter ocorrido dois fatos:

(1) todos os itens que são produzidos no par $(k, t)$ são proibidos de sair deste par;

(2) não existe $Z_{j+k}^{t^{\prime} k^{\prime}}>0$ para itens que são produzidos em $(k, t)$ e que são possíveis de serem transferidos. 
Em ambos os casos, o procedimento cria_transferência é executado e, se for possível criar uma transferência para um item que é proibido de deixar o par $(k, t)$, sua transferência é permitida. Observe mais uma vez que, no caso (1) todos as transferências possíveis contém atributos classificados como tabus, e estes são liberados desta condição, quando executa o procedimento cria_transferência.

\subsubsection{Procedimento para ReconfiguraÇão da SoluÇão - Procedimento} P4

Caso o número máximo de iterações preestabelecido para executar o procedimento de factibilização (P2) for atingido e a uma solução factível não foi obtida, a solução atual é reconfigurada de modo a obter um novo ponto de partida para o procedimento de factibilização. Esta alteração é feita pelo procedimento P4 e consiste de transferências de produção considerando os dois períodos iniciais. A interação entre o procedimento P2 e P4 está representado pela Figura 4.11

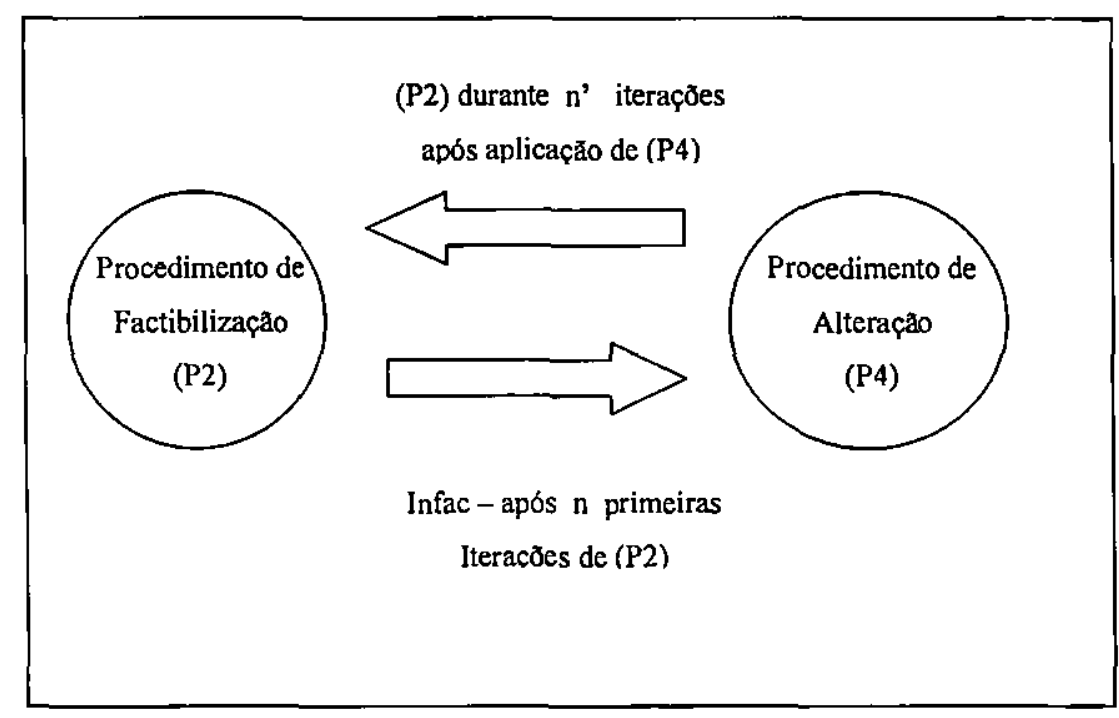

Figura 4. I I. Interação entre os procedimentos P2 e P4.

No procedimento P4 são feitas transferências considerando-se somente os dois períodos iniciais, pois durante os experimentos computacionais notou-se que a maioria das soluções infactíveis apresentava violações somente no primeiro período.

Neste procedimento, as máquinas no primeiro período são arranjadas em ordem decrescente de utilização de capacidade, ou seja, inicia-se com a máquina com maior utilização de capacidade até a máquina que tenha menor utilização. Com as máquinas assim 
ordenadas, e iniciando-se com a máquina com maior excesso de produção, tenta-se primeiramente executar transferências de produção entre máquinas de $t=1$ para $t=2$.

Se após esta primeira tentativa, a máquina analisada ainda apresentar violação, tentase transferir produção entre máquinas em $t=1$. As transferências entre máquinas em $t=1$ são feitas seqüencialmente, ou seja, das máquinas com maior excesso para as máquinas com menor excesso. Convém observar que as transferências entre máquinas são executadas sem verificar a existência de folga na máquina destino.

A transferência de produção entre $t=1$ e $t=2$ de um determinado item i somente é executada se houver produção do item em alguma máquina no período $t=2$. Esta medida serve para garantir a não existência de novas preparações em $t=2$. Caso haja mais de uma máquina que produza o item $i$ no período $t=2$, escolhe-se a máquina com maior folga .

$O$ item i que deverá ser transferido de $t=1$ para $t=2$ deve satisfazer a Expressão (4.25), ou seja, $\mathrm{i}$

$$
\mathrm{i}=\text { índice do item } \mathrm{i} \text { tal que } \mathrm{q}_{\mathrm{i}}=\max \left\{\mathrm{q}_{\mathrm{j}}\right\}
$$

onde:

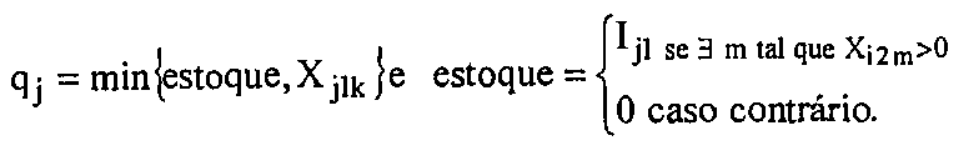

Assim, a quantidade a ser transferida de $t=1$ para $t=2$ é dada por: $q=q_{i} . O$ índice da máquina destino, $t=2$, que receberá a produção do item $i$, será o índice da máquina que está produzindo o item i em $\mathrm{t}=2$, como dito, e que tenha a maior folga. Pela expressão (4.25) podese observar a tentativa de transferir o máximo possível de produção entre períodos. Estas transferências têm o objetivo de deixar o período $t=1$ com folgas maiores.

Para transferências entre máquinas, tenta-se escolher $o$ índice do item i a ser transferido que satisfaça a seguinte condição:

$$
\mathrm{i} / \mathrm{X}_{\mathrm{ilk}}>\mathrm{X}_{\mathrm{i}^{\prime} 1 \mathrm{k}} \text { e ts } \mathrm{s}_{\mathrm{ik}}>\mathrm{ts}_{\mathrm{i}^{\prime} \mathrm{k}} \forall \mathrm{i}^{\prime}=1, \cdots, \mathrm{N} \text { e } \mathrm{i}^{\prime} \neq \mathrm{i} \text {. }
$$

Sendo que, a quantidade transferida da máquina $\mathrm{k}$ (máquina origem) para a máquina $\mathrm{j}$ (máquina destino), em $t=1$, é dada por:

$$
\mathrm{q}=\mathrm{X}_{\mathrm{i} 1 \mathrm{k}}
$$

Caso não exista nenhum item que satisfaça a expressão (4.26), escolhe-se aleatoriamente um item que tenha produção na máquina avaliada, com a quantidade a ser transferida dada por (4.27). Após as transferências de produção entre máquinas, uma máquina em $t=1$ que anteriormente não possuía excesso de produção, pode estar violada, pois as transferências em $t=1$ não levam em consideração as folgas. 
Depois de executado o procedimento $\mathrm{P} 4$, se a solução obtida for infactível, executa-se o procedimento P2, como ilustrado na Figura 4.11. No procedimento P2 executa-se primeiramente o passo progressivo no tempo e, em seguida, o passo regressivo no tempo, durante um certo número de iterações. Se a solução obtida no final da reaplicação do procedimento $\mathrm{P} 2$ for factível, aplica-se o procedimento $\mathrm{P} 3$ na tentativa de melhorar a qualidade da solução obtida, caso contrário, o método falha em determinar uma solução factível e a solução é analisada quanto ao grau de infactibilidade.

\subsection{Heurística de Melhoria - Procedimento P3}

O procedimento de melhoria parte da solução factível obtida no passo de factibilização e tenta encontrar outra de custo menor. Isto é feito também baseado em transferências de partes da produção progressivamente e regressivamente no tempo. É similar aos passos regressivos e progressivos do procedimento de factibilização $\mathrm{P} 2$, porém respeitando-se a factibilidade da solução. Os passos da heurística de melhoria são aplicados sucessivamente até que um passo regressivo e outro progressivo sejam efetuados sem que nenhuma transferência seja executada, ou seja, até não existir qualquer transferência que melhore o valor solução atual.

\section{Passo Progressivo}

Iniciaimente escolhe-se um par destino $\left(k^{\prime}, t^{\prime}\right)$ que tenha folga de capacidade, dada por: $-\Delta_{k^{\prime} t^{\prime}}>0$, onde $\Delta_{k^{\prime} t^{\prime}}=\sum_{i=1}^{N}\left(b_{i k^{\prime}} \hat{X}_{i^{\prime} k^{\prime}}+t s_{i k^{\prime}} \hat{Y}_{i^{\prime} k^{\prime}}\right)-C A P_{t^{\prime} k^{\prime}} \cdot$ Os pares são analisados para as máquinas $k^{\prime}=1, \ldots, \mathrm{K}$ e para os períodos $t^{\prime}=2, \ldots, T$, nesta ordem.

Uma vez determinado o par destino $\left(k^{\prime}, t^{\prime}\right)$, são considerados os pares de origem $(k, t)$, tal que, $k=1, \ldots, \mathrm{K}$ e os períodos $t=1, \ldots, t^{\prime}-\mathrm{I}$. Para todos os itens com produção em $t<t^{\prime}$, considerase a seguinte quantidade $q$ do item $i$ a ser transferida de $t$ para $t$ '

$$
q=\min \left\{\frac{\max \left\{0,-\left(\Delta_{\mathbf{k}^{\prime} \mathrm{t}^{\prime}}+v_{2} \cdot \mathrm{ts}_{\mathrm{ik}}\right)\right\}}{\mathrm{b}_{\mathrm{i}, \mathrm{k}^{\prime}}}, \mathrm{Z}_{\mathrm{i} \mathrm{tk}}^{\mathrm{t}^{\prime} \mathrm{k}^{\prime}}\right\}
$$

O primeiro termo na expressão acima representa a quantidade máxima do item i que pode ser transferida sem violar a capacidade em $\left(k^{\prime}, t^{\prime}\right)$. O segundo termo evita estoques negativos (expressão (4.17)). 
Para cada par destino $\left(\mathrm{k}^{\prime}, \mathrm{t}^{\prime}\right)$ com folga de capacidade, escolhe-se para transferência $o$ par origem $(k, t)$ que proporcione a maior redução no custo total da solução, dada por $\Delta$ custo (expressão (4.19)).

Se o custo de transferência for negativo, então a transferência será efetuada, garantindo assim uma melhoria no valor da solução atual. Depois da transferência, caso ainda exista folga em $\left(k^{\prime}, t^{\prime}\right)$ busca-se outro par origem capaz de diminuir o custo da solução corrente. Se não houver tal par, toma-se o próximo par destino e, repete-se o procedimento até o fim do horizonte de planejamento.

\section{PASSO RegRessivo}

Analogamente ao passo progressivo, escolhe-se um par destino $\left(k^{\prime}, t^{\prime}\right)$ que tenha folga de capacidade. Os pares são analisados para as máquinas $\mathrm{k}^{\prime}=1, \ldots, \mathrm{K}$ e para os períodos $t^{\prime}=\mathrm{T}-1, \ldots, 1$, nesta ordem.

Uma vez determinado um par destino $\left(k^{\prime}, t^{\prime}\right)$, são considerados os pares origens $(k, t)$ que envolvam as máquinas $k=1, \ldots, \mathrm{K}$ e os períodos $\mathrm{t}=\mathrm{T}, \ldots, \mathrm{t}^{\prime}+1$. Para todos os itens com produção em $t>t^{\prime}$, quantidade $q$ do item $i$ a ser transferida de $t$ para $t^{\prime}$ é análoga ao passo progressivo:

$$
q=\min \left\{\frac{\max \left\{0,-\Delta\left(\mathrm{k}^{\prime} \mathrm{t}^{\prime}\right)-v_{2} \cdot \mathrm{ts}_{\mathrm{ik}^{\prime}}\right\}}{\mathrm{b}_{\mathrm{ik} \mathbf{k}^{\prime}}}, \mathrm{Z}_{\mathrm{ikt}}^{\mathrm{t}^{\prime} \mathbf{k}^{\prime}}\right\}
$$

Como no caso anterior, o primeiro termo na expressão acima representa a quantidade máxima do item $\mathrm{i}$ que pode ser transferida sem violar a capacidade em $\left(k^{\prime}, t^{\prime}\right)$. $O$ segundo termo garante que os estoques são não-negativos (expressão (4.16)).

Para cada par destino $\left(k^{\prime}, t^{\prime}\right)$ com folga de capacidade, escolhe-se para transferência, a dupla origem que proporcione a maior diminuição do custo total da solução atual, dado por $\Delta$ custo (4.19).

Os dois passos da heurística de melhoria são repetidos sucessivamente até que um passo regressivo e progressivo seja efetuado sem que nenhuma transferência seja executada.

\subsection{LIMITANTE INFERIOR}

O problema (3.9)-(3.13) pode ser reformulado em termos de estoque de escalão. $O$ conceito de estoque de escalão foi introduzido por Clark e Scarf (1960) e utilizado por Afentakis et al. (1984). O problema (3.9)-(3.13) é reformulado em termos de estoque de 
escalão com o intuito de "facilitar" uma decomposição por itens após a relaxação. Tendo o problema decomponivel por itens, pode-se resolver os subproblemas utilizando procedimentos para resolução do problema com um único item. Por exemplo, o algoritmo de Wagner e Whitin pode ser utilizado para resolver cada subproblema. Nesta tese, o algoritmo proposto por Armentano e Toledo (1997) é utilizado para a resolução destes subproblemas.

O estoque de escalão de um item é a quantidade total do item presente no sistema, incluindo a quantidade do item em estoque mais a quantidade do item contida no estoque de seus sucessores. Matematicamente o estoque de escalão $\left(E_{i t}\right)$ é definido da seguinte maneira:

$$
E_{i t}=I_{i t}+\sum_{j \in S(i)} a_{i j} E_{i t}
$$

$\mathrm{O}$ custo de estoque de escalão $\left(\hat{\mathrm{h}}_{\mathrm{it}}\right)$ é definido a partir do custo de estoque convencional, de modo que seja mantida a equivalência

$$
\sum_{\mathrm{i}=1}^{N} \sum_{\mathrm{t}=1}^{\mathrm{T}} \hat{\mathrm{h}}_{\mathrm{it}} \mathrm{E}_{\mathrm{it}}=\sum_{\mathrm{i}=1}^{\mathrm{N}} \sum_{\mathrm{t}=1}^{\mathrm{T}} \mathrm{h}_{\mathrm{it}} \mathrm{l}_{\mathrm{it}}
$$

Assim, o custo unitário do estoque de escalão é obtido por:

$$
\hat{h}_{i t}=h_{i t}-\sum_{j \in P(i)} a_{i j} h_{j t}
$$

Para exemplificar como as restrições de balanço de estoque são reformuladas em termos de estoque de escalão, considere a estrutura de produtos serial com três itens representada na Figura 4.4 e a restrição de balanço de estoque para 0 item 2 ( $t$ fixo). Utilizando o estoque convencional, a restrição é dada por:

$$
\sum_{k=1}^{K} X_{2 t k}+I_{2(i-1)}-I_{2 t}-a_{2}: \sum_{k=1}^{K} X_{1 t k}=d_{21}
$$

Por sua vez, $\sum_{k=1}^{K} X_{1 t k}$ é determinada por $\sum_{k=1}^{K} X_{1+k}=I_{1 t}+d_{2 t}-I_{I(t-1)}$. Substituindo este valor na restrição acima, obtém-se:

$$
\sum_{k=1}^{K} X_{2 t k}+I_{2(t-1)}+a_{21} I_{1(t-1)}-I_{2 t}-a_{21} I_{1 t}=d_{2 t}+a_{21} d_{1 t} .
$$

Observe que:

$$
\begin{aligned}
& E_{2(t-1)}=I_{2(t-1)}+a_{21} l_{1(t-1)} e, \\
& E_{2 t}=I_{2 t}+a_{21} I_{1 t} .
\end{aligned}
$$

Substituindo estas duas relações em (4.28) obtém-se: 


$$
\sum_{k=1}^{K} X_{2 t k}+E_{2(t-1)}-E_{2 t}=d_{2 t}+a_{21} d_{1 t}
$$

Definido $D_{2 t}=d_{2 t}+a_{21} d_{1 t}$ como a demanda de escalão para o item 2, a restrição de balanço de estoque (4.29), torna-se:

$$
\sum_{k=1}^{K} X_{2 k}+E_{2(1-1)}-E_{2 t}=D_{2 t}
$$

Os passos acima podem ser facilmente generalizados. Assim, definindo $D_{i t}=d_{i t}+\sum_{j \in S(i)} a_{i j} d_{j t}$ como a demanda de escalão para o item $i$, as restrições de balanço de estoque para cada item i tornam-se:

$$
\sum_{k=1}^{K} x_{i t k}+E_{i(t-1)}-E_{i t}=D_{i t}, t=1, \ldots, T
$$

Da relação $E_{i t}=I_{i t}+\sum_{j \in S(i)} a_{i j} E_{i t}$, tem-se que, $1_{i t}=E_{i t}-\sum_{j \in S(i)} a_{i j} E_{i t}$. Como $I_{i t} \geq 0$, segue que $E_{i t} \geq \sum_{j \in S(i)} a_{i j} E_{i t}$. Observa-se que a inequação indica que o estoque de escalão do item i no período $\mathrm{t}$ deve ser suficiente para suprir o estoque de escalão de seus itens sucessores imediatos.

Assim, o modelo em termos de estoque convencional (3.9)-(3.13) pode ser reescrito como:

$$
\text { Minimize } Z=\sum_{\mathrm{i}=1}^{\mathrm{N}} \sum_{\mathrm{i}=1}^{\mathrm{T}}\left(\hat{\mathrm{h}}_{\mathrm{i}} \mathrm{E}_{\mathrm{it}}+\sum_{\mathrm{k}=1}^{\mathrm{K}} \mathrm{c}_{\mathrm{itk}} \mathrm{X}_{\mathrm{itk}}\right)+\sum_{\mathrm{t}=1}^{\mathrm{T}} \sum_{\mathrm{k}=1}^{\mathrm{K}} \sum_{\mathrm{i}=1}^{\mathrm{N}} \mathrm{cs}_{\mathrm{ik}} \mathrm{Y}_{\mathrm{itk}}
$$

Sujeito a:

$$
\begin{aligned}
& \sum_{k=1}^{K} x_{i t k}+E_{i(t-1)}-E_{i t}=D_{i t} \quad i=1, \ldots, N ~ t=1, \ldots T \\
& E_{i t} \geq \sum_{j \in S(i)} a_{i j} E_{i t} \quad i=1, \ldots, N t=1, \ldots T \\
& \sum_{i=1}^{N}\left(b_{i k} X_{i t k}+t_{i k} Y_{i t k}\right) \leq \text { cap }_{t k} \quad k=1, \ldots K t=1, \ldots, T \\
& \mathrm{X}_{\text {ttk }}-\mathrm{MY}_{\mathrm{itk}} \leq 0 \quad \mathrm{i}=1, \ldots, \mathrm{Nk}=1, \ldots \mathrm{K} \mathrm{t}=1, \ldots, \mathrm{T} \\
& E_{\text {it }} \geq 0, X_{\text {itk }} \geq 0, Y_{\text {rtk }}=0 \text { oul } \quad \mathrm{i}=1, \ldots, \mathrm{Nk}=1, \ldots \mathrm{K} \mathrm{t}=1, \ldots, \mathrm{T}
\end{aligned}
$$


Observe que no modelo formulado em termos de estoque de escalão é retirado a dependência entre os itens das restrições de balanço de estoque (4.31). Esta dependência, entretanto, encontra-se nas restrições (4.32).

\section{RELAXAÇÃo LAGRANGIANA - OBTENÇĀO DO LIMITANTE INFERIOR}

Considere os multiplicadores duais $\mu_{\mathrm{tk}} \geq 0(\mathrm{t}=1, \ldots, \mathrm{T}$ e $\mathrm{k}=1, \ldots, \mathrm{K})$, associados às restrições (4.33) e $\lambda_{\mathrm{it}} \geq 0(\mathrm{t}=1, \ldots, \mathrm{T}$ e $\mathrm{i}=1, \ldots, \mathrm{N})$ associados às restrições (4.32). $\mathrm{O}$ problema Lagrangiano pode ser escrito como:

$$
\mathrm{L}(\mu, \lambda)=\operatorname{minimize} \sum_{\mathrm{i}=1}^{\mathrm{N}} \sum_{\mathrm{i}=1}^{\mathrm{T}}\left(\mathrm{ce}_{\mathrm{it}} \mathrm{E}_{\mathrm{it}}+\sum_{\mathrm{k}=1}^{\mathrm{K}} \mathrm{cp}_{\mathrm{itk}} \mathrm{X}_{\mathrm{itk}}\right)+\sum_{\mathrm{t}=1}^{\mathrm{T}} \sum_{\mathrm{k}=1}^{\mathrm{K}} \sum_{\mathrm{i}=1}^{\mathrm{N}} \mathrm{csr} \mathrm{i}_{\mathrm{itk}} \mathrm{Y}_{\mathrm{itk}}-\text { Const }
$$

Sujeito a:

$$
\begin{array}{lc}
\sum_{k=1}^{K} X_{i t k}+E_{i(t-1)}-E_{i t}=D_{i t} & i=1, \ldots, N t=1, \ldots T \\
X_{i t k}-M Y_{i t k} \leq 0 & i=1, \ldots, N k=1, \ldots K t=1, \ldots, T \\
E_{i t} \geq 0, X_{i t k} \geq 0, Y_{i t k}=0 \text { ou } 1 & i=1, \ldots, N k=1, \ldots K t=1, \ldots, T
\end{array}
$$

onde:

$$
\begin{array}{ll}
\text { Const }=\sum_{\mathrm{t}=1}^{\mathrm{T}} \sum_{\mathrm{k}=1}^{\mathrm{k}} \mu_{\mathrm{tk}} \mathrm{Cap}_{\mathrm{tk}}, & \mathrm{ce}_{\mathrm{it}}=\hat{\mathrm{h}}_{\mathrm{it}}-\lambda_{\mathrm{it}}+\sum_{\mathrm{j} \in \mathrm{P}(\mathrm{i})} \mathrm{a}_{\mathrm{ji}} \lambda_{\mathrm{jt}} \\
\mathrm{cp}_{\mathrm{itk}}=\mathrm{c}_{\mathrm{itk}}+\mathrm{b}_{\mathrm{ik}} \mu_{\mathrm{tk}} \mathrm{e}, & \mathrm{csr}_{\mathrm{itk}}=\mathrm{cs}_{\mathrm{ik}}+\mu_{\mathrm{tk}} \mathrm{ts}_{\mathrm{ik}}
\end{array}
$$

Observe que o problema acima se decompõe em $\mathrm{N}$ problemas de dimensionamento de lotes monoestágio e máquinas paralelas com capacidade infinita de produção. Utiliza-se o algoritmo de programação dinâmica (Armentano e Toledo, 1997) para resolver cada um dos $\mathrm{N}$ problemas.

A maximização da função dual $\mathrm{L}(\mu, \lambda)$ é feita através do método do subgradiente, conforme proposto por Camerini et al. (1975). Foram utilizadas 200 iterações do método do subgradiente na tentativa de obtenção do melhor limitante inferior. 
Uma questão que sempre surge sobre a utilização do modelo em termos de escalão para o cálculo do limitante é se este limitante é melhor ou pior ao limitante quando se utiliza a formulação em termos do estoque convencional. No trabalho de Tempelmeier e Derstroff (1996) foi utilizada a formulação em termos de estoque convencional para o cálculo do limitante inferior. Já no trabalho de Berretta (1997) foi utilizada a formulação em termos de estoque de escalão. Nos Apêndices A e B mostra-se à equivalência ente as formulações no sentido que obtêm o mesmo valor do limitante. 


\section{CAPÍTULO 5}

\section{RESUlTAdOS COMPUTACIONAIS (MCMP)}

\subsection{Geração dos Dados}

Foram gerados aleatoriamente dois grupos de exemplos denominados, G1 e G2. O grupo G1 é composto por 240 exemplos de dimensões pequenas, com 48 até 96 variáveis binárias e, para alguns deles, o pacote CPLEX $4.0^{1}$ conseguiu encontrar a solução ótima. Os exemplos de dimensões médias estão no grupo G2, o qual é composto por 1080 exemplos, com 120 até 2880 variáveis binárias. As características destes grupos estão descritas na Tabela 5.1.

Os intervalos de valores utilizados para gerar os exemplos, os quais foram baseados nos trabalhos de França et al. (1997) e Toledo (1998), encontra-se na Tabela 5.2.

As heurísticas foram implementadas em linguagem $\mathrm{C}$ e os testes computacionais executados numa estação de trabalho SUN Ultra-1, utilizando o compilador gcc.

\footnotetext{
${ }^{1}$ Versão 4.0 de "Using the CPLEX Callable Library Incluging Using the CPLEX Base System with CPLEX Barrier and Mixed Integer Solvers", CPLEX Optimization, Inc. 1989-1995.
} 
Tabela 5.1. Características dos exemplos

\begin{tabular}{|c|c|c|}
\hline & Grupo G1 & Grupo G2 \\
\hline Estrutura & Serial e geral & Serial e geral \\
$\mathrm{N}$ & 5 & $10,17,40$ \\
$\mathrm{~T}$ & 4 & $6,12,18$ \\
$\mathrm{~K}$ & $2,3,4$ & $2,3,4$ \\
Custo de & Baixo e alto & Baixo e alto \\
preparação & & \\
Capacidade & Folgada & Normal \\
Sementes & 20 & 10 \\
\hline Total & $\mathbf{2 4 0}$ & $\mathbf{1 0 8 0}$ \\
\hline
\end{tabular}

Tabela 5.2. Parâmetros utilizados para geração

\begin{tabular}{|c|c|}
\hline Parâmetros & Intervalo \\
\hline $\mathrm{cs}_{\text {itk }}$ & $\mathrm{U}[1.5,2]$ \\
para custo baixo de & $\mathrm{U}[5,95]$ \\
$\mathrm{cs}_{\mathrm{ik}}$ para custo alto de & $\mathrm{U}[50,950]$ \\
preparação & \\
$\hat{\mathrm{h}}_{\mathrm{it}}$ & $\mathrm{U}[0.2,0.4]$ \\
$\mathrm{b}_{\mathrm{ik}}$ & $\mathrm{U}[2,3]$ \\
ts & $\mathrm{U}[150,250]$ \\
$\mathrm{d}_{\mathrm{it}}$ para itens finais & $\mathrm{U}[0,180]$ \\
$\mathrm{d}_{\mathrm{it}}$ para itens componentes & $\mathrm{U}[0,18]$ \\
\hline
\end{tabular}

(notação: $\mathrm{x} \in \mathrm{U}[\mathrm{a}, \mathrm{b}]$ significa que $\mathrm{x}$ foi gerado aleatoriamente segundo uma distribuição uniforme no intervalo $[\mathrm{a}, \mathrm{b}]$.)

Os custos de estoque convencional foram calculados utilizando-se a expressão $h_{i t}=\hat{h}_{i t}+\sum_{j \in P(i)} a_{j i} h_{j t}$, onde $\hat{h}_{i t}$ é o custo de estoque de escalão. O parâmetro $a_{i j}$ foi considerado constante com valor 1 .

O valor da capacidade por período foi calculado de forma que estivesse relacionado com os tempos das preparações e os valores das demandas geradas. Foi aplicado um procedimento semelhante ao utilizado por Toledo (1998), para determinar a capacidade nos períodos $t \geq 2$, adaptado para o problema de dimensionamento de lotes mutiestágio com máquinas paralelas. A demanda de cada item em cada período $(t \geq 2)$ é dividida igualmente entre máquinas. A política lote-por-lote é aplicada a cada uma das máquinas e, a seguir, tomase à média sobre o número de períodos e máquinas. 


$$
C a p=\frac{\sum_{i=2}^{T} \sum_{j=1}^{K} \sum_{i=1}^{N}\left(\frac{D_{i t}}{K}\right) b_{i k}+t s_{i k}}{K(T-1)}, \quad \text { onde } D_{i t}=d_{i t}+\sum_{j \in S(i)} a_{i j} D_{j t}
$$

A capacidade foi então calculada, para $t \geq 2$, da seguinte maneira:

$$
\mathrm{CAP}_{\mathrm{tk}}=((10-\mathrm{K}) 0.11) \mathrm{Cap} \quad \mathrm{t} \geq 2
$$

As capacidades para os períodos $t \geq 2$ foram ajustadas utilizando a expressão (5.2), enquanto que, as capacidades das máquinas em $t=1$ foram determinadas de modo a sempre existir uma solução factível neste período. O procedimento para a determinação das capacidades para $t=1$ consiste em produzir cada item que tenha demanda em $t=1$ na máquina que possua o maior tempo de preparação, com o objetivo de gerar capacidades maiores neste período. Com a atribuição dos itens para máquinas que tenham maiores tempos de preparação, pode ser que algumas máquinas deixem de produzir neste periodo. Para evitar que estas capacidades sejam nulas, ou seja, se existe alguma máquina $k^{\prime}$, em $t=1$, que $\operatorname{CAP}_{1 k^{\prime}}=0$, fazse $\mathrm{CAP}_{1 k^{*}}=\sum_{\mathrm{k}} \mathrm{CAP}_{1 \mathrm{k}} / \mathrm{K}$. 
Foram consideradas 4 estruturas gerais de produtos que são mostradas abaixo.

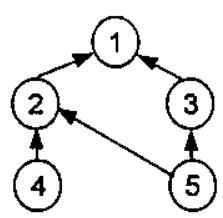

Figura 5.1. Estrutura Geral de produtos para $\mathrm{N}=5$ (Clark e Amentano, 1995).

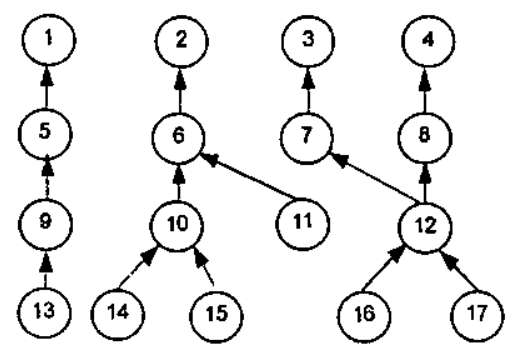

Figura 5.3. Estrutura Geral de produtos para $\mathrm{N}=17$ (Maes et al. 1991).

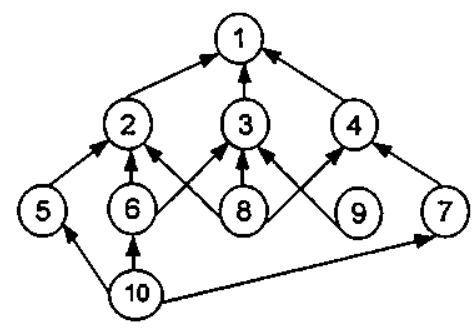

Figura 5.2. Estrutura Geral de produtos para $\mathrm{N}=10$ (Clark, 1990)

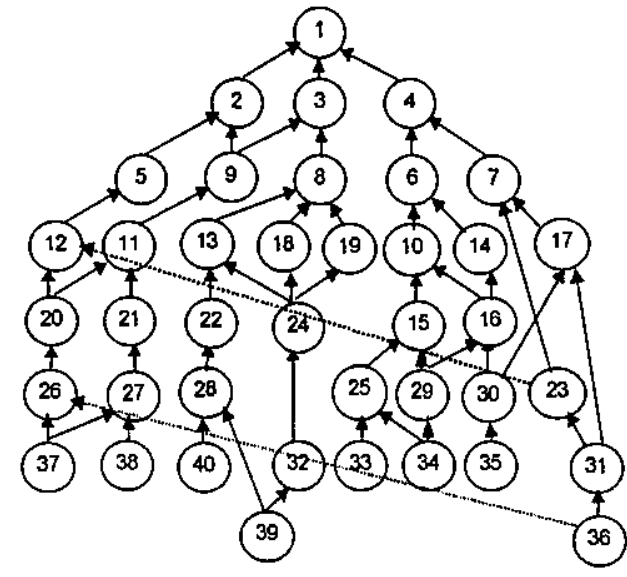

Figura 5.4. Estrutura Geral de Produtos para $N=40$ (Clark, 1990) 


\subsection{Medidas de Auxílio à Análise}

A análise dos resultados obtidos pelas heurísticas é baseada em quatro medidas:

\section{Soluções Factíveis Obtidas}

Inicialmente o desempenho da heurística é analisado em relação à porcentagem média de soluções factíveis obtida pela heurística. Este valor é definido como $\mathrm{FAC}=100\left(\frac{\mathrm{nf}}{\mathrm{ng}}\right)$, onde, nf é o número de exemplos onde foi possível obter uma solução factível e, ng é o número de exemplos gerados.

\section{Utilização Média da Capacidade}

É também contabilizada a porcentagem de recursos utilizados para produção e para preparação. A porcentagem de recursos utilizados para a produção $(\hat{X})$ e preparação $(\hat{Y})$ por máquina e período é dado por:

$$
\text { uso_cap }=100\left(\left(\sum_{t=1}^{T} \sum_{k=1}^{K} \sum_{i=1}^{N}\left(b_{i k} \hat{X}_{i t k}+t_{i k} \hat{Y}_{i t k}\right) / \text { cap }_{k t}\right) / K T\right) \text {. }
$$

As soluções iniciais são também analisadas em relação ao consumo de capacidade com o objetivo de verificar a variação de consumo das soluções iniciais em relação às soluções finais factíveis. É também determinada a porcentagem da capacidade utilizada para as preparações.

$$
\text { uso_setup }=100\left(\left(\sum_{t=1}^{\mathrm{T}} \sum_{\mathrm{k}=1}^{\mathrm{K}} \sum_{i=1}^{\mathrm{N}} \mathrm{ts}_{\text {ik }} \hat{\mathrm{Y}}_{\text {itk }} / \mathrm{KT}\right) / \mathrm{uso}_{\text {_cap }}\right) \text {. }
$$

\section{Análise das Infactibilidades}

Para os exemplos que a heurística não conseguiu obter uma solução factível, é contabilizada a quantidade média que está sendo utilizada além da capacidade por período que 
é uma medida do grau de infactibilidade da solução. Assim, são calculados o maior excesso encontrado em um período (exc_max), a porcentagem de períodos com excesso $(\operatorname{exc} t)$ e, a porcentagem de máquinas com excesso em um período $t$ (exc_k). Estes valores são dados por:

- exc_max $=\max _{t}\left\{\frac{100 \text { excesso(t) }}{K}\right\}$,

onde:

$$
\begin{aligned}
& \operatorname{excesso}(t)=\sum_{k}\left(\frac{\operatorname{excesso}(k, t)}{\operatorname{cap}(t, k)}\right) \\
& \operatorname{excesso}(k, t)=\max \left\{0,\left(\sum_{i=1}^{N}\left(b_{i k} \hat{X}_{i t k}+t s_{i k} \hat{Y}_{i t k}\right)-\operatorname{cap}_{k t}\right)\right\}
\end{aligned}
$$

Esta medida serve para avaliar a violação média de capacidade por máquina, nos períodos que apresentam maiores violações.

- $\quad$ exc_t $=100\left(\sum_{t} E x c_{t} / T\right)$,

onde: $\begin{cases}E_{1}=1 & \text { se excesso }(t)>0 \\ 0 & \text { c.c. }\end{cases}$

Esta medida serve para avaliar a porcentagem de periodos que apresentam violações. Com esta medida é possível verificar a porcentagem média de períodos com violações nas soluções iniciais e, nas soluções onde a heurística não determinou uma solução factível.

- exc_k $\max _{1}\left\{100\left(\sum_{\mathrm{k}} \operatorname{excm}(\mathrm{k}, \mathrm{t}) / \mathrm{K}\right)\right\}$,

onde: $\operatorname{excm}(k, t)= \begin{cases}1 & \text { se excesso }(k, t)>0 \\ 0 & \text { c.c. }\end{cases}$

Através dos valores de exc_k é possível ter uma estimativa da porcentagem máxima de máquinas com violações ao longo dos periodos. Ou seja, dentre todos os períodos infactiveis de uma solução, verifica-se a porcentagem máxima de máquinas com violações. Por exemplo, considere um determinado exemplo com $\mathrm{T}=3, \mathrm{~K}=2$, dos quais dois períodos estão violados na solução final $(\mathrm{t}=1, \mathrm{t}=2)$. Considerando-se que em $\mathrm{t}=1$ uma máquina é violada 
e, no período $t=2$ duas máquinas são violadas, então Exc_k=100, o que corresponde a duas máquinas violadas no período $t=2$.

\section{Qualidade das Soluções Obtidas.}

As soluções heurísticas obtidas pelas heurísticas são comparadas com as soluções ótimas (para os exemplos do grupo G1) e com o limitante inferior fornecido pela Relaxação Lagrangiana. Os valores de GapO e GapL são definidos como:

$$
\begin{aligned}
& \text { Gap } O=100\left(\frac{\mathrm{Z}_{\mathrm{H}}-\mathrm{Z}_{\mathrm{otm}}}{\mathrm{Z}_{\mathrm{otm}}}\right) \\
& \text { GapL }=100\left(\frac{\mathrm{Z}_{\mathrm{H}}-\mathrm{Z}_{\mathrm{LB}}}{\mathrm{Z}_{\mathrm{LB}}}\right)
\end{aligned}
$$

onde:

$Z_{\mathrm{H}}$ - é o valor da função objetivo dada por (3.9) calculado no ponto retornado pela heurística.

$Z_{\mathrm{otm}}$ - é o valor ótimo da função objetivo (3.9).

$\mathrm{Z}_{\mathrm{LB}}$ - é o valor do limitante inferior gerado pela relaxação Lagrangiana.

\subsection{Heurísticas em Análise}

As quatro medidas dadas são apresentadas para os resultados obtidos pela a heurística com o procedimento de factibilização constando dos passos detalhados anteriormente, mas são consideradas quatro versões da heurística de factibilização descritas na tabela seguinte. 
Tabela 5.3. Caracteristicas das heurísticas HT1, HT2, $\mathrm{HO} 1, \mathrm{HO} 2$.

\begin{tabular}{|c|l|}
\hline Heurística & \multicolumn{1}{c|}{ Características da Heurística } \\
\hline HO1 & $\begin{array}{r}\text { Passo P1- utiliza o algoritmo proposto por Armentano e Toledo (1998) (chamado de WW- } \\
\text { Paralelo e denotado por SIW) para determinação solução inicial. } \\
\text { Passo P2 - usa um contador de ciclos para evitar ciclagens entre máquinas num determinado } \\
\text { período. Não evita as ciclagens entre os passos progressivos e regressivos do } \\
\text { procedimento de factibilização. }\end{array}$ \\
\hline HO2 & $\begin{array}{l}\text { Passo P1- utiliza o algoritmo modificado de Armentano e Toledo (I998) (chamado de WW- } \\
\text { Paralelo Penalizado e definido por SIP) para determinação solução inicial. }\end{array}$ \\
\hline Passo P2 - como considerado em HO1. \\
Passos P3 e P4 considerado sem modificações.
\end{tabular}

Foram utilizadas diferentes maneiras para determinar o tempo de permanência tabu nas heurísticas HT1 e HT2. De todas estratégias testadas para determinar o tempo de permanência tabu, foi escolhida a estratégia que apresentou melhor desempenho geral na determinação de soluções factíveis. Primeiramente tentou-se utilizar um valor fixo para o tempo de permanência tabu mas, isto não apresentou bons resultados. Também se tentou gerar o tempo de permanência tabu dentro um intervalo, onde pelo menos um extremo deste intervalo estivesse relacionado com os dados do problema. Foram testados vários intervalos, entre eles, os intervalos ([1,T], $[1, T / 2],[T / 2, T],[1, N])$, no entanto, nenhum destes intervalos apresentou bons resultados gerais, isto é, para algumas dimensões apresentavam péssimos resultados. Finalmente, foram testados vários intervalos onde se pode perceber uma melhoria geral nos resultados. Dentre estes intervalos, foram testados $([1,3],[1,4],[1,5],[1,6],[1,7]$, $[1,8]$ ), sendo que, para o intervalo [1,5], as heurísticas apresentaram melhores desempenhos sobre todos os outros intervalos citados.

Foram consideradas 100 iterações para o procedimento de factibilização (P2) durante a primeira tentativa de factibilização, ou seja, durante 100 iterações são aplicados os passos regressivos e progressivos no tempo. Se este número de iterações for alcançado e nenhuma solução factível foi encontrada, aplica-se o procedimento (P4). Após a aplicação do procedimento (P4), o procedimento $(\mathrm{P} 2)$ é novamente executado durante 50 iterações. 


\subsection{Análise dos Resultados para os Exemplos do Grupo G1}

As soluções factiveis obtidas pelas heuristicas foram comparadas com as soluções ótimas obtidas pelo CPLEX 4.0. Os exemplos deste grupo foram gerados com a intenção de comparar as soluções ótimas obtidas utilizando o CPLEX 4.0 e as soluções heurísticas, portanto, as capacidades foram geradas folgadas, suficientemente para possibilitar o CPLEX 4.0 a obter soluções ótimas. As capacidades foram geradas $20 \%$ mais folgadas do que, as capacidades para os exemplos do grupo $\mathrm{G} 2$ (aumento em $\mathrm{CAP}_{\mathrm{tk}}$ de $20 \%$ ).

\subsubsection{Análise dos Resultados em Relação à Porcentagem de Soluções Factíveis Obtidas}

Primeiramente, observa-se que as heurísticas HT 1, HT2 e o CPLEX 4.0 determinaram soluções factiveis para todos os exemplos gerados, no entanto, as heurísticas $\mathrm{HOl}$ e $\mathrm{HO} 2$ não obtiveram soluções factíveis para todos os exemplos. Apesar do CPLEX 4.0 ter determinado $100 \%$ de soluções factiveis, não determinou soluções ótimas para a maioria dos exemplos. A Tabela 5.4 mostra as porcentagens de exemplos para os quais o CPLEX 4.0 encontrou uma solução ótima (OTM), as porcentagens de exemplos onde as heurísticas $\mathrm{HO}$ e $\mathrm{HO} 2$ determinaram uma solução factivel (FAC-HO1 e FAC-HO2) e, as porcentagens de exemplos onde as heurísticas HT1 e HT2 determinaram uma solução factível (FAC-HT1 e FAC-HT2). Convém observar mais uma vez que, foram gerados 20 exemplos para cada dimensão considerada, por exemplo, foram gerados 20 exemplos para estrutura geral de produtos, custo baixo de preparação e 2 máquinas. 
Tabela 5.4. FAC-HO1, FAC-HO2, FAC-HT1, FAC-HT2 para as heurísticas e porcentagens de soluções ótimas obtidas pelo CPLEX 4.0

\begin{tabular}{|c|c|c|c|c|c|c|c|c|c|c|c|}
\hline \multirow[b]{2}{*}{ Estrutura } & \multirow[b]{2}{*}{$\mathbf{K}$} & \multicolumn{5}{|c|}{ Custo baixo de preparaçio } & \multicolumn{5}{|c|}{ Custo Aito de preparaçăo } \\
\hline & & FAC-HT1 & $\begin{array}{l}\text { FAC- } \\
\text { HT2 }\end{array}$ & $\begin{array}{l}\text { FAC. } \\
\text { HO1 }\end{array}$ & $\begin{array}{l}\text { FAC. } \\
\text { HO2 }\end{array}$ & OTM & $\begin{array}{l}\text { FAC- } \\
\text { HTI }\end{array}$ & $\begin{array}{l}\text { FAC- } \\
\text { HT2 }\end{array}$ & $\begin{array}{l}\text { FAC- } \\
\text { HOI }\end{array}$ & $\begin{array}{l}\text { FAC- } \\
\text { HO2 }\end{array}$ & OTM \\
\hline \multirow{3}{*}{ Serial } & 2 & 100.0 & 100.0 & 100.0 & 100.0 & 65.0 & 100.0 & 100.0 & 90.0 & 95.0 & 90.0 \\
\hline & 3 & 100.0 & 100.0 & 100.0 & 100.0 & i5.0 & 100.0 & 100.0 & 65.0 & 95.0 & 25.0 \\
\hline & 4 & 100.0 & 100.0 & 100.0 & 100.0 & 0.0 & 100.0 & 100.0 & 85.0 & 100.0 & 15.0 \\
\hline \multicolumn{2}{|c|}{ Média } & 100.0 & 100.0 & 100.0 & 100.0 & 40.0 & 100.0 & 100.0 & 80.0 & 96.7 & 43.3 \\
\hline \multirow{3}{*}{ Gera] } & 2 & 100.0 & 100.0 & 100.0 & 100.0 & 75.0 & 100.0 & 100.0 & 100.0 & 100.0 & 85.0 \\
\hline & 3 & 100.0 & 100.0 & 100.0 & 100.0 & 25.0 & 100.0 & 100.0 & 75.0 & 100.0 & 30.0 \\
\hline & 4 & 100.0 & 100.0 & 100.0 & 100.0 & 0.0 & 100.0 & 100.0 & 95.0 & 100.0 & 15.0 \\
\hline \multicolumn{2}{|c|}{ Média } & 100.0 & 100.0 & 100.0 & 100.0 & 50.0 & 100.0 & 100.0 & 90.0 & 100.0 & 43.3 \\
\hline
\end{tabular}

Observe que o CPLEX 4.0 não determinou soluções ótimas para todos os exemplos com custo baixo de preparação, estruturas serial e geral com 4 máquinas. Isto pode ter ocorrido porque, a produção é mais dividida entre as máquinas para os exemplos com custo baixo de preparação, o que possivelmente dificulta a enumeração implícita contida no CPLEX 4.0. Considerando esta mesma dimensão e custo alto de preparação, observa-se que, o CPLEX 4.0 foi capaz de determinar soluções ótimas para $15 \%$ dos exemplos gerados para ambas estruturas, o que corresponde a 3 exemplos para cada estrutura. Observe também que a heurística $\mathrm{HOl}$ não foi eficiente na determinação de soluções factíveis para todos os exemplos gerados. A heurística $\mathrm{HOl}$ obteve pior desempenho para os exemplos com estrutura serial e custo alto de preparação.

A heuristica $\mathrm{HO} 2$ não determinou $100 \%$ de soluções factíveis para os exemplos com estrutura serial e custo alto de preparação, no entanto, apresentou melhor desempenho do que a heurística HOl. Como estes exemplos foram gerados folgados para possibilitar o CPLEX 4.0 a obter soluções ótimas e, para comparar estas soluções com as obtidas pelas as heurísticas, então são consideradas as heurísticas que apresentam melhores desempenhos na obtenção de soluções factíveis, neste caso, as heurísticas HT1, HT2 e HO2. Assim, todas as comparações relacionadas à qualidade das soluções e utilização da capacidade são feitas utilizando os resultados obtidos por estas heurísticas.

Convém salientar aqui que, as heurísticas obtêm uma solução factível utilizando um tempo computacional médio de 0.11 segundos, enquanto que o CPLEX utiliza, em média, 410 segundos. Todos os parâmetros usados no CPLEX 4.0 foram os padrões.

A tabela seguinte mostra uma comparação entre os dois procedimentos de determinação de soluções iniciais em relação à porcentagem de soluções iniciais factíveis obtidas. Observe que o procedimento que considera o algoritmo WW-Paralelo Penalizado obtém uma porcentagem grande de soluções iniciais factíveis, sendo então necessário somente à aplicação do procedimento de melhoria a estas soluções. 
Tabela 5.5. Porcentagem de soluçðes inicialmente factiveis.

\begin{tabular}{|c|c|c|c|c|c|}
\hline \multirow{2}{*}{\multicolumn{2}{|c|}{ Estruturas }} & \multicolumn{2}{|c|}{ custo baixo de preparaçăo } & \multicolumn{2}{|c|}{ Custo alto de preparação } \\
\hline & & HT1 e HO1 & HT2 e HO2 & HT1 e HO1 & $\mathrm{HT2}$ e $\mathrm{HO} 2$ \\
\hline \multirow{3}{*}{ Serial } & $\mathrm{K}=2$ & 15.0 & 75.0 & 0.0 & 20.0 \\
\hline & $\mathrm{K}=3$ & 0.0 & 65.0 & 0.0 & 25.0 \\
\hline & $\mathrm{K}=4$ & 0.0 & 40.0 & 0.0 & 55.0 \\
\hline \multicolumn{2}{|c|}{ Média } & 5.0 & 60.0 & 0.0 & 33.3 \\
\hline \multirow{3}{*}{ Geral } & $\mathrm{K}=2$ & 5.0 & 45.0 & 0.0 & 20.0 \\
\hline & $\mathrm{K}=3$ & 5.0 & 20.0 & 0.0 & 15.0 \\
\hline & $\mathrm{K}=4$ & 0.0 & 0.0 & 0.0 & 20.0 \\
\hline \multicolumn{2}{|c|}{ Média } & 3.3 & 21.7 & 0.0 & 18.3 \\
\hline
\end{tabular}

Observe na Tabela 5.5 que, para os exemplos com custo baixo de preparação e estrutura serial, o procedimento para determinação das soluções iniciais que leva informações da utilização de capacidade, ou seja, o algoritmo WW-Paralelo Penalizado, determina, em média, $60 \%$ de soluções iniciais factiveis (HT2 e HO2), enquanto que, o procedimento que utiliza o algoritmo sem informações da utilização da capacidade, determina, em média, $5 \%$ de soluções iniciais factíveis. 


\subsubsection{Análise dos Resultados em Relação à Qualidade das Soluções Obtidas}

A Tabela 5.6 mostra os valores dos GapO, GapL e GapFac para a heurística HT1. O GapO é somente calculado se o CPLEX 4.0 encontrar uma solução ótima, o GapL foi calculado apenas para os exemplos onde foi possível obter o GapO e, GapFac é calculado para os exemplos que o CPLEX 4.0 não determinou uma solução ótima, mas uma solução factível. O objetivo do GapFac é mostrar a qualidade das soluções obtidas pelas heurísticas em relação a soluções factíveis obtidas pelo CPLEX 4.0 e, é definido como:

GapFac $=100\left(\frac{\mathrm{Z}_{\mathrm{H}}-\mathrm{Z}_{\mathrm{FC}}}{\mathrm{Z}_{\mathrm{FC}}}\right)$

onde:

$Z_{\mathrm{FC}}$ - é o valor da função objetivo avaliada na melhor solução factivel (não ótima) produzida pelo CPLEX 4.0.

\section{- Heurística HT1}

Tabeia 5.6. GapO, GapL e GapFac para o grupo GI.

\begin{tabular}{|c|c|c|c|c|c|c|c|}
\hline \multirow[b]{2}{*}{ Estrutura } & \multirow[b]{2}{*}{$\mathbf{K}$} & \multicolumn{3}{|c|}{ Custo baixo de preparação } & \multicolumn{3}{|c|}{ Custo a ito de preparação } \\
\hline & & $G a p O$ & GapL & GapFac & GapO & GapL & $\overline{G a p F a c}$ \\
\hline \multirow{3}{*}{ Serial } & 2 & 0.6 & 1.7 & 0.4 & 19.8 & 34.0 & 13.2 \\
\hline & 3 & 0.7 & 1.6 & 0.1 & 8.9 & 22.5 & 9.2 \\
\hline & 4 & $* * *$ & $* * *$ & -1.1 & 9.4 & 25.4 & -2.0 \\
\hline \multicolumn{2}{|c|}{ Média } & 0.7 & 1.7 & -0.2 & 13.0 & 27.3 & 6.8 \\
\hline \multirow{3}{*}{ Geral } & 2 & 0.9 & 2.0 & 0.6 & 13.0 & 22.9 & 11.3 \\
\hline & 3 & 1.3 & 2.5 & -0.3 & 7.2 & 17.4 & 4.4 \\
\hline & 4 & $* * *$ & $* * *$ & -0.3 & 13.7 & 26.1 & 2.4 \\
\hline \multicolumn{2}{|c|}{ Média } & 1.1 & 2.3 & 0.0 & 11.3 & 22.1 & 6.0 \\
\hline
\end{tabular}

A Tabela 5.6 mostra que o limitante inferior para os exemplos com alto custo de preparação é ruim e, isto pode levar a falsas conclusões em relação à eficiência da heurística. Por exemplo, o GapL para estrutura serial e alto custo de preparação é $\mathbf{2 7 . 3} \%$, enquanto que o GapO é $\mathbf{1 3 . 0} \%$. Existem resultados na literatura que chegam à mesma conclusão (Billington et al., 1986 e Clark e Armentano, 1995). Observe também nesta tabela, que para alguns 
exemplos, a heurística HT1 apresenta soluções de melhor qualidade do que, as soluções factíveis obtidas pelo CPLEX 4.0. Por exemplo, para estrutura serial e custo baixo de preparação, a heurística HT1 apresenta soluções $0.2 \%$ melhores.

\section{- Heurística HT2}

\begin{tabular}{|c|c|c|c|c|c|c|c|}
\hline \multirow[b]{2}{*}{ Estruturas } & \multirow[b]{2}{*}{$\mathbf{K}$} & \multicolumn{3}{|c|}{ Custo baixo de preparaça } & \multicolumn{3}{|c|}{ Custo alto de preparaçāo } \\
\hline & & GapO & GapL & GapFac & GapO & GapL & GapFac \\
\hline \multirow{3}{*}{ Serial } & 2 & 2.2 & 3.2 & 2.0 & 8.6 & 20.8 & 11.0 \\
\hline & 3 & 0.7 & 1.6 & 2.5 & 10.2 & 20.2 & 3.6 \\
\hline & 4 & $* * *$ & *** & 0.6 & 4.2 & 19.2 & 1.7 \\
\hline \multicolumn{2}{|c|}{ Média } & 1.5 & 2.4 & 1.7 & 7.7 & 20.1 & 5.4 \\
\hline \multirow{3}{*}{ Geral } & 2 & 0.9 & 2.0 & 0.6 & 9.1 & 18.6 & 5.7 \\
\hline & 3 & 1.3 & 2.5 & -0.3 & 10.6 & 21.4 & 0.9 \\
\hline & 4 & *** & $* * *$ & -0.3 & 17.0 & 30.4 & 4.6 \\
\hline \multicolumn{2}{|c|}{ Média } & 1.1 & 2.3 & 0.0 & 12.2 & 23.5 & 3.7 \\
\hline
\end{tabular}

Pelas tabelas 5.7 e 5.8 pode-se notar que as heurísticas HT2 e $\mathrm{HO} 2$ apresentam, em média, para alguns exemplos com custo alto de preparação, valores de GapO e GapL inferiores aos apresentados pela heurística HTI. Estas duas heurísticas utilizam o mesmo procedimento para obtenção da solução inicial. Como a heurística HTI utiliza o algoritmo WW-Paralelo, o qual é somente baseado nos custos, tende a fazer lotes maiores, o que pode ter influenciado os procedimentos de factibilização e melhoria. As heurísticas HT2 e $\mathrm{HO} 2$ provavelmente apresentaram soluções com produções "mais divididas" entre os períodos, o que pode ter causado a obtenção de soluções de melhor qualidade. As heurísticas HT2 e HO2 obtiveram soluções de melhor qualidade principalmente para os exemplos com custo alto de preparação com 2 máquinas. 


\section{- Heurística HO2}

\begin{tabular}{|c|c|c|c|c|c|c|c|}
\hline \multirow[b]{2}{*}{ Estrutura } & \multirow[b]{2}{*}{$\mathbf{K}$} & \multicolumn{3}{|c|}{ Custo baixo de preparação } & \multicolumn{3}{|c|}{ Custo aito de preparação } \\
\hline & & GapO & GapL & GapFac & GapO & GapL & GapFac \\
\hline \multirow{3}{*}{ Serial } & 2 & 2.4 & 3.4 & 2.0 & 8.8 & 20.8 & 11.0 \\
\hline & 3 & 0.7 & 1.6 & 2.5 & 10.2 & 20.2 & 3.6 \\
\hline & 4 & $* * *$ & $* * *$ & 0.6 & 4.2 & 19.2 & 1.7 \\
\hline \multicolumn{2}{|c|}{ Média } & 1.6 & 2.5 & 1.7 & 7.7 & 21.5 & 6.5 \\
\hline \multirow{3}{*}{ Geral } & 2 & i.8 & 2.8 & 2.2 & 9.3 & 18.8 & 5.7 \\
\hline & 3 & 1.7 & 2.8 & 1.6 & 10.6 & 21.4 & $2 . i$ \\
\hline & 4 & $* * *$ & $* * *$ & 1.1 & 17.0 & 30.4 & 4.7 \\
\hline \multicolumn{2}{|c|}{ Média } & 1.8 & 2.8 & 1.6 & 12.3 & 23.5 & 4.2 \\
\hline
\end{tabular}

Os valores de GapO, GapL e GapFac para alguns exemplos com custo baixo de preparação foram, em média, maiores para as heurísticas HT2 e HO2, do que para a heurística HT1. Assim, pode-se dizer que a heurística HT1, no geral, determina soluções com melhores qualidades do que as heurísticas $\mathrm{HT} 2$ e $\mathrm{HO}_{2}$ para os exemplos com custo baixo de preparação. No entanto, considerando custos altos de preparação, as heurísticas HT2 e HO2, apresentam, no geral, soluções melhores do que a heurística HT1. Na tabela seguinte é apresentado um resumo dos valores médios de GapL, GapO e GapFac com o objetivo de visualizar esta comparação dos resultados obtidos pelas três heurísticas. Os valores que aparecem nesta tabela são os valores médios apresentados nas tabelas anteriores.

Tabela 5.9. GapO, GapL e GapFac para o grupo G1 das heuristicas HO2, HT1 e HT2.

\begin{tabular}{|c|c|ccc|ccc|}
\hline \multirow{3}{*}{ Estrutura } & \multirow{3}{*}{ Serial } & \multicolumn{3}{|c|}{ Custo baixo de preparação } & \multicolumn{3}{c|}{ Custo alto de preparação } \\
\cline { 3 - 8 } & heurítica & GapO & GapL & GapFac & GapO & GapL & Gap Fac \\
\hline \multirow{3}{*}{ Geral } & HT1 & $\mathbf{0 . 7}$ & $\mathbf{1 . 7}$ & $\mathbf{- 0 . 2}$ & 13.0 & 27.3 & 6.8 \\
& HT2 & 1.5 & 2.4 & 1.7 & 7.7 & $\mathbf{2 0 . 1}$ & $\mathbf{5 . 4}$ \\
& HO2 & 1.6 & 2.5 & 1.7 & 7.7 & 21.5 & 6.5 \\
& HT1 & 1.1 & $\mathbf{2 . 3}$ & $\mathbf{0 . 0}$ & $\mathbf{1 1 . 3}$ & $\mathbf{2 2 . 1}$ & 6.0 \\
& HT2 & $\mathbf{1 . 1}$ & $\mathbf{2 . 3}$ & 0.0 & 12.2 & 23.5 & $\mathbf{3 . 7}$ \\
& HO2 & 1.8 & 2.8 & 1.6 & 12.3 & 23.5 & 4.2 \\
\hline
\end{tabular}

Vale a pena ressaltar, utilizando os valores médios apresentados na Tabela 5.9, que a heurística $\mathrm{HO} 2$ apresentou soluções, na média, de piores qualidades do que as heurísticas HT1 e HT2. 


\subsubsection{Análise dos Resultados Relacionados ao Consumo de Capacidade Gerada}

Nas tabelas apresentadas a seguir são apresentadas as porcentagens médias de uso da capacidade gerada por máquina e, a quantidade desta capacidade que é utilizada para as preparações das máquinas das soluções obtidas pelas heurísticas HT1, HT2 e HO2.

\section{- Heurística HT1}

\begin{tabular}{|c|c|c|c|c|c|}
\hline \multirow[t]{2}{*}{ Estrutura } & \multirow[t]{2}{*}{$\mathbf{K}$} & \multicolumn{2}{|c|}{$\begin{array}{c}\text { Custo baixo de } \\
\text { preparação }\end{array}$} & \multicolumn{2}{|c|}{$\begin{array}{l}\text { Custo alto de } \\
\text { preparaçāo }\end{array}$} \\
\hline & & uso_cap & uso_setup & uso_cap & uso_setup \\
\hline \multirow{3}{*}{ Serial } & 2 & 64.6 & 36.2 & 60.3 & 29.1 \\
\hline & 3 & 58.6 & 35.7 & 51.6 & 24.6 \\
\hline & 4 & 52.7 & 31.6 & 45.7 & 20.8 \\
\hline \multicolumn{2}{|l|}{ Média } & 58.6 & 34.5 & 52.5 & 24.8 \\
\hline \multirow{3}{*}{ Geral } & 2 & 65 & 33.8 & 59.2 & 25.1 \\
\hline & 3 & 58.8 & 32.5 & 52.5 & 23.2 \\
\hline & 4 & 54.6 & 32.3 & 46.1 & 20.8 \\
\hline \multicolumn{2}{|l|}{ Média } & 59.6 & 32.9 & 52.6 & 23.0 \\
\hline
\end{tabular}

A utilização da capacidade para os exemplos com custo baixo de preparação e estrutura serial foi em média de $58.6 \%$ da capacidade gerada, sendo que $34.5 \%$ desta quantidade está sendo utilizada para preparação das máquinas. Para os exemplos com custo baixo de preparação e estrutura geral o uso da capacidade por máquina foi em média de $59.6 \%$. Enquanto que, para os exemplos com custo alto de preparação, a utilização da capacidade média por máquina foi de $52.5 \%$ para os exemplos com estrutura serial e, de $52.6 \%$ para os exemplos com estrutura geral. Estes resultados mostram que apesar de que os exemplos serem folgados, obteve-se uma utilização média da capacidade por máquina e período superior a $50 \%$. 


\section{- Heurística HT2}

Tabela 5.11. Consumo médio da capacidade pelas soluçð̃es da heuristica HT2.

\begin{tabular}{|c|c|c|c|c|c|}
\hline \multirow{2}{*}{ Estrutura } & \multirow[t]{2}{*}{$\mathbf{K}$} & \multicolumn{2}{|c|}{$\begin{array}{c}\text { Custo baixo de } \\
\text { preparação }\end{array}$} & \multicolumn{2}{|c|}{$\begin{array}{c}\text { Custo alto de } \\
\text { preparação }\end{array}$} \\
\hline & & uso_cap & uso_setup & uso_cap & uso_setup \\
\hline \multirow{3}{*}{ Serial } & 2 & 65.5 & 40.2 & 59.3 & 28.3 \\
\hline & 3 & 61.4 & 41.6 & 54.1 & 30.2 \\
\hline & 4 & 52.9 & 35.6 & 47.5 & 25.9 \\
\hline \multicolumn{2}{|l|}{ Média } & 59.9 & 39.1 & 53.6 & 28.1 \\
\hline \multirow{3}{*}{ Geral } & 2 & 66.0 & 37.7 & 59.3 & 28.5 \\
\hline & 3 & 59.9 & 38.8 & 53.2 & 27.1 \\
\hline & 4 & 54.3 & 35.0 & 49.7 & 26.9 \\
\hline \multicolumn{2}{|l|}{ Média } & 60.1 & 37.2 & 54.1 & 27.5 \\
\hline
\end{tabular}

\section{- Heurística HO2}

\begin{tabular}{|c|c|c|c|c|c|}
\hline \multirow[t]{2}{*}{ Estrutura } & \multirow[t]{2}{*}{$\mathbf{K}$} & \multicolumn{2}{|c|}{$\begin{array}{c}\text { Custo baixo de } \\
\text { preparaçāo }\end{array}$} & \multicolumn{2}{|c|}{$\begin{array}{l}\text { Custo alto de } \\
\text { pre paraçāo }\end{array}$} \\
\hline & & uso_cap & uso_setup & uso_cap & uso_setup \\
\hline \multirow{3}{*}{ Serial } & 2 & 65.5 & 40.2 & 59.3 & 27.8 \\
\hline & 3 & 61.4 & 41.6 & 54.1 & 30.2 \\
\hline & 4 & 52.9 & 35.6 & 47.5 & 25.9 \\
\hline \multicolumn{2}{|l|}{ Média } & 59.9 & 39.1 & 53.6 & 28.0 \\
\hline \multirow{3}{*}{ Geral } & 2 & 66.0 & 37.7 & 59.5 & 28.6 \\
\hline & 3 & 59.9 & 38.8 & 53.4 & 27.4 \\
\hline & 4 & 54.3 & 35.0 & 49.8 & 27.2 \\
\hline \multicolumn{2}{|l|}{ Média } & 60.1 & 37.2 & 54.2 & 27.7 \\
\hline
\end{tabular}

Na Tabela 5.13 é apresentado um resumo do consumo médio da capacidade para produção e para preparação, com o objetivo de facilitar a comparação dos resultados obtidos pelas três heurísticas.

Tabela 5.13. Resumo do consumo mėdio da capacidade pelas soluçð̃es das heuristicas.

\begin{tabular}{|c|c|c|c|c|c|}
\hline Estrutura & heuristica & \multicolumn{2}{c|}{$\begin{array}{c}\text { Custo baixo de } \\
\text { preparaçâo }\end{array}$} & \multicolumn{2}{c|}{$\begin{array}{c}\text { Custo alto de } \\
\text { preparação }\end{array}$} \\
\cline { 3 - 6 } & & uso_cap & uso_setup & uso_cap & uso_setup \\
\hline \multirow{4}{*}{ Serial } & HT1 & 58.6 & 34.5 & 52.5 & 24.8 \\
\cline { 3 - 6 } & HT2 & $\mathbf{5 9 . 9}$ & 39.1 & 53.6 & $\mathbf{2 8 . 1}$ \\
\cline { 3 - 6 } & HO2 & $\mathbf{5 9 . 9}$ & 39.1 & $\mathbf{5 3 . 6}$ & 28.0 \\
\hline \multirow{3}{*}{ Geral } & HT1 & 59.6 & 32.9 & 52.6 & 23.0 \\
\cline { 3 - 6 } & HT2 & 60.1 & 37.2 & 54.1 & 27.5 \\
\cline { 3 - 6 } & HO2 & $\mathbf{6 0 . 1}$ & 37.2 & $\mathbf{5 4 . 2}$ & $\mathbf{2 7 . 7}$ \\
\hline
\end{tabular}


Como pode ser visto, o consumo médio de capacidade apresentado pelas soluções obtidas pela heurística HT1 é um pouco inferior aos consumos médios das heuristicas HT2 e HO2. Nota-se também que a quantidade média utilizada para as preparações é maior para os exemplos resolvidos pelas heuristicas HT2 e HO2. Este comportamento deve-se ao fato de que o procedimento para obtenção da solução inicial destas heurísticas leva em consideração a utilização da capacidade, obtendo assim soluçōes de partida provavelmente com um maior número de preparação. 


\subsection{Análise dos Resultados para os Exemplos do Grupo G2}

Para os exemplos do grupo G2 são apresentados primeiramente os resultados obtidos considerando a porcentagem de soluções factíveis obtidas pelas heurísticas originais (HO1 e HO2) e heurísticas com estratégias de Busca Tabu (HT1 e HT2). A seguir, as soluções são analisadas em relação ao uso da capacidade gerada por máquina. As soluções infactiveis são analisadas em relação ao grau de infactibilidade da solução inicial e das soluções heurísticas. São também apresentadas tabelas comparando as soluções heurísticas com os valores dos limitantes inferiores obtidos através da relaxação Lagrangiana.

\subsubsection{Análise dos Resultados em Relação à Porcentagem de Soluções Factíveis Obtidas}

As tabelas seguintes apresentam as porcentagens de soluções factiveis obtidas pelas heurísticas HT1, HT2, HO1 e HO2.

Os resultados obtidos para os exemplos considerando as estruturas seriais, com custo baixo e alto de preparação, são apresentados na Tabela 5.14. Na Tabela 5.15 estão os resultados para os exemplos com as estruturas gerais considerados e, com custo baixo e alto de preparação. Nestas tabelas têm-se as dimensões dos exemplos representados por: N-T-K, onde $\mathrm{N}$ é o numero de itens, $\mathrm{T}$ é o número de períodos e $\mathrm{K}$ é o número de máquinas. 
Tabela 5.14. Porcentagem de soluçōes factiveis obtidas pelas heuristicas para os exemplos com estruturas seriais.

\begin{tabular}{|c|c|c|c|c|c|c|c|c|}
\hline \multirow{2}{*}{$\begin{array}{c}\text { FAC(\%) } \\
\text { N-T-K } \\
\end{array}$} & \multicolumn{4}{|c|}{ custo baixo de preparaçao } & \multicolumn{4}{|c|}{ custo alto de preparaçăo } \\
\hline & HT1 & IIT2 & HO1 & $\mathrm{HO} 2$ & HT 1 & HT2 & HOI & $\mathrm{HO} 2$ \\
\hline $10-6-2$ & 100.0 & 100.0 & 80.0 & 60.0 & 100.0 & 100.0 & 0.0 & 20.0 \\
\hline $10-6-3$ & 100.0 & 100.0 & 50.0 & 60.0 & 100.0 & 100.0 & 10.0 & 40.0 \\
\hline $10-6-4$ & 100.0 & 100.0 & 70.0 & 90.0 & 100.0 & 100.0 & 0.0 & 100.0 \\
\hline $10-12-2$ & 90.0 & 80.0 & 30.0 & 70.0 & 80.0 & 90.0 & 10.0 & 10.0 \\
\hline $10-12-3$ & 100.0 & 100.0 & 70.0 & 80.0 & 100.0 & 100.0 & 0.0 & 70.0 \\
\hline $10-12-4$ & 90.0 & 100.0 & 40.0 & 90.0 & 100.0 & 100.0 & 0.0 & 40.0 \\
\hline $10-18-2$ & 90.0 & 90.0 & 30.0 & 60.0 & 90.0 & 90.0 & 0.0 & 20.0 \\
\hline $10-18-3$ & 100.0 & 100.0 & 50.0 & 70.0 & 100.0 & 100.0 & 0.0 & 50.0 \\
\hline $10-18-4$ & 100.0 & 90.0 & 50.0 & 80.0 & 100.0 & 90.0 & 10.0 & 60.0 \\
\hline Média & 96.7 & 95.6 & 52.2 & 73.3 & 96.7 & 96.7 & 3.3 & 45.6 \\
\hline $17-6-2$ & 100.0 & 100.0 & 60.0 & 40.0 & 100.0 & 100.0 & 0.0 & 30.0 \\
\hline $17-6-3$ & 100.0 & 100.0 & 80.0 & 90.0 & 100.0 & 100.0 & 0.0 & 50.0 \\
\hline $17-6-4$ & 100.0 & 100.0 & 80.0 & 90.0 & 100.0 & 100.0 & 30.0 & 90.0 \\
\hline $17-12-2$ & 100.0 & 100.0 & 60.0 & 90,0 & 100.0 & 90.0 & 0.0 & 20.0 \\
\hline $17-12-3$ & 100.0 & 100.0 & 50.0 & 80.0 & 100.0 & 100.0 & 10.0 & 70.0 \\
\hline $17-12-4$ & 100.0 & 100.0 & 40.0 & 90.0 & 100.0 & 100.0 & 20.0 & 70.0 \\
\hline $17-18-2$ & 100.0 & 100.0 & 50.0 & 80.0 & 100.0 & 100.0 & 0.0 & 40.0 \\
\hline $17-18-3$ & 100.0 & 100.0 & 70.0 & 90.0 & 100.0 & 100.0 & 20.0 & 70.0 \\
\hline $17-18-4$ & 100.0 & 100.0 & 50.0 & 80.0 & 100.0 & 100.0 & 0.0 & 90.0 \\
\hline Média & 100.0 & 100.0 & 60.0 & 81.1 & 100.0 & 98.9 & 8.9 & 58.9 \\
\hline $40-6-2$ & 100.0 & 100.0 & 70.0 & 90.0 & 100.0 & 100.0 & 10.0 & 40.0 \\
\hline $40-6-3$ & 100.0 & 100.0 & 80.0 & 90.0 & 90.0 & 100.0 & 50.0 & 100.0 \\
\hline $40-6-4$ & 100.0 & 100.0 & 90.0 & 80.0 & 90.0 & 100.0 & 40.0 & 90.0 \\
\hline $40-12-2$ & 80.0 & 80.0 & 50.0 & 10.0 & 90.0 & 80.0 & 0.0 & 60.0 \\
\hline $40-12-3$ & 100.0 & 100.0 & 50.0 & 30.0 & 100.0 & 100.0 & 10.0 & 70.0 \\
\hline $40-12-4$ & 100.0 & 100.0 & 30.0 & 20.0 & 90.0 & 100.0 & 10.0 & 50.0 \\
\hline $40-18-2$ & 1000 & 100.0 & 30.0 & 50.0 & 90.0 & 90.0 & 10.0 & 30.0 \\
\hline $40-18-3$ & 1000 & 100.0 & 40.0 & 60.0 & 90.0 & 100.0 & 0.0 & 70.0 \\
\hline $40-18-4$ & 100.0 & 100.0 & 10.0 & 50.0 & 100.0 & 100,0 & 0.0 & 40.0 \\
\hline Média & 97.8 & 97.8 & 50.0 & 53.3 & 93.3 & 96.7 & 14.4 & 61.1 \\
\hline Média Tota! & 98.1 & 97.8 & 54.1 & 69.3 & 96.7 & 97.4 & 8.9 & 55.2 \\
\hline
\end{tabular}

A Tabela 5.14 mostra que as heurísticas HT1 e HT2 apresentam bons desempenhos na obtenção de soluções factíveis, o que não ocorre com as heurísticas HO1 e HO2. No geral, a heurística $\mathrm{HOl}$ tem o pior desempenho em relação ao número de soluções factíveis obtidas. Esta heurística apresenta este comportamento devido ao problema de ciclagem, ou seja, um passo da heurística de factibilização desfaz o movimento executado pelo outro passo da heurística. Por exemplo, para os exemplos com 40 itens, 18 periodos, 2 máquinas e custo baixo de preparação, a heurística $\mathrm{HOl}$ obteve $30 \%$ de soluções factíveis, enquanto que, as heurísticas $\mathrm{HT} 1$, $\mathrm{HT} 2$ e $\mathrm{HO} 2$ obtiveram $100 \%, 100 \%$ e $50 \%$, respectivamente. Considerando todas as dimensões dos exemplos com 10 itens, custo alto de preparação e estrutura serial, 
pode-se notar o péssimo desempenho da heurística $\mathrm{HOl}$ e, isto provavelmente acontece porque, o algoritmo que determina a solução inicial tende a fazer lotes maiores influenciados pelo alto custo de preparação. Para estes exemplos, HOl obteve $3.3 \%$ de soluções factíveis, o que corresponde a resolução de 3 exemplos dos 90 gerados. Convém salientar aqui que foram gerados 10 exemplos para cada dimensão considerada. A heurística $\mathrm{HO}$, não teve o mesmo comportamento das heurísticas HT1 e HT2 na determinação de soluções factíveis, no entanto, teve um desempenho razoável na obtenção de soluções factíveis. Para este mesmo grupo de exemplos, $\mathrm{HO} 2$ obteve $45.6 \%$ de soluções factíveis, sendo este o seu pior caso para os exemplos com estruturas seriais.

Analisando o desempenho das heurísticas HT1 e HT2, percebe-se que elas não apresentam grandes variações nas porcentagens médias de soluções obtidas, como é o caso dos exemplos considerando estrutura serial, 10 itens e custo baixo de preparação. A heurística HT1 obteve $96.7 \%$ de soluções factíveis e $95.6 \%$ para HT2.

Para os exemplos com estruturas gerais de produtos (Tabela 5.15), observe que as heurísticas HT1 e HT2 não apresentaram o mesmo desempenho na obtenção de soluções factíveis para os exemplos com 10 e 40 itens, como apresentaram para os exemplos com estruturas seriais, para os quais foram obtidas porcentagens superiores a $90 \%$. No entanto, determinam $100 \%$ de soluções factíveis para os exemplos com 17 itens, tanto para os exemplos com custo baixo de preparação, quanto para os exemplos com alto custo de preparação. Observe que a estrutura geral com 17 itens (Figura 5.3), a interdependência entre os itens é menor que nas estruturas gerais para 10 e 40 itens (figuras 5.2 e 5.4) e, isto pode ter influenciado o procedimento de factibilização.

Pode-se notar que as heurísticas HT1 e HT2 apresentaram piores desempenhos na determinação de soluções factíveis para os exemplos com 40 itens, principalmente para os exemplos com alto custo de preparação. Observe que para os exemplos com 40 itens, 12 períodos e 2 máquinas, HT1 e HT2 obtiveram $60 \%$ de soluções factíveis para os exemplos com custo baixo de preparação, no entanto, obtiveram somente $30 \%$ e $40 \%$ para os exemplos com custo alto de preparação. Porém, para estes exemplos, a heurística HT2 determinou $14.4 \%$ a mais de soluções factiveis do que a heurística HT1, pois HT1 determinou $51.1 \%$ de soluções factiveis, contra $65.6 \%$ de HT2.

Considerando todas as estruturas gerais de produtos, nota-se que a heurística HT2 apresentou um desempenho superior à heuristica $\mathrm{HT} 1$ na determinação de soluções factiveis. Já as heurísticas $\mathrm{HO} 1$ e $\mathrm{HO} 2$ tiveram um mau desempenho na determinação de soluções 
factiveis, sendo que, a heurística $\mathrm{HOl}$ apresentou o pior desempenho geral, como aconteceu para os exemplos com estruturas seriais de produtos.

Tabela 5.15. Porcentagem de soluçð̃es factiveis para problemas com custo altos de preparação e estruturas gerais.

\begin{tabular}{|c|c|c|c|c|c|c|c|c|}
\hline \multirow{2}{*}{$\begin{array}{c}\text { FAC (\%) } \\
\text { N-T-K } \\
\end{array}$} & \multicolumn{4}{|c|}{ custo baixo de preparaçāo } & \multicolumn{4}{|c|}{ custo alto de preparaçāo } \\
\hline & HT1 & HT2 & HO1 & $\mathrm{HO2}$ & HT1 & HT2 & HOI & $\mathrm{HO} 2$ \\
\hline $10-6-2$ & 70.0 & 70.0 & 40.0 & 60.0 & 70.0 & 60.0 & 0.0 & 40.0 \\
\hline $10-6-3$ & 100.0 & 100.0 & 10.0 & 80.0 & 90.0 & 100.0 & 0.0 & 40.0 \\
\hline $10-6-4$ & 100.0 & 100.0 & 90.0 & 100.0 & 100.0 & 100.0 & 20.0 & 80.0 \\
\hline $10-12-2$ & 60.0 & 70.0 & 50.0 & 60.0 & 70.0 & 60.0 & 0.0 & 20.0 \\
\hline $10-12-3$ & 70.0 & 70.0 & 40.0 & 70.0 & 80.0 & 70.0 & 20.0 & 60.0 \\
\hline $10-12-4$ & 80.0 & 90.0 & 10.0 & 70.0 & 80.0 & 80.0 & 20.0 & 60.0 \\
\hline $10-18-2$ & 60.0 & 60.0 & 40.0 & 60.0 & 50.0 & 60.0 & 10.0 & 50.0 \\
\hline $10-18-3$ & 90.0 & 100.0 & 60.0 & 80.0 & 100.0 & 100.0 & 10.0 & 40.0 \\
\hline $10-18-4$ & 100.0 & 80.0 & 50.0 & 80.0 & 80.0 & 90.0 & 10.0 & 60.0 \\
\hline Média & 81.1 & 82.2 & 43.3 & 73.3 & 80.0 & 80.0 & 10.0 & 50.0 \\
\hline $17-6-2$ & 100.0 & 100.0 & 80.0 & 80.0 & 100.0 & 100.0 & 20.0 & 50.0 \\
\hline $17-6-3$ & 100.0 & 100.0 & 90.0 & 100.0 & 100.0 & 100.0 & 10.0 & 70.0 \\
\hline $17-6-4$ & 100.0 & 100.0 & 70.0 & 100.0 & 100.0 & 100.0 & 30.0 & 80.0 \\
\hline $17-12-2$ & 100.0 & 100.0 & 100.0 & 100.0 & 100.0 & 100.0 & 10.0 & 70.0 \\
\hline $17-12-3$ & 100.0 & 100.0 & 80.0 & 100.0 & 100.0 & 100.0 & 20.0 & 80.0 \\
\hline $17-12-4$ & 100.0 & 100.0 & 80.0 & 90.0 & 100.0 & 100.0 & 10.0 & 70.0 \\
\hline $17-18-2$ & 100.0 & 100.0 & 90.0 & 90.0 & 100.0 & 100.0 & 0.0 & 60.0 \\
\hline $17-18-3$ & 100.0 & 100.0 & 70.0 & 90.0 & 100.0 & 100.0 & 10.0 & 80.0 \\
\hline $17-18-4$ & 100.0 & 100.0 & 80.0 & 90.0 & 100.0 & 100.0 & 10.0 & 90.0 \\
\hline Média & 100.0 & 100.0 & 82.2 & 93.3 & 100.0 & 100.0 & 13.3 & 72.2 \\
\hline $40-6-2$ & 40.0 & 40.0 & 30.0 & 40.0 & 40.0 & 20.0 & 0.0 & 0.0 \\
\hline $40-6-3$ & 100.0 & 100.0 & 50.0 & 60.0 & 70.0 & 90.0 & 0.0 & 30.0 \\
\hline $40.6-4$ & 100.0 & 100.0 & 50.0 & 70.0 & 70.0 & 90.0 & 0.0 & 10.0 \\
\hline $40-12-2$ & 60.0 & 60.0 & 40.0 & 40.0 & 30.0 & 40.0 & 0.0 & 0.0 \\
\hline $40-12-3$ & 80.0 & 80.0 & 60.0 & 60.0 & 50.0 & 80.0 & 0.0 & 20.0 \\
\hline $40-12-4$ & 80.0 & 80.0 & 50.0 & 60.0 & 50.0 & 80.0 & 0.0 & 40.0 \\
\hline $40-18-2$ & 60.0 & 60.0 & 50.0 & 40.0 & 40.0 & 60.0 & 0.0 & 10.0 \\
\hline $40-18-3$ & 80.0 & 80.0 & 50.0 & 60.0 & 40.0 & 60.0 & 0.0 & 20.0 \\
\hline $40-18-4$ & 80.0 & 80.0 & 50.0 & 50.0 & 70.0 & 70.0 & 0.0 & 20.0 \\
\hline Média & 75.6 & 75.6 & 47.8 & 53.3 & 51.1 & 65.6 & 0.0 & 16.7 \\
\hline Média Total & 85.6 & 85.9 & 57.8 & 73.3 & 77.0 & 81.9 & 7.8 & 46.3 \\
\hline
\end{tabular}

Finalmente, analisando os resultados médios das porcentagens de soluções factíveis (FAC), agregados por periodos e máquinas, apresentados na Tabela 5.16, observa-se que as heurísticas conseguem obter um maior número de soluções factiveis para exemplos com custo baixo de preparação. Uma das razões é que as soluções iniciais obtidas por esses exemplos têm suas produções mais "distribuídas" entre períodos e máquinas, pois o custo de preparação é baixo. As soluções iniciais são obtidas por um procedimento que não considera as restrições de capacidade, porém, um dos procedimentos considera uma penalidade, que leva em 
-ruuuduae, apesar de não considerar explicitamente estas restrições. Nos exemplos com custo alto de preparação, a tendência foi de ter soluções com altos níveis de produção em alguns períodos-máquinas, o que dificulta o trabalho da heurística de factibilização. Pode-se notar que a heurística HT2, que utiliza um procedimento para determinação das soluções iniciais que leva informações sobre a utilização das capacidades, obtém uma maior porcentagem de soluções factíveis, em média, para os exemplos com custos altos de preparação do que a heurística HT1. O procedimento utilizado pela HT2 tende a distribuir melhor a produção entre períodos, apesar da tendência destes exemplos apresentarem altos niveis de produção em determinados períodos, e isto, provavelmente, explicaria o melhor desempenho de HT2 para os exemplos com custo alto de preparação.

Tabela 5.16. Porcentagem de soluçðes factiveis (FAC) obtido por cada heurística.

\begin{tabular}{|c|c|c|c|c|c|c|c|}
\hline \multicolumn{2}{|c}{ Estruturas } & \multicolumn{3}{c|}{ Seriais } & \multicolumn{3}{c|}{ Gerais } \\
\cline { 3 - 8 } & & $\mathbf{1 0}$ & $\mathbf{1 7}$ & $\mathbf{4 0}$ & $\mathbf{1 0}$ & 17 & $\mathbf{4 0}$ \\
\hline \multirow{4}{*}{ Custo baixo } & HO1 & 52.2 & 60.0 & 50.0 & $\mathbf{4 3 . 3}$ & 82.2 & $\mathbf{4 7 . 8}$ \\
de preparação & HO2 & 73.3 & 81.1 & 53.3 & 73.3 & 93.3 & 53.3 \\
& HT1 & $\mathbf{9 6 . 7}$ & $\mathbf{1 0 0}$ & $\mathbf{9 7 . 8}$ & 81.1 & 100 & $\mathbf{7 5 . 6}$ \\
& HT2 & 95.6 & $\mathbf{1 0 0}$ & $\mathbf{9 7 . 8}$ & $\mathbf{8 2 . 2}$ & $\mathbf{1 0 0}$ & $\mathbf{7 5 . 6}$ \\
\hline \multirow{4}{*}{ Custo alto de } & HO1 & 3.3 & 8.9 & $\mathbf{1 4 . 4}$ & 10.0 & 13.3 & 0.0 \\
preparação & HO2 & $\mathbf{4 5 . 6}$ & 58.9 & 61.1 & 50.0 & $\mathbf{7 2 . 2}$ & 16.7 \\
& HT1 & 96.7 & 100 & 93.3 & $\mathbf{8 0 . 0}$ & $\mathbf{1 0 0}$ & 51.1 \\
& HT2 & $\mathbf{9 6 . 7}$ & $\mathbf{9 8 . 9}$ & $\mathbf{9 6 . 7}$ & $\mathbf{8 0 . 0}$ & $\mathbf{1 0 0}$ & $\mathbf{6 5 . 6}$ \\
\hline
\end{tabular}

Como ressaltado anteriormente, a heurística $\mathrm{HOl}$ obteve um desempenho muito ruim na obtenção de soluções factíveis, principalmente para os exemplos com custo alto de preparação. Observe que para os exemplos com estrutura serial com 17 itens, custo alto de preparação, a heurística $\mathrm{HOl}$ obteve uma porcentagem de soluçōes factíveis de $8.9 \%$, que corresponde a 8 exemplos em 90, enquanto que as heurísticas HT1, HT2 e HO2 obtiveram $100 \%, 98.9 \%$ e $58.9 \%$ de soluções factíveis, respectivamente.

\section{- Influência dos Parâmetros T e K na Obtenção de Soluções Factíveis.}

Os gráficos (5.1)-(5.6) foram gerados com o objetivo de avaliar a influência dos parâmetros $\mathrm{K}, \mathrm{T}$ e $\mathrm{N}$ em relação à porcentagem de soluções factíveis obtidas pelas heurísticas, e para factlitar a análise dos resultados apresentados nas tabelas anteriores. Os gráficos 5.1, 5.2 e 5.3 representam os exemplos com estruturas seriais, os gráficos $5.4,5.5$ e 5.6 
representam os exemplos com estruturas gerais. Os resultados são valores médios considerando os exemplos com custos baixos e altos de preparação agrupados.

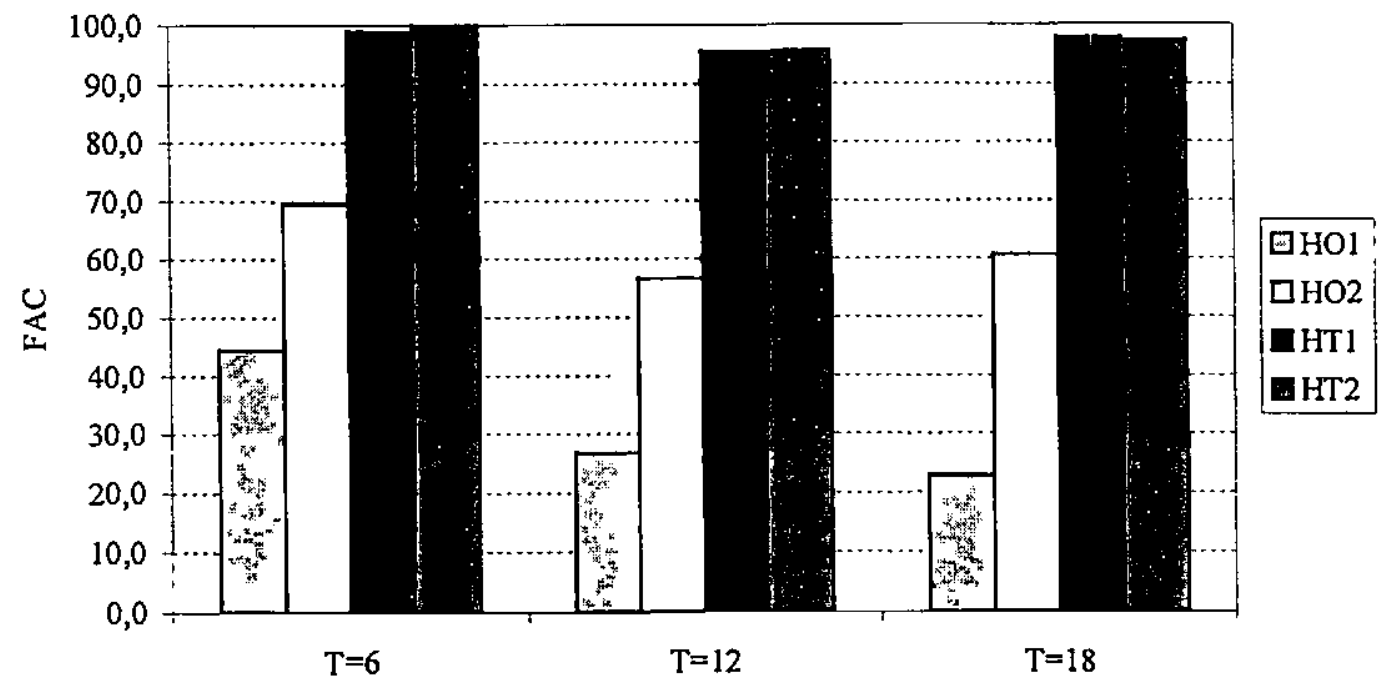

Gráfico 5.1. FAC para os exemplos com estruturas seriais com 10, 17 e 40 itens (parâmetro T).

No Gráfico 5.1 pode-se observar que a heurística $\mathrm{HOl}$ é mais sensivel ao aumento do número de periodo pois, a porcentagem de soluçðes factíveis obtidas por esta heurística diminui gradativamente com o aumento do número de períodos. As heurísticas HT1 e HT2 não apresentam variações significativas na porcentagem de soluções factíveis obtidas.

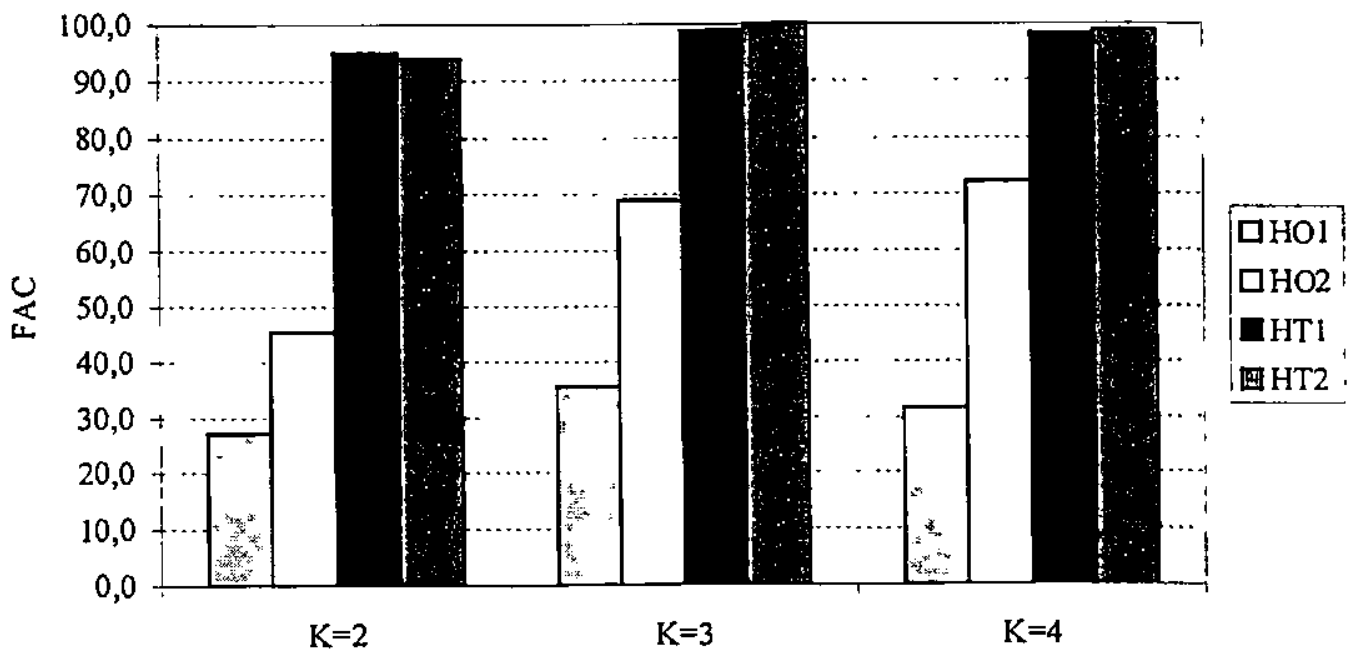

Gráfico 5.2. FAC para os exemplos com 10, 17 e 40 itens com estruturas seriais (parâmetro $\mathrm{K}$ ) 
Como se pode observar no Gráfico 5.2, quando o número de máquinas aumenta, a porcentagem de soluções factíveis obtidas pelas heurísticas aumenta, porém sendo mais significativa para a heurística $\mathrm{HO} 2$.

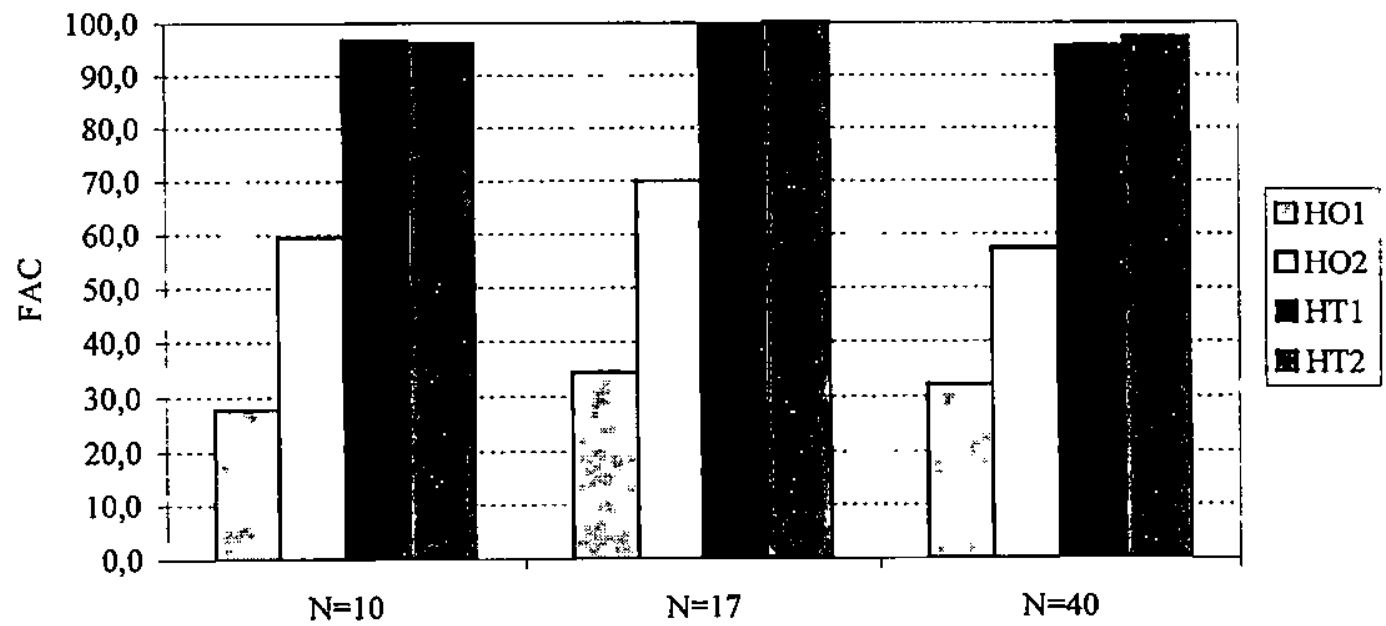

Gráfico 5.3. FAC para os exemplos com 10, 17 e 40 itens com estruturas seriais (parâmetro $\mathrm{N}$ )

O Gráfico 5.3 está representado os resultados considerando os exemplos com custo alto e baixo de preparação e estruturas seriais de produtos. Como visto anteriormente (Tabela 5.14), as heurísticas HT1 e HT2 não são tão sensíveis ao aumento do número de itens.

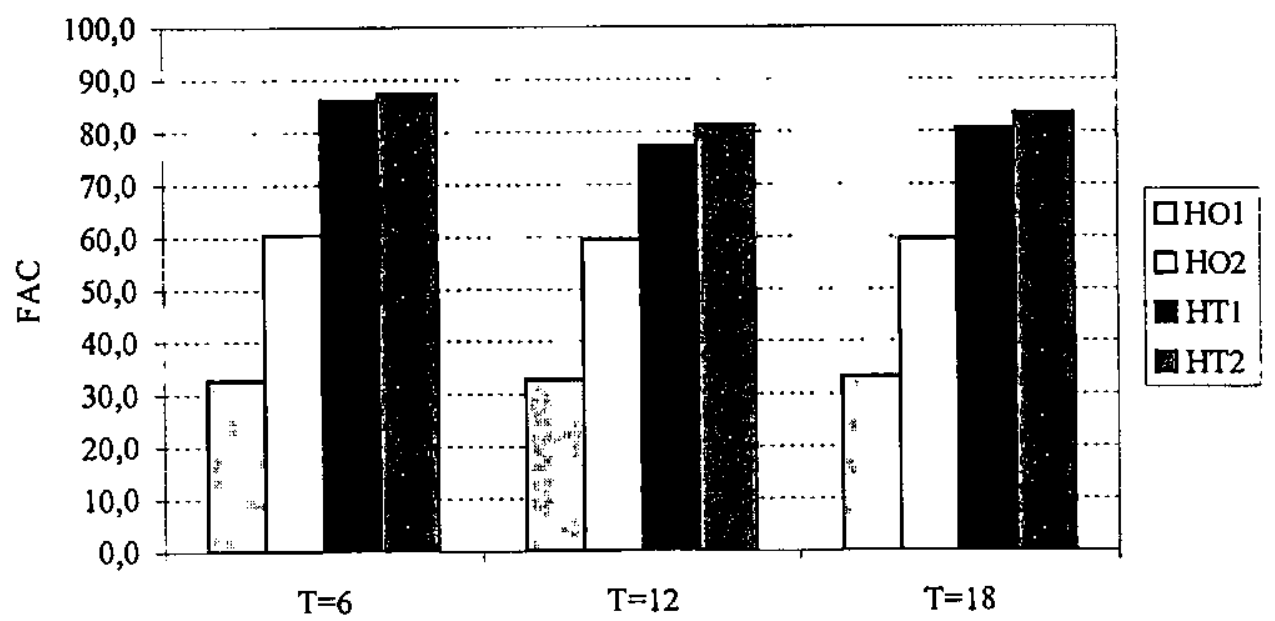

Gráfico 5.4. FAC para os exemplos com estruturas gerais com 10, 17 e 40 itens (parâmetro T).

O Gráfico 5.4 revela que as heurísticas $\mathrm{HOl}$ e $\mathrm{HO} 2$ não são sensiveis ao aumento do número de periodos, pois as porcentagens de soluções factíveis obtidas por estas heurísticas 
são, em média, constantes com o aumento do número de períodos. O número de soluç̧⿸es factíveis obtidos pelas heurísticas HT1 e HT2 oscilam com o aumento do número de períodos.

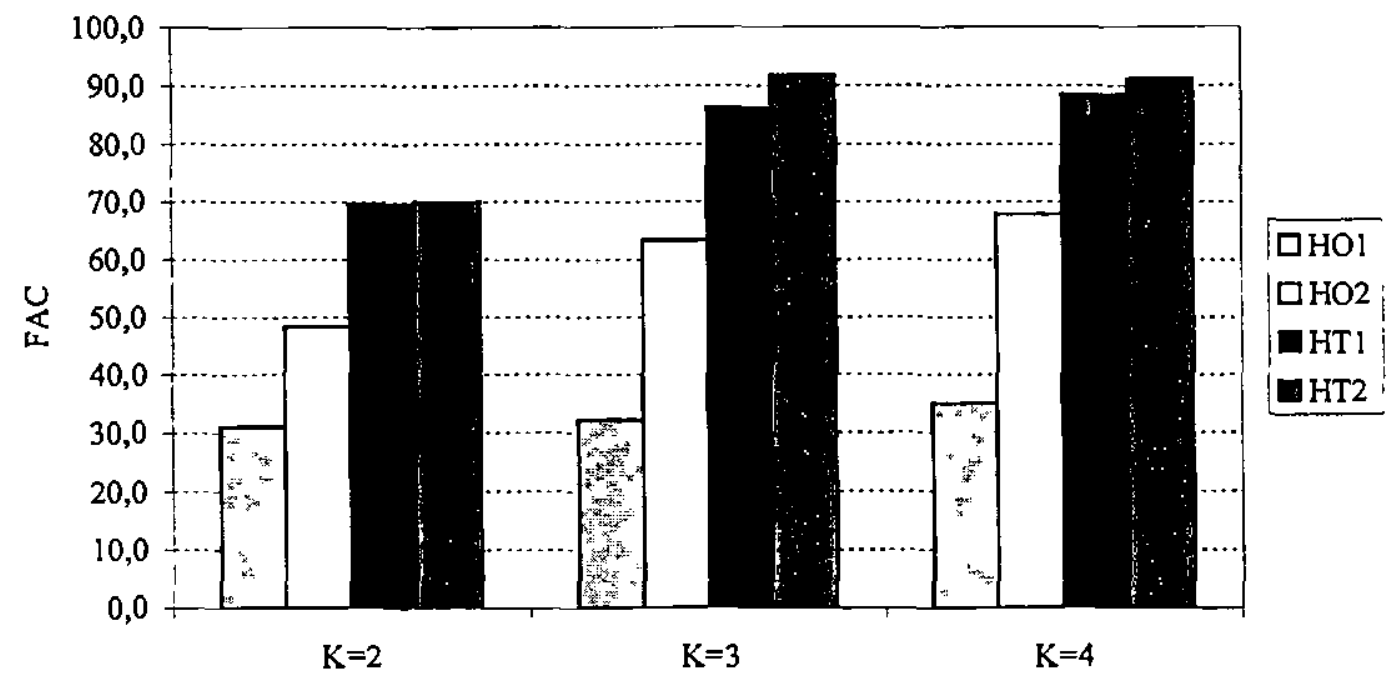

Gráfico 5.5. FAC para os exemplos com estruturas gerais com 10,17 e 40 itens (parâmetro K).

As heurísticas apresentam um sensivel aumento no número de soluções factíveis obtidas para os exemplos com estruturas gerais, quando se aumenta o número de máquinas como mostrado no Gráfico 5.5 .

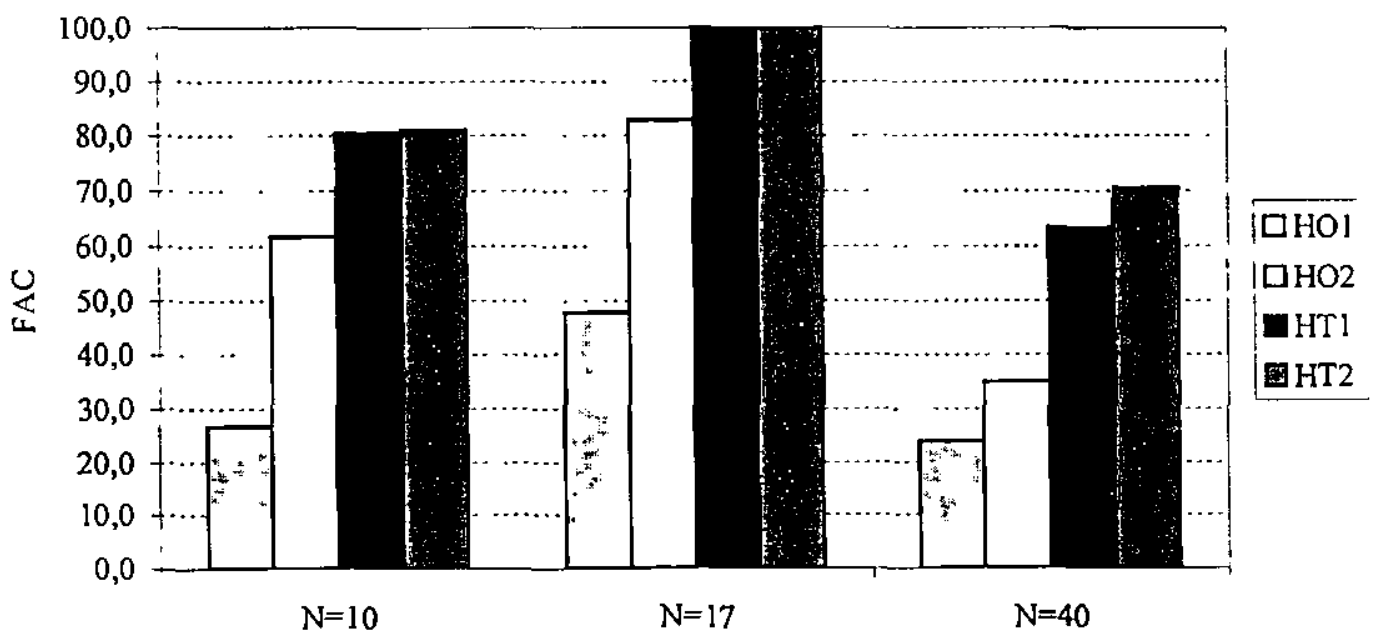

Gráfico 5.6. FAC para os exemplos com estruturas gerais com 10, 17 e 40 itens (parâmetro $\mathrm{N}$ ). 
Como visto anteriormente na Tabela 5.15 e agora no Gráfico 5.6, houve um aumento da porcentagem de soluções factíveis dos exemplos com 10 itens para 17 itens, e um decréscimo considerável no valor de FAC, para os exemplos com 40 itens. Este comportamento ocorreu para todos as heurísticas. Pode-se concluir que com o aumento do número de itens e dependendo do aumento das relações entre os itens na estrutura de produtos (ver figuras 5.2, 5.3 e 5.4), a porcentagem de soluçőes factíveis obtidas tenderá a apresentar decréscimo.

\section{- Influência do Procedimento Auxiliar ao Procedimento de Factibilização}

A Tabela 5.17 ilustra a influência do procedimento cria_transferência no processo de factibilização da heurística HT1. Observa-se que o procedimento apresenta maior impacto para os exemplos com custo alto de preparação. Por exemplo, para os exemplos com 40 itens e custo alto de preparação e estrutura serial de itens, o procedimento cria_transferência é responsável por pelo menos $23.33 \%$ de soluções factíveis obtidas pela heurística HT1. Porém, para os exemplos com custo baixo de preparação, o procedimento cria_transferência tem pouca influência no procedimento factibilização. Embora não apresentados aqui, os experimentos computacionais mostraram que, o procedimento cria_transferência influenciou no processo de factibilização para a heurística HO1. Os resultados da influência do procedimento cria_transferência, para heurística $\mathrm{HOl}$, não são apresentados devido ao baixo número de soluçőes factíveis obtidas (veja tabelas 5.14 e 5.15).

Tabela 5.17. Influência do procedimento cria transferência na obtenção de soluções factiveis em HT1.

\begin{tabular}{|c|c|c|c|c|c|c|c|}
\hline \multicolumn{2}{|c|}{ Estruturas } & \multicolumn{3}{c|}{ Seriais } & \multicolumn{3}{c|}{ Gerais } \\
\cline { 3 - 8 } \multicolumn{2}{|c|}{} & 10 & 17 & $\mathbf{4 0}$ & $\mathbf{1 0}$ & 17 & 40 \\
\hline Custo baixo & HTI-Sem Cria & 96.8 & 100 & $\mathbf{9 7 . 8}$ & $\mathbf{8 2 . 2}$ & $\mathbf{1 0 0}$ & 74.4 \\
de preparação & HTl-Com Cria & $\mathbf{9 6 . 8}$ & 100 & $\mathbf{9 7 . 8}$ & 81.1 & 100 & 75.6 \\
\hline Custo alto de & HTl-Sem Cria & 96.7 & 97.8 & 70.0 & 78.9 & 100 & 40.0 \\
preparação & HTl-Com Cria & 96.7 & 100 & $\mathbf{9 3 . 3}$ & $\mathbf{8 0 . 0}$ & 100 & $\mathbf{5 1 . 1}$ \\
\hline
\end{tabular}

$\mathrm{Na}$ tabela seguinte ilustra a influência do procedimento cria_transferência na determinação de soluções factíveis da heurística HT2. 
Tabela 5.18. Influência do procedimento cria transferência na obtenção de soluções factíveis em HT2.

\begin{tabular}{|c|c|c|c|c|c|c|c|}
\hline \multicolumn{2}{|c|}{$\begin{array}{c}\text { Estruturas } \\
\text { de produtos }\end{array}$} & \multicolumn{3}{c|}{ Seriais } & \multicolumn{3}{c|}{ Gerais } \\
\cline { 2 - 8 } & $\mathbf{1 0}$ & $\mathbf{1 7}$ & $\mathbf{4 0}$ & $\mathbf{1 0}$ & $\mathbf{1 7}$ & $\mathbf{4 0}$ \\
\hline Custo baixxo & HT2-Sem Cria & 94.4 & 100 & $\mathbf{9 7 . 8}$ & $\mathbf{8 2 . 2}$ & $\mathbf{1 0 0}$ & $\mathbf{7 5 . 6}$ \\
de preparação & HT2-Com Cria & 95.6 & 100 & $\mathbf{9 7 . 8}$ & $\mathbf{8 2 . 2}$ & 100 & $\mathbf{7 5 . 6}$ \\
\hline Custo aito de & HT2-Sem Cria & 94.4 & $\mathbf{1 0 0}$ & $\mathbf{9 6 . 7}$ & $\mathbf{8 2 . 2}$ & $\mathbf{1 0 0}$ & 63.3 \\
preparação & HT2-Com Cria & 96.7 & 98.9 & 96.7 & 80.0 & 100 & $\mathbf{6 5 . 6}$ \\
\hline
\end{tabular}

Os resultados apresentados na Tabela 5.18 mostram que o procedimento cria_transferência pouco influenciou na heurística HT2. Considerando os exemplos com estrutura geral, custo alto de preparação e 40 itens, verifica-se que a porcentagem de soluções factíveis obtidas com e sem o procedimento de cria_transferência é praticamente a mesma, o que não acontece na heurística HTl. Os resultados também mostram que para os exemplos com custo alto de preparação e estruturas seriais com 17 itens e gerais com 10 itens, este procedimento atrapalhou o procedimento de factibilizaçâo. Apesar dos resultados apresentados na Tabela 5.18, todas as comparações feitas entre as heurísticas neste capítulo, consideram-se as heurísticas com o procedimento cria_transferência.

A Tabela 5.19 mostra a influência do procedimento cria_transferência no auxilio ao procedimento de factibilização da heurística $\mathrm{HO} 2$.

Tabela 5.19. Influência do procedimento cria transferência na obtenção de soluçōes factiveis em HO2.

\begin{tabular}{|c|c|c|c|c|c|c|c|}
\hline \multicolumn{2}{|c|}{$\begin{array}{c}\text { Estruturas } \\
\text { de produtos }\end{array}$} & \multicolumn{3}{c|}{ Seriais } & \multicolumn{3}{c|}{ Gerais } \\
\cline { 2 - 8 } & HO2-Sem Cria & 73.3 & $\mathbf{1 0}$ & $\mathbf{4 0}$ & $\mathbf{1 0}$ & $\mathbf{1 7}$ & $\mathbf{4 0}$ \\
\hline Custo baixo & HO & 53.3 & 73.3 & 93.3 & 53.3 \\
de preparação & HO2-Com Cria & 73.3 & 81.1 & 53.3 & 73.3 & 93.3 & 53.3 \\
\hline Custo alto de & HO2-Sem Cria & 45.6 & 58.9 & 61.1 & 50.0 & 72.2 & 16.7 \\
preparação & HO2-Com Cria & 45.6 & 58.9 & 61.1 & 50.0 & 72.2 & 16.7 \\
\hline
\end{tabular}

O procedimento cria_transferência não influencia na quantidade de soluç̃oes factíveis obtidas pela heurística HO2, como pode ser visto na Tabela 5.19. Algo similar acontece com a heurística HT2. Convém observar aqui que ambas heurísticas partem da mesma solução inicial, o que provavelmente ocasionou estes resultados.

Os resultados mostrados nas tabelas anteriores, relacionados à influência do procedimento cria_transferência na fase de factibilização, demonstram que as heurísticas que utilizam o procedimento WW-Paralelo Penalizado para obtenção da solução inicial, não são influenciadas na obtenção de soluçס̃es factiveis com a retirada deste procedimento. 
A Tabela 5.20 mostra o número médio de iterações gasto para cada heurística, com e sem o procedimento cria_transferência, na obtenção de soluções factíveis. Os exemplos foram agrupados considerando o número de itens, períodos e máquinas.

Tabela 5.20. Número de iteraçoes médias gasta para factibilização para cada heurística.

\begin{tabular}{|c|cc|cc|}
\hline \multirow{2}{*}{ Estruturas } & \multicolumn{2}{|c|}{ Custo baixo preparaçăo } & \multicolumn{2}{c|}{ Custo alto preparaçăo } \\
\cline { 2 - 5 } & Seriais & Gerais & Seriais & Gerais \\
\hline HT1-Sem Cria & 11.6 & 13.8 & 42.8 & 61.2 \\
HT1-Com Cria & 10.8 & 13.6 & 30.1 & 49.9 \\
\hline HT2-Sem Cria & 7.9 & 7.9 & 16.2 & 23.0 \\
HT2-Com Cria & 7.9 & 7.9 & 13.4 & 22.0 \\
\hline HO2-Sem Cria & 12.7 & 8.4 & 13.9 & 22.2 \\
HO2-Com Cria & 12.7 & 8.4 & 13.9 & 22.2 \\
\hline
\end{tabular}

Como pode ser visto nas tabelas anteriores, a heurística que mais depende do procedimento de cria_transferência é a heurística HT1. Na Tabela 5.20, pode-se notar que os números médios de iterações para obtenção de soluções factíveis para as heurísticas HT2 e $\mathrm{HO} 2$ são pouco influenciados pelo procedimento cria_transferência. Já para heurística HTI, houve um acréscimo no número de iterações médio de até $42.2 \%$ (exemplos com estruturas seriais e custo alto de preparação) quando retirou o procedimento para auxiliar as transferências.

Embora não apresentados aqui, o número de chamadas do procedimento cria_transferência foi duas vezes maior na heurística HT1 do que na heurística HT2, sendo que para a heurística $\mathrm{HO}$, não houve chamadas a este procedimento na resolução dos exemplos com custo baixo de preparação. Para os exemplos com custo alto de preparação, a heurística $\mathrm{HO} 2$ apresentou pouquíssimas chamadas a este procedimento.

\section{- Influência do Procedimento de Alteração (Procedimento P4)}

Nesta seção é testada também a influência do procedimento (P4) na determinação de soluções factíveis, como foi feito anteriormente para o procedimento cria_transferência. $\mathrm{Na}$ Tabela 5.21 são apresentados os resultados para a heurística HT1 e, na Tabela 5.22, os resultados para a heurística $\mathrm{HT} 2$. Os resultados para as demais heurísticas não são apresentados pelos motivos apresentados anteriormente. 
Tabela 5.21. Influência do procedimento (P4) na obtençã̃o de soluçø̃es factíveis em HT1.

\begin{tabular}{|c|c|c|c|c|c|c|c|}
\hline \multicolumn{2}{|c|}{ Estruturas } & \multicolumn{3}{c|}{ Seriais } & \multicolumn{3}{c|}{ Gerais } \\
\cline { 3 - 8 } & & $\mathbf{1 0}$ & $\mathbf{1 7}$ & $\mathbf{4 0}$ & $\mathbf{1 0}$ & $\mathbf{1 7}$ & $\mathbf{4 0}$ \\
\hline Custo baixo & HTl-Sem P4 & 95.6 & $\mathbf{1 0 0}$ & 96.7 & $\mathbf{8 1 . 1}$ & $\mathbf{9 8 . 9}$ & $\mathbf{7 2 . 2}$ \\
de preparação & HT1-Com P4 & $\mathbf{9 6 . 8}$ & 100 & $\mathbf{9 7 . 8}$ & $\mathbf{8 1 . 1}$ & $\mathbf{1 0 0}$ & $\mathbf{7 5 . 6}$ \\
\hline Custo alto de & HTl-Sem P4 & 92.2 & 100 & 83.3 & 74.4 & 97.8 & 32.2 \\
preparaçāo & HTl-Com P4 & $\mathbf{9 6 . 7}$ & 100 & $\mathbf{9 3 . 3}$ & $\mathbf{8 0 . 0}$ & $\mathbf{1 0 0}$ & $\mathbf{5 1 . 1}$ \\
\hline
\end{tabular}

A tabela seguinte ilustra a influência do procedimento de alteração (P4) na determinação de soluções factiveis da heurística HT2.

Tabela 5.22. Influência do procedimento (P4) na obtenção de soluçōes factíveis em HT2.

\begin{tabular}{|c|c|c|c|c|c|c|c|}
\hline \multirow{2}{*}{$\begin{array}{c}\text { Estruturas } \\
\text { de produtos }\end{array}$} & \multicolumn{3}{c|}{ Seriais } & \multicolumn{3}{c|}{ Gerais } \\
\cline { 2 - 8 } & $\mathbf{1 0}$ & $\mathbf{1 7}$ & $\mathbf{4 0}$ & $\mathbf{1 0}$ & 17 & $\mathbf{4 0}$ \\
\hline Custo baixo & HT2-Sem P4 & 94.4 & $\mathbf{1 0 0}$ & $\mathbf{9 7 . 8}$ & 78.9 & 100 & $\mathbf{7 5 . 6}$ \\
de preparação & HT2-Com P4 & $\mathbf{9 5 . 6}$ & $\mathbf{1 0 0}$ & $\mathbf{9 7 . 8}$ & $\mathbf{8 2 . 2}$ & 100 & 75.6 \\
\hline Custo alto de & HT2-Sem P4 & 94.4 & $\mathbf{9 8 . 9}$ & 96.7 & 78.9 & 100 & 57.8 \\
preparação & HT2-Com P4 & 96.7 & $\mathbf{9 8 . 9}$ & $\mathbf{9 6 . 7}$ & $\mathbf{8 0 . 0}$ & 100 & 65.6 \\
\hline
\end{tabular}

Os resultados apresentados nas tabelas 5.21 e 5.22 mostram que o procedimento $\mathrm{P} 4$ é relevante para as duas heurísticas, sendo que, a heurística HT1 é mais dependente deste procedimento do que a heurística HT2. Observe os exemplos com 40 itens, estrutura geral e custo alto de preparação, a heurística HT1 apresentou perda de $37 \%$ no número de soluções factíveis, ou seja, com P4 obteve 51.1\%, enquanto que, sem P4 obteve $32.2 \%$ de soluções factiveis. A heurística HT2 foi menos sensivel a retirada deste procedimento, no entanto, apresentou uma perda de $11.9 \%$ no número de soluções factíveis obtidas para este mesmo grupo de exemplo, (veja Tabela 5.22).

\section{- Utilização do CPLEX 4.0 para Verificação das Soluções Heurísticas}

O problema de otimização linear obtido com a fixação das variáveis inteiras fornecidas pelas heurísticas HT1, HT2 foi resolvido utilizando o software CPLEX 4.0. O software CPLEX foi utilizado para verificar a possibilidade de obter uma solução de melhor qualidade, caso as heurísticas tenham obtido uma solução factível, ou para tentar obter uma solução factivel, no caso em que a solução obtida é infactivel. Os números de soluções factíveis obtidas pelas heurísticas HT1 e HT2 e pelo CPLEX 4.0 estão nas tabelas 5.23 e 5.24, nas quais, os resultados foram agrupados por máquinas e períodos. 
Tabela 5.23. Porcentagem de soluçð̃es factiveis obtidas pela heuristica HT1 e pelo CPLEX 4.0.

\begin{tabular}{|c|c|c|c|c|c|c|c|}
\hline \multicolumn{2}{|c|}{ Estruturas } & \multicolumn{3}{c|}{ Seriais } & \multicolumn{3}{c|}{ Gerais } \\
\cline { 3 - 8 } & & $\mathbf{1 0}$ & 17 & 40 & 10 & 17 & $\mathbf{4 0}$ \\
\hline Custo baixo & CPLEX 4.0 & 96.7 & 100 & 97.8 & $\mathbf{8 1 . 1}$ & $\mathbf{1 0 0}$ & $\mathbf{7 5 . 6}$ \\
de preparação & HT1 & 96.7 & 100 & 97.8 & $\mathbf{8 1 . 1}$ & 100 & $\mathbf{7 5 . 6}$ \\
\hline Custo alto de & CPLEX 4.0 & 96.7 & 100 & 94.4 & $\mathbf{8 4 . 4}$ & 100 & 54.4 \\
preparação & HT1 & 96.7 & 100 & 93.3 & 80.0 & 100 & 51.1 \\
\hline
\end{tabular}

Pode-se observar na Tabela 5.23 que o CPLEX 4.0, resolvendo o problema de otimização linear utilizando-se os valores das variáveis de preparação determinados pela heurística HTl, determinou uma porcentagem maior de soluções factíveis para alguns exemplos com custo alto de preparação, por exemplo, para os exemplos com custo alto de preparação e estrutura geral com 10 itens, a heurística $\mathrm{HTl}$ obteve $80 \%$ de soluções factíveis, enquanto que o CPLEX 4.0 determinou $84.4 \%$ de soluções factiveis, o que leva a conclusão de que, o desempenho da heurística HT1, na obtenção de soluções factiveis, para os exemplos com custo alto de preparação pode ser melhorado.

Tabela 5.24. Porcentagem de soluções factíveis obtidas pela heuristica HT2 e pelo CPLEX 4.0.

\begin{tabular}{|c|c|c|c|c|c|c|c|}
\hline \multicolumn{2}{|c|}{ Estruturas } & \multicolumn{3}{c|}{ Seriais } & \multicolumn{3}{c|}{ Gerais } \\
\cline { 3 - 8 } \multicolumn{2}{|c|}{} & $\mathbf{1 0}$ & $\mathbf{1 7}$ & $\mathbf{4 0}$ & $\mathbf{1 0}$ & $\mathbf{1 7}$ & $\mathbf{4 0}$ \\
\hline Custo baixo & CPLEX 4.0 & 95.6 & 100 & 97.8 & $\mathbf{8 2 . 2}$ & 100 & $\mathbf{7 5 . 6}$ \\
de preparação & HT2 & 95.6 & 100 & 97.8 & 82.2 & 100 & 75.6 \\
\hline Custo alto de & CPLEX 4.0 & 96.7 & 98.9 & 96.7 & 80.0 & 100 & $\mathbf{6 6 . 7}$ \\
preparação & HT2 & 96.7 & 98.9 & 96.7 & 80.0 & 100 & 65.6 \\
\hline
\end{tabular}

Para os exemplos com custo alto de preparação e estrutura geral de produtos, o CPLEX4.0 apresentou uma pequena porcentagem a mais de soluções factíveis do que a heuristica HT2, como mostrado na Tabela 5.24. Para os demais exemplos, o CPLEX 4.0 não aumentou o percentual de soluções factíveis obtidas pela heuristica HT2.

Os resultados obtidos pelas heurísticas $\mathrm{HO}$ e $\mathrm{HO} 2$ não foram utilizados para execução do CPLEX 4.0 por não apresentarem um bom desempenho na determinação de soluções factíveis, principalmente para os exemplos com custo alto de preparação.

Os estudos que serão apresentados daqui para frente, sobre a porcentagem de soluções factíveis são relacionados somente com as heurísticas HT1 e HT2, pelo mesmo motivo citado acima, ou seja, por estas apresentarem bom desempenho na determinação de soluções factiveis. 


\section{- Avaliação do Desempenho das Heurísticas na Obtenção de Soluções}

Factíveis com Ajustes da Capacidade.

Foi feito também um estudo para verificar o desempenho das heurísticas HT1 e HT2 na obtenção de soluções factíveis, quando se mudavam os valores das capacidades geradas. Para todos os grupos de exemplos, foram consideradas três variações nos valores das capacidades geradas. Primeiramente, as capacidades foram reduzidas em $5 \%$ (redução em $\mathrm{CAP}_{\mathrm{lk}}$ de $5 \%$ ), obtendo exemplos que foram considerados "apertados" em relação a capacidade normal, em seguida, as capacidades foram aumentadas em $5 \%$ (aumento em $\mathrm{CAP}_{\mathrm{tk}}$ de $5 \%$ ), obtendo exemplos que foram considerados "folgados".

Os resultados em relação ao número de soluções factíveis obtidas pela heurística HT1 estão ilustrados nas tabelas 5.25 e 5.26, onde foi utilizada 0.95 cap para representar os exemplos com capacidade apertada, 1.0 cap para os exemplos cujos resultados foram reportados anteriormente e, 1.05 cap, que representa os exemplos folgados.

Nota-se na Tabela 5.25, que o desempenho da heurística HTl na obtenção de soluções factíveis é mais afetado para os exemplos com 40 itens. Para os exemplos com 40 itens e custo baixo de preparação, a heurística HT1 obteve $97.8 \%$ de soluções factíveis considerando a capacidade normal, mas quando a capacidade foi reduzida de $5 \%$, a porcentagem de soluções factíveis caiu para $68.9 \%$, uma redução de $29.6 \%$ no número de soluções factíveis, e, obteve $100 \%$ de soluções factíveis quando considerou a capacidade folgada. Já para os exemplos com 40 itens e custo alto de preparação, a heurística HTI obteve $58.9 \%$ de soluções factiveis para os exemplos com capacidade apertada, $93.3 \%$ para os exemplos com capacidade normal e $91.1 \%$ para os exemplos folgados. Pode-se notar ainda que o desempenho da heurística na obtenção de soluções factíveis é dependente da capacidade gerada, pois se nota que uma redução de $5 \%$ na capacidade influenciou muito no número de soluções factíveis obtidas. 
Tabeia 5.25. FAC para os exemplos com capacidades apertada, normal e folgada e estruturas seriais (heuristica HTI).

\begin{tabular}{|c|c|c|c|c|c|c|}
\hline FAC & \multicolumn{3}{|c|}{ Custo baixo de preparação } & \multicolumn{3}{|c|}{ Custo alto de preparação } \\
\hline N-T-K & 0.95 cap & 1.0 cap & 1.05 cap & 0.95 cap & 1.0 cap & 1.05 cap \\
\hline $10-6-2$ & 60.0 & 100.0 & 100.0 & 60.0 & 100.0 & 100.0 \\
\hline $10-6-3$ & 70.0 & 100.0 & 100.0 & 70.0 & 100.0 & 100.0 \\
\hline $10-6-4$ & 90.0 & 100.0 & 100.0 & 90.0 & 100.0 & 100.0 \\
\hline $10-12-2$ & 50.0 & 90.0 & 100.0 & 40.0 & 80.0 & 100.0 \\
\hline $10-12-3$ & 80.0 & 100.0 & 100.0 & 80.0 & 100,0 & 100.0 \\
\hline $10-12-4$ & 80.0 & 90.0 & 100.0 & 80.0 & 100.0 & 100.0 \\
\hline $10-18-2$ & 40.0 & 90.0 & 100.0 & 50.0 & 90.0 & 100.0 \\
\hline $10-18-3$ & 70.0 & 100.0 & 100.0 & 70.0 & 100.0 & 100.0 \\
\hline $10-18-4$ & 90.0 & 100.0 & 100.0 & 90.0 & 100.0 & 100.0 \\
\hline Média & 70.0 & 96.7 & 100.0 & 70.0 & 96.7 & 100.0 \\
\hline $17-6-2$ & 40.0 & 100.0 & 100.0 & 30.0 & 100.0 & 100.0 \\
\hline $17-6-3$ & 100.0 & 100.0 & 100,0 & 100.0 & 100.0 & 100.0 \\
\hline $17-6-4$ & 90.0 & 100.0 & 100.0 & 90.0 & 100.0 & 100.0 \\
\hline $17-12-2$ & 50.0 & 100.0 & 100.0 & 60.0 & 100.0 & 100.0 \\
\hline $17-12-3$ & 100.0 & 100.0 & 100.0 & 100.0 & 100.0 & 100.0 \\
\hline $17-12-4$ & 100.0 & 100.0 & 100.0 & 70.0 & 100.0 & 100.0 \\
\hline $17-18-2$ & 60.0 & 100.0 & 100.0 & 60.0 & 100.0 & 100.0 \\
\hline $17-18-3$ & 90.0 & 100.0 & 100.0 & 90.0 & 100.0 & 100.0 \\
\hline $17-18-4$ & 90.0 & 100.0 & 100.0 & 100.0 & 100.0 & 100.0 \\
\hline Média & 80.0 & 100.0 & 100.0 & 77.8 & 100.0 & 100.0 \\
\hline $40-6-2$ & 30.0 & 100.0 & 100.0 & 40.0 & 100.0 & 100.0 \\
\hline $40-6-3$ & 90.0 & 100.0 & 100.0 & 80.0 & 90.0 & 90.0 \\
\hline $40-6-4$ & 90.0 & 100.0 & 100.0 & 80.0 & 90.0 & 80.0 \\
\hline $40-12-2$ & 30.0 & 80.0 & 100.0 & 40.0 & 90.0 & 100.0 \\
\hline $40-12-3$ & 70.0 & 100.0 & 100.0 & 70.0 & 100.0 & 90.0 \\
\hline $40-12-4$ & 70.0 & 100.0 & 100.0 & 50.0 & 90.0 & 90.0 \\
\hline $40-18-2$ & 40.0 & 100.0 & 100.0 & 40.0 & 90.0 & 100.0 \\
\hline $40-18-3$ & 100.0 & 100.0 & 100.0 & 80.0 & 90.0 & 90.0 \\
\hline $40-18-4$ & 100.0 & 100.0 & 100.0 & 50.0 & 100.0 & 80.0 \\
\hline Média & 68.9 & 97.8 & 100.0 & 58.9 & 93.3 & 91.1 \\
\hline Média Total & 73.0 & 98.1 & 100.0 & 68.9 & 96.7 & 97.0 \\
\hline
\end{tabular}


Tabela 5.26. FAC para os exemplos com capacidades apertada, normal e folgada e estruturas gerais (heuristica

\begin{tabular}{|c|c|c|c|c|c|c|}
\hline \multirow{2}{*}{$\begin{array}{l}\text { FAC } \\
\text { N-T-K }\end{array}$} & \multicolumn{3}{|c|}{ Custo baixo de preparaç̧̄o } & \multicolumn{3}{|c|}{ Custo alto de preparaçăo } \\
\hline & 0.95 cap & 1.0 cap & 1.05 cap & 0.95 cap & 1.0 cap & 1.05 cap \\
\hline $10-6-2$ & 30.0 & 70.0 & 100.0 & 20.0 & 70.0 & 100.0 \\
\hline $10-6-3$ & 40.0 & 100.0 & 100.0 & 40.0 & 90.0 & 100.0 \\
\hline $10-6-4$ & 90.0 & 100.0 & 100.0 & 100.0 & 100.0 & 100.0 \\
\hline $10-12-2$ & 30.0 & 60.0 & 80.0 & 30.0 & 70.0 & 80.0 \\
\hline $10-12-3$ & 60.0 & 70.0 & 100.0 & 70.0 & 80.0 & 100.0 \\
\hline $10-12-4$ & 70.0 & 80.0 & 100.0 & 70.0 & 80.0 & 100.0 \\
\hline $10-18-2$ & 50.0 & 60.0 & 70.0 & 40.0 & 50.0 & 70.0 \\
\hline $10-18-3$ & 50.0 & 90.0 & 100.0 & 60.0 & 100.0 & 100.0 \\
\hline $10-18-4$ & 70.0 & 100.0 & 100.0 & 80.0 & 80.0 & 100.0 \\
\hline Média & 54.4 & 81.1 & 94.4 & 56.7 & 80.0 & 94.4 \\
\hline $17-6-2$ & 50.0 & 100.0 & 100.0 & 50.0 & 100.0 & 100.0 \\
\hline $17-6-3$ & 100.0 & 100.0 & 100.0 & 40.0 & 100.0 & 100.0 \\
\hline $17-6-4$ & 100.0 & 100.0 & 100.0 & 90.0 & 100.0 & 100.0 \\
\hline $17-12-2$ & 100.0 & 100.0 & 100.0 & 100.0 & 100.0 & 100.0 \\
\hline $17-12-3$ & 90.0 & 100.0 & 100.0 & 70.0 & 100.0 & 100.0 \\
\hline $17-12-4$ & 90.0 & 100.0 & 100.0 & 100.0 & 100.0 & 100.0 \\
\hline $17-18-2$ & 90.0 & 100.0 & 100.0 & 80.0 & 100.0 & 100.0 \\
\hline $17-18-3$ & 100.0 & 100.0 & 100.0 & 60.0 & 100.0 & 100.0 \\
\hline $17-18-4$ & 90.0 & 100.0 & 100.0 & 90.0 & 100.0 & 100.0 \\
\hline Média & 90.0 & 100.0 & 100.0 & 75.6 & 100.0 & 100.0 \\
\hline $40-6-2$ & 30.0 & 40.0 & 100.0 & 10.0 & 40.0 & 80.0 \\
\hline $40-6-3$ & 40.0 & 100.0 & 100.0 & 10.0 & 70.0 & 100.0 \\
\hline $40-6-4$ & 50.0 & 100.0 & 1000 & 10.0 & 70.0 & 80.0 \\
\hline $40-12-2$ & 30.0 & 60.0 & 70.0 & 20.0 & 30.0 & 60.0 \\
\hline $40-12-3$ & 50.0 & 80.0 & 100.0 & 10.0 & 50.0 & 80.0 \\
\hline $40-12-4$ & 60.0 & 80.0 & 100.0 & 20.0 & 50.0 & 70.0 \\
\hline $40-18-2$ & 40.0 & 60.0 & 70.0 & 10.0 & 40.0 & 70.0 \\
\hline $40-18-3$ & 50.0 & 80.0 & 100.0 & 20.0 & 40.0 & 70.0 \\
\hline $40-18-4$ & 60.0 & 80.0 & 100.0 & 20.0 & 70.0 & 80.0 \\
\hline Média & 45.6 & $\overline{75.6}$ & 93.3 & 14.4 & 51.1 & 76.7 \\
\hline Média Total & 63.3 & 85.6 & 95.9 & 48.9 & 77.0 & 90.4 \\
\hline
\end{tabular}

Na Tabela 5.26, pode-se mais uma vez comprovar que o desempenho da heurística, na obtenção de soluções factíveis, é dependente de como as capacidades são ajustadas. Note que, com a redução de $5 \%$ da capacidade, a porcentagem de soluções factíveis caiu em até $71.8 \%$, como aconteceu para os exemplos com custo alto de preparação e 40 itens, pois a heurística HT1, para os exemplos com 1.0 cap, obteve $51.1 \%$ de soluções factíveis e $14.4 \%$ para 0.95 cap. Já com o aumento de $5 \%$ na capacidade gerada, a porcentagem de soluções factíveis 
aumentou em $50.1 \%$, para estes mesmos exemplos, pois a heurística HT1 obteve $76.7 \%$ de soluções factíveis para 1.05 cap.

Os resultados em relação ao número de soluções factíveis obtidas pela heurística HT2 estão ilustrados nas tabelas 5.27 e 5.28 .

Tabela 5.27. FAC para os exemplos com capacidades apertada, nomal e folgada e estruturas seriais (heuristica HT2).

\begin{tabular}{|c|c|c|c|c|c|c|}
\hline FAC & \multicolumn{2}{|c|}{ Custo balxo de preparaç̃o } & \multicolumn{3}{c|}{ Custo alto de preparaçăo } \\
\hline N-T-K & $\mathbf{0 . 9 5}$ cap & 1.0 cap & 1.05 cap & $\mathbf{0 . 9 5}$ cap & 1.0 cap & 1.05 cap \\
\hline $10-6-2$ & 70.0 & 100.0 & 100.0 & 50.0 & 100.0 & 100.0 \\
$10-6-3$ & 70.0 & 100.0 & 100.0 & 60.0 & 100.0 & 100.0 \\
$10-6-4$ & 100.0 & 100.0 & 100.0 & 80.0 & 100.0 & 100.0 \\
$10-12-2$ & 50.0 & 80.0 & 100.0 & 40.0 & 90.0 & 100.0 \\
$10-12-3$ & 90.0 & 100.0 & 100.0 & 90.0 & 100.0 & 100.0 \\
$10-12-4$ & 90.0 & 100.0 & 100.0 & 70.0 & 100.0 & 100.0 \\
$10-18-2$ & 40.0 & 90.0 & 100.0 & 50.0 & 90.0 & 100.0 \\
$10-18-3$ & 80.0 & 100.0 & 100.0 & 60.0 & 100.0 & 100.0 \\
$10-18-4$ & 90.0 & 90.0 & 100.0 & 100.0 & 90.0 & 100.0 \\
\hline Média & 75.6 & 95.6 & 100.0 & 66.7 & 96.7 & 100.0 \\
\hline $17-6-2$ & 50.0 & 100.0 & 100.0 & 40.0 & 100.0 & 100.0 \\
$17-6-3$ & 100.0 & 100.0 & 100.0 & 80.0 & 100.0 & 100.0 \\
$17-6-4$ & 90.0 & 100.0 & 100.0 & 90.0 & 100.0 & 100.0 \\
$17-12-2$ & 60.0 & 100.0 & 100.0 & 60.0 & 90.0 & 100.0 \\
$17-12-3$ & 100.0 & 100.0 & 100.0 & 100.0 & 100.0 & 100.0 \\
$17-12-4$ & 90.0 & 100.0 & 100.0 & 90.0 & 100.0 & 100.0 \\
$17-18-2$ & 70.0 & 100.0 & 100.0 & 70.0 & 100.0 & 100.0 \\
$17-18-3$ & 90.0 & 100.0 & 100.0 & 90.0 & 100.0 & 100.0 \\
$17-18-4$ & 100.0 & 100.0 & 100.0 & 100.0 & 100.0 & 100.0 \\
\hline Média & 83.3 & 100.0 & 100.0 & 80.0 & 98.9 & 100.0 \\
\hline $40-6-2$ & 30.0 & 100.0 & 100.0 & 30.0 & 100.0 & 100.0 \\
$40-6-3$ & 90.0 & 100.0 & 100.0 & 90.0 & 100.0 & 100.0 \\
$40-6-4$ & 100.0 & 100.0 & 100.0 & 100.0 & 100.0 & 100.0 \\
$40-12-2$ & 30.0 & 80.0 & 100.0 & 30.0 & 80.0 & 100.0 \\
$40-12-3$ & 60.0 & 100.0 & 100.0 & 70.0 & 100.0 & 100.0 \\
$40-12-4$ & 90.0 & 100.0 & 100.0 & 70.0 & 100.0 & 100.0 \\
$40-18-2$ & 50.0 & 100.0 & 100.0 & 40.0 & 90.0 & 100.0 \\
$40-18-3$ & 100.0 & 100.0 & 100.0 & 80.0 & 100.0 & 100.0 \\
$40-18-4$ & 90.0 & 100.0 & 100.0 & 100.0 & 100.0 & 100.0 \\
\hline Média & 71.1 & 97.8 & 100.0 & 67.8 & 96.7 & 100.0 \\
\hline Média Total & 76.7 & 97.8 & 100.0 & 71.5 & 97.4 & 100.0 \\
\hline & & & & & & \\
\hline
\end{tabular}

Considerando os exemplos com 40 itens e custo baixo de preparação, observa-se que a heurística HT2 obteve $97.8 \%$ de soluções factíveis para os exemplos com capacidade normal, e com a redução da capacidade de $5 \%$, a porcentagem de soluções factíveis caiu para $71.1 \%$, uma redução de $27.3 \%$ no número de soluções factíveis, um valor inferior ao apresentado pela heurística HTl (veja Tabela 5.25). 
Tabela 5.28. FAC para os exemplos com capacidades apertada, normal e folgada e estruturas gerais (heuristica HT2).

\begin{tabular}{|c|c|c|c|c|c|c|}
\hline FAC & \multicolumn{2}{|c|}{ Custo baixo de preparaç\$o } & \multicolumn{3}{c|}{ Custo alto de preparaçso } \\
\hline N-T-K & 0.95 cap & 1.0 cap & 1.05 cap & $\mathbf{0 . 9 5}$ cap & 1.0 cap & 1.05 cap \\
\hline $10-6-2$ & 30.0 & 70.0 & 100.0 & 20.0 & 60.0 & 100.0 \\
$10-6-3$ & 40.0 & 100.0 & 100.0 & 40.0 & 100.0 & 100.0 \\
$10-6-4$ & 90.0 & 100.0 & 100.0 & 100.0 & 100.0 & 100.0 \\
$10-12-2$ & 30.0 & 70.0 & 80.0 & 30.0 & 60.0 & 80.0 \\
$10-12-3$ & 70.0 & 70.0 & 100.0 & 70.0 & 70.0 & 100.0 \\
$10-12-4$ & 70.0 & 90.0 & 100.0 & 60.0 & 80.0 & 100.0 \\
$10-18-2$ & 50.0 & 60.0 & 80.0 & 50.0 & 60.0 & 80.0 \\
$10-18-3$ & 50.0 & 100.0 & 100.0 & 60.0 & 100.0 & 100.0 \\
$10-18-4$ & 90.0 & 80.0 & 100.0 & 80.0 & 90.0 & 100.0 \\
\hline Média & $\mathbf{5 7 . 8}$ & $\mathbf{8 2 . 2}$ & 95.6 & $\mathbf{5 6 . 7}$ & $\mathbf{8 0 . 0}$ & 95.6 \\
\hline $17-6-2$ & 50.0 & 100.0 & 100.0 & 50.0 & 100.0 & 100.0 \\
$17-6-3$ & 100.0 & 100.0 & 100.0 & 100.0 & 100.0 & 100.0 \\
$17-6-4$ & 90.0 & 100.0 & 100.0 & 100.0 & 100.0 & 100.0 \\
$17-12-2$ & 100.0 & 100.0 & 100.0 & 100.0 & 100.0 & 100.0 \\
$17-12-3$ & 100.0 & 100.0 & 100.0 & 100.0 & 100.0 & 100.0 \\
$17-12-4$ & 100.0 & 100.0 & 100.0 & 90.0 & 100.0 & 100.0 \\
$17-18-2$ & 90.0 & 100.0 & 100.0 & 90.0 & 100.0 & 100.0 \\
$17-18-3$ & 100.0 & 100.0 & 100.0 & 100.0 & 100.0 & 100.0 \\
$17-18-4$ & 100.0 & 100.0 & 100.0 & 100.0 & 100.0 & 100.0 \\
\hline Média & 92.2 & 100.0 & 100.0 & 92.2 & 100.0 & 100.0 \\
\hline $40-6-2$ & 30.0 & 40.0 & 100.0 & 10.0 & 20.0 & 80.0 \\
$40-6-3$ & 30.0 & 100.0 & 100.0 & 30.0 & 90.0 & 100.0 \\
$40-6-4$ & 60.0 & 100.0 & 100.0 & 60.0 & 90.0 & 100.0 \\
$40-12-2$ & 30.0 & 60.0 & 70.0 & 10.0 & 40.0 & 70.0 \\
$40-12-3$ & 60.0 & 80.0 & 100.0 & 50.0 & 80.0 & 100.0 \\
$40-12-4$ & 70.0 & 80.0 & 100.0 & 40.0 & 80.0 & 90.0 \\
$40-18-2$ & 30.0 & 60.0 & 70.0 & 20.0 & 60.0 & 70.0 \\
$40-18-3$ & 50.0 & 80.0 & 100.0 & 30.0 & 60.0 & 100.0 \\
$40-18-4$ & 60.0 & 80.0 & 100.0 & 60.0 & 70.0 & 100.0 \\
\hline Média & $\mathbf{4 6 . 7}$ & $\mathbf{7 5 . 6}$ & 93.3 & 34.4 & 65.6 & 90.0 \\
\hline Média Tota1 & 65.6 & $\mathbf{8 5 . 9}$ & 96.3 & 61.1 & 81.9 & 95.2 \\
\hline & & & & & & \\
\hline
\end{tabular}

Com o objetivo de verificar qual das heurísticas é mais sensível ao ajuste das capacidades, apresenta-se na tabela seguinte, um resumo com os valores médios das porcentagens de soluções factíveis obtidas para os exemplos agrupados por períodos, itens e máquinas. Apresenta-se também nesta tabela, o decréscimo da porcentagem de soluções factiveis obtidas quando é feito 0 aperto de $5 \%$ das capacidades, e o acréscimo desta porcentagem quando se aumenta em $5 \%$ a capacidade. 
Tabela 5.29. Porcentagem de soluçőes factiveis obtidas pelas heuristicas HT1 e HT2.

\begin{tabular}{|c|c|c|c|c|c|c|c|c|c|c|c|}
\hline \multicolumn{2}{|c|}{ Estruturas } & \multicolumn{5}{|c|}{ Custo Baixo de preparaçåo } & \multicolumn{5}{|c|}{ Custo alto de preparaçăo } \\
\hline & & 0.95 cap & decréscimo & 1.0 cap & $\longdiv { \text { acréscimo } }$ & $1.05 \mathrm{cap}$ & 0.95 cap & decréscimo & 1.0 cap & acréscimo & 1.05 cap \\
\hline \multirow{2}{*}{ Seriais } & HTl & 73.0 & $25.6 \%$ & 98.1 & $1.9 \%$ & 100.0 & 68,9 & $28.8 \%$ & 96.7 & $0.3 \%$ & 97.0 \\
\hline & HT2 & 76.7 & $21.6 \%$ & 97.8 & $2.2 \%$ & 100.0 & 71.5 & $26.6 \%$ & 97.4 & $2.6 \%$ & 100.0 \\
\hline \multirow{2}{*}{ Gerais } & $\mathrm{HT} 1$ & 63.3 & $26.1 \%$ & 85.6 & $10.7 \%$ & 95.9 & 48.9 & $36.5 \%$ & 77.0 & $14.8 \%$ & 90.4 \\
\hline & HT2 & 60.0 & $25.0 \%$ & 80.0 & $20.0 \%$ & 100.0 & 60.0 & $14.3 \%$ & 70.0 & $30.0 \%$ & 100.0 \\
\hline
\end{tabular}

Pela tabela acima, pode-se notar que o desempenho da heurística HT1 em obter soluções factíveis é mais sensível ao da heurística HT2, quando as capacidades são mais justas. Note que, para os exemplos com estruturas gerais, custo alto de preparação, a heurística HTI apresentou um decréscimo de $36.5 \%$ no número de soluções obtidas, enquanto que a heurística HT2 apresentou $14.3 \%$ de decréscimo. Com o aumento da capacidade, a heurística HT2 obteve maiores acréscimos, em média, na porcentagem de soluções factíveis obtidas para os exemplos.

\section{- Conclusões}

Nesta seção foram apresentados resultados com relação ao número de soluções obtidas por quatro versões da heurística para resolução do problema de dimensionamento de lotes com máquinas paralelas descrito no Capítulo 3. Das quatro heurísticas consideradas, duas apresentaram nitidamente desempenho superior às demais, para as quais resultados foram apresentados para verificação da eficiência de alguns procedimentos na obtenção de soluções factiveis. Assim, para os exemplos gerados pode-se tirar as seguintes conclusões:

- A heurística HT2 tem melhor desempenho na obtenção de soluções factiveis.

- Os procedimentos cria_transferência e de alteração têm maior influência na heurística HTl.

- O número médio de iterações para obtenção de soluções factíveis é menor para a heurística HT2.

- Os tempos computacionais (apresentados na Seção 5.5.4) médios, gastos para resolução dos exemplos pela heurística HT2 são inferiores aos gastos pela heurística HT1.

Pelas observações acima, a heurística HT2 é a mais indicada para resolução do problema de dimensionamento de lotes, quando a medida de desempenho considerada é o número de soluções factiveis obtidas.

Na seção seguinte, as soluções obtidas pelas heurísticas HTI e HT2 são analisadas em relação ao consumo da capacidade por máquina e período. 


\subsubsection{Análise dos Resultados Relacionados ao Uso da Capacidade Gerada}

Nos gráficos a seguir, são apresentadas as porcentagens médias da utilização da capacidade, por máquina e período, para cada dimensão dos exemplos. São descritas as quantidades de capacidade utilizadas por máquina e período (uso_cap) para a solução inicial obtida pelo algoritmo de WW-Paralelo (denominadas nos gráficos por SIW), e para a solução inicial fornecida pelo algoritmo WW-Paralelo Penalizado (chamado de SIP). Sobre o valor da capacidade média utilizada, é calculada a porcentagem utilizada para as preparações de máquinas (uso_setup). São também comparadas as utilizações das capacidades para as soluções fornecidas pelas heurísticas HT1 (iniciada com SIW) e HT2 (iniciada com SIP).

Apesar da maioria das soluções iniciais serem infactíveis, elas apresentam utilização inferior ao total de capacidade disponivel. No entanto, convém salientar que os valores apresentados são medidas médias considerando todas as máquinas e, como os exemplos considerados têm múltiplas máquinas, nem todas estarão violadas na solução inicial.

Não são apresentados os resultados referentes às soluções das heurísticas $\mathrm{HO} 1$ e HO2, por apresentarem consumos similares aos das heurísticas HT1 e HT2. 
No Gráfico 5.7 são apresentados os consumos médios da capacidade para os exemplos com estruturas gerais e, a porcentagem sobre a capacidade consumida utilizada para as preparações das máquinas. Os exemplos foram agrupados por itens e períodos. As expressões utilizadas para determinar a utilização da capacidade e porcentagens utilizadas para as preparações são dadas por (5.3) e (5.4).

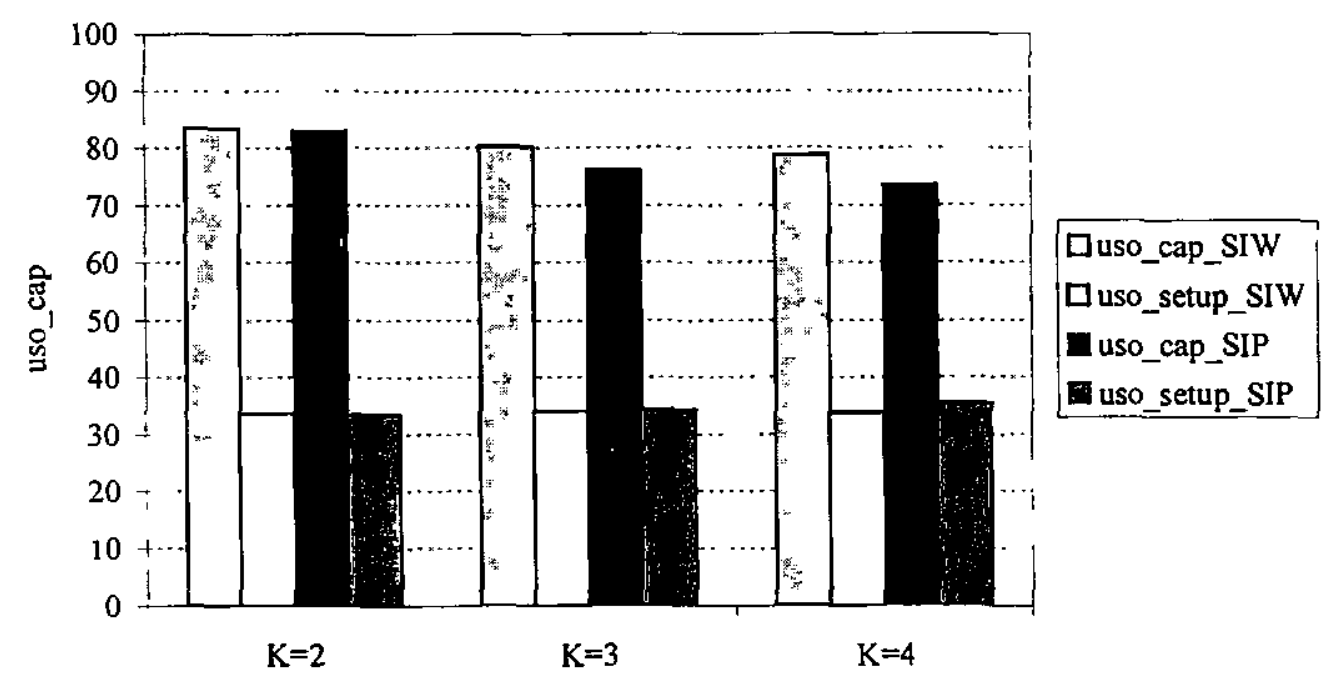

Gráfico 5.7. Consumo de capacidade para os exemplos com estruturas gerais e custo baixo de preparação (soluçðes iniciais)

Observe no Gráfico 5.7, que as soluções iniciais para os exemplos com estruturas gerais e duas máquinas apresentam maiores consumos da capacidade disponível para produções e preparações, e este consumo decresce pouco com o aumento do número de máquinas. Nota-se também que, as soluções iniciais SIW apresentam um consumo médio da capacidade superior ao consumo das soluções SIP. 


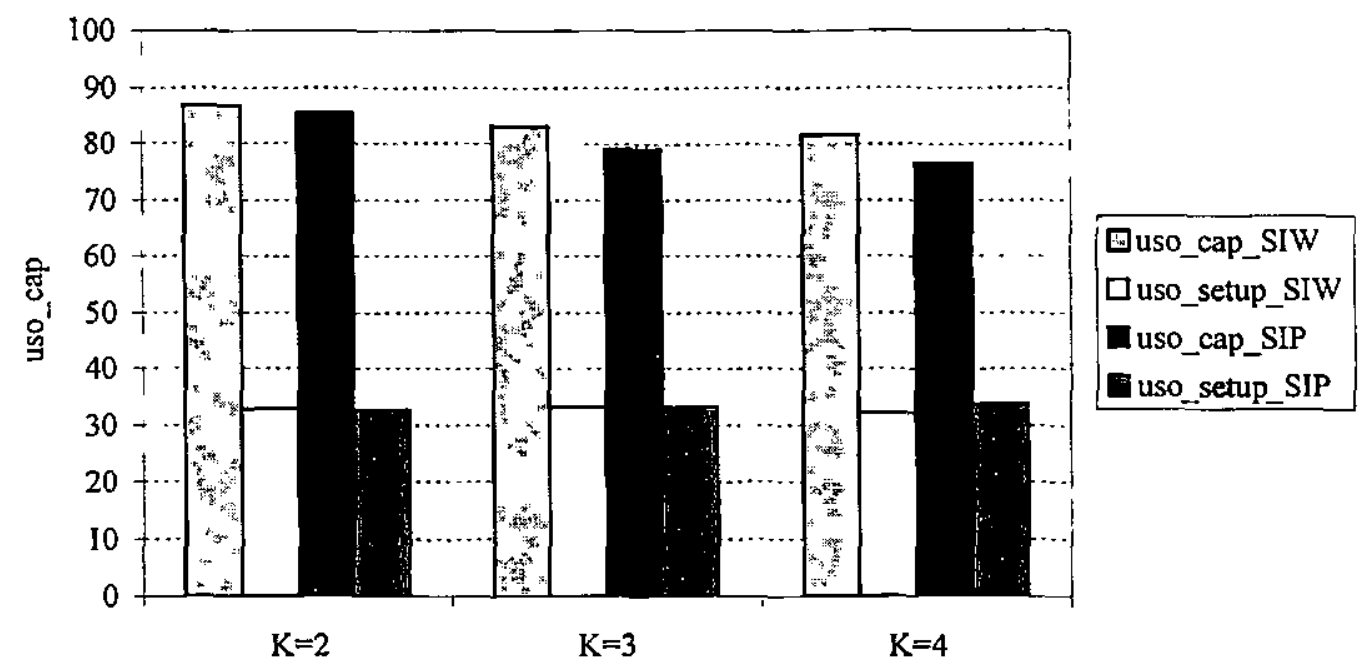

Gráfico 5.8. Consumo da capacidade gerada para os exemplos com estruturas seriais e custo baixo de preparaçăo (soluç̃̄es iniciais)

Pode ser visto no Gráfico 5.8 que para os exemplos com estruturas seriais e custo baixo de preparação, as soluções iniciais SIW e SIP apresentam o mesmo comportamento do Gráfico 5.7.

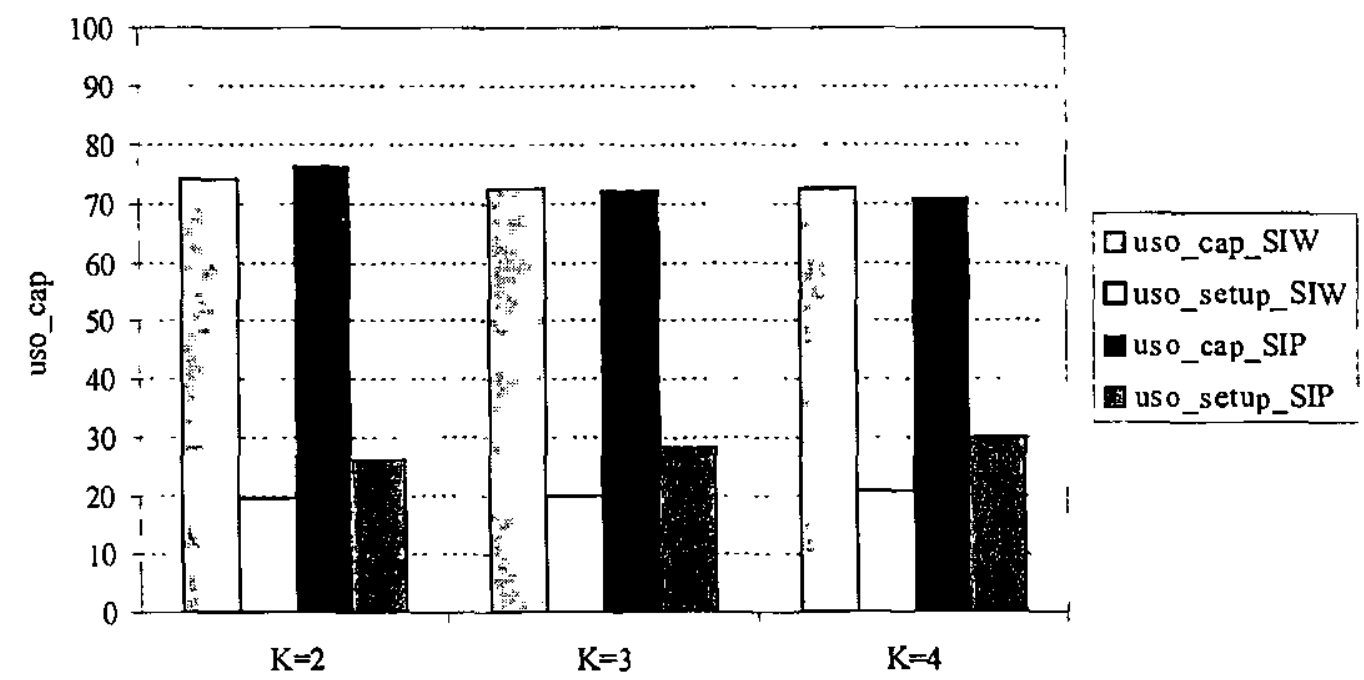

Gráfico 5.9. Consumo da capacidade para os exemplos com estruturas gerais e custo alto de preparação (soluções iniciais).

Observe que as soluções iniciais para os exemplos com custo alto de preparação apresentam uma média de consumo da capacidade inferior aos exemplos com custo baixo de 
preparação, (Gráfico 5.7). Este comportamento se deve ao fato que as soluções iniciais tendem a fazer um número menor de preparações e conseqủentemente, a utilização média de capacidade será menor do que para os exemplos com custo baixo de preparação. Observe também que as soluções iniciais SIW tendem a fazer um número menor de preparações do que as soluções iniciais SIP, como pode ser visto nos gráficos 5.9 e 5.10 , porque o algoritmo SIW não leva nenhuma informação sobre a utilização da capacidade.

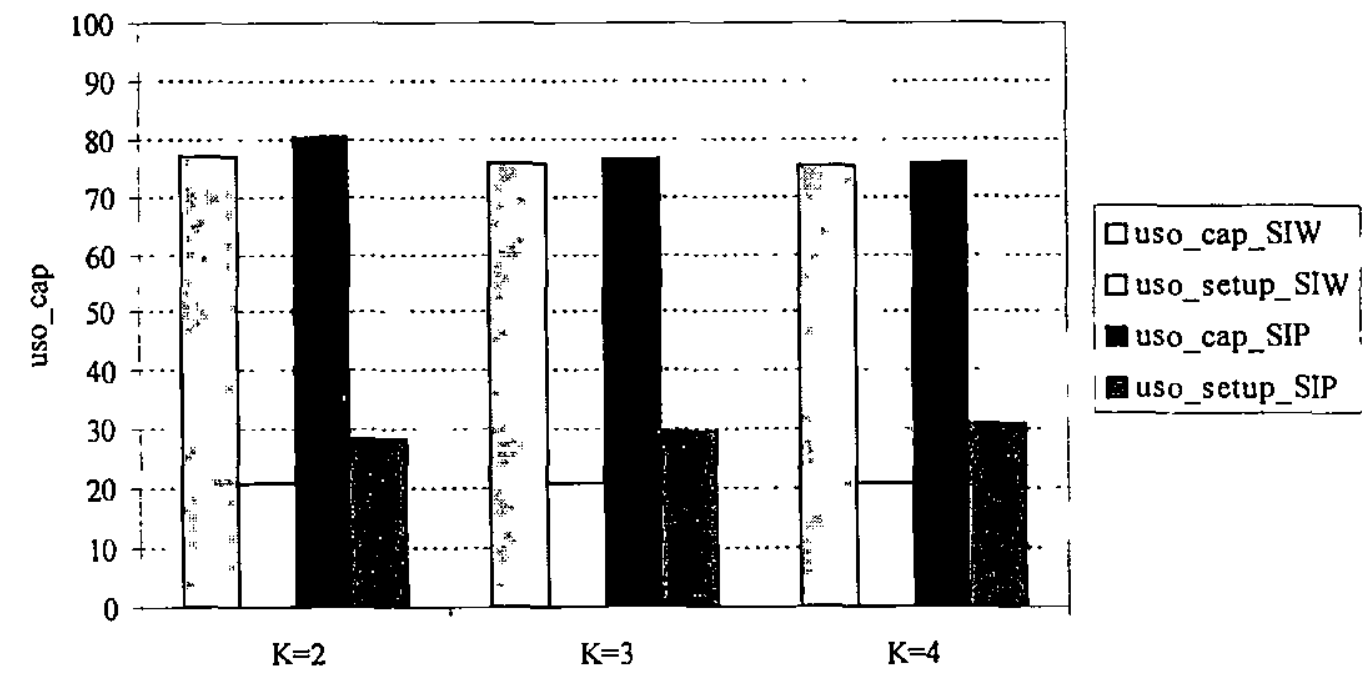

Gráfico 5.10. Consumo da capacidade para os exemplos com estruturas seriais e custo alto de preparação pelas soluçðes iniciais.

A seguir, os gráficos representando os percentuais da utilização da capacidade são apresentados detalhados por itens, períodos e máquinas para as soluções heurísticas HTI e HT2. Estes resultados serão detalhados para ilustrar o consumo da capacidade por itens com o objetivo de tentar explicar, por exemplo, porque as heurísticas para os exemplos com 17 itens e estruturas gerais apresentaram um melhor desempenho na obtenção de soluções factíveis do que para os exemplos com 10 itens e 40 itens. Convém observar aqui que o consumo da capacidade é considerado somente se ambas as heurísticas determinam uma solução factível para o exemplo gerado.

Os percentuais de uso da capacidade obtidos para os exemplos considerando as estruturas gerais e seriais, com custo baixo de preparação, são apresentados nos gráficos 5.11 e 5.13, enquanto que, nos gráficos 5.13 e 5.14 ilustram os percentuais para custo alto de preparação. 


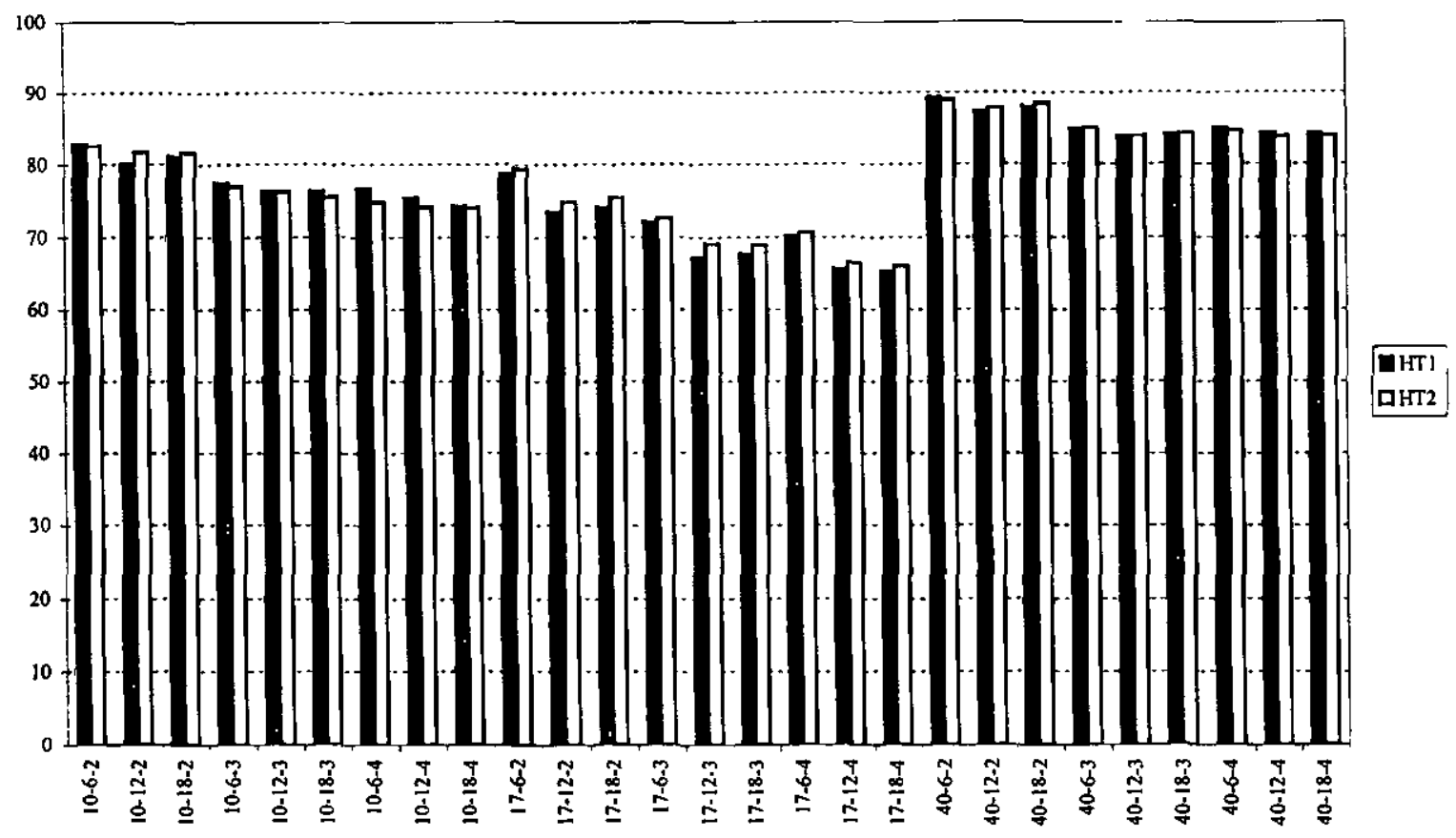

Gráfico 5.11. Consumo da capacidade para os exemplos com estruturas gerais e custo baixo de preparaçăo (heuristicas HT1 e HT2).

Nos gráficos 5.11 e 5.12, pode-se notar que as heurísticas apresentaram um consumo médio da capacidade para os exemplos com custo baixo de preparação similar. Observe também, no Gráfico 5.11 que, para os exemplos com estrutura geral e 17 itens ambas heurísticas apresentaram utilização média da capacidade inferior do que para os exemplos com 10 e 40 itens. 1sto pode sugerir que estes exemplos são mais folgados, e conseqüentemente pode levar a conclusão porque das heurísticas obterem uma porcentagem de maior de soluções factíveis para estes exemplos (veja Tabela 5.15). 


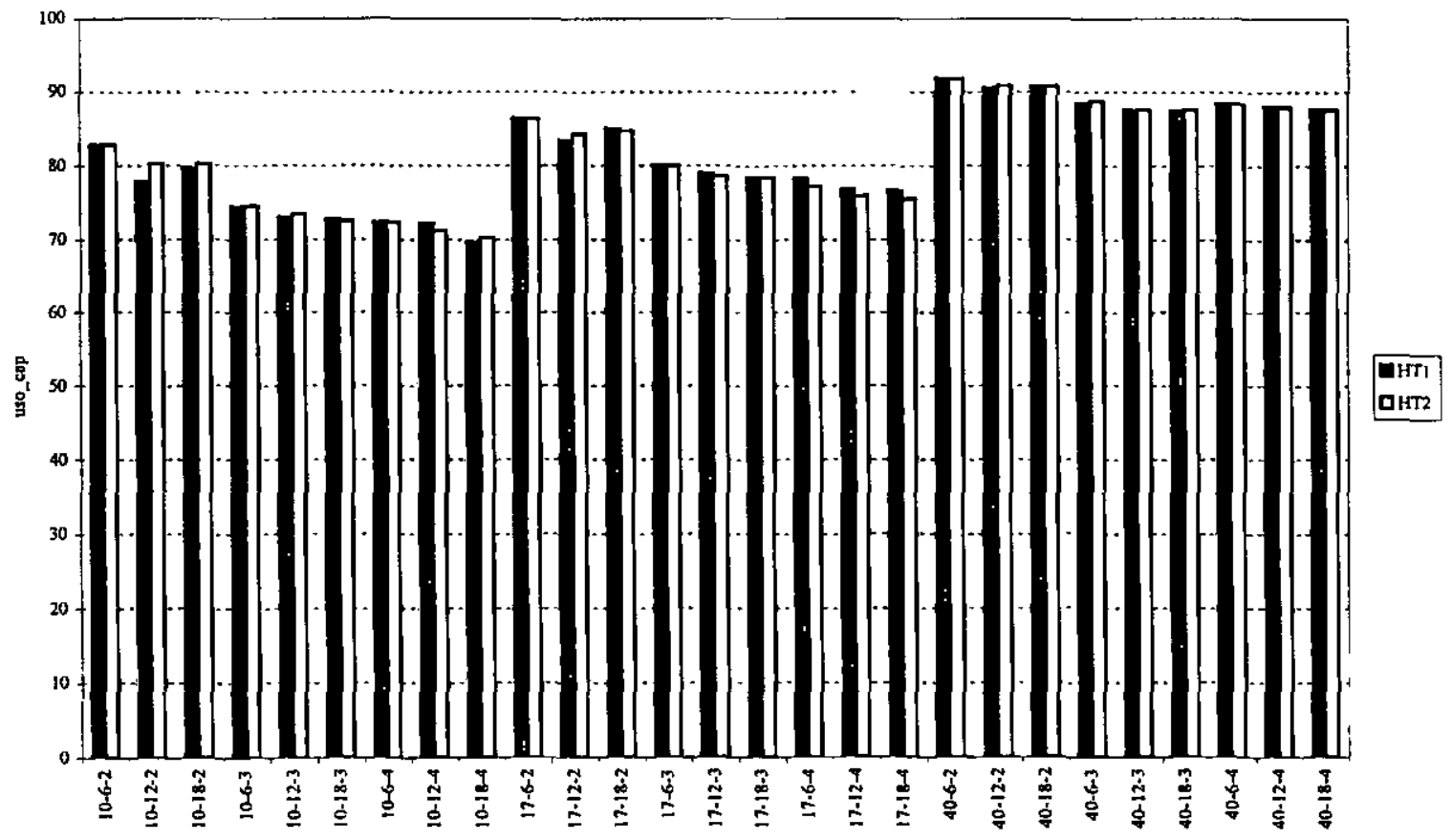

Gráfico 5.12. Consumo da capacidade para os exemplos com estruturas seriais e custo baixo de preparação.

Para os exemplos com estruturas seriais de produtos e custo baixo de preparação, Gráfico 5.12, quanto maior o número de itens na estrutura de produtos, maior o consumo médio da capacidade por máquina. No entanto, este comportamento não afetou o desempenho das heurísticas na obtenção de soluções factíveis (veja Tabela 5.14). 


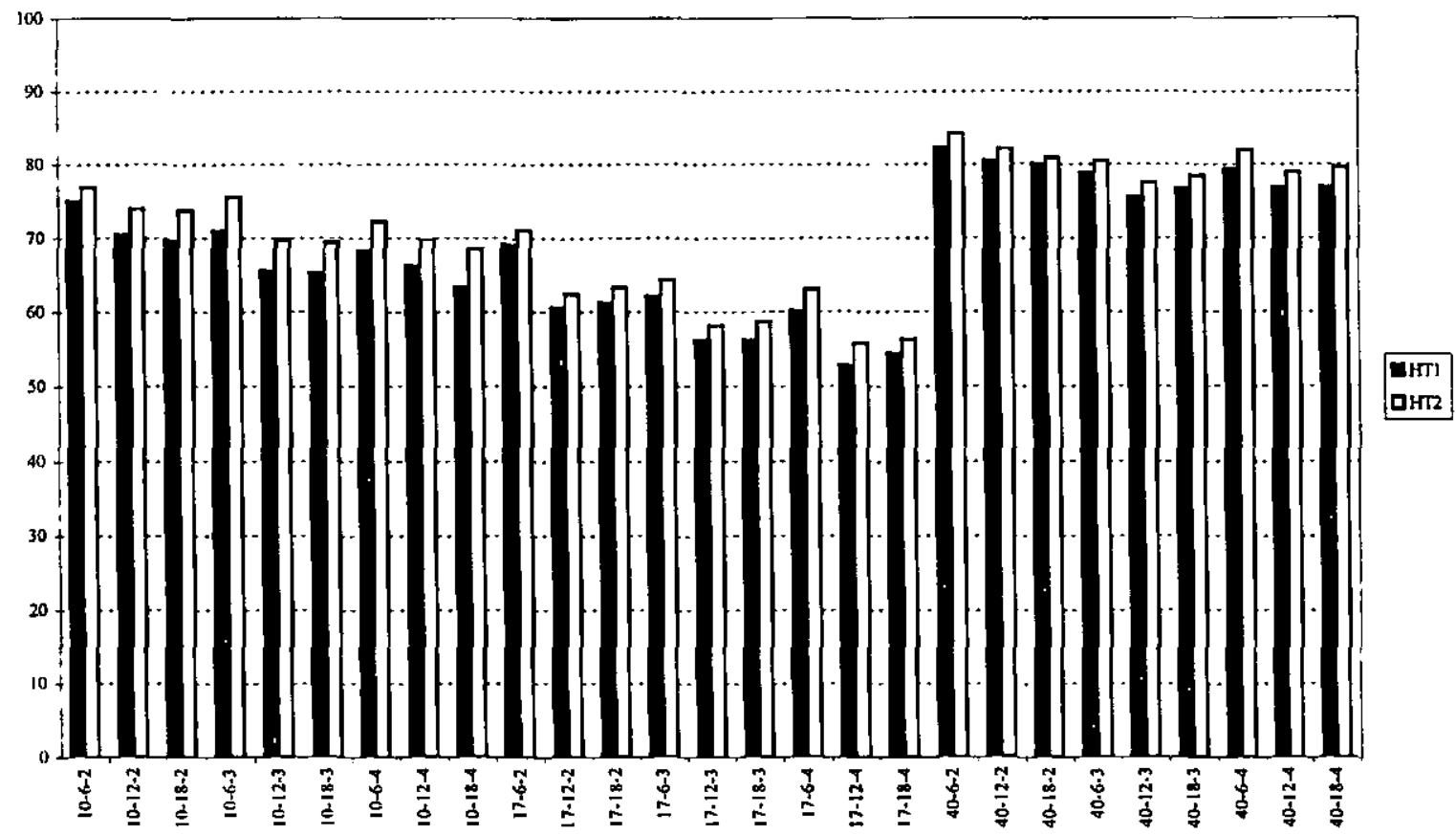

Gráfico 5.13. Consumo da capacidade para os exemplos com estruturas gerais e custo alto de preparação.

Nota-se no Gráfico 5.13 que a heurística HT2 apresenta um consumo médio da capacidade superior ao da heurística HT1. Este comportamento foi comentado para os exemplos do Grupo GI (veja Tabelas 5.10, 5.11, 5.12). Os exemplos com custo alto de preparação apresentam uma utilização média da capacidade gerada inferior aos exemplos com custo baixo de preparação. Este comportamento se deve ao fato de que ambas as heurísticas dependem das soluções iniciais, as quais são baseadas no algoritmo de Wagner e Whitin e, tendem a fazer um número menor de preparações do que para os exemplos com custo baixo de preparação. 


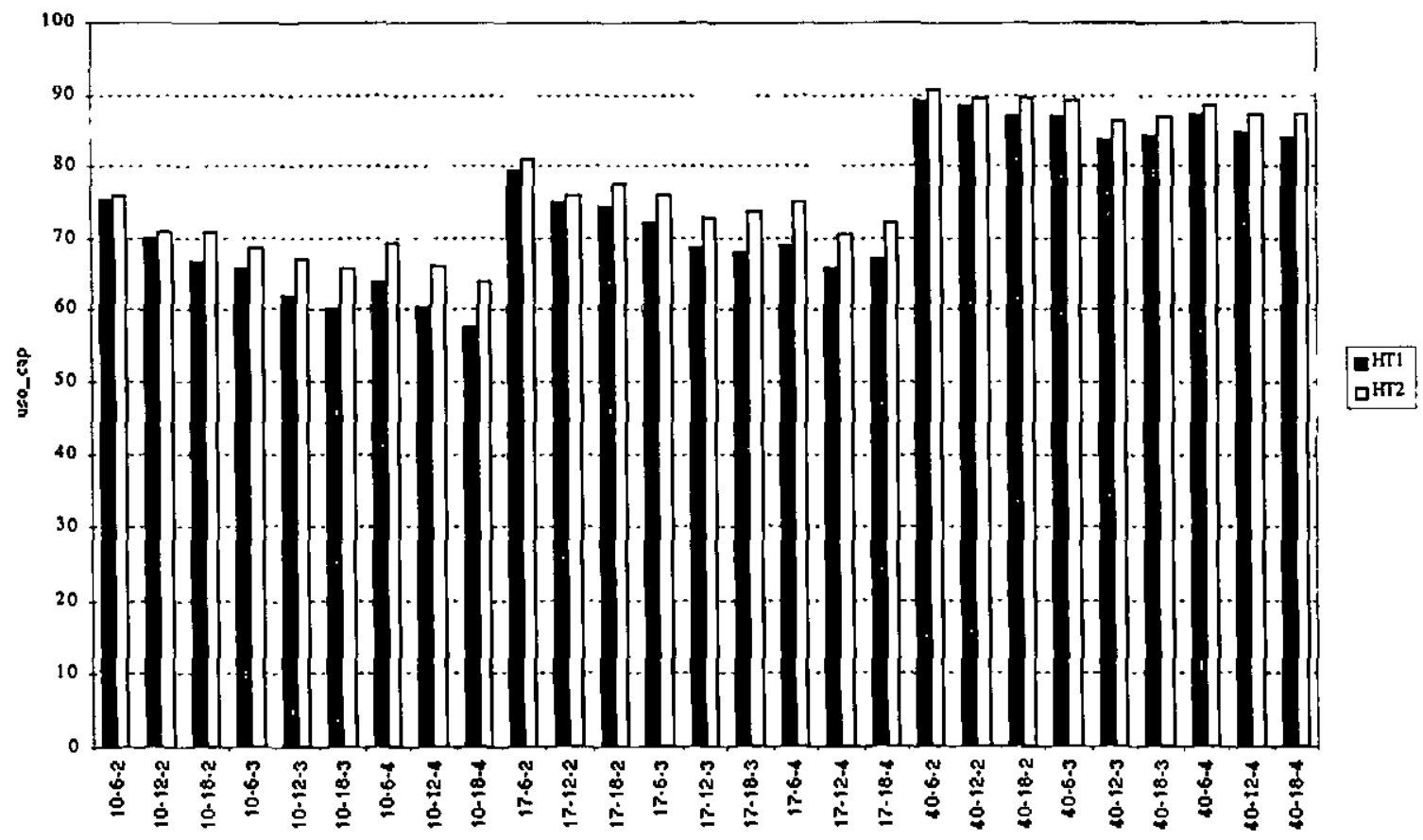

Gráfico 5.14. Consumo da capacidade para os exemplos com estruturas seriais e custo alto de preparação.

A Tabela 5.30 apresenta um resumo da utilização média da capacidade por máquina, para ambas as heurísticas, onde os resultados foram agregados por períodos e máquinas, com o objetivo de facilitar a compreensão dos resultados apresentados nos gráficos (5.11)-(5.14). Mostra-se também nesta tabela, o quanto foi utilizado da capacidade e para as preparações.

Tabela 5.30. Porcentagem da utilização da capacidade para produção e preparação para as heuristicas HT1 e HT2.

\begin{tabular}{|c|c|c|c|c|c|c|c|}
\hline \multicolumn{2}{|c|}{ Estruturas } & \multicolumn{3}{c|}{ Seriais } & \multicolumn{3}{c|}{ Gerais } \\
\cline { 3 - 8 } & & $\mathbf{1 0}$ & 17 & 40 & 10 & 17 & $\mathbf{4 0}$ \\
\hline \multirow{4}{*}{$\begin{array}{c}\text { Custo baixo } \\
\text { de }\end{array}$} & Uso_cap_HT1 & 81.5 & 80.5 & 89.0 & 77.9 & 70.5 & 85.7 \\
\cline { 2 - 8 } preparação & Uso_selup_HT1 & 39.2 & 34.8 & 24.8 & 33.8 & 36.7 & 27.6 \\
\cline { 2 - 8 } & Uso_cap_HT2 & 75.3 & 80.2 & 89.1 & 77.5 & 71.4 & 85.7 \\
\hline \multirow{4}{*}{ Custo alto_setup_HT2 } & 40.5 & 34.9 & 24.8 & 35.6 & 38.1 & 27.2 \\
de & Uso_cap_HT1 & 64.6 & 71.1 & 86.3 & 68.3 & 59.2 & 78.6 \\
preparação & Uso_selup_HT1 & 24.9 & 25.4 & 23.5 & 22.2 & 21.6 & 19.7 \\
\cline { 2 - 8 } & Uso_cap_HT2 & 68.7 & 75.0 & 88.4 & 72.2 & 61.4 & 80.5 \\
& Uso_selup_HT2 & 31.3 & 29.5 & 23.8 & 27.2 & 26.1 & 20.8 \\
\hline
\end{tabular}

Da Tabela 5.30 pode-se observar novamente que os exemplos com custo alto de preparação apresentam uma utilização média da capacidade inferior aos exemplos com custo baixo de preparação. Por exemplo, para os exemplos com 17 itens e estrutura serial e custo baixo de preparação, o consumo médio da capacidade para produção e preparação, para a 
heurística HT1, foi de $80.5 \%$, sendo que, $34.8 \%$ desta quantidade foi utilizada para as preparações das máquinas. Para heurística HT2 o consumo foi de $80.2 \%$ sendo $34.9 \%$ para preparação. Considerando os mesmos exemplos com custo alto de preparação, observa-se que a utilização média da capacidade para a heuristica HT1 (HT2) foi de $71.1 \%$ (75.0\%), sendo que, $25.4 \%(29.5 \%)$ representa o quanto foi utilizado para as preparações das máquinas.

\section{- Influência do Ajuste da Capacidade no uso_cap pelas Soluções}

\section{Heurísticas}

Foram feitos ajustes nas capacidades geradas para observar o desempenho das heurísticas em obter soluções factíveis e para verificar a qualidade das soluções fornecidas. As capacidades foram reduzidas e aumentadas em $5 \%$. Nas tabelas seguintes são reportados os consumos médios da capacidade por máquina, considerando estes ajustes das capacidades. Convém observar aqui, que o consumo da capacidade média é calculado para todos os exemplos que as heurísticas HT1 e HT2 obtiveram soluções factiveis considerando os três ajustes da capacidade.

Tabela 5.31. Consumo de capacidade por máquina para os três ajustes da capacidade e estruturas seriais de produtos.

\begin{tabular}{|c|c|c|c|c|c|c|c|c|c|c|}
\hline & Itens & & 10 & & & 17 & & & 40 & \\
\hline & justes & 0.95 cap & $1.0 \operatorname{cap}$ & $1.05 \mathrm{cap}$ & 0.95 cap & 1.0 cap & .05 cap & 0.95 cap & 1.0 cap & 1.05 cap \\
\hline & uso_cap_HT1 & 78.8 & 75.0 & 71.5 & 83.9 & 80.5 & 77 & 92.8 & 89 & 85.1 \\
\hline custo bajxo & uso_setup_HTI & 39.6 & 39.3 & 38.9 & 35.1 & 348 & 34.8 & 24.8 & 24.8 & 24.8 \\
\hline de & uso_cap_HT2 & 79.0 & 75.3 & 71.9 & 83.6 & 80.2 & 76.7 & 92.8 & 89.1 & 85.2 \\
\hline & uso_setup_HT2 & 40.7 & 40.5 & 40.4 & 35 & 34.9 & 34.8 & 24.7 & 24.8 & 24.8 \\
\hline & uso_cap_HT1 & 68.3 & 64.7 & 61.1 & 75.5 & 71.1 & 67.2 & 90.4 & 86.3 & 82.4 \\
\hline custo alto & uso_setup_HTI & 26.9 & 25 & 23.4 & 26.9 & 25.4 & 23.6 & 24 & 23.4 & 23.3 \\
\hline de & uso_cap_HT2 & 71.8 & 68.7 & 65.3 & 79.1 & 75 & 71.3 & 92.4 & 88.3 & 84.3 \\
\hline & uso_setup_HT2 & 31.9 & 31.4 & 30.4 & 30.2 & 29.5 & 28.7 & 23.8 & 23.8 & 23.7 \\
\hline
\end{tabular}

Pela Tabela 5.31 verifica-se que a variação da utilização da capacidade por máquina considerando os três ajustes da capacidade, para ambas as heurísticas, foi em torno de $5 \%$, tal qual foi a redução e o aumento da capacidade. Por exemplo, para os exemplos com 10 itens e custo baixo de preparação, os resultados obtidos para a heurística HTl para os exemplos com 0.95 cap apresentaram um consumo médio de $78.8 \%$ (79.0\% para HT2) e, para os exemplos com 1.0 cap o consumo foi de $75 \%$ (75.3\% para HT2) e, para 1.05 cap apresentou um consumo médio por máquina de $71.5 \%$ da capacidade e $71.9 \%$ para HT2. 
Tabela 5.32. Consumo de capacidade por máquina para os três ajustes da capacidade e estruturas gerais.

\begin{tabular}{|c|c|c|c|c|c|c|c|c|c|c|}
\hline \multicolumn{2}{|c|}{ Itens } & \multicolumn{3}{|c|}{10} & \multicolumn{3}{|c|}{17} & \multicolumn{3}{|c|}{40} \\
\hline \multicolumn{2}{|c|}{ Ajustes } & 0.95 cap & I.0 cap & .05 cap & 0.95 cap & $1.0 \mathrm{cap}$ & $1.05 \mathrm{cap}$ & 0.95 cap & 1.0 cap & $1.05 \mathrm{cap}$ \\
\hline \multirow{4}{*}{$\begin{array}{l}\text { custo baixo } \\
\text { de } \\
\text { preparação }\end{array}$} & uso_cap_HTI & 81.6 & 77.9 & 74 & 74 & 70.5 & 67.1 & 89.9 & 85.7 & 82 \\
\hline & uso_setup_HT1 & 34.3 & 33.8 & 33.9 & 36.8 & 36.7 & 36.4 & 26.8 & 27.6 & 28.1 \\
\hline & uso_cap_HT2 & 81.2 & 77.4 & 73.8 & 75.1 & 71.4 & 68 & 89.7 & 85.7 & 82 \\
\hline & uso_setup_HT2 & 35.7 & 35.7 & 36 & 38.3 & 38.1 & 37.7 & 26.6 & 27.2 & 27.7 \\
\hline \multirow{4}{*}{$\begin{array}{l}\text { custo alto } \\
\text { de } \\
\text { preparação }\end{array}$} & uso_cap_HT1 & 71.7 & 68.5 & 65.2 & 62.7 & 59.2 & 56.2 & 84.7 & 78.4 & 74.7 \\
\hline & uso_setup_HTl & 22.7 & 22.2 & 20.7 & 22.5 & 21.6 & 20.9 & 19.5 & 19.8 & 19.9 \\
\hline & uso_cap_HT2 & 74.8 & 71.9 & 68.5 & 65.1 & 61.4 & 58.2 & 84.9 & 80.6 & 76.6 \\
\hline & uso_setup_HT2 & 28.4 & 28 & 27.5 & 27 & 26.1 & 25.4 & 21.1 & 21.2 & 21.5 \\
\hline
\end{tabular}

A Tabela 5.32 mostra o consumo médio da capacidade gerada para os exemplos com estruturas gerais de produtos e custo alto e baixo de preparação. Observa-se mais uma vez que os exemplos com 17 itens apresentam baixa utilização da capacidade principalmente para os exemplos com custo alto de preparação. Considerando ainda os exemplos com 17 itens e custo alto de preparação, observa-se que a variação do consumo da capacidade de $59.2 \%$ da heurística HT1 (1.0 cap) para 62.7\% (0.95 cap) é aparentemente muito pequena. No entanto, a heurística $\mathrm{HTl}$ obteve $75.6 \%$ de soluções factíveis para 0.95 cap, enquanto que, com 1.0 cap, a heurística HT1 obteve $100 \%$ de soluções factíveis (veja Tabela 5.26). Jả para a heurística HT2, esta variação do consumo foi de $61.4 \%$ (1.0 cap) para $65.1 \%$ para ( 0.95 cap), na mesma proporção de HT1. No entanto, a heurística HT2 obteve $92.2 \%$ de soluções factíveis quando reduziu a capacidade, e com a capacidade normal (1.0 cap) obteve $100 \%$ de soluções factíveis (veja Tabela 5.28).

\section{- Conclusões}

Os resultados apresentados nesta seção mostram que, na média, as soluções fornecidas pela heurística HT2 apresentam consumos da capacidade superior as soluções de HT1. Como a heurística HT2 utiliza o algoritmo WW-Paralelo Penalizado para determinação das soluções iniciais, as soluções obtidas por esta heurística tende a consumir um percentual maior da capacidade para as preparações das máquinas, como visto nos gráficos (5.7)-(5.10).

Pelas tabelas 5.25 e 5.26, observa-se que o desempenho das heurísticas é sensível a variação da capacidade gerada. Pequenas variações das capacidades podem levar as heurísticas a obter um número menor de soluções factíveis, com a redução da capacidade ou, 
a obtenção de um número maior de soluções factíveis, caso aumente a capacidade, no entanto, a variação da utilização da capacidade não altera em grandes porcentagens (Veja tabelas 5.31 e 5.32). 


\subsubsection{Análise dos Resultados com Relação as Infactibilidades}

Nesta seção são feitas análises dos resultados em relação ao grau de infactibilidade das soluções iniciais (SIW e SIP) e das soluções infactíveis fornecidas pelas heuristicas.

São descritos os valores médios dos excessos máximos nos períodos apresentados pelas soluções infactíveis (exc_max), e os valores médios das porcentagens de periodos com violações (exc_t). Dentre todos os períodos infactíveis de uma solução, verifica-se a porcentagem máxima de máquinas com violações (exc_k). As expressões para o cálculo de exc_max, exc_t e exc_k, são descritas pelas expressões (5.5), (5.6) e (5.7).

Dentre todos os valores de exc_max (máximo excesso por período) para os exemplos que apresentam violações, é escolhido o exemplo que apresenta o valor máximo de exc_max e o exemplo com o valor mínimo de exc_max. Estes valores são descritos abaixo de exc_max nas tabelas seguintes. São apresentados também os valores máximos e mínimos de exc_t, ou seja, é escolhido o exemplo que apresenta o valor máximo de exc_t e o exemplo que apresenta o valor mínimo de exc_t.

Convém observar aqui que as comparações entre as heurísticas relacionadas às medidas médias acima não são feitos, pois os exemplos infactíveis não são os mesmos. No entanto, pode-se verificar quais heurísticas apresentam os maiores desvios, ou seja, que apresentam os exemplos com valores máximo e mínimo de excesso por período.

Dentre os resultados obtidos foram escolhidos, para cada estrutura de produtos, os piores casos em relação ao número de soluções factíveis obtidas. De outra forma, para os exemplos com estruturas gerais ou seriais com 10, 17 e 40 itens, escolhe-se a estrutura de produtos (para cada variação de custo de preparação) que apresentou os piores resultados em relação ao número de soluções factíveis obtidas. Por exemplo, para os exemplos com custo alto de preparação e estruturas gerais, observa-se na Tabela 5.15, que o grupo de exemplos que apresentou pior resultado em relação ao número de soluções factíveis, foi com 40 itens, pois as heurísticas HT1 e HT2 determinaram somente $51.1 \%$ e $65.6 \%$ de soluções factíveis, respectivamente.

Os resultados são apresentados primeiramente para os exemplos com custo baixo e alto de preparação e estruturas seriais, seguidas dos resultados para os exemplos com estruturas gerais com custo baixo e alto de preparação.

A Tabela 5.33 mostra o grau de infactibilidade das soluções obtidas pelas heurísticas $\mathrm{HOl}$ e HTI dos exemplos com estrutura serial com 10 itens e custo baixo de preparação pois, 
dentre os exemplos com custo baixo de preparação e estruturas seriais com 10, 17 e 40 itens, os exemplos que apresentaram os piores resultados em relação ao número de soluções factiveis, foram os com 10 itens (veja Tabela 5.14). Os resultados das heurísticas HTl e HOl são apresentados na mesma tabela, pois estas utilizam a mesma solução inicial (SIW).

Tabela 5.33.-Excessos máximos para as soluçōes heuristicas HOl e HTl para os exemplos com estrutura serial com 10 ilens e custo baixo de preparação.

\begin{tabular}{|c|c|c|c|c|c|c|c|c|c|}
\hline \multirow{2}{*}{ N-T-K } & \multicolumn{3}{|c|}{ SIW } & \multicolumn{3}{c|}{ HO1 } & \multicolumn{3}{c|}{ HTI } \\
\cline { 2 - 10 } & ex__max & exc_k & exc_t & ex__max & exc_k & ex__t & ex__max & exc_k & ex__1 \\
\hline $10-6-2$ & 31.3 & 50 & 58.3 & 3.8 & 50 & 25 & 0 & 0 & 0 \\
& $(6.6 ; 93)$ & & $(33.3 ; 100)$ & $(3.3 ; 4.2)$ & & $(16.7 ; 33.3)$ & $(0 ; 0)$ & & $(0 ; 0)$ \\
\hline $10-6-3$ & 82.5 & 56.7 & 61.7 & 2.1 & 25 & 16.7 & 0 & 0 & 0 \\
& $(18.6 ; 156)$ & & $(50 ; 83.3)$ & $(0.8 ; 5.3)$ & & $(16.7 ; 16.7)$ & $(0 ; 0)$ & & $(0 ; 0)$ \\
\hline $10-6-4$ & 50.4 & 52.5 & 68.3 & 2.1 & 25 & 16.7 & 0 & 0 & 0 \\
& $(5.4 ; 121.7)$ & & $(33.3 ; 100)$ & $(0.6 ; 3.7)$ & & $(16.7 ; 16.7)$ & $(0 ; 0)$ & & $(0 ; 0)$ \\
\hline $10-12-2$ & 32.8 & 85 & 54.2 & 5.1 & 50 & 9.5 & 19.6 & 50 & 16.7 \\
& $(15.7 ; 55.3)$ & & $(25 ; 66.7)$ & $(0.1 ; 10.8)$ & & $(8.3 ; 16.7)$ & $(19.6 ; 19.6)$ & & $(16.7 ; 16.7)$ \\
\hline $10-12-3$ & 48.1 & 63.3 & 64.3 & 1.9 & 33.3 & 11.1 & 0 & 0 & 0 \\
& $(16.2 ; 109.6)$ & & $(41.7 ; 91.7)$ & $(0.7 ; 3.4)$ & & $(8.3 ; 16.7)$ & $(0 ; 0)$ & & $(0 ; 0)$ \\
\hline $10-12-4$ & 55.4 & 57.5 & 64.2 & 3.5 & 25 & 11.1 & 10.1 & 25 & 8.3 \\
& $(12.4 ; 161.3)$ & & $(50 ; 75)$ & $(1.8 ; 5.4)$ & & $(8.3 ; 16.7)$ & $(10.1 ; 10.1)$ & & $(8.3 ; 8.3)$ \\
\hline $10-18-2$ & 33.1 & 55 & 61.7 & 4.6 & 50 & 6.3 & 14.6 & 50 & 11.1 \\
& $(18 ; 55.3)$ & & $(44.4 ; 77.8)$ & $(1.7 ; 8.7)$ & & $(5.6: 11.1)$ & $(14.6 ; 14.6)$ & & $(11.1 ; 11.1)$ \\
\hline $10-18-3$ & 56.3 & 60 & 52.8 & 5.3 & 33.3 & 10 & 0 & 0 & 0 \\
& $(20.2 ; 95)$ & & $(38.9 ; 83.3)$ & $(2.6 ; 8.9)$ & & $(5.6 ; 16.7)$ & $(0 ; 0)$ & & $(0 ; 0)$ \\
\hline $10-18-4$ & 48 & 52.5 & 66.7 & 1.3 & 25 & 6.7 & 0 & 0 & 0 \\
& $(18.9 ; 72.4)$ & & $(38.9 ; 94.4)$ & $(0.1 ; 3.6)$ & & $(5.6 ; 11.1)$ & $(0 ; 0)$ & & $(0 ; 0)$ \\
\hline
\end{tabular}

Observe na Tabela 5.33, que os exemplos com 12 períodos e 2 máquinas apresentam um excesso médio de $32.8 \%$ nas soluções iniciais, sendo que, o exemplo que apresenta maior excesso em um determinado período está utilizando $55.3 \%$ a mais de capacidade por máquina e, o exemplo que apresenta menor consumo entre os exemplos com violações, está utilizando $15.7 \%$ a mais de capacidade por máquina. Para este caso, pode-se verificar que as soluções iniciais apresentam soluções infactíveis com até $66.7 \%$ de períodos com violações de capacidade, o que corresponde a 8 períodos com violações. Na média, estas soluções iniciais apresentam $54.2 \%$ dos períodos excedendo a capacidade.

As soluções fornecidas pela heurística $\mathrm{HOl}$ apresentam uma porcentagem baixa de excesso nos períodos com violações de capacidade. Por exemplo, considerando na Tabela 5.33, os exemplos com 12 períodos e 2 máquinas, pode-se perceber que o exemplo que apresenta o maior excesso por periodo, está utilizando $10.8 \%$ a mais de capacidade por máquina no período com maior excesso, enquanto que, o exemplo que apresenta menor 
excesso está excedendo em $0.1 \%$. Considerando todos os exemplos, com 12 itens e 2 máquinas, com violações de capacidade, observa-se que o valor médio de excesso, por período, apresentado pela heurística $\mathrm{HOl}$ foi de $5.1 \%$.

A heurística HT1 não encontrou uma solução factível somente para 3 exemplos, sendo um exemplo para cada uma das seguintes dimensões: 12 períodos e 2 máquinas, 12 períodos e 4 máquinas e, 18 períodos e 2 máquinas. Dentre estes exemplos, o que apresentou maior excesso foi o exemplo com 12 períodos e 2 máquinas e, está consumindo $19.6 \%$ a mais de capacidade por máquina.

A Tabela 5.34 mostra o grau de infactibilidade das soluções infactíveis obtidas pelas heurísticas HO2 e HT2 dos exemplos com estrutura serial com 10 itens e custo baixo de preparação, e mostra também uma análise da infactibilidade das soluções iniciais SIP.

Tabela 5.34. Excessos máximos para as soluçðes heuristicas HO2 e HT2 para os exemplos com estrutura serial com 10 itens e custo baixo de preparação.

\begin{tabular}{|c|c|c|c|c|c|c|c|c|c|}
\hline \multirow{2}{*}{ N-T-K } & \multicolumn{3}{|c|}{ SIP } & \multicolumn{3}{c|}{ HO2 } & \multicolumn{2}{c|}{ HT2 } \\
\cline { 2 - 10 } & exc_max & exc_k & exc_t & exc_max & exc_k & ex__t & exc_max & exc_k & exc_t \\
\hline $10-6-2$ & 5.3 & 45 & 25 & 3.2 & 50 & 20.8 & 0 & 0 & 0 \\
& $(0.0 ; 13.5)$ & & $(0.0 ; 50.0)$ & $(11 ; 5 \mathrm{I})$ & & $(16.7 ; 33.3)$ & & & \\
\hline $10-6-3$ & 3.8 & 43.3 & 25 & 4.1 & 33.3 & 16.7 & 0 & 0 & 0 \\
& $(0.0 ; 7.2)$ & & $(0.0 ; 50.0)$ & $(2.9 ; 5.7)$ & & $(16.7 ; 16.7)$ & & & \\
\hline $10-6-4$ & 2.5 & 32.5 & 30 & 0.2 & 25.0 & 16.7 & 0 & 0 & 0 \\
& $(0.0 ; 5.2)$ & & $(0.0 ; 66.7)$ & $(0.2 ; 0.2)$ & & $(16.7 ; 16.7)$ & & & \\
\hline $10-12-2$ & 5.2 & 60 & 20 & 3.4 & 50 & 11.1 & 13.5 & 75 & 12.5 \\
& $(0.0 ; 17.7)$ & & $(0.0 ; 33.3)$ & $(1.6 ; 5.4)$ & & $(8.3 ; 16.7)$ & $(8.5 ; 17.7)$ & & $(8.3 ; 16.7)$ \\
\hline $10-12-3$ & 3.6 & 36.7 & 20.8 & 2.6 & 33.3 & 8.3 & 0 & 0 & 0 \\
& $(0.0 ; 7.7)$ & & $(0.0 ; 41.7)$ & $(1.4 ; 3.8)$ & & $(8.3 ; 8.3)$ & & & \\
\hline $10-12-4$ & 5.5 & 37.5 & 28.3 & 2.0 & 25.0 & 8.3 & 0 & 0 & 0 \\
& $(1.7 ; 9.1)$ & & $(8.3 ; 41.7)$ & $(2.0 ; 2.0)$ & & $(8.3 ; 8.3)$ & & & \\
\hline $10-18-2$ & 6.2 & 65 & 20.6 & 4.0 & 50 & 6.9 & 19.1 & 50 & 5.6 \\
& $(0.3 ; 18.1)$ & & $(5.6 ; 33.3)$ & $(0.8 ; 8.2)$ & & $(5.6: 111)$ & $(19.1 ; 19.1)$ & & $(5.6 ; 5.6)$ \\
\hline $10-18-3$ & 3.7 & 36.7 & 18.3 & 3.9 & 33.3 & 5.6 & 0 & 0 & 0 \\
& $(1.3 ; 9.8)$ & & $(5.6 ; 27.8)$ & $(1.7 ; 6.3)$ & & $(5.6 ; 5.6)$ & & & \\
\hline $10-18-4$ & 5.5 & 35 & 26.7 & 3.0 & 25.0 & 5.6 & 77 & 25 & 5.6 \\
& $(0.0 ; 14.8)$ & & $(0.0 ; 44.4)$ & $(2.7 ; 3.3)$ & & $(5.6 ; 5.6)$ & $(7.7 ; 7.7)$ & & $(5.6 ; 5.6)$ \\
\hline
\end{tabular}

Os resultados apresentados na Tabela 5.34 mostram os valores médios dos excessos por período das soluções iniciais SIP são bem menores do que os excessos das soluções iniciais SIW (veja Tabela 5.33). Note também, que muitas soluções iniciais apresentam exemplos onde os excessos são nulos. Por exemplo, veja na tabela que os exemplos com 6 períodos e 2 máquinas apresentam $5.3 \%$ de excesso médio das soluções iniciais por período, 
sendo que o exemplo que tem o menor excesso entre os exemplos utiliza $0 \%$ a mais de capacidade (uma solução factível) e, o exemplo com maior violação, está utilizando $13.5 \%$ a mais de capacidade por período e máquina. Para soluções iniciais, foram analisadas todas as soluções, assim, até as factíveis foram contabilizadas, porém, para as soluções obtidas pelas heurísticas, são contabilizadas apenas as infactiveis. Nas soluções iniciais SIW', Tabela 5.33, para este mesmo grupo de exemplos, pode ser visto que o exemplo, que apresenta o menor valor de exc_max, tem $6.6 \%$, e o exemplo que apresenta o maior valor entre todos os valores de exc_max, tem $93 \%$ de excesso, um valor bem superior aos $13.5 \%$ fornecido pelas soluções iniciais SIP. Observe também que os valores mínimos e máximos de exc_t das soluções iniciais SIP são inferiores aos apresentados pelas soluções iniciais SIW.

As soluções infactíveis fornecidas pela heurística $\mathrm{HO} 2$ apresentam valores máximos de exc_max são inferiores aos apresentados pela solução inicial SIP, mostrando o desempenho da heurística em diminuir as infactibilidades. Por exemplo, considerando o grupo de exemplos com 18 períodos e 3 máquinas, as soluções iniciais apresentam violações no intervalo (1.3;9.8), enquanto que, as soluções da heurística HO2 apresentam violações no intervalo (1.7;6.3).

Já para a heurística HT2, o único exemplo, para o qual não foi capaz de determinar uma solução factível considerando 18 períodos e 2 máquinas, apresenta um período com maior utilização do que o valor apresentado inicialmente pela solução SIP. As soluções SIP apresentam excessos máximos dentro do intervalo $(0.3,18.1)$, e a heuristica HT2 o intervalo $(19.1 ; 19.1)$, o que mostra que as transferências feitas pela heurística de factibilização, às vezes, podem aumentar o nível de produção em um determinado periodo, levando a soluções com excessos maiores em determinados períodos e máquinas do que os apresentados pelas soluções iniciais.

A Tabela 5.35 mostra o grau de infactibilidade das soluções dos exemplos com estrutura serial com 40 itens e custo alto de preparação fornecidas pelas heurísticas HOl e HTI. 
Tabela 5.35. Excessos máximos para estrutura serial com 40 itens e custo alto de preparação das heurísticas HO1 e HT1.

\begin{tabular}{|c|c|c|c|c|c|c|c|c|c|}
\hline \multirow{2}{*}{ N-T-K } & \multicolumn{3}{|c|}{ SIW } & \multicolumn{3}{c|}{ HO1 } & \multicolumn{3}{c|}{ HTI } \\
\cline { 2 - 9 } & exc_max & ex__k & ex__t & exe_max & exc_k & exc_t & exc_max & exc_k & exc_t \\
\hline $40-6-2$ & 43.5 & 80 & 61.7 & 19.1 & 50 & 25.9 & 0 & 0 & 0 \\
& $(26.7 ; 67.2)$ & & $(33.3 ; 100)$ & $(3.4 ; 41.8)$ & & $(16.7 ; 50.0)$ & $(0 ; 0)$ & & $(0 ; 0)$ \\
\hline $40-6-3$ & 36.6 & 70 & 75 & 10.5 & 53.3 & 23.3 & 6.3 & 33.3 & 16.7 \\
& $(15.8 ; 59.3)$ & & $(50 ; 100)$ & $(0.6 ; 28.9)$ & & $(16.7 ; 33.3)$ & $(6.3 ; 6.3)$ & & $(16.7 ; 16.7)$ \\
\hline $40-6-4$ & 35.4 & 62.5 & 80 & 10.9 & 29.2 & 19.4 & 9.8 & 50 & 16.7 \\
& $(13.1 ; 78.5)$ & & $(50 ; 100)$ & $(1.3 ; 27.9)$ & & $(16.7 ; 33.3)$ & $(9.8 ; 9.8)$ & & $(16.7 ; 16.7)$ \\
\hline $40-12-2$ & 59.9 & 100 & 60 & 15.9 & 50 & 26.7 & 5.8 & 50 & 16.7 \\
& $(40.7 ; 76.8)$ & & $(41.7 ; 75)$ & $(7.5 ; 33.0)$ & & $(8.3 ; 33.3)$ & $(5.8 ; 5.8)$ & & $(16.7 ; 16.7)$ \\
\hline $40-12-3$ & 42.4 & 93.3 & 65.8 & 17.2 & 51.9 & 21.3 & 0 & 0 & 0 \\
& $(23.5 ; 62)$ & & $(50 ; 83.3)$ & $(4.0 ; 42.9)$ & & $(8.3 ; 33.3)$ & $(0 ; 0)$ & & $(0 ; 0)$ \\
\hline $40-12-4$ & 41.4 & 87.5 & 73.3 & 11.5 & 41.7 & 20.4 & 8.2 & 25 & 8.3 \\
& $(28.3,61)$ & & $(50 ; 91.7)$ & $(0.4 ; 33.3)$ & & $(8.3 ; 50)$ & $(8.2 ; 8.2)$ & & $(8.3 ; 8.3)$ \\
\hline $40-18-2$ & 53.4 & 95 & 62.2 & 18.3 & 50 & 23.5 & 3.1 & 50 & 5.6 \\
& $(20.1 ; 71.3)$ & & $(50 ; 83.3)$ & $(8.2 ; 30.9)$ & & $(16.7 ; 38.9)$ & $(3.1 ; 3.1)$ & & $(5.6 ; 5.6)$ \\
\hline $40-18-3$ & 59.2 & 90 & 65.6 & 22.3 & 56.7 & 16.1 & 1.2 & 33.3 & 5.6 \\
& $(35.7 ; 116.6)$ & & $(50 ; 88.9)$ & $(8.6 ; 72.8)$ & & $(5.6 ; 278)$ & $(1.2 ; 1.2)$ & & $(5.6: 5.6)$ \\
\hline $40-18-4$ & 47.3 & 85 & 70 & 11.9 & 47.5 & 26.1 & 0 & 0 & 0 \\
& $(23.5 ; 73.5)$ & & $(50: 94.4)$ & $(0.9 ; 22.3)$ & & $(16.7 ; 33.3)$ & $(0 ; 0)$ & & $(0 ; 0)$ \\
\hline
\end{tabular}

Na Tabela 5.35 pode-se notar que, apesar das soluções iniciais apresentarem uma porcentagem alta de excesso da capacidade por periodo, as soluções heurísticas apresentam valores bem inferiores, o que mostra a eficácia das heurísticas em diminuir as infactibilidades. Considere os exemplos com 12 períodos e 4 máquinas, as soluções iniciais apresentam violações no intervalo $(28.3,61.0)$, a heurística $\mathrm{HOl}$ apresenta excessos no intervalo (0.4; 33.3) por máquina, enquanto que, a heurística HT1 apresenta um único exemplo com violação de capacidade e, este está com um excesso de $8.2 \%$ por máquina no período que apresenta com maior violação. 
Tabela 5.36. Excessos máximos para estrutura serial com 40 itens e custo alto de preparação das heuristicas HO2 e HT2.

\begin{tabular}{|c|c|c|c|c|c|c|c|c|c|}
\hline \multirow{2}{*}{ N-T-K } & \multicolumn{3}{|c|}{ SIP } & \multicolumn{3}{c|}{ HO2 } & \multicolumn{3}{c|}{ HT2 } \\
\cline { 2 - 10 } & exc_max & exc_k & exc_t & exc_max & exc_k & ex__t & exc_max & ex__k & exc_t \\
\hline $40-6-2$ & 6.8 & 75 & 39.7 & 1.6 & 50 & 19.4 & 0.0 & 0.0 & 0.0 \\
& $(2.2 ; 13.1)$ & & $(16.7 ; 66.7)$ & $(0.4 ; 5.2)$ & & $(16.7 ; 33.3)$ & & & \\
\hline $40-6-3$ & 6.5 & 56.7 & 45 & 0.0 & 0.0 & 0.0 & 0.0 & 0.0 & 0.0 \\
& $(1.6 ; 13.6)$ & & $(16.7 ; 66.7)$ & & & & & & \\
\hline $40-6-4$ & 5.4 & 57.5 & 50.0 & 1.3 & 25 & 16.7 & 0.0 & 0.0 & 0.0 \\
& $(3.5 ; 8.8)$ & & $(16.7 ; 66.7)$ & $(1.3 ; 1.3)$ & & $(16.7 ; 16.7)$ & & & \\
\hline $40-12-2$ & 7.2 & 90 & 29.2 & 5.3 & 50 & 12.5 & 4.1 & 50 & 16.7 \\
& $(2.2 ; 12.7)$ & & $(16.7 ; 58.3)$ & $(0.2 ; 7.3)$ & & $(8.3 ; 16.7)$ & $(0.6 ; 7.7)$ & & $(16.7 ; 16.7)$ \\
\hline $40-12-3$ & 5.1 & 66.7 & 31.7 & 0.9 & 33.3 & 8.3 & 0.0 & 0.0 & 0.0 \\
& $(0.1 ; 8.9)$ & & $(8.3 ; 50)$ & $(0.1 ; 1.8)$ & & $(8.3 ; 8.3)$ & & & \\
\hline $40-12-4$ & 8.4 & 60 & 54.2 & 0.7 & 25 & 13.3 & 0.0 & 0.0 & 0.0 \\
& $(2.0 ; 15.2)$ & & $(33.3 ; 75.0)$ & $(0.2 ; 2.1)$ & & $(8.3 ; 25.0)$ & & & \\
\hline $40-18-2$ & 7.8 & 80 & 35.6 & 3.8 & 50 & 7.9 & 3.0 & 50 & 11.1 \\
& $(3.8 ; 15.7)$ & & $(11.1 ; 50)$ & $(0.7 ; 9)$ & & $(5.6 ; 11.1)$ & $(3.0 ; 3.0)$ & & $(11.1 ; 11.1)$ \\
\hline $40-18-3$ & 8.1 & 70 & 36.7 & 2.0 & 33.3 & 5.6 & 0.0 & 0.0 & 0.0 \\
& $(4.6 ; 14.4)$ & & $(16.7 ; 50)$ & $(0.6 ; 4.7)$ & & $(5.6: 5.6)$ & & & \\
\hline $40-18-4$ & 8.2 & 70 & 517 & 0.6 & 25 & 9.3 & 0.0 & 0.0 & 0.0 \\
& $(5.2: 13.0)$ & & $(38.9 ; 722)$ & $(0.2 ; 1.3)$ & & $(5.6 ; 16.7)$ & & & \\
\hline
\end{tabular}

Nas tabelas 5.35 e 5.36 pôde ser observado o mesmo comportamento apresentado pelas soluções iniciais SIP, as quais apresentam intervalos das violações inferiores aos apresentados pelas soluções iniciais SIW. Considerando as heurísticas $\mathrm{HO} 1$ e $\mathrm{HO} 2$ nestas duas tabelas, as quais utilizam o mesmo procedimento de factibilização e soluções iniciais diferentes, pode-se perceber que a heurística $\mathrm{HO} 2$ apresenta intervalos de violações com os valores máximos inferiores aos apresentados pela heurística $\mathrm{HO1}$, como pode ser visto ao considerar os exemplos com 12 períodos e 2 máquinas, com os intervalos $(7.5 ; 33.0)$ de violações para $\mathrm{HO} 1$ (Tabela 5.35) e $(0.2 ; 7.3)$ para $\mathrm{HO} 2$ (Tabela 5.36). Uma vez mais, estes resultados demostram a importância de um bom procedimento de inicialização. 
Tabela 5.37. Excessos para os exemplos com estrutura geral com 40 itens e custo baixo de preparação para as heurísticas HOl e HTI.

\begin{tabular}{|l|c|c|c|c|c|c|c|c|c|}
\hline \multirow{2}{*}{ NTK } & \multicolumn{3}{|c|}{ SIW } & \multicolumn{3}{c|}{ HO1 } & \multicolumn{3}{c|}{ HT1 } \\
\cline { 2 - 9 } & exe_max & exc_k & exc_t & exc_max & exc_k & exc_t & exc_max & exc_k & exc_t \\
\hline $40-6-2$ & 29.2 & 75 & 61.7 & 8.7 & 50 & 21.4 & 9 & 66.7 & 30.6 \\
& $(6.8 ; 59.1)$ & & $(33.3 ; 66.7)$ & $(2.0 ; 16.8)$ & & $(16.7 ; 33.3)$ & $(4.3 ; 19.9)$ & & $(16.7 ; 50.0)$ \\
\hline $40-6-3$ & 24.1 & 83.3 & 60 & 4.9 & 33.3 & 16.7 & 0 & 0 & 0 \\
& $(16.8 ; 40.7)$ & & $(33.3 ; 83.3)$ & $(0.8 ; 12.3)$ & & $(16.7 ; 16.7)$ & $(0 ; 0)$ & & $(0 ; 0)$ \\
\hline $40-6-4$ & 30.2 & 57.5 & 71.7 & 4.7 & 25 & 16.7 & 0 & 0 & 0 \\
& $(18.8 ; 44.9)$ & & $(50.0 ; 100.0)$ & $(0.2 ; 7.6)$ & & $(16.7 ; 16.7)$ & $(0 ; 0)$ & & $(0 ; 0)$ \\
\hline $40-12-2$ & 40.9 & 95 & 54.2 & 13.4 & 50 & 12.5 & 14.4 & 87.5 & 16.7 \\
& $(29 ; 52.5)$ & & $(41.7 ; 66.7)$ & $(3.9 ; 24.2)$ & & $(8.3 ; 167)$ & $(3.7 ; 20.4)$ & & $(8.3 ; 25.0)$ \\
\hline $40-12-3$ & 32.4 & 83.3 & 19.4 & 8.1 & 33.3 & 12.5 & 5.4 & 66.7 & 16.7 \\
& $(24 ; 44.3)$ & & $(50.0 ; 66.7)$ & $(2.6 ; 12.8)$ & & $(8.3 ; 16.7)$ & $(4.5 ; 6.3)$ & & $(16.7 ; 16.7)$ \\
\hline $40-12-4$ & 34.6 & 75 & 63.3 & 8.0 & 30 & 10.0 & 3.1 & 25 & 12.5 \\
& $(27 ; 46)$ & & $(50.0 ; 75.0)$ & $(0.1 ; 15.4)$ & & $(8.3 ; 16.7)$ & $(1.3 ; 4.9)$ & & $(8.3 ; 16.7)$ \\
\hline $40-18-2$ & 37.8 & 90 & 53.9 & 21.3 & 60 & 7.8 & 26.4 & 75 & 12.5 \\
& $(22.1 ; 49.6)$ & & $(38.9 ; 66.7)$ & $(8.5 ; 34.5)$ & & $(5.6 ; 11.1)$ & $(7.4 ; 47.6)$ & & $(5.6 ; 22.2)$ \\
\hline $40-18-3$ & 38.4 & 80 & 55.6 & 10.7 & 33.3 & 6.7 & 10.5 & 83.3 & 13.9 \\
& $(29.4 ; 56.3)$ & & $(38.9 ; 77.8)$ & $(0.7 ; 22.4)$ & & $(5.6 ; 11.1)$ & $(9.5 ; 11.5)$ & & $(11.1 ; 16.7)$ \\
\hline $40-18-4$ & 37.2 & 82.5 & 63.9 & 11.4 & 30 & 8.9 & 5.7 & 25 & 56 \\
& $(26.7 ; 52.6)$ & & $(55.6 ; 83.3)$ & $(1.3 ; 18.9)$ & & $(5.6 ; 11.1)$ & $(4.8: 6.6)$ & & $(5.6 ; 5.6)$ \\
\hline
\end{tabular}

Tabela 5.38. Excessos para os exemplos com estrutura geral com 40 itens e custo baixo de preparação para as heuristicas $\mathrm{HO} 2 \mathrm{e}$ HT2

\begin{tabular}{|c|c|c|c|c|c|c|c|c|c|}
\hline \multirow{2}{*}{ NTK } & \multicolumn{3}{|c|}{ SIP } & \multicolumn{3}{|c|}{$\mathrm{HO} 2$} & \multicolumn{3}{|c|}{ HT2 } \\
\hline & exc_max & exc_k & exc_t & exc_max & exc_k & exc_t & $e x c_{-} \max$ & exc_k & exc_t \\
\hline $40-6-2$ & $\begin{array}{c}11.8 \\
(2.7 ; 21,8) \\
\end{array}$ & 95 & $\begin{array}{c}39.3 \\
(16.7 ; 66.7) \\
\end{array}$ & $\begin{array}{c}9.3 \\
(5.5,13.2) \\
\end{array}$ & 58.3 & $\begin{array}{c}27.8 \\
(16.7 ; 33.3) \\
\end{array}$ & $\begin{array}{c}10.1 \\
(3.5 ; 21.3) \\
\end{array}$ & 75 & $\begin{array}{c}25 \\
(16.7 ; 33.3) \\
\end{array}$ \\
\hline $40-6-3$ & $\begin{array}{c}8.3 \\
(1.8: 14.5) \\
\end{array}$ & 73.3 & $\begin{array}{c}33.3 \\
(16.7 ; 66.7) \\
\end{array}$ & $\begin{array}{c}5.3 \\
(0.9 ; 11.8) \\
\end{array}$ & 33.3 & $\begin{array}{c}16.7 \\
(16.7 ; 16.7) \\
\end{array}$ & 0 & 0 & 0 \\
\hline $40-6-4$ & $\begin{array}{c}8.8 \\
(1.6: 19.8) \\
\end{array}$ & 70 & $\begin{array}{c}38.3 \\
(16.7 ; 66.7) \\
\end{array}$ & $\begin{array}{c}4.0 \\
(0.003: 9.7) \\
\end{array}$ & 25 & $\begin{array}{c}22.2 \\
(16.7: 33.3) \\
\end{array}$ & 0 & 0 & 0 \\
\hline $40-12-2$ & $\begin{array}{c}16.0 \\
(4.7: 26.4) \\
\end{array}$ & 90 & $\begin{array}{c}31.7 \\
(16.7: 50) \\
\end{array}$ & $\begin{array}{c}11.1 \\
(0.4 ; 23.5)\end{array}$ & 58.3 & $\begin{array}{c}9.7 \\
(8.3 ; 16.7) \\
\end{array}$ & $\begin{array}{c}19.5 \\
(2.9 ; 31.7)\end{array}$ & 87.5 & $\begin{array}{c}16.7 \\
(8.3 ; 25) \\
\end{array}$ \\
\hline $40-12-3$ & $\begin{array}{c}11.6 \\
(0.8 ; 22) \\
\end{array}$ & 90 & $\begin{array}{c}26.7 \\
(8.3 ; 41.7) \\
\end{array}$ & $\begin{array}{c}6.6 \\
(0.6 ; 12.3) \\
\end{array}$ & 41.7 & $\begin{array}{c}10.4 \\
(8.3 ; 16.7) \\
\end{array}$ & $\begin{array}{c}9.2 \\
(6.3 ; 12.2)\end{array}$ & 66.7 & $\begin{array}{c}8.3 \\
(8.3 ; 8.3) \\
\end{array}$ \\
\hline $40-12-4$ & $\begin{array}{c}12.5 \\
(2.6 ; 21.1) \\
\end{array}$ & 82.5 & $\begin{array}{c}35.8 \\
(25 ; 50) \\
\end{array}$ & $\begin{array}{c}7.9 \\
(2.6: 13.6) \\
\end{array}$ & 25 & $\begin{array}{c}8.3 \\
(8.3 ; 8.3) \\
\end{array}$ & $\begin{array}{r}4.2 \\
(1 ; 7.3) \\
\end{array}$ & 50 & $\begin{array}{c}8.3 \\
(8.3 ; 8.3) \\
\end{array}$ \\
\hline $40-18-2$ & $\begin{array}{c}20 \\
(10 ; 33.2) \\
\end{array}$ & 100 & $\begin{array}{c}35 \\
(16.7 ; 44.4) \\
\end{array}$ & $\begin{array}{c}15.8 \\
(1.0: 33.7) \\
\end{array}$ & 66.7 & $\begin{array}{c}8.3 \\
(5.6 ; 16.7) \\
\end{array}$ & $\begin{array}{c}20.2 \\
(6.9 ; 32.5) \\
\end{array}$ & 75 & $\begin{array}{c}12.5 \\
(5.6 ; 16.7) \\
\end{array}$ \\
\hline $40-18-3$ & $\begin{array}{c}14.8 \\
(9.5 ; 25.9)\end{array}$ & 96.7 & $\begin{array}{c}36.1 \\
(16.7 ; 66.7) \\
\end{array}$ & $\begin{array}{c}6.2 \\
(0.3 ; 11.1) \\
\end{array}$ & 33.3 & $\begin{array}{c}6.9 \\
(5.6 ; 11.1)\end{array}$ & $\begin{array}{c}15.3 \\
(12 ; 18.6) \\
\end{array}$ & 66.7 & $\begin{array}{c}5.6 \\
(5.6 ; 5.6) \\
\end{array}$ \\
\hline $40-18-4$ & $\begin{array}{c}15.4 \\
(8.2 ; 24.5)\end{array}$ & 90 & $\begin{array}{c}34.4 \\
(16.7 ; 55.6)\end{array}$ & $\begin{array}{c}6.5 \\
(0.9 ; 13.1)\end{array}$ & 25 & $\begin{array}{c}5.6 \\
(5.6 ; 5.6)\end{array}$ & $\begin{array}{c}8.1 \\
(7.2 ; 9)\end{array}$ & 25 & $\begin{array}{c}5.6 \\
(5.6 ; 5.6) \\
\end{array}$ \\
\hline
\end{tabular}

Observe nas tabelas 5.37 e 5.38 que os excessos médios, por períodos, para as soluções iniciais SIW são bem mais altos do que os fornecidos pelas soluções iniciais SIP, veja os exemplos com $\mathrm{T}=18 \mathrm{e} \mathrm{K}=3$. Esses exemplos apresentam um excesso médio de $38.4 \%$ 
para SIW nos períodos que apresentam maiores violações, sendo que o caso que tem máximo excesso entre os dez exemplos gerados apresenta excesso máximo de 56.3\% (25.9\% para SIP), e o exemplo que tem excesso mínimo apresenta um excesso $29.4 \%$ ( $9.5 \%$ para SIP). Considerando este mesmo exemplo, pode-se observar que as soluções iniciais apresentam em média, soluções com até $77.8 \%$ (66.7\% para SIP) de períodos com violações da capacidade disponível.

As próximas tabelas mostram os valores dos excessos das soluções iniciais e heurísticas considerando a estrutura geral com 40 itens e custo alto de preparação.

Tabela 5.39. Excess os para os exemplos com estrutura geral com 40 itens e custo alto de preparação para as heursticas HO1 e HT1

\begin{tabular}{|c|c|c|c|c|c|c|c|c|c|}
\hline \multirow{2}{*}{ N-T-K } & \multicolumn{3}{|c|}{ SI } & \multicolumn{3}{c|}{ HO } & \multicolumn{3}{c|}{ HT1 } \\
\cline { 2 - 9 } & Exc_max & Exc_k & Exc_t & Exc_max & Ex_k & Ex__t & Exc_max & Exc_k & Exc_t \\
\hline $40-6-2$ & 94.7 & 90 & 45 & 32.8 & 60.0 & 23.3 & 10.7 & 75 & 30.6 \\
& $(31.2 ; 145.2)$ & & $(33.3 ; 66.7)$ & $(14.0 ; 63.5)$ & & $(16.7 ; 33.3)$ & $(2.6 ; 15.4)$ & & $(16.7 ; 33.3)$ \\
\hline $40-6-3$ & 74.8 & 86.7 & $\overline{48.3}$ & 35.4 & 53.3 & 23.3 & 6 & 44.4 & 27.8 \\
& $(38.8 ; 105.9)$ & & $(33.3 ; 66.7)$ & $(2.8 ; 70.6)$ & & $(16.7 ; 33.3)$ & $(2.7 ; 9.7)$ & & $(16.7 ; 33.3)$ \\
\hline $40-6-4$ & 70.5 & 85 & 51.7 & 24 & 37.5 & 20 & 7.2 & 33.3 & 16.7 \\
& $(33.7 ; 110.7)$ & & $(33.3 ; 66.7)$ & $(6,9 ; 38.5)$ & & $(16.7 ; 33.3)$ & $(2,4 ; 13.2)$ & & $(16.7 ; 16.7)$ \\
\hline $40-12-2$ & 113.4 & 100 & 41.7 & 36.8 & 50.0 & 11.7 & 19.8 & 71.4 & 13.1 \\
& $(87.5 ; 137.4)$ & & $(33.3 ; 50.0)$ & $(9.4 ; 62.3)$ & & $(8.3 ; 16.7)$ & $(4.0 ; 74.1)$ & & $(8.3 ; 25)$ \\
\hline $40-12-3$ & 92.8 & 93.3 & 46.7 & 30.6 & 60.0 & 10.0 & 6.7 & 53.3 & 15 \\
& $(66.7 ; 116.8)$ & & $(41.7 ; 58.3)$ & $(4.7 ; 57.9)$ & & $(8.3 ; 16.7)$ & $(08 ; 15.2)$ & & $(8.3 ; 25.0)$ \\
\hline $40-12-4$ & 86.7 & 95 & 51.7 & 31.0 & 50.0 & 9.2 & 8.4 & 40 & 15 \\
& $(62.5 ; 12 t .4)$ & & $(41.7 ; 66.7)$ & $(5.3 ; 57.8)$ & & $(8.3 ; 16.7)$ & $(1.4 ; 16.7)$ & & $(8.3: 25.0)$ \\
\hline $40-18-2$ & 112.8 & 100 & 44.4 & 38.8 & 60.0 & 7.8 & 18.1 & 75 & 9.3 \\
& $(89.0 ; 153.5)$ & & $(33.3 ; 55.6)$ & $(5.0 ; 74.1)$ & & $(5.6 ; 11.1)$ & $(5.2 ; 31.6)$ & & $(5.6 ; 16.7)$ \\
\hline $40-18-3$ & 106.4 & 100 & 44.4 & 35.1 & 56.7 & 6.7 & 8.5 & 50 & 9.3 \\
& $(64.8 ; 148.9)$ & & $(33.3 ; 61.1)$ & $(7.3 ; 84.2)$ & & $(5.6: 11.1)$ & $(0.8 ; 14.3)$ & & $(5.6 ; 16.7)$ \\
\hline $40-18-4$ & 88.3 & 95 & 50.6 & 29.7 & 42.5 & 6.1 & 13.2 & 58.3 & 7.4 \\
& $(59.4 ; 139.4)$ & & $(38.9 ; 61.1)$ & $(3.9 ; 70.6)$ & & $(5.6 ; 11.1)$ & $(10.0 ; 14.9)$ & & $(5.6 ; 11.1)$ \\
\hline
\end{tabular}

Observe também na Tabela 5.39 que as soluções iniciais apresentam altos excessos médios, mas, apesar dos altos excessos, a heurística HTl foi capaz de diminuir os excessos médios, porém só determinou $51.1 \%$ de soluções factíveis (veja Tabela 5.15). Nota-se que alguns exemplos resolvidos pela heurística $\mathrm{HTl}$ apresentaram excessos máximos por período inferiores a $1 \%$, veja os problemas com 12 períodos e 3 máquinas. Na prática, estes exemplos por apresentarem um nível tão baixo de infactibilidade, provavelmente seriam considerados aplicáveis. 
Tabela 5.40. Excessos para os exemplos com estrutura geral com 40 itens e custo alto de preparação para as heuristicas $\mathrm{HO} 2$

e HT2.

\begin{tabular}{|c|c|c|c|c|c|c|c|c|c|}
\hline \multirow{2}{*}{ N-T-K } & \multicolumn{3}{|c|}{ SIP } & \multicolumn{3}{|c|}{ HO2 } & \multicolumn{3}{c|}{ HT2 } \\
\cline { 2 - 9 } & exc_max & exc_k & exc_t & exc_max & exc_k & exc_t & exc_max & ex__k & ex__l \\
\hline $40-6-2$ & 24.2 & 100 & 35 & 15.1 & 50 & 18.3 & 11.5 & 68.8 & 27.1 \\
& $(12.4 ; 40.1)$ & & $(16.7 ; 50)$ & $(1.3 ; 27.2)$ & & $(16.7 ; 33.3)$ & $(1.3 ; 20)$ & & $(16.7 ; 50)$ \\
\hline $40-6-3$ & 12 & 83.3 & 38.3 & 6.3 & 42.9 & 19 & 7.1 & 66.7 & 16.7 \\
& $(4.4 ; 25.4)$ & & $(16.7 ; 50)$ & $(1.2 ; 13.2)$ & & $(16.7 ; 33.3)$ & $(7.1 ; 7.1)$ & & $(16.7 ; 16.7)$ \\
\hline $40-6-4$ & 9.4 & 72.5 & 45 & 2.8 & 30.6 & 18.5 & 1.3 & 25 & 16.7 \\
& $(6.2 ; 13.9)$ & & $(16.7 ; 66.7)$ & $(0.2 ; 8.6)$ & & $(16.7 ; 33.3)$ & $(1.3 ; 1.3)$ & & $(16.7 ; 16.7)$ \\
\hline $40-12-2$ & 25.3 & 100 & 20 & 16.5 & 50 & 10.8 & 15.2 & 75 & 15.3 \\
& $(9.3 ; 44)$ & & $(8.3 ; 41.7)$ & $(3.1 ; 37.1)$ & & $(8.3 ; 16.7)$ & $(5.6 ; 34.1)$ & & $(8.3 ; 25)$ \\
\hline $40-12-3$ & 12.6 & 86.7 & 25.8 & 8.3 & 45.8 & 10.4 & 18.2 & 66.7 & 12.5 \\
& $(3.3 ; 19.1)$ & & $(8.3 ; 41.7)$ & $(2 ; 17.5)$ & & $(8.3 ; 16.7)$ & $(14.1 ; 22.3)$ & & $(8.3 ; 16.7)$ \\
\hline $40-12-4$ & 12.2 & 82.5 & 34.2 & 8.5 & 33.3 & 8.3 & 7 & 37.5 & 12.5 \\
& $(4.7 ; 25.3)$ & & $(8.3 ; 58.3)$ & $(0.7 ; 21.3)$ & & $(8.3 ; 8.3)$ & $(5.0 ; 9.0)$ & & $(8.3 ; 16.7)$ \\
\hline $40-18-2$ & 25.1 & 95 & 20.6 & 21.4 & 611 & 6.8 & 26.5 & 75 & 12.5 \\
& $(7.1 ; 36.7)$ & & $(5.6 ; 38.9)$ & $(1.4 ; 46.5)$ & & $(5.6 ; 11.1)$ & $(5.8 ; 37.2)$ & & $(5.6 ; 16.7)$ \\
\hline $40-18-3$ & 16.9 & 86.7 & 26.7 & 11.5 & 41.7 & 6.2 & 8.6 & 66.7 & 9.7 \\
& $(5.8 ; 35.4)$ & & $(11.1 ; 44.4)$ & $(0.4 ; 25.6)$ & & $(5.6 ; 11.1)$ & $(1.4 ; 14.6)$ & & $(5.6 ; 16.7)$ \\
\hline $40-18-4$ & 12.3 & 77.5 & 38.9 & 6.3 & 31.2 & 6.2 & 6.6 & 58.3 & 5.6 \\
& $(7.1 ; 18.2)$ & & $(11.1 ; 61.1)$ & $(0.7 ; 16.6)$ & & $(5.6 ; 11.1)$ & $(3.7 ; 11.6)$ & & $(5.6 ; 5.6)$ \\
\hline
\end{tabular}

Pode ser visto mais uma vez na Tabela 5.40 que as soluções iniciais SIP apresentam excessos inferiores aos fornecidos pelas soluções iniciais SIW. As soluções iniciais SIW (veja Tabela 5.39) apresentam excessos em intervalos de violações com os máximos valores superiores a $100 \%$, enquanto que para as soluções iniciais SIP, estes intervalos nunca apresentaram valor superior a $50 \%$. Pode-se notar que a porcentagem média de períodos com violações é bem inferior para as soluções iniciais SIP do que para as soluções SIW.

\section{- Conclusões}

No geral, as soluções iniciais fornecidas pelo algoritmo WW-Paralelo Penalizado (SIP) apresentam violações médias de capacidades inferiores aos apresentados pelas soluções iniciais fornecidas pelo algoritmo WW-Paralelo, soluções SIW. As soluções infactíveis fornecidas pelas heurísticas $\mathrm{HT} 1$ e $\mathrm{HO} 2$, algumas vezes apresentavam intervalos de violações inferiores aos apresentados pelas heurísticas HT2 e HO2. No entanto, na maioria das vezes, as heurísticas HT2 e $\mathrm{HO} 2$ apresentaram intervalos de violações inferiores. Em relação à porcentagem de períodos com violações (exc_t) e máquinas (exc_k), pode-se chegar à mesma conclusão anterior, de que o procedimento de obtenção de uma solução inicial influencia fortemente na qualidade das soluções obtidas, tendo SIP se mostrado mais eficaz que SIW, quando a medida em análise foi o grau de infactibilidade das soluções. 


\subsubsection{Análise dos Resultados em Relação à Qualidade das Soluções Obtidas}

Nesta seção são comparados os valores das funções objetivos das soluções atingidas pelas soluções heurísticas HT1, HT2, HO1 e HO2. Os valores de GapL, apresentados nas tabelas seguintes, são as médias dos valores obtidos após aplicar o procedimento de melhoria em todos os exemplos factíveis determinados pelas heurísticas. Primeiramente, são apresentados os valores de GapL para as soluções determinadas pelas heurísticas HT1 e HT2 separadamente, sendo apresentado um estudo sobre a influência de alguns procedimentos na qualidade das soluções obtidas por estas heurísticas. Estas heurísticas foram escolhidas para análise por obterem um maior número de soluções factíveis do que as outras duas (veja tabelas 5.14 e 5.15). Após a apresentação dos resultados detalhados para as heurísticas HT1 e HT2, é feita uma comparação da qualidade das soluções obtidas pelas quatro heurísticas. Para isto, são consideradas somente as soluções em que todas as heurísticas determinaram uma solução factível, ou seja, os exemplos em que todas as heurísticas em comparação, falharam em obter uma solução factível são excluídos. O valor de GapL é determinado utilizando a expressão (5.9). 


\subsubsection{Qualidade das Soluções Fornecidas pela Heurística HT1}

\begin{tabular}{|c|c|c|c|c|}
\hline \multirow{2}{*}{\begin{tabular}{|c|} 
Estruturas \\
Heuristica \\
HT1
\end{tabular}} & \multicolumn{2}{|c|}{ Seriais } & \multicolumn{2}{|c|}{ Gerais } \\
\hline & $\begin{array}{c}\text { custo baixo de } \\
\text { preparação }\end{array}$ & $\begin{array}{l}\text { custo alto de } \\
\text { preparação }\end{array}$ & \begin{tabular}{|c|} 
custo baixo de \\
preparaçāo
\end{tabular} & $\begin{array}{l}\text { custo alto de } \\
\text { preparação }\end{array}$ \\
\hline $10-6-2$ & 3.9 & 42.3 & 3.5 & 33.0 \\
\hline $10-6-3$ & 2.7 & 39.7 & 3.9 & 42.9 \\
\hline $10-6-4$ & 3.3 & 52.0 & 4.7 & 48.8 \\
\hline $10-12-2$ & 3.8 & 50.0 & 3.3 & 28.8 \\
\hline $10-12-3$ & 3.2 & 40.9 & 3.7 & 31.3 \\
\hline $10-12-4$ & 3.0 & 40.2 & 5.7 & 35.0 \\
\hline $10-18-2$ & 4.0 & 37.1 & 4.7 & 23.4 \\
\hline $10-18-3$ & 2.9 & 36.2 & 3.9 & 28.0 \\
\hline $10-18-4$ & 3.0 & 36.3 & 4.7 & 24.9 \\
\hline Média & 3.3 & 41.6 & 4.2 & 32.9 \\
\hline $17-6-2$ & 3.0 & 35.8 & 1.9 & 23.5 \\
\hline $17-6-3$ & 1.6 & 34.7 & 1.8 & 21.5 \\
\hline $17-6-4$ & 1.7 & 38.1 & 1.7 & 18.9 \\
\hline $17-12-2$ & 2.6 & 37.6 & 1.5 & 14.8 \\
\hline $17-12-3$ & 2.4 & 32.9 & 1.9 & 16.6 \\
\hline $17-12-4$ & 2.0 & 31.0 & 1.6 & 14.8 \\
\hline $17-18-2$ & 3.5 & 36.9 & 1.8 & 14.7 \\
\hline $17-18-3$ & 2.1 & 33.4 & 1.5 & 13.0 \\
\hline $17-18-4$ & 2.0 & 28.9 & 1.4 & 12.8 \\
\hline Média & 2.3 & 34.4 & 1.7 & 16.7 \\
\hline $40-6-2$ & 1.4 & 26.0 & 1.7 & 20.7 \\
\hline $40-6-3$ & 1.1 & 19.3 & 2.6 & 23.0 \\
\hline $40-6-4$ & 1.2 & 19.0 & 3.2 & 24.0 \\
\hline $40-12-2$ & 2.1 & 33.3 & 3.9 & 25.9 \\
\hline $40-12-3$ & 1.6 & 24.5 & 3.1 & 17.5 \\
\hline $40-12-4$ & 2.3 & 24.0 & 3.4 & 18.4 \\
\hline $40-18-2$ & 2.0 & 30.4 & 4.3 & 16.7 \\
\hline $40-18-3$ & 1.4 & 26.3 & 3.4 & 16.0 \\
\hline $40-18-4$ & 2.0 & 27.0 & 4.1 & 17.9 \\
\hline Media & 1.7 & 25.5 & 3.3 & 20.0 \\
\hline Média Total & 2.4 & 33.8 & 3.1 & 23.2 \\
\hline
\end{tabular}

Observando a tabela 5.41, pode-se notar que os exemplos com alto custo de preparação possuem altos valores de GapL. Parte destas grandezas pode ser devido aos pobres valores dos limitantes inferiores. Por exemplo, considerando os exemplos com estrutura geral com 10 itens, 6 períodos e 4 máquinas com custo alto de preparação, pode-se observar que o 
GapL foi de $48.8 \%$, já para os exemplos com estrutura geral e custo baixo de preparação, o GapL foi de $4.7 \%$. Observe também na Tabela 5.41, que para os exemplos com estrutura serial, 10 itens e custo baixo de preparação, o GapL médio foi 3.3\%. Para todas as estruturas seriais consideradas, ou seja, para 10,17 e 40 itens, e custo baixo de preparação, o GapL médio foi de $2.4 \%$, enquanto que, para os exemplos com custo alto de preparação, o GapL médio foi de $33.8 \%$. Convém salientar que os resultados apresentados podem ser melhores do que os que os números indicam, ou seja, o valor do limitante do limitante inferior pode incorporar um gap de dualidade do problema. Observe também que os valores dos gaps tendem a diminuir com o aumento do número de itens.

\section{- Influência do Procedimento Auxiliar ao Procedimento de Factibilização em HT1}

$\mathrm{Na}$ tabela seguinte, mostra-se a influência do procedimento cria_transferência na qualidade das soluções obtidas pela heurística HT1. Para cada estrutura de produto, apresentase o valor médio de GapL, onde os exemplos foram agrupados por períodos. A heurística HTI sem o procedimento cria_transferência é denominada de HTISc e com o procedimento cria_transferência é denominada de HT1Cc. Os valores de GapL são computados se ambas as heurísticas determinaram uma solução factível para o exemplo considerado.

Tabela 5.42. Influência do procedimento cria_transferência na qualidade das soluçōes obtidas pela heuristica HTl.

\begin{tabular}{|c|c|c|c|c|c|c|c|c|c|c|c|c|c|}
\hline \multirow{3}{*}{$\begin{array}{c}\text { Estrutur } \\
\mathbf{a}\end{array}$} & \multirow{3}{*}{$\mathbf{K}$} & \multicolumn{6}{|c|}{ Custo bairo de preparaça } & \multicolumn{6}{|c|}{ Custo alto de preparaçåo } \\
\hline & & \multicolumn{2}{|c|}{$N=10$} & \multicolumn{2}{|c|}{$N=17$} & \multicolumn{2}{|c|}{$\mathrm{N}=\mathbf{4 0}$} & \multicolumn{2}{|c|}{$N=10$} & \multicolumn{2}{|c|}{$\mathrm{N}=17$} & \multicolumn{2}{|c|}{$\mathrm{N}=40$} \\
\hline & & HTISe & HTICe & HTISc & HT1Ce & HTIS $\mathrm{C}$ & HTICe & HTISE & Hrice & HTiSc & HTICe & HTISe & HTiCe \\
\hline \multirow{3}{*}{ Serial } & 2 & 3.8 & 3.9 & 3.0 & 3.0 & 1.8 & 1.8 & 38.7 & 43.1 & $\sqrt{37.2}$ & 36.7 & 28.0 & 28.7 \\
\hline & 3 & 2.9 & 2.9 & 2.0 & 2.0 & 1.3 & 1.3 & 38.3 & 38.9 & 33.9 & 33.7 & 23.4 & 23.3 \\
\hline & 4 & 3.1 & 3.1 & 1.9 & 1.9 & 1.9 & 1.9 & 40.1 & 42.8 & 32.6 & 32.7 & 23.0 & 23.0 \\
\hline \multicolumn{2}{|c|}{ Média } & 3.3 & 3.3 & 2.3 & 2.3 & 1.7 & 1.7 & 39.1 & 41.6 & $\longdiv { 3 4 . 6 }$ & 34.4 & 24.8 & 25.0 \\
\hline \multirow{3}{*}{ Geral } & 2 & 3.8 & 3.8 & 1.8 & 1.8 & 3.3 & 3,3 & 30.2 & 28.4 & 170 & 17.7 & 19.5 & 19.5 \\
\hline & 3 & 3.9 & 3.8 & 1.7 & 1.7 & 3.0 & 3.0 & 31.5 & 33.1 & 16.0 & 17.0 & 16.2 & 16.2 \\
\hline & 4 & 5.1 & 5.1 & 1.6 & 1.6 & 3.6 & 3.6 & 35.2 & 36.2 & 15.5 & 15.5 & 19.7 & 19.8 \\
\hline \multicolumn{2}{|c|}{ Média } & 4.3 & 4.2 & 1.7 & 1.7 & 3.3 & 3.3 & 32.3 & 32.6 & 16.2 & 16.7 & 18.5 & 18.5 \\
\hline
\end{tabular}

$\mathrm{Na}$ Tabela 5.42, pode-se notar que o procedimento cria_transferência não teve grande influência na qualidade das soluções obtidas. A diferença percentual dos valores de GapL obtidos pela heurística HTl, com e sem o procedimento cria_transferência, foi menor que $3 \%$. Por exemplo, para os exemplos com custo alto de preparação e estrutura serial com 10 itens, o GapL médio foi de $39.1 \%$ para as soluções fornecidas pela heurística HTl sem o procedimento cria_transferência, e de $44.0 \%$ para a heurística com o cria_transferência. Porém, em geral, a heurística sem o procedimento cria_transferência fornece soluções de melhor qualidade, principalmente para os exemplos com custo alto de preparação. No entanto, 
se considerar a porcentagem de soluções factíveis obtidas, este procedimento é importante, principalmente, para os exemplos com custo alto de preparação (veja Tabela 5.17).

\section{- Influência do Procedimento de Melhoria P3 em HT1}

A tabela seguinte apresenta os valores médios de melhoria da qualidade das soluções, após a aplicação do procedimento de melhoria P3. Esta quantidade, para cada exemplo, é fornecida pela seguinte expressão:

$$
\text { \%melhoria }=100\left(\frac{Z_{H_{-} P 2}-Z_{H_{-} P 3}}{Z_{H_{-} P 3}}\right) \text {, }
$$

onde:

$\mathrm{Z}_{\mathrm{H}_{-} \mathrm{P} 2}$ é o valor da função objetivo fornecido pela heurística para a solução factível fornecido pelo procedimento de factibilização $\mathrm{P} 2$.

$\mathrm{Z}_{\mathrm{H}_{-} \mathrm{P} 3}$ é o valor da função objetivo calculado na solução fornecida pelo procedimento $\mathrm{P} 3$.

Pode-se observar, na Tabela 5.43, que o procedimento de melhoria P3 foi mais expressivo para os exemplos com custo alto de preparação, sendo que, para os exemplos com dimensões menores, apresentou melhor desempenho. Por exemplo, ao considerar os exemplos com 10 itens, 12 períodos e 3 máquinas, nota-se que foi obtida uma melhoria de $0.8 \%$ para os exemplos com custo baixo de preparação e estrutura serial de itens, e $17.7 \%$ para a mesma estrutura, considerando custo alto de preparação. Considerando as mesmas dimensões, custo baixo de preparação e estrutura geral obteve-se uma melhoria de $1.0 \%$, enquanto que, para os exemplos com custo alto de preparação, a melhoria foi de $8.5 \%$. Em geral, o procedimento de melhoria P3 foi mais eficiente para os exemplos com estrutura serial com 10 itens e custo alto de preparação, pois obteve $13.7 \%$ na melhoria da qualidade das soluções. 
Tabela 5.43. Porcentagens de melhoria relativa das soluç̋̃es obtidas pela heuristica HTl.

\begin{tabular}{|c|c|c|c|c|}
\hline Heurística HT1 & \multicolumn{2}{|c|}{ Estrutura Seria] } & \multicolumn{2}{|c|}{ Estrutura Geral } \\
\hline N-T-K & $\begin{array}{l}\text { Custo bairo } \\
\text { de preparaça }\end{array}$ & $\begin{array}{c}\text { Custo alto } \\
\text { de preparaço }\end{array}$ & $\begin{array}{l}\text { Custo baixo } \\
\text { de preparaça }\end{array}$ & $\begin{array}{c}\text { Custo alto } \\
\text { de preparaça }\end{array}$ \\
\hline $10-6-2$ & 0.8 & 12.0 & 0.7 & $\overline{12.5}$ \\
\hline $10-6-3$ & 0.6 & 17.6 & 1.6 & 11.1 \\
\hline $10-6-4$ & 0.5 & 174 & 1.5 & 11.1 \\
\hline $10+12-2$ & 1.2 & 14.2 & 0.5 & 11.0 \\
\hline $10-12-3$ & 0.8 & 17.7 & 1.0 & 8.5 \\
\hline $10-12-4$ & 0.6 & 13.7 & 1.4 & 7.6 \\
\hline $10-18-2$ & 1.0 & 8.4 & 1.2 & 7.8 \\
\hline $10-18-3$ & 0.9 & 9.5 & 1.3 & 6.5 \\
\hline $10-18-4$ & 0.6 & 12.7 & 1.1 & 9.8 \\
\hline Média & 0.8 & 13.7 & 1.1 & 9.5 \\
\hline $17-6-2$ & 0.2 & 15.5 & 0.3 & 7.0 \\
\hline $17-6-3$ & 0.2 & 16.5 & 0.4 & 10.3 \\
\hline $17-6-4$ & 0.3 & 7.0 & 0.4 & 10.6 \\
\hline $17-12-2$ & 0.6 & 15.9 & 0.3 & 7.1 \\
\hline $17-12-3$ & 0.4 & 11.9 & 0.4 & 5.6 \\
\hline $17-12-4$ & 0.4 & 11.7 & 0.4 & 5.3 \\
\hline $17-18-2$ & 0.6 & 16.5 & 0.6 & 5.6 \\
\hline $17-18-3$ & 0.2 & 11.5 & 0.3 & 5.0 \\
\hline $17-18-4$ & 0.4 & 10.0 & 0.5 & 5.1 \\
\hline Média & 0.4 & 12.9 & 0.4 & 6.8 \\
\hline $40-6-2$ & 0.02 & 5.7 & 0.2 & 7.3 \\
\hline $40-6-3$ & 0.04 & 3.3 & 0.2 & 4.7 \\
\hline $40-6-4$ & 0.1 & 3.7 & 0.2 & 3.7 \\
\hline $40 \cdot 12-2$ & 0.2 & 8.7 & 0.4 & 4.4 \\
\hline $40-12-3$ & 0.2 & 7.1 & 0.4 & 3.4 \\
\hline $40-12-4$ & 0.2 & 4.7 & 0.4 & 2.7 \\
\hline $40-18-2$ & 0.1 & 8.3 & 0.4 & 3.6 \\
\hline $40-18-3$ & 0.2 & 5.1 & 0.3 & 4.1 \\
\hline $40-18-4$ & 0.2 & 5.5 & 0.5 & 3.6 \\
\hline Média & 0.12 & 5.8 & 0.3 & 4.2 \\
\hline Média TotaI & 0.4 & 10.8 & 0.6 & 6.8 \\
\hline
\end{tabular}

\section{- Utilização do CPLEX 4.0 para Verificação das Soluções Fornecidas por HT1}

Os valores das funções objetivos das soluções factíveis obtidas pela heurística HT1 também foram comparados com as soluções obtidas pelo CPLEX 4.0, fixando-se as variáve is 0-1 conforme as soluções heurísticas. Os resultados são apresentados na Tabela 5.44, sendo que os valores nesta tabela podem ser expressos pela seguinte expressão:

$$
100\left(\frac{Z_{H}-Z_{F C}}{Z_{F C}}\right)
$$


onde:

$\mathrm{Z}_{\mathrm{FC}}$ - é o valor da função objetivo avaliada solução ótima produzida pelo CPLEX 4.0 na resolução do programa de programação linear.

Tabela 5.44. Melhoria percentual das soluçðes obtidas pela CPLEX 4.0 em relação às soluç̃̃es obtidas pela heuristica HTI.

\begin{tabular}{|c|c|c|c|c|}
\hline Estruturas & \multicolumn{2}{|c|}{ Estruturas Seriais } & \multicolumn{2}{c|}{ Estruturas Gerais } \\
\hline Itens & $\begin{array}{c}\text { Custo baixo de } \\
\text { preparaçåo }\end{array}$ & $\begin{array}{c}\text { Custo alto de } \\
\text { preparação }\end{array}$ & $\begin{array}{c}\text { Custo baixo de } \\
\text { preparação }\end{array}$ & $\begin{array}{c}\text { Custo alto de } \\
\text { pre paração }\end{array}$ \\
\hline 10 & 0.03 & 0.04 & 0.14 & 0.06 \\
\hline 17 & 0.03 & 0.05 & 0.008 & 0.02 \\
\hline 40 & 0.04 & 0.04 & 0.18 & 0.06 \\
\hline Média Total & $\mathbf{0 . 0 3}$ & $\mathbf{0 . 0 4}$ & $\mathbf{0 . 1 1}$ & $\mathbf{0 . 0 5}$ \\
\hline
\end{tabular}

Da Tabela 5.44 nota-se que as soluções obtidas pela heuristica HT1 apresentam boa qualidade, pois, o CPLEX 4.0 obteve, no melhor caso, soluções $0.11 \%$ melhores que as soluções obtidas pela heurística, exemplos com estruturas gerais, 10, 17 e 40 itens e custo baixo de preparação.

\section{- Avaliação da Qualidade das Soluções Fornecidas por HT1 com Ajustes da Capacidade}

As tabelas 5.45 e 5.46 mostram a influência da capacidade gerada na qualidade das soluções obtidas pela heurística HT1. As capacidades geradas foram reduzidas e aumentadas em $5 \%$. Os exemplos gerados com as capacidades "folgadas" e "apertadas" foram resolvidos utilizando a heurística HT1, e os resultados obtidos foram comparados. Nas tabelas utiliza-se 0.95 cap para os exemplos apertados, 1.0 cap para os exemplos com capacidade normal e, 1.05 cap para os exemplos folgados. Observa-se que o valor de GapL é considerado se a heurística HTl obteve uma solução factível para os três ajustes de capacidade. 
Tabela 5.45. GapL para os exemplos com estruturas seriais e três ajustes de capacidade (heuristica HTl).

\begin{tabular}{|c|c|c|c|c|c|c|}
\hline GapL & \multicolumn{2}{|c|}{ Custo baixo de preparaçăo } & \multicolumn{3}{c|}{ Custo alto de preparaçāo } \\
\hline N-T-K & 0.95 cap & 1.0 cap & 1.05 cap & 0.95 cap & 1.0 cap & 1.05 cap \\
\hline $10-6-2$ & 4.7 & 4.1 & 2.4 & 42.8 & 41.0 & 36.9 \\
$10-6-3$ & 3.9 & 2.8 & 2.3 & 46.9 & 36.4 & 36.8 \\
$10-6-4$ & 4.4 & 3.1 & 2.3 & 59.1 & 46.0 & 37.3 \\
$10-12-2$ & 4.6 & 3.4 & 2.9 & 47.1 & 46.6 & 39.4 \\
$10-12-3$ & 3.7 & 2.9 & 2.3 & 43.2 & 35.7 & 36.1 \\
$10-12-4$ & 4.6 & 3.0 & 2.3 & 49.7 & 39.6 & 34.2 \\
$10-18-2$ & 5.7 & 4.9 & 3.0 & 36.9 & 37.9 & 29.2 \\
$10-18-3$ & 4.3 & 2.8 & 2.3 & 36.3 & 36.2 & 27.5 \\
$10-18-4$ & 4.5 & 3.0 & 2.5 & 41.8 & 36.0 & 32.7 \\
\hline Média & 4.5 & 3.3 & 2.5 & 44.9 & 39.5 & 34.5 \\
\hline $17-6-2$ & 2.8 & 2.0 & 1.6 & 54.3 & 32.6 & 26.2 \\
$17-6-3$ & 2.5 & 1.6 & 1.3 & 40.3 & 34.7 & 24.9 \\
$17-6-4$ & 2.3 & 1.6 & 1.2 & 43.1 & 40.1 & 29.5 \\
$17-12-2$ & 2.7 & 2.1 & 1.7 & 39.2 & 35.5 & 28.6 \\
$17-12-3$ & 3.2 & 2.4 & 1.8 & 37.2 & 33.9 & 28.8 \\
$17-12-4$ & 3.2 & 2.0 & 1.5 & 40.7 & 30.9 & 26.9 \\
$17-18-2$ & 5.0 & 3.2 & 3.1 & 44.3 & 37.9 & 33.5 \\
$17-18-3$ & 3.0 & 2.1 & 1.9 & 37.8 & 33.7 & 28.7 \\
$17-18-4$ & 2.9 & 1.9 & 1.5 & 34.1 & 28.9 & 24.3 \\
\hline Média & 3.1 & 2.1 & 1.7 & 41.2 & 34.2 & 27.9 \\
\hline $40-6-2$ & 1.3 & 0.6 & 0.5 & 29.4 & 27.5 & 25.4 \\
$40-6-3$ & 2.3 & 1.1 & 0.8 & 23.5 & 18.3 & 18.1 \\
$40-6-4$ & 3.0 & 1.3 & 0.8 & 26.7 & 17.3 & 15.0 \\
$40-12-2$ & 3.6 & 2.3 & 1.7 & 37.9 & 36.5 & 30.2 \\
$40-12-3$ & 2.8 & 1.5 & 1.0 & 29.5 & 24.3 & 22.3 \\
$40-12-4$ & 3.8 & 2.3 & 1.4 & 28.8 & 21.3 & 19.0 \\
$40-18-2$ & 2.9 & 1.3 & 0.8 & 38.3 & 29.1 & 26.7 \\
$40-18-3$ & 2.8 & 1.4 & 0.8 & 31.6 & 26.7 & 22.1 \\
$40-18-4$ & 3.9 & 2.0 & 1.1 & 337 & 26.1 & 22.0 \\
\hline Média & 2.9 & 1.5 & 1.0 & 31.0 & 25.2 & 22.3 \\
\hline Média Total & 3.5 & 2.3 & 1.7 & 39.0 & 33.0 & 28.2 \\
\hline
\end{tabular}

Os resultados apresentados nas tabelas 5.45 e 5.46 mostram que os valores de GapL são dependentes do ajuste da capacidade. De outro modo, quanto maior a redução dos valores das capacidades, tem-se piores valores médios de GapL, enquanto que, quanto mais folgado o exemplo, menor o valor médio de GapL. Por exemplo, para os exemplos com estrutura serial de 10 itens e custo alto de preparação, tem-se os seguintes valores de GapL médio $44.9 \%$ para 0.95 cap, $39.5 \%$ para 1.0 cap e, 34.5 para 1.05 cap. 
Tabela 5.46. GapL para os exemplos com estruturas gerais e três ajustes de capacidade (heuristicaHTl)

\begin{tabular}{|c|c|c|c|c|c|c|}
\hline \multirow{2}{*}{$\begin{array}{c}\text { GapL } \\
\text { N-T-K }\end{array}$} & \multicolumn{3}{|c|}{ Custo baixo de preparaçāo } & \multicolumn{3}{|c|}{ Custo alto de preparação } \\
\hline & 0.95 cap & 1.0 cap & $1.05 \mathrm{cap}$ & 0.95 cap & 1.0 cap & 1.05 cap \\
\hline $10-6-2$ & 3.1 & 1.8 & 1.5 & 33.3 & 34.4 & 23.1 \\
\hline $10-6-3$ & 3.7 & 3.2 & 2.4 & 36.5 & 41.0 & 29.4 \\
\hline $10-6-4$ & 8.3 & 4.9 & 3.1 & 54.0 & 48.8 & 38.2 \\
\hline $10-12-2$ & 3.2 & 2.9 & 2.4 & 33.7 & 28.0 & 30.7 \\
\hline $10-12-3$ & 4.8 & 3.6 & 2.8 & 34.5 & 28.7 & 25.4 \\
\hline $10-12-4$ & 7.7 & 6.0 & 4.9 & 40.3 & 34.6 & 27.4 \\
\hline $10+18-2$ & 5.9 & 4.6 & 3.7 & 27.3 & 252 & 20.7 \\
\hline $10-18-3$ & 5.5 & 3.5 & 2.4 & 25.6 & 23.8 & 19.4 \\
\hline $10-18-4$ & 5.8 & 4.4 & 3.3 & 27.6 & 24.9 & 20.8 \\
\hline Média & 5.3 & 3.9 & 2.9 & 34.8 & 32.2 & 26.1 \\
\hline $17-6-2$ & 1.9 & 1.6 & 1.2 & 25.4 & 252 & 24.0 \\
\hline $17-6-3$ & 1.9 & 1.8 & 1.3 & 22.2 & 21.3 & 18.0 \\
\hline $17-6-4$ & 2.5 & 1.7 & 1.4 & 21.4 & 18.6 & 19.0 \\
\hline $17-12-2$ & 1.8 & 1.5 & 1.4 & 17.9 & 14.8 & 15.1 \\
\hline $17-12-3$ & 2.2 & 1.8 & 1.5 & 16.0 & 16.6 & 13.1 \\
\hline $17-12-4$ & 1.9 & 1.6 & 1.4 & 16.7 & 14.8 & 11.8 \\
\hline $17-18-2$ & 2.1 & 1.8 & 1.5 & 16.7 & 14.7 & 12.6 \\
\hline $17-18-3$ & 1.8 & 1.5 & 1.3 & 14.3 & 132 & 12.0 \\
\hline $17-18-4$ & 1.7 & 1.4 & 1.2 & 15.1 & 12.8 & 10.9 \\
\hline Média & 2.0 & 1.6 & 1.6 & 18.4 & 16.9 & 15.2 \\
\hline $40-6+2$ & 2.6 & 1.4 & 1.1 & 17.0 & 16.9 & 14.5 \\
\hline $40-6-3$ & 2.2 & 1.4 & 1.0 & 19.4 & 17.3 & 12.8 \\
\hline $40-6-4$ & 3.9 & 2.6 & 1.4 & 25.8 & 19.0 & 12.5 \\
\hline $40-12-2$ & 6.0 & 4.5 & 3.5 & 23.9 & 23.0 & 22.1 \\
\hline $40-12-3$ & 4.5 & 3.1 & 2.1 & 24.6 & 17.5 & 15.5 \\
\hline $40-12-4$ & 5.0 & 3.2 & 2.2 & 19.4 & 18.0 & 16.2 \\
\hline $40-18-2$ & 4.9 & 2.9 & 2.1 & 201 & 15.7 & 14.8 \\
\hline $40 \cdot 18-3$ & 6.1 & 4.0 & 2.8 & 19.8 & 17.4 & 15.9 \\
\hline $40-18-4$ & 6.7 & 4.3 & 2.8 & 19.9 & 17.7 & 14.9 \\
\hline Média & 4.7 & 3.0 & 2.1 & 21.1 & 19.1 & 15.5 \\
\hline Média Total & 4.0 & 2.9 & 2.1 & 24.8 & 22.4 & 18.9 \\
\hline
\end{tabular}

Para facilitar a análise da qualidade das soluções fornecidas pela heurística HT1, um resumo dos resultados é apresentado. Apresenta-se também na Tabela 5.47, o decréscimo médio da qualidade das soluções obtidas quando é feito o aperto de $5 \%$ da capacidade, e o acréscimo da qualidade quando se aumenta em $5 \%$ a capacidade. Estes valores são calculados utilizando:

$$
\begin{aligned}
& \text { decréscimo }=100 * \frac{\left(G a p L_{0.95 \mathrm{cap}}-G a p L_{1.00 \mathrm{cap}}\right)}{G a p L_{1.00 \mathrm{cap}}}, \\
& \text { acréscimo }=100 * \frac{\left(G a p L_{1.00 \mathrm{cap}}-G a p L_{1.05 \mathrm{cap}}\right)}{G a p L_{1.00 \mathrm{cap}}}
\end{aligned}
$$


Tabela 5.47. GapL para os exemplos resolvidos pela heurística HT1

\begin{tabular}{|c|c|c|c|c|c|c|c|c|c|c|c|}
\hline \multirow{2}{*}{\multicolumn{2}{|c|}{ Estruturas }} & \multicolumn{5}{|c|}{ Custo Baixo de preparaça } & \multicolumn{5}{|c|}{ Custo alto de preparaço } \\
\hline & & 0.95 cap & decréscimo & 1.0 cap & acréscimo & 1.05 cap & 0.95 cap & decréscimo & 1.0 cap & acréscimo & 1.05 cap \\
\hline \multirow{3}{*}{ Seriais } & 10 & 4.5 & $36 \%$ & 3.3 & $32 \%$ & $\overline{2.5}$ & 44.9 & $14 \%$ & 39.5 & $14 \%$ & 34.5 \\
\hline & 17 & 3.1 & $48 \%$ & 2.1 & $24 \%$ & 1.7 & 41.2 & $20 \%$ & 34.2 & $23 \%$ & 27.9 \\
\hline & 40 & 2.9 & $93 \%$ & 1.5 & $50 \%$ & 1.0 & 31.0 & $23 \%$ & 25.2 & $13 \%$ & 22.3 \\
\hline \multicolumn{2}{|c|}{ Média } & 3.5 & $59 \%$ & 2.3 & $35 \%$ & 1.7 & 39.0 & $19 \%$ & 3.0 & $17 \%$ & 28.2 \\
\hline \multirow{3}{*}{ Gerais } & 10 & 5.3 & $36 \%$ & 3.9 & $34 \%$ & 2.9 & 34.8 & $8 \%$ & 32.2 & $23 \%$ & 26.1 \\
\hline & 17 & 2.0 & $25 \%$ & 1.6 & $0 \%$ & 1.6 & 18.4 & $9 \%$ & 16.9 & $11 \%$ & 15.2 \\
\hline & 40 & 4.7 & $57 \%$ & 3.0 & $43 \%$ & 2.1 & 21.1 & $10 \%$ & 19.1 & $23 \%$ & 15.5 \\
\hline \multicolumn{2}{|c|}{ Média } & 4.0 & $39 \%$ & 2.8 & $26 \%$ & 2.2 & 24.8 & $9 \%$ & 22.7 & $19 \%$ & 18.9 \\
\hline
\end{tabular}

Observe que os exemplos com estruturas seriais de produtos, na média, apresentaram uma variação maior dos valores de GapL do que os exemplos com estruturas gerais. Por exemplo, com o ajuste de $5 \%$, os exemplos com custo baixo de preparação, estrutura serial com 40 itens, apresentou um GapL médio de $2.9 \%$ para 0.95 cap e $1.5 \%$ para 1.0 cap.

Nas tabelas seguintes são apresentados os resultados obtidos pela heuristica HT2, como foi feito para os resultados obtidos pela heurística HT1. 


\subsubsection{Qualidade das Soluções Fornecidas pela Heurística HT2}

Tabela 5.48. GapL para as soluçð̃es obtidas pela heuristica HT2.

\begin{tabular}{|c|c|c|c|c|}
\hline \multirow{2}{*}{\begin{tabular}{|c|} 
Heurística HT2 \\
GapL \\
N-T-K
\end{tabular}} & \multicolumn{2}{|c|}{ Estrutura Serial } & \multicolumn{2}{|c|}{ Estrutura Geral } \\
\hline & $\begin{array}{c}\text { Custo baixo } \\
\text { de preparação }\end{array}$ & \begin{tabular}{c|} 
Custo alto \\
de preparação
\end{tabular} & $\begin{array}{l}\text { Custo baixo } \\
\text { de preparaçăo }\end{array}$ & $\begin{array}{c}\text { Custo alto } \\
\text { de preparação }\end{array}$ \\
\hline $10-6-2$ & 4.5 & 37 & 4.0 & 28.4 \\
\hline $10-6-3$ & 3.9 & 36.3 & 4.6 & 29.7 \\
\hline $10-6-4$ & 3.6 & 40.1 & 4.5 & 38.6 \\
\hline $10-12-2$ & 4.7 & 48.0 & 3.9 & 33.4 \\
\hline $10-12-3$ & 4.8 & 45.1 & 4.8 & 30.2 \\
\hline $10-12-4$ & 4.3 & 39.1 & 5.9 & 34.5 \\
\hline $10-18-2$ & 4.7 & 44.5 & 4.6 & 28.5 \\
\hline $10-18-3$ & 3.9 & 36.8 & 4.0 & 30.5 \\
\hline $10-18-4$ & 4.0 & 35.7 & 5.5 & 32.6 \\
\hline Média & 4.3 & 40.3 & 4.6 & 31.8 \\
\hline $17-6-2$ & 3.7 & 35.9 & 2.3 & 23.0 \\
\hline $17-6-3$ & 2.4 & 27.2 & 2.2 & 14.2 \\
\hline $17-6-4$ & 2.5 & 27.3 & 2.2 & 16.4 \\
\hline $17-12-2$ & 2.7 & 35.7 & 2.2 & 17.6 \\
\hline $17-12-3$ & 3.1 & 33.1 & 2.5 & 15.5 \\
\hline $17-12-4$ & 2.5 & 30.0 & 2.2 & 17.3 \\
\hline $17-18-2$ & 3.4 & 41.8 & 2.4 & 19.8 \\
\hline $17-18-3$ & 2.6 & 32.0 & 2.0 & 15.6 \\
\hline $17-18-4$ & 2.5 & 26.4 & 2.1 & 14.6 \\
\hline Média & 2.8 & 32.2 & 2.2 & 17.1 \\
\hline $40-6-2$ & 1.8 & 21.2 & 1.9 & 19.3 \\
\hline $40-6-3$ & 1.5 & 18.7 & 3.0 & 17.3 \\
\hline $40-6-4$ & 1.9 & 17.5 & 3.6 & 20.9 \\
\hline $40-12-2$ & 2.2 & 28.6 & 3.7 & 20.3 \\
\hline $40-12-3$ & 1.8 & 23.8 & 3.2 & 19.0 \\
\hline $40-12-4$ & 2.7 & 21.8 & 3.9 & 20.0 \\
\hline $40-18-2$ & 2.0 & 29.4 & 4.6 & 20.0 \\
\hline $40-18-3$ & 1.7 & 23.5 & 3.5 & 17.5 \\
\hline $40-18-4$ & 2.4 & 23.8 & 4.3 & 20.3 \\
\hline Média & 2.0 & 23.1 & 3.5 & 19.4 \\
\hline Média Total & 3.0 & 31.9 & 3.5 & 22.8 \\
\hline
\end{tabular}

Mais uma vez pode ser observado na Tabela 5.48, que os exemplos com custo alto de preparação possuem um valor alto de GapL. Por exemplo, considerando os exemplos com estrutura geral com 10 itens, 6 períodos e 4 máquinas com custo alto de preparação, pode-se observar que o GapL foi de $38.6 \%$, já para os exemplos com estrutura geral e custo baixo de preparação, o GapL foi de $4.5 \%$. Para todas as estruturas seriais consideradas, ou seja, para 10,17 e 40 itens, e custo baixo de preparação, o GapL médio foi de $3.0 \%$, enquanto que, para os exemplos com custo alto de preparação, o GapL médio foi de $31.9 \%$. 


\section{- Influência do Procedimento Auxiliar ao Procedimento de Factibilização em HT2}

A Tabela 5.49 mostra a influência do procedimento cria_transferência na qualidade das soluções obtidas pela heurística HT2. Para cada estrutura de produto, apresenta-se o valor médio de $G a p L$, onde os exemplos foram agrupados por períodos. A heurística HT2 sem o procedimento cria_transferência é denominada de HT2Sc e com o procedimento cria_transferência de HT2Cc. Os valores de GapL são computados se ambas as heurísticas determinaram uma solução factível para o exemplo considerado.

Tabela 5.49. Influência do procedimento cria_transferência na qualidade das soluçôes obtidas pela heuristica HT2.

\begin{tabular}{|c|c|c|c|c|c|c|c|c|c|c|c|c|c|}
\hline \multirow{3}{*}{ Estrutura } & \multirow{3}{*}{$\mathbf{K}$} & \multicolumn{6}{|c|}{ Custo baixo de preparaçăo } & \multicolumn{6}{|c|}{ Custo alto de preparaça } \\
\hline & & \multicolumn{2}{|c|}{$N=10$} & \multicolumn{2}{|c|}{$\mathrm{N}=17$} & \multicolumn{2}{|c|}{$\mathrm{N}=40$} & \multicolumn{2}{|c|}{$\mathrm{N}=10$} & \multicolumn{2}{|c|}{$N=17$} & \multicolumn{2}{|c|}{$N=40$} \\
\hline & & HT2Sc & HT2Cc & HT2Sc & HT2Cc & HT2Sc & $\mathrm{HT} 2 \mathrm{Cc}$ & HT2Sc & $\mathrm{HT2Cc}$ & HT2Sc & HT2Cc & HT2SC & HT2Cc \\
\hline \multirow{3}{*}{ Serial } & 2 & 4.5 & 4.5 & 3.3 & 3.3 & 2.0 & 2.0 & 42.4 & 41.8 & $\overline{36.8}$ & 37.8 & 26.4 & 26.4 \\
\hline & 3 & 4.2 & 4.2 & 2.7 & 2.7 & 1.7 & 1.7 & 39.3 & 39.4 & 28.7 & 30.8 & 22.0 & 22.0 \\
\hline & 4 & 4.0 & 4.0 & 2.5 & 2.5 & 2.3 & 2.3 & 38.3 & 38.3 & 27.9 & 27.9 & 21.0 & 21.0 \\
\hline \multicolumn{2}{|c|}{ Média } & 4.2 & 4.2 & 2.8 & 2.8 & 2.0 & 2.0 & 40.0 & 39.8 & 31.1 & 32.2 & $23 . \overline{1}$ & 23.1 \\
\hline \multirow{3}{*}{ Geral } & 2 & 4.2 & 4.2 & $2 . \overline{3}$ & 2.3 & 3.4 & 3.4 & 298 & 29.6 & 20.0 & 20.1 & 19.7 & 19.7 \\
\hline & 3 & 4.5 & 4.5 & 2.2 & 2.2 & 3.2 & 3.2 & 30.1 & 30.1 & 15.1 & 15.1 & 17.9 & 17.9 \\
\hline & 4 & 5.3 & 5.3 & 2.2 & 2.2 & 3.9 & 3.9 & 35.2 & 35.2 & 16.1 & 16.1 & 20.1 & 20.4 \\
\hline \multicolumn{2}{|c|}{ Média } & 4.7 & 4.7 & 2.2 & 2.2 & 3.5 & 3.5 & 31.7 & 31.6 & 17.1 & 17.1 & \begin{tabular}{|l|}
19.2 \\
\end{tabular} & 19.3 \\
\hline
\end{tabular}

Pela Tabela 5.49, pode-se notar que o procedimento cria_transferência teve menos influência na qualidade das soluções obtidas por HT2 do que para a heurística HT1 (veja Tabela 5.42). A diferença percentual dos valores de GapL obtidos pela heurística HT2, com e sem o procedimento cria_transferência, foi, em média, menor que $1.1 \%$. Os valores de GapL para os exemplos com custo baixo de preparação não apresentaram variações quando este procedimento foi retirado. Para os exemplos com custo alto de preparação, os valores de GapL apresentaram uma diferença percentual muito pequena, sendo que às vezes, a heurística com o procedimento aparentava soluções de melhor qualidade e, outras vezes, a heurística sem o procedimento apresentava soluções de melhor qualidade. Considerando os exemplos com 10 itens e 2 máquinas, custo alto de preparação, pode ser visto que o valor de GapL fornecido pela heurística HT2Sc, foi em média, de $42.4 \%$ e pela heurística HT2Cc foi de $41.8 \%$. Já para os exemplos com 10 itens e 2 máquinas, os valores de GapL foram de $39.3 \%$ para $\mathrm{HT} 2 \mathrm{Sc}$ e $39.4 \%$ para HT2Cc.

\section{- Influência do Procedimento de Melhoria P3 em HT2}

A tabela seguinte apresenta os valores médios de melhoria da qualidade das soluções obtidas por HT2, após a aplicação do procedimento de melhoria P3. 
Tabela 5.50. Porcentagens de melhoria causada por P3 na heuristica HT2.

\begin{tabular}{|c|c|c|c|c|}
\hline \multirow{2}{*}{ Heuristica HT2 } & \multicolumn{2}{|c|}{ Estrutura Serial } & \multicolumn{2}{|c|}{ Estrutura Geral } \\
\hline & $\begin{array}{c}\text { Custo baixo } \\
\text { de preparaça }\end{array}$ & $\begin{array}{c}\text { Custo alto } \\
\text { de preparaçao }\end{array}$ & $\begin{array}{l}\text { Custo baixo } \\
\text { de preparaçắo }\end{array}$ & $\begin{array}{c}\text { Custo alto } \\
\text { de preparaçào }\end{array}$ \\
\hline $10-6-2$ & 1.6 & 9.4 & 1.3 & 5.8 \\
\hline $10-6-3$ & 2.9 & 8.0 & 1.8 & 5.4 \\
\hline $10-6-4$ & 3.8 & 7.0 & 3.4 & 6.7 \\
\hline $10-12-2$ & 1.2 & 8.2 & 1.7 & 6.1 \\
\hline $10-12-3$ & 3.3 & 7.7 & 2.9 & 8.9 \\
\hline $10-12-4$ & 4.1 & 8.1 & 3.8 & 8.7 \\
\hline $10-18-2$ & 1.7 & 7.7 & 1.5 & 7.5 \\
\hline $10-18-3$ & 3.2 & 7.4 & 2.8 & 7.9 \\
\hline $10-18-4$ & 3.7 & 8.8 & 4,0 & 9.1 \\
\hline Média & 2.8 & 8.0 & 2.6 & 7.3 \\
\hline $17-6-2$ & 14 & 6.8 & 2.3 & 5.8 \\
\hline $17-6-3$ & 2.4 & 6.9 & 4.0 & 11.7 \\
\hline $17-6-4$ & 36 & 5.2 & 5.5 & 10.5 \\
\hline $17-12-2$ & 1.6 & 7.5 & 3.3 & 11.6 \\
\hline $17-12-3$ & 3.3 & 6.4 & 5.3 & 13.3 \\
\hline $17-12-4$ & 4.2 & 7.5 & 5.5 & 11.2 \\
\hline $17-18-2$ & 1.9 & 6.2 & 3.3 & 10.4 \\
\hline $17-18-3$ & 2.3 & 5.5 & 4.4 & 116 \\
\hline $17-18-4$ & 3.6 & 8.1 & 6.0 & 14.3 \\
\hline Média & 2.7 & 6.7 & 4.4 & 11.2 \\
\hline $40-6-2$ & 0.7 & 15 & 1.1 & 2.9 \\
\hline $40-6-3$ & 1.5 & 2.0 & 1.5 & 3.8 \\
\hline $40-6-4$ & 19 & 2.1 & 1.9 & 3.5 \\
\hline $40-12-2$ & 0.8 & 1.2 & 1.1 & 4.2 \\
\hline $40-12-3$ & 14 & 2.6 & 2.0 & 5.0 \\
\hline $40-12-4$ & 1.8 & 3.3 & 2.2 & 5.7 \\
\hline $40-18-2$ & 0.9 & 1.9 & 1.0 & 3.8 \\
\hline $40-18-3$ & 1.5 & 2.3 & 1.6 & 4.8 \\
\hline $40-18-4$ & 2.4 & 3.3 & 2.0 & 5.6 \\
\hline Média & 1.4 & 2.2 & 1.6 & 4.4 \\
\hline Média Total & 2.3 & 5.7 & 2.9 & 7.6 \\
\hline
\end{tabular}

A melhoria da qualidade das soluções fornecidas pelo procedimento (P3) calculada pela expressão (5.10), foi mais expressivo para os exemplos com custo alto de preparação, à semelhança do ocorrido com a heuristica HT1. Pode-se também notar que, o procedimento de melhoria para os exemplos com custo alto de preparação foi, em média, num percentual maior para as soluções fornecidas pela heurística HTl (veja Tabela 5.43). O procedimento P3 foi mais efetivo para a heurística HT2 do que para HT1, quando se analisa os exemplos com custo baixo de preparação. Considere os exemplos com 17 itens e estrutura geral, a porcentagem de melhoria foi de $4.4 \%$ para a heurística HT2 e de $0.4 \%$ para a heuristica HT1 (Tabela 5.43). 
- Avaliação da Qualidade das Soluções Fornecidas por HT2 com Ajustes da Capacidade

As tabelas 5.51 e 5.52 mostram a influência do ajuste das capacidades na qualidade das soluções obtidas pela heurística HT2.

Tabela 5.51. GapL para os exemplos com estruturas seriais e três ajustes de capacidade (heurística HT2).

\begin{tabular}{|c|c|c|c|c|c|c|}
\hline \multirow{2}{*}{$\frac{G a p L}{\text { N-T-K }}$} & \multicolumn{3}{|c|}{ Custo baixo de preparaça } & \multicolumn{3}{|c|}{ Custo alto de spreparação } \\
\hline & 0.95 cap & $1.0 \mathrm{cap}$ & 1.05 cap & 0.95 cap & 1.0 cap & 1.05 cap \\
\hline $10-6-2$ & 4.4 & 4.1 & 3.4 & 33.6 & 34.3 & 33.5 \\
\hline $10-6-3$ & 4.9 & 4.4 & 3.5 & 46.1 & 39.2 & 35.6 \\
\hline $10-6-4$ & 5,2 & 3.6 & 3.3 & 44.9 & 40.8 & 32.2 \\
\hline $10-12-2$ & 5.1 & 4.4 & 4.0 & 50.4 & 48.1 & 41.0 \\
\hline $10-12-3$ & 5.4 & 4.8 & 3.9 & 48.1 & 43.2 & 36.5 \\
\hline $10-12-4$ & 5.8 & 4.4 & 3.7 & 43.9 & 37.8 & 33.8 \\
\hline $10-18-2$ & 6.2 & 4.5 & 3.7 & 40.9 & 37.4 & 33.8 \\
\hline $10-18-3$ & 4.8 & 4.0 & 3.2 & 36.1 & 34.4 & 30.5 \\
\hline $10-18-4$ & 5.0 & 4.0 & 3.2 & 40.7 & 35.7 & 33.0 \\
\hline Média & 5.2 & 4.2 & 3.5 & 42.7 & 39.0 & 34.4 \\
\hline $17-6-2$ & 3.7 & 3.2 & 2.4 & 52.9 & 40.5 & 35.9 \\
\hline $17-6-3$ & 3.3 & 2.4 & 1.9 & 30.0 & 27.3 & 24.5 \\
\hline $17-6-4$ & 3.2 & 2.3 & 1.6 & 35.5 & 28.7 & 27.2 \\
\hline $17-12-2$ & 3.3 & 2.4 & 2.1 & 37.0 & 32.4 & 28.1 \\
\hline $17-12-3$ & 4.0 & 3.1 & 2.2 & 37.0 & 33.1 & 30.2 \\
\hline $17-12-4$ & 3.4 & 2.5 & 1.9 & 33.7 & 30.6 & 29.1 \\
\hline $17-18-2$ & 5.8 & 3.6 & 3.1 & 46.8 & 42.2 & 38.1 \\
\hline $17-18-3$ & 3.3 & 2.6 & 2.0 & 34.5 & 31.4 & 28.7 \\
\hline $17-18-4$ & 3.6 & 2.5 & 1.9 & 30.2 & 26.4 & 24.5 \\
\hline Média & 3.7 & 2.7 & 2.1 & 37.5 & 32.5 & 29.6 \\
\hline $40-6-2$ & 2.0 & 0.8 & 0.6 & 21.8 & 21.5 & 22.2 \\
\hline $40-6-3$ & 2.7 & 1.3 & 0.8 & 21.9 & 17.8 & 17.6 \\
\hline $40-6-4$ & 3.7 & 1.9 & 1.2 & 25.4 & 17.5 & 16.5 \\
\hline $40-12-2$ & 4.6 & 2.6 & 1.8 & 33.0 & 29.8 & 28.8 \\
\hline $40-12-3$ & 2.5 & 1.5 & 1.0 & 28.2 & 23.9 & 22.2 \\
\hline $40-12-4$ & 4.3 & 2.6 & 1.7 & 27.0 & 21.2 & 19.2 \\
\hline $40-18-2$ & 4.1 & 1.9 & 1.1 & 321 & 28.2 & 26.8 \\
\hline $40-18-3$ & 3.2 & 17 & 1.0 & 272 & 23.8 & 22.4 \\
\hline $40-18-4$ & 4.2 & 2.4 & 1.5 & 30.1 & 23.8 & 21.0 \\
\hline Média & 3.5 & 1.9 & 1.2 & 27.4 & 23.1 & 21.9 \\
\hline Média Total & 4.1 & 1.9 & 2.3 & 35.9 & 31.5 & 28.6 \\
\hline
\end{tabular}

Os resultados apresentados nas tabelas 5.51 e 5.52 mostram mais uma vez que, os valores de GapL são dependentes do ajuste da capacidade. 
Tabela 5.52. GapL para os exemplos com estruturas gerais e três ajustes de capacidade (heurística HT2)

\begin{tabular}{|c|c|c|c|c|c|c|}
\hline \multicolumn{7}{|c|}{ Estrutura Geral } \\
\hline GapL & Custc & xo de pre & ação & Cus & to de pre & ç̧̄̃o \\
\hline N-T-K & 0.95 cap & 1.0 cap & 1.05 cap & 0.95 cap & $1.0 \mathrm{c} \approx \mathrm{p}$ & 1.05 cap \\
\hline $10-6-2$ & 3.5 & 3.2 & 2.3 & 21.7 & 22.9 & 15.4 \\
\hline $10-6-3$ & 5.5 & 4.6 & 3.3 & 42.3 & 29.7 & 27.1 \\
\hline $10-6-4$ & 6.3 & 4.2 & 3.6 & 48.2 & 38.6 & 28.5 \\
\hline $10-12-2$ & 3.9 & 4.0 & 3.2 & 39.9 & 34.8 & 31.3 \\
\hline $10-12-3$ & 5.8 & 4.8 & 3.9 & 34.6 & 30.2 & 27.5 \\
\hline $10-12-4$ & 7.2 & 5.9 & 4.6 & 40.1 & 36.0 & 30.4 \\
\hline $10-18-2$ & 5.9 & 4.6 & 3.9 & 30.9 & 27.0 & 24.8 \\
\hline $10-18-3$ & 5.3 & 4.1 & 3.2 & 33.4 & 28.6 & 25.2 \\
\hline $10-18-4$ & 6.7 & 5.5 & 4.5 & 34.0 & 30.8 & 27.7 \\
\hline Média & 5.6 & 4.5 & 3.6 & 36.1 & 31.0 & 26.4 \\
\hline $17-6-2$ & 2.4 & 1.9 & 1.7 & 21.9 & 22.8 & 13.2 \\
\hline $17-6-3$ & 2.5 & 2.2 & 1.7 & 18.5 & 14.2 & 12.1 \\
\hline $17-6-4$ & 2.9 & 2.2 & 1.9 & 21.5 & 16.4 & 15.7 \\
\hline $17-12-2$ & 2.8 & 2.2 & 2.0 & 21.2 & 17.6 & 14.6 \\
\hline $17-12-3$ & 3.0 & 2.5 & 2.3 & 18.9 & 15.5 & 13.6 \\
\hline $17-12-4$ & 2.6 & 2.2 & 2.0 & 21.7 & 17.7 & 16.1 \\
\hline $17-18-2$ & 2.9 & 2.4 & 2.2 & 22.2 & 20.3 & 16.8 \\
\hline $17-18-3$ & 2.3 & 2.0 & 1.8 & 17.9 & 156 & 13.5 \\
\hline $17-18-4$ & 2.4 & 2.1 & 1.8 & 169 & 14.6 & 13.6 \\
\hline Média & 2.6 & 2.2 & 1.9 & 20.1 & 17.2 & 14.4 \\
\hline $40-6-2$ & 2.4 & 1.6 & 1.3 & 22.1 & 22.1 & 19.4 \\
\hline $40-6-3$ & 2.9 & 1.8 & 1.3 & 19.8 & 14.9 & 13.2 \\
\hline $40-6-4$ & 4.9 & 2.8 & 1.8 & 231 & 18.9 & 14.2 \\
\hline $40-12-2$ & 5.2 & 3.8 & 3.1 & 231 & 21.2 & 19.0 \\
\hline $40-12-3$ & 4.4 & 3.3 & 2.6 & 21.1 & 18.2 & 16.1 \\
\hline $40-12-4$ & 5.6 & 3.7 & 2.6 & 20.7 & 16.3 & 15.1 \\
\hline $40-18-2$ & 6.0 & 3.9 & 27 & 21.6 & 18.9 & 17.5 \\
\hline $40-18-3$ & 6.2 & 3.8 & 2.8 & 192 & 15.8 & 14.8 \\
\hline $40-18-4$ & 6.7 & 4.4 & 3.2 & 21.3 & 18.5 & 16.7 \\
\hline Média & 4.9 & 3.2 & 2.4 & 21.3 & 18.3 & 16.2 \\
\hline Média Total & 4.4 & 3.3 & 2.6 & 25.8 & 22.2 & 19.0 \\
\hline
\end{tabular}

Na próxima tabela é apresentado um resumo dos valores dos GapL para a heurística HT2 quando são feitos os ajustes da capacidade (tabelas 5.51 e 5.52). Nesta tabela são apresentados os valores percentuais da melhoria da qualidade das soluções quando as capacidades são "folgadas" em $5 \% \mathrm{e}$, o quanto piorou quanto às capacidades são "apertadas". As expressões para determinar o decréscimo e o acréscimo são dadas por (5.12) e (5.13),respectivamente. 
Tabela 5.53. GapL para os exemplos resolvidos pela heuristica HT2

\begin{tabular}{|c|c|c|c|c|c|c|c|c|c|c|c|}
\hline \multicolumn{2}{|c|}{ Estruturas } & \multicolumn{5}{|c|}{ Custo Baixo de preparaçāo } & \multicolumn{5}{|c|}{ Custo alto de preparação } \\
\hline & & 0.95 cap & decréscimo & 1.0 cap & acréscimo & 1.05 cap & 0.95 cap & decréscimo & $1.0 \mathrm{cap}$ & acréscimo & 1.05 cap \\
\hline \multirow{3}{*}{ Seriais } & 10 & 5.2 & $24 \%$ & 4.2 & $20 \%$ & 3.5 & 42.7 & $10 \%$ & 39.0 & $13 \%$ & 34.4 \\
\hline & 17 & 3.7 & $37 \%$ & 2.7 & $29 \%$ & 2.1 & 37.5 & $15 \%$ & 32.5 & $10 \%$ & 29.6 \\
\hline & 40 & 3.5 & $84 \%$ & 1.9 & $56 \%$ & 1.2 & 27.4 & $19 \%$ & 23.1 & $5 \%$ & 21.9 \\
\hline \multicolumn{2}{|c|}{ Média } & 4.1 & $48 \%$ & 2.9 & $35 \%$ & 2.3 & 35.9 & $15 \%$ & 31.5 & $9 \%$ & 28.6 \\
\hline \multirow{3}{*}{ Gerais } & 10 & 5.6 & $22 \%$ & 4.5 & $26 \%$ & 3.6 & 36.1 & $17 \%$ & 31.0 & $17 \%$ & 26.4 \\
\hline & 17 & 2.6 & $21 \%$ & 2.2 & $13 \%$ & 1.9 & 20.1 & $17 \%$ & 17.2 & $20 \%$ & 14.4 \\
\hline & 40 & 4.9 & $52 \%$ & 3.2 & $36 \%$ & 2.4 & 21.3 & $17 \%$ & 18.3 & $13 \%$ & 16.2 \\
\hline \multicolumn{2}{|c|}{ Média } & 4.4 & $32 \%$ & 3.3 & $25 \%$ & 2.6 & 25.8 & $17 \%$ & 22.2 & $17 \%$ & 19.0 \\
\hline
\end{tabular}

Observe que, em geral, a deterioração da qualidade da solução é maior quando se aperta a capacidade, do que quando se relaxa. Observe o que ocontece para os exemplos com 40 itens, estrutura geral e custo alto de preparação. Para 1.00 cap, o valor médio de GapL é de $18.3 \%$, mas quando se aperta a capacidade em $5 \%$, o valor de GapL decresce $17 \%$; já para 1.05 cap, o valor médio de GapL melhorou de $13 \%$.

\section{- Utilização do CPLEX 4.0 para Verificação das Soluções fornecidas por HT2}

Os valores apresentados na Tabela 5.54 mostram que as soluções obtidas pela heurística HT2 apresentam boa qualidade. Observe que CPLEX 4.0 melhorou muito pouco a qualidade das soluções. No entanto, poderia acrescentar novas estratégias no procedimento de melhoria da heurística para tentar encontrar soluções melhores do que as encontradas pelo CPLEX 4.0, como por exemplo, investir em estratégias da Busca Tabu baseada na memória de longo prazo para procurar novas regiões de busca.

Tabela 5.54. Melhoria percentual das soluçðes obtidas pela CPLEX 4.0 em relação às soluçðes obtidas pela heuristica HT2.

\begin{tabular}{|c|c|c|c|c|}
\hline Estruturas & \multicolumn{2}{|c|}{ Estruturas Seriais } & \multicolumn{2}{c|}{ Estruturas Gerais } \\
\hline $\begin{array}{c}\text { 1tens } \\
(\mathrm{N})\end{array}$ & $\begin{array}{c}\text { Custo baixo de } \\
\text { preparaçào }\end{array}$ & $\begin{array}{c}\text { Custo alto de } \\
\text { preparaçāo }\end{array}$ & $\begin{array}{c}\text { Custo baixo de } \\
\text { prepa ração }\end{array}$ & $\begin{array}{c}\text { Custo alto de } \\
\text { preparação }\end{array}$ \\
\hline 10 & $\mathbf{0 . 0 1}$ & 0.02 & 0.07 & 0.04 \\
\hline 17 & 0.01 & 0.02 & 0.001 & $\mathbf{0 . 0 1}$ \\
\hline 40 & $\mathbf{0 . 0 2}$ & 0.01 & 0.12 & 0.03 \\
\hline Média Total & $\mathbf{0 . 0 2}$ & $\mathbf{0 . 0 2}$ & 0.06 & $\mathbf{0 . 0 3}$ \\
\hline
\end{tabular}




\subsubsection{Comparação das Soluçōes Fornecidas pelas Heurísticas}

Nas tabelas seguintes as soluções fornecidas pelas heurísticas são comparadas para verificar a qualidade destas soluções.

\section{Qualidade das Soluções Heurísticas HT1 Versus Qualidade das Soluções Heurísticas HT2}

Nas tabelas seguintes são apresentadas as comparações entre as soluções fornecidas pelas heurísticas HT1 e HT2. É também apresentado o quanto melhora uma solução em relação à outra para os exemplos com custo alto e baixo de preparação. Esta melhoria é expressa por:

$$
\text { Melhoria }=100 *\left(\frac{G a p L_{\mathrm{HT} 1}-G a p L_{\mathrm{HT} 2}}{G a p L_{\mathrm{HT} 2}}\right)
$$

Os resultados da Tabela 5.55 mostram que a heurística HTl apresenta soluções de melhor qualidade que a heurística HT2 para os exemplos com custo baixo de preparação, isto considerando o GapL como uma medida de qualidade. Para todos os exemplos com 10 itens e custo baixo de preparação, a heurística HT2 obteve soluções com o GapL médio de $4.3 \%$ e a heurística HTl obteve soluções com um GapL médio de 3.3. Para os exemplos com custo alto de preparação, pode ser verificado que a heurística HT2 apresenta, em média, soluções melhores do que a heurística HT1. Considere os exemplos com 10 itens e custo alto de preparação, a heurística HTl obteve um GapL médio de $41.6 \%$ enquanto que, HT2 obteve um GapL médio de $40.3 \%$, uma melhoria média de $3 \%$ para HT2. 
Tabela 5.55. GapL para os exemplos com estruturas seriais obtidos pelas heuristicas HT1 e HT2.

\begin{tabular}{|c|c|c|c|c|c|c|}
\hline \multirow{2}{*}{$\begin{array}{c}\text { GapL } \\
\text { N-T-K }\end{array}$} & \multicolumn{3}{|c|}{ Custo baixo de preparaçĩo } & \multicolumn{3}{|c|}{ Custo alto de preparação } \\
\hline & HT1 & HT2 & Melhoria & HT1 & HT2 & Melhoria \\
\hline $10-6-2$ & 3.9 & 4.5 & $-13 \%$ & 42.3 & 37.0 & $14 \%$ \\
\hline $10-6-3$ & 2.7 & 3.9 & $-31 \%$ & 39.7 & 36.3 & $9 \%$ \\
\hline $10-6-4$ & 3.3 & 3.6 & $-8 \%$ & 52.0 & 40.1 & $30 \%$ \\
\hline $10-12-2$ & 4.0 & 4.7 & $-15 \%$ & 50.0 & 48.4 & $3 \%$ \\
\hline $10-12-3$ & 3.2 & 4.8 & $-33 \%$ & 40.9 & 45.1 & $-9 \%$ \\
\hline $10 \cdot 12-4$ & 3.0 & 4.4 & $-32 \%$ & 40.2 & 39.1 & $3 \%$ \\
\hline $10-18-2$ & 4.0 & 4.7 & $.15 \%$ & 37.1 & 44.5 & $-17 \%$ \\
\hline $10-18-3$ & 2.9 & 3.9 & $-26 \%$ & 36.2 & 36.8 & $-2 \%$ \\
\hline $10-18-4$ & 3.0 & 4.0 & $-25 \%$ & 36.0 & 35.7 & $1 \%$ \\
\hline Média & 3.3 & 4.3 & $-22 \%$ & 41.6 & 40.3 & $3 \%$ \\
\hline $17-6-2$ & 3.0 & 3.7 & $-19 \%$ & 35.8 & 35.9 & $0 \%$ \\
\hline $17-6-3$ & 1.6 & 2.4 & $-33 \%$ & 34.7 & 27.2 & $28 \%$ \\
\hline $17-6-4$ & 1.7 & 2.5 & $-32 \%$ & 38.1 & 27.3 & $40 \%$ \\
\hline $17-12-2$ & 2.6 & 2.7 & $-4 \%$ & 35.9 & 35.7 & $1 \%$ \\
\hline $17 \cdot 12 \cdot 3$ & 2.4 & 3.1 & $-23 \%$ & 32.9 & 33.1 & $-1 \%$ \\
\hline $17-12-4$ & 2.0 & 2.5 & $-20 \%$ & 31.0 & 30.0 & $3 \%$ \\
\hline $17-18-2$ & 3.5 & 3.4 & $3 \%$ & 36.9 & 41.8 & $-12 \%$ \\
\hline $17-18-3$ & 2.1 & 2.6 & $.19 \%$ & 33.4 & 32.0 & $4 \%$ \\
\hline $17 \cdot 18-4$ & 2.0 & 2.5 & $-20 \%$ & 28.9 & 26.4 & $9 \%$ \\
\hline Média & 2.3 & 2.8 & $-18 \%$ & 34.2 & 32.2 & $6 \%$ \\
\hline $40-6-2$ & 1.4 & 1.8 & $-22 \%$ & 26.0 & 21.2 & $23 \%$ \\
\hline $40-6-3$ & 1.1 & 1.5 & $-27 \%$ & 19.3 & 18.1 & $7 \%$ \\
\hline $40-6-4$ & 1.2 & 1.9 & $-37 \%$ & 19.0 & 16.8 & $13 \%$ \\
\hline $40-12-2$ & 2.1 & 2.2 & $-5 \%$ & 34.8 & 28.6 & $22 \%$ \\
\hline $40-12-3$ & 1.6 & 1.8 & $-11 \%$ & 24.5 & 23.8 & $3 \%$ \\
\hline $40-12-4$ & 2.3 & 2.7 & $-15 \%$ & 24.0 & 21.6 & $11 \%$ \\
\hline $40-18-2$ & 2.0 & 2.0 & $0 \%$ & 30.4 & 29.4 & $3 \%$ \\
\hline $40-18-3$ & 1.4 & 1.7 & $-18 \%$ & 26.3 & 23.3 & $13 \%$ \\
\hline $40-18-4$ & 2.0 & 2.4 & $-17 \%$ & 27.0 & 23.8 & $13 \%$ \\
\hline Média & 1.7 & 2.0 & $-16 \%$ & 25.7 & 23.0 & $12 \%$ \\
\hline Média Total & 2.4 & 3.0 & $-19 \%$ & 33.8 & 31.8 & $6 \%$ \\
\hline
\end{tabular}


Tabela 5.56. GapL para os exemplos com estruturas gerais obtidos pelas heuristicas HT1 e HT2.

\begin{tabular}{|c|c|c|c|c|c|c|}
\hline \multirow{2}{*}{$\frac{\text { GapL }}{\text { N-T-K }}$} & \multicolumn{3}{|c|}{ Custo baixo de preparaçăo } & \multicolumn{3}{|c|}{ Custo alto de preparaçāo } \\
\hline & HT1 & HT2 & Melhoria & HT1 & HT2 & Melhoria \\
\hline $10-6-2$ & 3.7 & 3.5 & $6 \%$ & 34.4 & 28.4 & $21 \%$ \\
\hline $10-6-3$ & 3.9 & 4.6 & $-15 \%$ & 42.9 & 27.8 & $54 \%$ \\
\hline $10-6-4$ & 4.7 & 4.5 & $4 \%$ & 48.8 & 38.6 & $26 \%$ \\
\hline $10-12-2$ & 3.3 & 4.1 & $-20 \%$ & 27.5 & 33.4 & $-18 \%$ \\
\hline $10-12-3$ & 3.7 & 4.8 & $-23 \%$ & 28.7 & 30.2 & $-5 \%$ \\
\hline $10-12-4$ & 5.7 & 5.9 & $-3 \%$ & 35.0 & 34.5 & $1 \%$ \\
\hline $10-18-2$ & 4.7 & 4.6 & $2 \%$ & 23.4 & 27.0 & $-13 \%$ \\
\hline $10-18-3$ & 3.9 & 4 & $-3 \%$ & 28.0 & 30.5 & $-8 \%$ \\
\hline $10-18-4$ & 4.6 & 5.5 & $-16 \%$ & 24.9 & 30.8 & $-19 \%$ \\
\hline Média & 4.2 & 4.6 & $-8 \%$ & 32.6 & 31.2 & $4 \%$ \\
\hline $17-6-2$ & 1.9 & 2.3 & $-17 \%$ & 23.5 & 23.0 & $2 \%$ \\
\hline $17-6-3$ & 1.8 & 2.2 & $-18 \%$ & 21.5 & 14.2 & $51 \%$ \\
\hline $17-6-4$ & 1.7 & 2.2 & $-23 \%$ & 18.9 & 16.4 & $15 \%$ \\
\hline $17-12-2$ & 1.5 & 2.2 & $-32 \%$ & 14.8 & 17.6 & $-16 \%$ \\
\hline $17-12-3$ & 1.9 & 2.5 & $-24 \%$ & 16.6 & 15.5 & $7 \%$ \\
\hline $17-12-4$ & 1.6 & 2.2 & $-27 \%$ & 14.8 & 17.3 & $-14 \%$ \\
\hline $17-18-2$ & 1.8 & 2.4 & $-25 \%$ & 14.7 & 19.8 & $-26 \%$ \\
\hline $17-18-3$ & 1.5 & 2 & $-25 \%$ & 13.1 & 15.6 & $-16 \%$ \\
\hline $17-18-4$ & 1.4 & 2.1 & $-33 \%$ & 12.8 & 14.6 & $-12 \%$ \\
\hline Média & 1.7 & 2.2 & $-25 \%$ & 16.7 & 17.1 & $-2 \%$ \\
\hline $40-6-2$ & 1.7 & 1.9 & $-11 \%$ & 18.3 & 19.3 & $-5 \%$ \\
\hline $40-6-3$ & 2.6 & 3 & $-13 \%$ & 23.0 & 17.1 & $35 \%$ \\
\hline $40-6-4$ & 3.2 & 3.6 & $-11 \%$ & 24.0 & 18.1 & $33 \%$ \\
\hline $40-12+2$ & 3.9 & 3.7 & $5 \%$ & 23.0 & 22.2 & $4 \%$ \\
\hline $40-12-3$ & 3.1 & 3.2 & $-3 \%$ & 17.5 & 18.2 & $-4 \%$ \\
\hline $40-12-4$ & 3.4 & 3.9 & $-13 \%$ & 18.5 & 18.5 & $0 \%$ \\
\hline $40-18-2$ & 4.3 & 4.6 & $-7 \%$ & 16.7 & 19.3 & $-13 \%$ \\
\hline $40-18+3$ & 3.4 & 3.5 & $-3 \%$ & 16.0 & 17.8 & $-10 \%$ \\
\hline $40-18-4$ & 4.1 & 4.3 & $-5 \%$ & 17.9 & 20.3 & $-12 \%$ \\
\hline Média & 3.3 & 3.5 & $-6 \%$ & 19.4 & 19.0 & $2 \%$ \\
\hline Média Total & 3.1 & 3.5 & $-11 \%$ & 22.9 & 22.4 & $2 \%$ \\
\hline
\end{tabular}

Na Tabela 5.56 pode ser notado mais uma vez que, a heurística HT1 fomece soluções de melhor qualidade para os exemplos com custo baixo de preparação. No entanto, para os exemplos com estruturas gerais de produtos, em geral, esta quantidade é inferior do que para os exemplos com estruturas seriais e custo baixo de preparação (Veja Tabela 5.55). Para os exemplos com custo alto de preparação, a heurística HT2 obteve, em média, soluções 
melhores para 10 e 40 itens. Para os exemplos com 17 itens e custo alto de preparação, a heuristica HT1 apresentou melhor desempenho do que HT2. Apesar dos valores mostrados nas tabelas 5.55 e 5.56 de que, para um grande número de exemplos, HT1 fornece soluções melhores do que as soluções fornecidas pela heuristica HT2, porém, a heurística HT2, em geral, determina um número maior de soluçōes factíveis (veja tabelas 5.14 e 5.15).

A seguir é apresentada uma tabela com os tempos computacionais médios que as heurísticas HT1 e HT2 gastaram para resolver os exemplos, para os quais os valores de GapL foram apresentados nas tabelas 5.55 e 5.56 .

Tabela 5.57. Tempos computacionais médios em segundos gastos por HT1 e HT2
\begin{tabular}{|c|c|c|c|c|c|}
\hline Estruturas & \multirow{2}{*}{ N } & \multicolumn{2}{c|}{$\begin{array}{c}\text { Custo baixo de } \\
\text { preparaçăo }\end{array}$} & \multicolumn{2}{c|}{$\begin{array}{c}\text { Custo alto de } \\
\text { prepa raçāo }\end{array}$} \\
\cline { 3 - 7 } & & HT1 & HT2 & HT1 & HT2 \\
\hline \multirow{3}{*}{ Seriais } & 10 & 1.3 & 1.2 & 1.8 & 1.3 \\
& 17 & 2.2 & 2.3 & 3.7 & 2.4 \\
& 40 & 9.3 & 9.1 & 18.1 & 8.2 \\
\hline \multicolumn{2}{|c|}{ Média } & 4.3 & 4.2 & 7.9 & 4.0 \\
\hline \multirow{2}{*}{ Gerais } & 10 & 1.4 & 1.3 & 1.7 & 1.3 \\
& 17 & 2.2 & 2.3 & 2.7 & 2.4 \\
& 40 & 11.8 & 10.4 & 17.3 & 10.1 \\
\hline \multicolumn{2}{|c|}{ Média } & 5.1 & 4.7 & 7.2 & 4.6 \\
\hline
\end{tabular}

Note que para os exemplos com custo baixo de preparação, a diferença no valor dos tempos gastos, em média, pelas as heurísticas HT1 e HT2 é pequena (menor que 0.4). Já para os exemplos com custo alto de preparação, esta diferença é maior. Para os exemplos com estruturas seriais de itens e custo alto de preparação, a diferença no valor dos tempos é, em média, de 3.9 segundos. Como foi comentado anteriormente para os exemplos do grupo G1, a heurística HT2 encontra uma solução factível utilizando um tempo médio menor do que a heurística HTl. Embora não apresentados aqui (pois são apresentadas apenas as médias), o tempo máximo gasto pela heurística HT2 para resolver um exemplo foi de 53.31 segundos, para o exemplo com estrutura geral de produtos com 40 itens, custo alto de preparação, 18 perfodos e 4 máquinas. A heurística HT1 utilizou um tempo máximo de 103.81 segundos para resolver um exemplo com estrutura serial de produtos com 40 itens, 18 períodos e 4 máquinas.

Observando mais uma vez a Tabela 5.57, pode ser notado que, com o aumento do número de itens, o tempo computacional aumenta também. Isto também ocorre quando se fixa o número de itens e aumenta o número de períodos. Quando aumenta o número de máquinas e fixa o número de itens e períodos, o tempo computacional também aumenta, no entanto, numa 
razão menor. Para um melhor esclarecimento, considere os dois gráficos seguintes, onde é fixado o número de itens em 40.

O Gráfico 5.15 apresenta os tempos computacionais médios para os exemplos com custo alto de preparação e estruturas seriais com 40 itens. Neste gráfico pode-se notar o comportamento citado acima. Quando se aumenta o número de períodos, o tempo computacional cresce sensivelmente. Para o número de máquinas, houve um aumento menos significativo sendo que, os exemplos com 6 períodos, houve um decréscimo no tempo computacional.

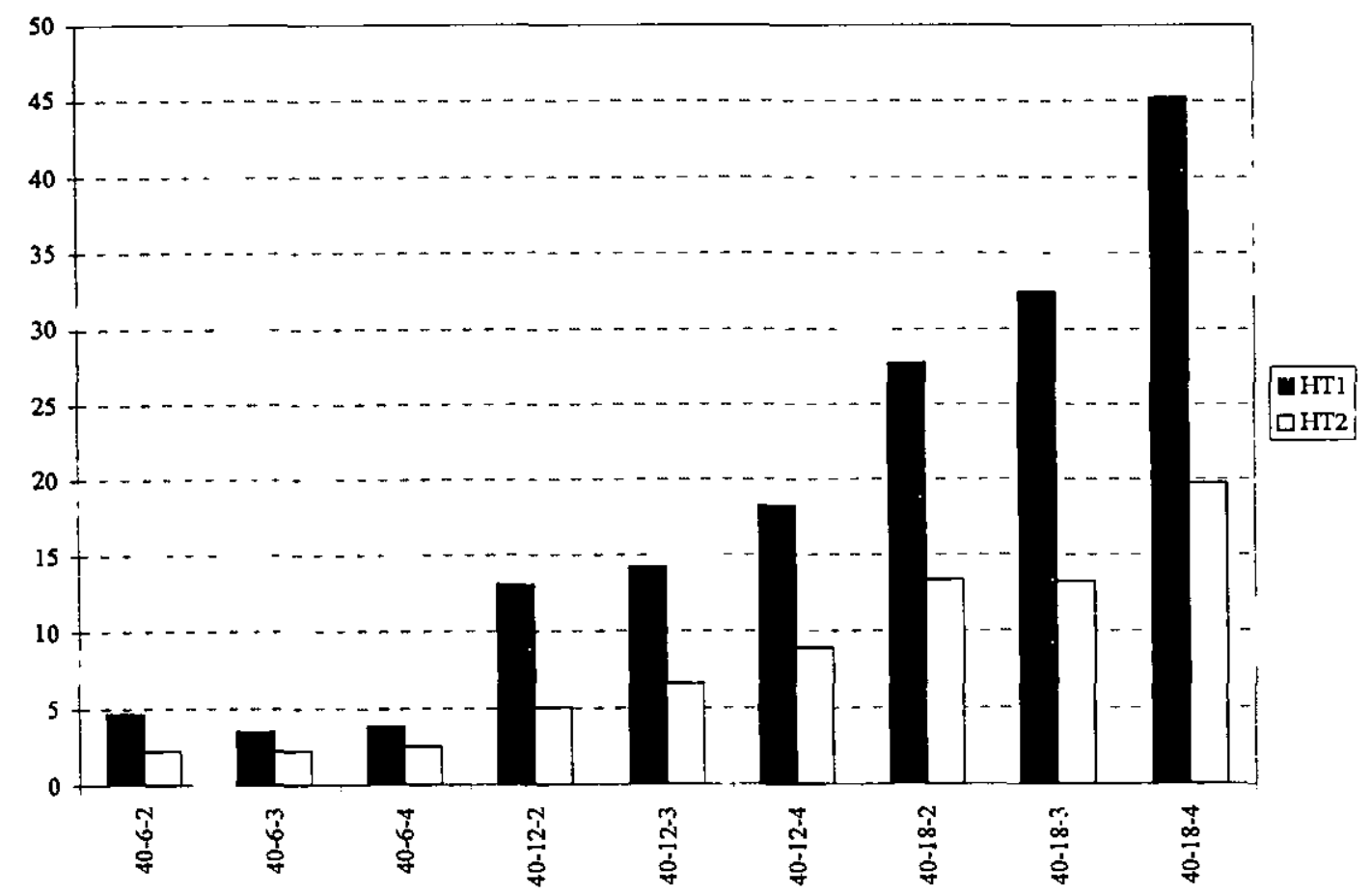

Gráfico 5.15. Tempos computacionais médios em segundos para exemplos com estruturas seriais com 40 itens e custo alto de preparação

Os tempos médios apresentados no Gráfico 5.16 servem para reafirmar que com o aumento do número de períodos e máquinas, os tempos computacionais tendem a aumentar também. 


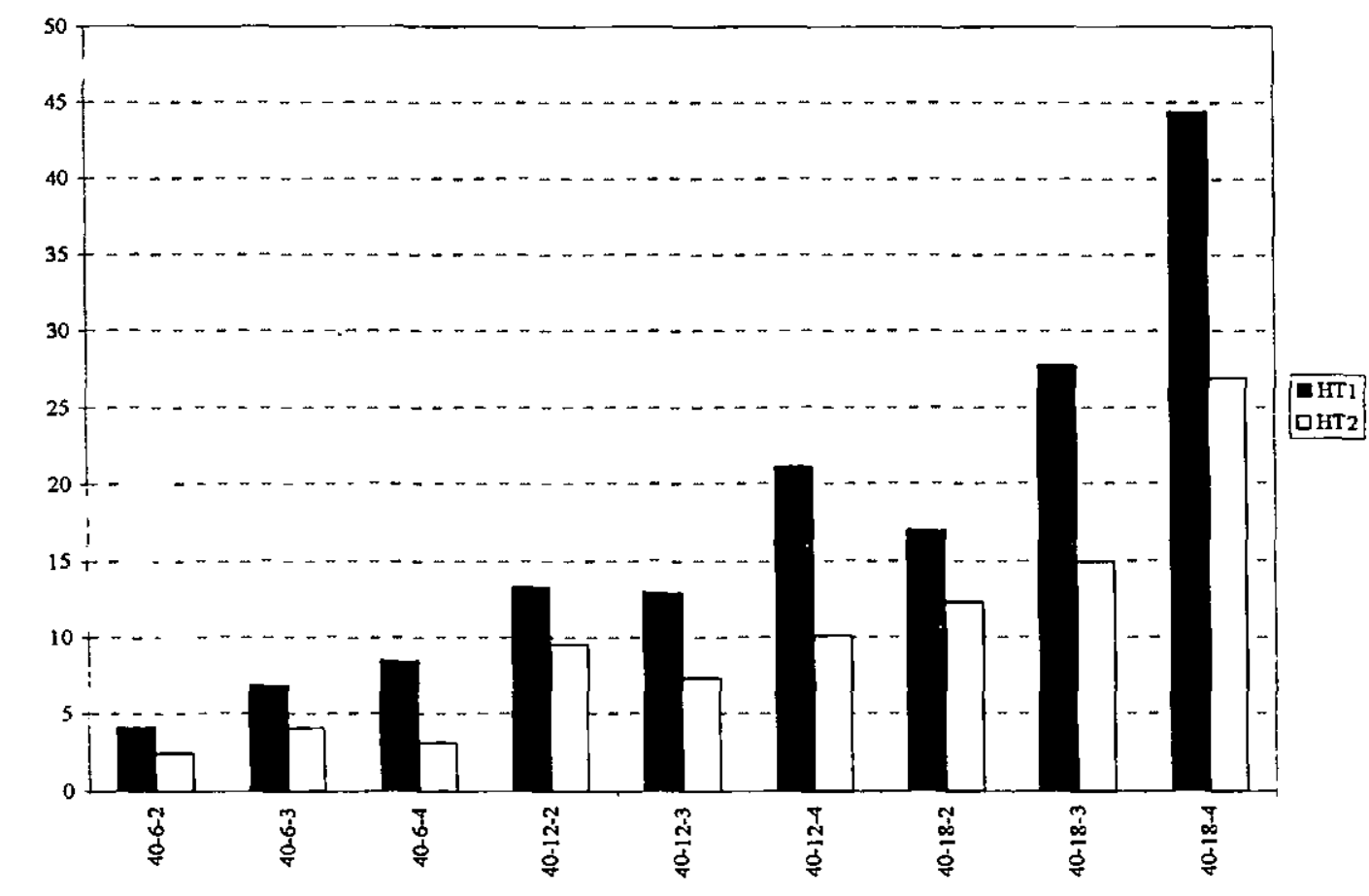

Gráfico 5.16. Tempos computacionais médios em segundos para exemplos com estruturas gerais com 40 itens e custo alto de preparação

\section{Qualidade das Soluções Heurísticas HT2 Versus Qualidade das Soluções Heurísticas $\mathrm{HO} 2$}

Nesta seção são comparadas as soluções fornecidas pelas heuristicas HT2 e HO2. Ambas heurísticas consideram o mesmo procedimento para obtenção da solução inicial, sendo que a diferença está no procedimento de factibilização. Na heurística HT2 são consideradas estratégias da Busca Tabu baseada na memória de curto prazo para evitar as ciclagens que ocorrem durante o procedimento de factibilização. Na heurística $\mathrm{HO} 2$ é considerado um contador de ciclos para evitar ciclagens, no entanto, este contador de ciclos tenta evitar ciclos somente entre máquinas dentro de um mesmo período, não evitando as ciclagens que ocorrem entre os passos progressivos e regressivos do processo de factibilização, como foi dito anteriormente. Esta comparação tem como objetivo verificar se as soluções fornecidas pela heurística com estratégias da Busca Tabu (HT2) apresentam qualidades superiores as soluções fornecidas por HO2. 
Nas tabelas seguintes, as soluções fornecidas pelas heurísticas HT2 e HO2 são comparadas. É também apresentado o quanto melhora uma solução em relação à outra para os exemplos com custo alto e baixo de preparação. Esta melhoria é expressa por:

$$
\text { Melhoria }=100 *\left(\frac{G a p L_{\mathrm{HO} 2}-G a p L_{\mathrm{HT} 2}}{G a p L_{\mathrm{HT} 2}}\right)
$$

Tabela 5.58. GapL para os exemplos com estruturas seriais obtidos pelas heuristicas HT2 e H02

\begin{tabular}{|c|c|c|c|c|c|c|}
\hline GapL & \multicolumn{3}{|c|}{ Custo baixo de preparaçå̃o } & \multicolumn{3}{|c|}{ Custo alto de preparaçăo } \\
\hline N-T-K & HT2 & HO2 & Melhoria & HT2 & HO2 & Melhoria \\
\hline $10-6-2$ & 4.5 & 3.8 & $-16 \%$ & 31.1 & 28.5 & $-8 \%$ \\
\hline $10-6-3$ & 3.6 & 3.6 & $0 \%$ & 34.2 & 32.9 & $-4 \%$ \\
\hline $10-6-4$ & 3.4 & 3.4 & $0 \%$ & 40.1 & 38.3 & $-4 \%$ \\
\hline $10-12-2$ & 4.9 & 4.9 & $0 \%$ & 36.6 & 35.0 & $-4 \%$ \\
\hline $10-12-3$ & 4.6 & 4.6 & $0 \%$ & 42.4 & 39.9 & $-6 \%$ \\
\hline $10-12-4$ & 4.4 & 4.4 & $0 \%$ & 38.8 & 38.8 & $0 \%$ \\
\hline $10-18-2$ & 4.6 & 4.4 & $-4 \%$ & 32.0 & 31.6 & $-1 \%$ \\
\hline $10-18-3$ & 3.7 & 3.7 & $0 \%$ & 35.5 & 35.5 & $0 \%$ \\
\hline $10-18-4$ & 3.7 & 3.7 & $0 \%$ & 34.4 & 34.3 & $0 \%$ \\
\hline Média & 4.2 & 4.1 & $-2 \%$ & 36.1 & 35.0 & $-3 \%$ \\
\hline $17-6-2$ & 3.0 & 2.9 & $-3 \%$ & 29.6 & 25.6 & $-14 \%$ \\
\hline $17-6-3$ & 2.3 & 2.2 & $-4 \%$ & 26.1 & 26.1 & $0 \%$ \\
\hline $17-6-4$ & 2.3 & 2.3 & $0 \%$ & 27.3 & 27.6 & $1 \%$ \\
\hline $17-12-2$ & 2.5 & 2.4 & $-4 \%$ & 27.6 & 27.2 & $-1 \%$ \\
\hline $17-12-3$ & 3.0 & 2.9 & $-3 \%$ & 31.7 & 31.6 & $0 \%$ \\
\hline $17-12-4$ & 2.5 & 2.5 & $0 \%$ & 30.2 & 29.9 & $-1 \%$ \\
\hline $17-18-2$ & 3.3 & 3.3 & $0 \%$ & 35.0 & 35.5 & $1 \%$ \\
\hline $17-18-3$ & 2.6 & 2.6 & $0 \%$ & 31.3 & 30.6 & $.2 \%$ \\
\hline $17-18-4$ & 2.4 & 2.4 & $0 \%$ & 26.2 & 26.4 & $1 \%$ \\
\hline Média & 2.7 & 2.6 & $.2 \%$ & 29.4 & 28.9 & $-2 \%$ \\
\hline $40-6-2$ & 1.8 & 1.6 & $-11 \%$ & 19.3 & 19.4 & $1 \%$ \\
\hline $40-6-3$ & 1.4 & 1.4 & $0 \%$ & 18.7 & 17.9 & $.4 \%$ \\
\hline $40-6-4$ & 1.7 & 1.6 & $-6 \%$ & 16.8 & 16.7 & $-1 \%$ \\
\hline $40-12-2$ & 2.1 & 2.1 & $0 \%$ & 29.6 & 29.5 & $0 \%$ \\
\hline $40-12-3$ & 1.6 & 1.5 & $-6 \%$ & 23.1 & 23.0 & $0 \%$ \\
\hline $40-12-4$ & 2.3 & 2.3 & $0 \%$ & 19.7 & 19.9 & $1 \%$ \\
\hline $40-18-2$ & 1.3 & 1.4 & $8 \%$ & 27.5 & 27.5 & $0 \%$ \\
\hline $40-18-3$ & 1.7 & 1.6 & $-6 \%$ & 23.0 & 23.0 & $0 \%$ \\
\hline $40-18-4$ & 2.0 & 2.0 & $0 \%$ & 22.0 & 21.8 & $-1 \%$ \\
\hline Média & 1.8 & 1.7 & $-3 \%$ & 22.2 & 22.1 & $-1 \%$ \\
\hline Média Total & 2.9 & 2.8 & $-2 \%$ & 29.3 & 28.7 & $-2 \%$ \\
\hline
\end{tabular}

Os resultados apresentados na Tabela 5.58 mostram que a heurística $\mathrm{HO} 2$ apresenta soluções de melhor qualidade que a heurística HT2, isto considerando o GapL como uma medida de qualidade. No entanto, a heurística HT2 determina um número maior de soluções factíveis (veja Tabela 5.14) e, as diferenças nos valores dos gaps entre as heurísticas são muito pequenas. 
Tabela 5.59. GapL para os exemplos com estruturas gerais obtidos pelas heuristicas HT2 e H02.

\begin{tabular}{|c|c|c|c|c|c|c|}
\hline \multirow{2}{*}{$\begin{array}{l}\text { GapL } \\
\text { N-T-K }\end{array}$} & \multicolumn{3}{|c|}{ Custo baixo de preparação } & \multicolumn{3}{|c|}{ Custo alto de preparaçăo } \\
\hline & ET2 & $\mathrm{HO2}$ & Melhoria & HT2 & $\mathrm{HO2}$ & Melhoria \\
\hline $10-6-2$ & 3.6 & 3.8 & $6 \%$ & 20.5 & 19.4 & $-5 \%$ \\
\hline $10-6-3$ & 4.8 & 4.5 & $-6 \%$ & 29.7 & 29.7 & $0 \%$ \\
\hline $10-6 \cdot 4$ & 4.5 & 4.5 & $0 \%$ & 33.7 & 33.4 & $-1 \%$ \\
\hline $10-12-2$ & 4.1 & 4.1 & $0 \%$ & 31.3 & 32.1 & $3 \%$ \\
\hline $10-12-3$ & 4.8 & 4.8 & $0 \%$ & 30.6 & 30.1 & $-2 \%$ \\
\hline $10-12-4$ & 5.9 & 5.9 & $0 \%$ & 34.0 & 31.9 & $-6 \%$ \\
\hline $10-18-2$ & 4.6 & 4.6 & $0 \%$ & 27.0 & 26.0 & $-4 \%$ \\
\hline $10-18-3$ & 4.1 & 4.2 & $2 \%$ & 27.7 & 28.0 & $1 \%$ \\
\hline $10-18-4$ & 5.5 & 5.5 & $0 \%$ & 30.3 & 29.2 & $-4 \%$ \\
\hline Média & 4.7 & 4.7 & $0 \%$ & 29.4 & 28.9 & $-2 \%$ \\
\hline $17-6-2$ & 2.0 & 2.0 & $0 \%$ & 20.0 & 18.5 & $-8 \%$ \\
\hline $17-6-3$ & 2.2 & 2.2 & $0 \%$ & 12.1 & 12.3 & $2 \%$ \\
\hline $17-6-4$ & 2.2 & 2,2 & $0 \%$ & 15.3 & 15.3 & $0 \%$ \\
\hline $17-12-2$ & 2.2 & 2.2 & $0 \%$ & 16.4 & 15.2 & $-7 \%$ \\
\hline $17-12-3$ & 2.5 & 2.5 & $0 \%$ & 14.3 & 14.2 & $-1 \%$ \\
\hline $17-12-4$ & 2.3 & 2.3 & $0 \%$ & 16.8 & 17.0 & $1 \%$ \\
\hline $17-18-2$ & 2.5 & 2.5 & $0 \%$ & 18.3 & 17.1 & $-7 \%$ \\
\hline $17-18-3$ & 2.0 & 2.0 & $0 \%$ & 16.4 & 16.0 & $-2 \%$ \\
\hline $17-18-4$ & 2.0 & 2.0 & $0 \%$ & 14.8 & 14.9 & $1 \%$ \\
\hline Média & 2.2 & 2.2 & $0 \%$ & 16.0 & 15.6 & $-3 \%$ \\
\hline $40-6-2$ & 1.9 & 1.9 & $0 \%$ & **** & $* * *$ & o*** \\
\hline $40-6-3$ & 2.2 & 2.2 & $0 \%$ & 14.4 & 13.8 & $-4 \%$ \\
\hline $40-6-4$ & 2.7 & 2.7 & $0 \%$ & 18.2 & 17.9 & $-2 \%$ \\
\hline $40-12-2$ & 3.6 & 3.6 & $0 \%$ & $* 0 *$ & $* * *$ & $* * *$ \\
\hline $40-12-3$ & 3.3 & 3.4 & $3 \%$ & 17.8 & 17.9 & $1 \%$ \\
\hline $40-12-4$ & 3.3 & 3.3 & $0 \%$ & 16.3 & 15.7 & $-4 \%$ \\
\hline $40-18-2$ & 3.6 & 3.6 & $0 \%$ & 19.1 & 19.1 & $0 \%$ \\
\hline $40-18-3$ & 3.6 & 3.6 & $0 \%$ & 15.6 & 15.4 & $-1 \%$ \\
\hline $40-18-4$ & 3.4 & 3.4 & $0 \%$ & 19.6 & 19.4 & $-1 \%$ \\
\hline Média & 3.1 & 3.1 & $0 \%$ & 17.3 & 17.0 & $-1 \%$ \\
\hline Média Total & 3.3 & 3.3 & $0 \%$ & 21.2 & 20.8 & $-2 \%$ \\
\hline
\end{tabular}

Os resultados da Tabela 5.59 mostram a tendência da heurística $\mathrm{HO} 2$ de fornecer soluçōes de melhor qualidade do que a heurística HT2. No entanto, a diferença nos valores dos gaps entre as soluções heurísticas para os exemplos com custo baixo de preparação é mínima, sendo mais expressiva para os exemplos com custo alto de preparação. Veja também que para os exemplos com custo alto de preparação, 40 itens, 2 máquinas e com 6 e 12 períodos, não foi possível a comparação porque a heurística $\mathrm{HO} 2$ não determinou soluções factiveis para estes exemplos.

A tabela seguinte mostra os tempos computacionais médios que ambas as heurísticas gastaram para resolver os exemplos, para os quais os valores dos GapL foram apresentados nas tabelas 5.58 e 5.59 . 
Tabela 5.60. Tempos computacionais médios em segundos gastos por $\mathrm{HO} 2$ e HT2.

\begin{tabular}{|c|c|c|c|c|c|}
\hline \multirow{2}{*}{ Estruturas } & \multirow{2}{*}{$\mathrm{N}$} & \multicolumn{2}{c|}{$\begin{array}{c}\text { Custo baixo de } \\
\text { preparação }\end{array}$} & \multicolumn{2}{c|}{$\begin{array}{c}\text { Custo alto de } \\
\text { preparação }\end{array}$} \\
\cline { 3 - 6 } & & HO2 & HT2 & HO2 & HT2 \\
\hline \multirow{3}{*}{ Seriais } & 10 & 1.3 & 1.1 & 1.6 & 1.2 \\
& 17 & 2.4 & 2.2 & 2.8 & 2.1 \\
& 40 & 9.3 & 8.2 & 7.5 & 7.0 \\
\hline \multicolumn{2}{c|}{ Média } & 4.3 & 3.8 & 4.0 & 3.4 \\
\hline \multirow{3}{*}{ Gerais } & 10 & 1.4 & 1.3 & 1.6 & 1.2 \\
& 17 & 2.3 & 2.3 & 2.8 & 2.1 \\
& 40 & 9.4 & 8.8 & 10.4 & 9.5 \\
\hline \multicolumn{2}{|c|}{ Média } & 4.4 & 4.1 & 4.9 & 4.3 \\
\hline
\end{tabular}

Como era de se esperar, a heurística com estratégias de Busca Tabu encontra uma solução factlvel num tempo menor do que a heurística $\mathrm{HO} 2$. Veja os exemplos com 40 itens, custo alto de preparação e estrutura geral, a heurística HT2 utilizou um tempo médio de 9.5 segundos, enquanto que, a heurística $\mathrm{HO} 2$ utilizou 10.4 segundos.

\section{Soluções Fornecidas pelas Heurísticas HO1, HO2, HT2 e HT1}

Apesar do baixo número de soluções factíveis obtidas pela heurística $\mathrm{HOl}$ é feita uma comparação para verificar a qualidade das soluções fornecidas pelas quatro versões heurísticas. Convém observar aqui que, a heurística $\mathrm{HOI}$ não obteve soluções factíveis para os exemplos com custo alto de preparação e estruturas gerais com 40 itens, sendo neste caso, impossivel fazer a comparação para estes exemplos. Para os outros exemplos, com custo alto de preparação, a porcentagem de soluções factíveis obtidas foi muito baixa (veja tabelas 5.14 e 5.15). Assim, as comparações podem levar a conclusões erradas da qualidade das soluções, principalmente para os exemplos com custo alto de preparação. 
Tabela 5.61. GapL para os exemplos com estruturas gerais obtidos pelas heuristicas HT2, HT1, HO1 e H02.

\begin{tabular}{|c|c|c|c|c|c|c|c|c|c|}
\hline \multirow[b]{2}{*}{ Estruturas } & \multirow[b]{2}{*}{ itens } & \multicolumn{4}{|c|}{ custo baixo de preparaçāo } & \multicolumn{4}{|c|}{ custo alto de preparação } \\
\hline & & HO1 & HO2 & HT2 & HT1 & HO1 & $\mathrm{HO2}$ & HT2 & HT1 \\
\hline \multirow{6}{*}{ Seriais } & 10 & 2.7 & 3.9 & 4.0 & 2.8 & 32.2 & 36.6 & 36.9 & 43.1 \\
\hline & $\begin{array}{l}\text { Desvio } \\
\text { padrao }\end{array}$ & 0.4 & 0.5 & 0.5 & 0.4 & 10.0 & 4.7 & 6.8 & 18.2 \\
\hline & 17 & 1.9 & 2.5 & 2.8 & 1.9 & 22.1 & 29.0 & 28.9 & 26.7 \\
\hline & $\begin{array}{l}\text { Desvio } \\
\text { padrao }\end{array}$ & 0.4 & 0.4 & 0.4 & 0.4 & 9.8 & 4.4 & 4.5 & 4.4 \\
\hline & 40 & 1.3 & 1.6 & 1.7 & 1.4 & 18.1 & 19.3 & 19.1 & 18.9 \\
\hline & $\begin{array}{l}\text { Desvio } \\
\text { padrao }\end{array}$ & 0.3 & 0.6 & 0.4 & 0.3 & 8.6 & 4.5 & 4.7 & 4.1 \\
\hline \multicolumn{2}{|c|}{ GapL médio } & 2.0 & 2.7 & 2.8 & 2.0 & 24.1 & 28.3 & 28.3 & 29.6 \\
\hline \multirow{6}{*}{ Gerais } & 10 & 3.7 & 4.6 & 4.5 & 3.7 & 17.8 & 28.1 & 28.5 & 22.5 \\
\hline & $\begin{array}{l}\text { Desvio } \\
\text { padrao }\end{array}$ & 0.8 & 0.8 & 0.7 & 0.8 & 5.7 & 3.1 & 3.4 & 7.3 \\
\hline & 17 & 1.5 & 2.2 & 2.2 & 1.6 & 12.8 & 14.2 & 14.5 & 13.3 \\
\hline & $\begin{array}{l}\text { Desvio } \\
\text { padrao }\end{array}$ & 0.2 & 0.3 & 0.3 & 0.2 & 5.0 & 2.4 & 2.0 & 3.5 \\
\hline & 40 & 2.9 & 3.1 & 3.1 & $2 . \overline{9}$ & $\hbar \star \star *$ & $\hbar \star \star *$ & *** & $\star \star \star$ \\
\hline & $\begin{array}{l}\text { Desvio } \\
\text { padrao }\end{array}$ & 1.0 & 0.9 & 0.9 & 1.0 & $\star \star \star$ & $* * *$ & 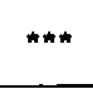 & $\star \star \star$ \\
\hline \multicolumn{2}{|c|}{ GapL médio } & 2.7 & 3.3 & 3.3 & 2.7 & 15.3 & 21.2 & 21.5 & 17.9 \\
\hline
\end{tabular}

Os resultados apresentados na Tabela 5.61 mostram que a heurística $\mathrm{HOl}$ fornece soluções de melhor qualidade, no entanto, o desempenho desta heuristica é péssimo quando se considera factibilidade (veja tabelas 5.14 e 5.15). Para os exemplos com custo baixo de preparação, a diferença nos valores dos gaps é minima quando se compara a heurística $\mathrm{HOl}$ e HT1; já para os exemplos com custo alto de preparação esta diferença é maior. Observe também que, para os exemplos com custo alto de preparação, a heurística HTl fornece soluções melhores do que a heurística HT2, no entanto, quando utilizou um número maior de exemplos para comparação foi notado que, às vezes, a heurística HT2 fornecia soluções melhores (veja tabelas 5.55 e 5.56). 


\section{- Conclusões}

Neste capítulo foram apresentadas quatro variantes de uma heurística para resolução do problema de dimensionamento de lotes proposto nesta tese. Entre as quatro heurísticas, duas apresentaram desempenho melhor sobre as outras na determinação das soluções factíveis. As heurísticas que tiveram o pior desempenho não utilizavam estratégias baseadas na memória de curto prazo da Busca Tabu, para evitar as ciclagens, que ocorre entre as máquinas dentro de um certo período e, entre os passos do procedimento de factibilização. Os resultados computacionais, realizados com um conjunto grande de exemplos, permitiram comprovar a eficiência desta estratégia no controle dos ciclos e, com isto, obteve um grande número de soluçōes factíveis para os exemplos gerados.

As duas melhores heurísticas HT1 e HT2 diferem apenas no procedimento da determinação das soluções iniciais. A heurística HT2, que utiliza o algoritmo WW-Paralelo Penalizado, pode ser considerada a heurística mais indicada para resolução do problema considerado, apesar de não ter conseguido, em média, soluções de melhor qualidade do que HT1 para algumas dimensões dos exemplos gerados. Os fatores que levaram a considerar a heurística HT2, como a heurística mais indicada, foram:

Em média, apresentava maior porcentagem de soluções factíveis .

Utiliza um número menor de iterações.

Utiliza menos tempo computacional.

Solicita menos chamadas ao procedimento cria_transferência.

Solicita menos chamadas do procedimento de alteração (P4).

Apresenta soluções iniciais com menores excessos da capacidade.

A seguir, no Capitulo 6 é apresentada uma proposta de resolução para um problema de dimensionamento e sequenciamento de lotes. 


\section{CAPÍTULO 6}

\section{UM PROBLEMA DE DIMENSIONAMENTO E \\ SEQUeNCIAMENTO de Lotes E UM PROCEDIMENTO DE RESOLUÇÃO}

\subsection{Introdução}

Neste capítulo é considerado o problema de dimensionamento e sequenciamento de lotes em um sistema de produção multiestágio, onde cada estágio é composto por máquinas paralelas com capacidade limitada. O problema consiste em determinar um plano de produção que atenda a demanda dos itens finais e de seus componentes em cada período de um horizonte finito de planejamento. Os tempos (custos) das preparações são dependentes da sequiência de produção dos itens.

O objetivo do problema é determinar qual a melhor seqüência de produção para cada periodo e máquina que minimize os custos de produção, preparação e de estoque. Um método heurístico para a resolução deste problema é proposto. Relaxando-se as restrições de capacidade, uma solução inicial (seqüência inicial), possivelmente infactível, para cada período e máquina é obtida utilizando um algoritmo de programação dinâmica (Armentano e Toledo, 1997). Este algoritmo é aplicado primeiramente aos itens finais, e a seguir, para os seus itens componentes. Em seguida, se a solução obtida for infactível, tenta-se obter um plano de produção factível em relação às restrições de capacidade. $O$ procedimento de 
factibilização consta de dois passos principais: pré-factibilização e factibilização final. $O$ procedimento de pré-factibilização consiste na resolução do problema do caixeiro viajante para cada período e máquina na tentativa de obter uma seqüência melhor de produção dos itens, em relação aos tempos de preparação (uma sequência alternativa pode diminuir os tempos de preparação e até factibilizar a solução). Após o procedimento de pré-factibilização, faz-se transferências de produção entre períodos e máquinas na tentativa de encontrar uma solução factível.

\subsection{Formulação do Problema}

A formulação do problema não será apresentada aqui, mas as variáveis e os dados necessários são definidos para uma futura formulação do modelo. Estas definições são necessárias para o entendimento do procedimento de resolução proposto.

O problema consiste em determinar o tamanho dos lotes de produção de cada item e uma seqüência de produção, em cada período e máquina, em um horizonte de tempo finito. É considerado que vários itens podem ser produzidos em um determinado período, assim, este problema é considerado como um "large bucket problem" (Haase e Kimms, 2000). Os custos considerados são os de produção, estoque e preparação, sendo este último dependente da seqüência de produção na máquina e período. É suposto que os recursos são gastos com produção e preparação (dependente da seqüência de produção).

Como em Haase e Kimms (2000) é assumido que as preparações são preservadas entre períodos de folga. Isto é, se um determinado item i foi produzido no final do periodo $t$ numa máquina $k$, e se não houver produção de nenhum item até um certo período $t^{\prime \prime}$ nesta máquina $\left(t \rightarrow t+1 \rightarrow \cdots \rightarrow t^{\prime \prime}\right)$, então não há a necessidade de uma nova preparação se ocorrer a decisão de produzir o item i na máquina $k$ no inicio do período $t$ ".

A seguinte notação adicional é considerada e a notação anterior, apresentadas nos capítulos 2 e 3 , será mantida.

Índices adicionais

$\mathrm{i}, \mathrm{j}, \mathrm{r}=0, \ldots, \mathrm{N}$ Número de itens ( 0 é um item artificial, que deverá estar programado em cada máquina no início do planejamento).

Dados adicionais

$c s_{\mathrm{j} j \mathrm{tk}}$ - Custo de preparação do item i para o item $\mathrm{j}$, no período $\mathrm{t}$, na maquina $\mathrm{k}$. 
$t_{\mathrm{ijtk}}$ - Tempo de preparação do item i para o item j, no período t, na máquina $\mathrm{k}$.

Variáveis adicionais

seq $(k, t)$ - Sequência ordenada de índices dos itens que são produzidos na máquina $k$ e período t.

$\mathrm{Y}_{\mathrm{jit} \mathrm{k}}= \begin{cases}1, & \text { se } \mathrm{i} \text { é produzido após o item } \mathrm{j} \text { no período t na máquina } \mathrm{k} \\ 0, & \text { caso contrário }\end{cases}$

$Z_{\mathrm{itk}}=\left\{\begin{array}{l}1, \text { se a máquina } \mathrm{k} \text { é preparada para a produção do item i no final do perfodo } t \\ 0, \text { caso contrário }\end{array}\right.$

Supõem-se que os custos (tempos) das preparações devem satisfazer a desigualdade triangular, isto é, para todo, $i, j, n=1, \cdots, N$, tem-se:

$$
c s_{j i t k} \leq c s_{j n i k}+c s_{n i t k}\left(t s_{j i l k} \leq t s_{j n i k}+t s_{n i t k}\right) \text {. }
$$

Neste trabalho assume-se que os custos e tempos de preparações devem satisfazer a desigualdade triangular, no entanto, em Kang et al. (1999) comenta-se que em alguns casos, podem existir certos itens para os quais a desigualdade triangular não precisa ser satisfeita. Neste caso, pode ocorrer preparação para um determinado item sem que ocorra produção. Este é o caso de um "rinsing" produto que pode ocorrer em uma indústria química (Fleischmann, 1994).

No trabalho de Haase e Kimms (2000) é considerado $c s_{j i t k}=f_{i}+f_{s c} * t s_{j i t k}$, onde $f_{i}$ é um custo fixo e $\mathrm{f}_{\mathrm{sc}}$ é um custo de oportunidade por unidade de tempo de preparação. Para o cálculo dos custos das preparações, pretende-se adotar esta mesma expressão. Os estoques iniciais e finais, para cada item i, são considerados nulos para o problema em estudo.

Convém observar também que, para cada item i a ser produzido em um determinado periodo $t$ e máquina $\mathrm{k}$, é permitido fazer somente uma preparação dentro deste periodo, ou seja, a produção de um lote de cada item i deve ocorrer somente uma vez em um determinado perfodo e máquina.

\subsection{Solução Inicial (Seqüência Inicial)}

Novamente o algoritmo para a resolução do problema de dimensionamento de lotes, único item e máquinas paralelas, proposto por Armentano e Toledo (1997), é utilizado para obtenção de uma solução inicial. Para isto, primeiramente as restrições de capacidade são abandonadas, obtendo-se um problema multiestágio e sequêencia dependente com máquinas 
paralelas sem limitações de capacidade. A seguir, o algoritmo de Armentano e Toledo (1997) é utilizado para produzir uma solução factível para problema em relação às restrições de balanço de estoque da seguinte forma.

Supondo conhecido qual item $\mathrm{j}$ antecede $o$ item $\mathrm{i}$, nas sequêencias para cada máquina $\mathrm{e}$ período, resolve-se, para cada item $\mathrm{i}, \mathrm{i}=1, \ldots, \mathrm{N}$, o problema de dimensionamento de lotes multiestágio sem limitações de capacidade, a partir dos itens finais, pois tais itens não possuem sucessores $(S(i)=\varnothing)$, de modo que o lado direito da equação (3.10) reduz-se a $d_{i t}$, descendo a estrutura do produto o termo do lado direito de (3.10) fica sempre determinado, como apresentado no Capítulo 4.

A resolução do problema para o primeiro item final $\mathrm{i}=1$ determina a primeira posição da sequêencia inicial para cada máquina e período. Os custos de preparação para este item, neste procedimento, será $\mathrm{cs}_{1 \mathrm{tk}}=\mathrm{cs}_{01 \mathrm{tk}}(0$ é o item artificial) uma vez que ele vai ocupar a primeira posição das seqüências, caso seja produzido.

$\mathrm{O}$ próximo item $\mathrm{i}=2$ a ser produzido terá o custo $\mathrm{cs}_{2 \mathrm{tk}}=\mathrm{cs}_{12 \mathrm{tk}}$, já que pode ter ocorrido a produção do item $\mathrm{i}=1$ no período $t$ na máquina $\mathrm{k}$ e, será $\operatorname{cs}_{2 \mathrm{t}}=\mathrm{cs}_{02 \mathrm{t}}$, se não houve produção do item $\mathrm{i}=1$ no período $\mathrm{t}$, na máquina $\mathrm{k}$. Resolvendo o problema multiestágio seqüencialmente para $\mathrm{i}=1$ até $\mathrm{i}=\mathrm{N}$, as sequências de produção são determinadas para cada máquina e período.

As preparações são preservadas entre períodos ociosos, ou seja, se estiver determinando o plano de produção para o item i no período te máquina $\mathrm{k}$, verifica-se qual é o item que está sendo produzido na máquina $\mathrm{k}$ no período $\mathrm{t}-1$. Caso a máquina $\mathrm{k}$ esteja ociosa no período $\mathrm{t}-1$, verifica-se qual é o item que está sendo produzido no período $\mathrm{t}-2 \mathrm{e}$ assim por diante.

Esta solução inicial (sequiência inicial) é construída de modo que é factível em relação às restrições de balanceamento de estoques e produção, ou seja, que o plano de produção atenda as demandas sem atrasos.

\subsection{Procurando uma Solução Factível}

Depois de determinada a seqüência inicial, caso a solução inicial seja infactivel, tentase determinar uma solução factível. O procedimento da busca de uma solução factível consiste de dois passos: pré-factibilização e factibilização. No procedimento de préfactibilização tenta-se obter uma seqüência melhor para cada par (máquina, período), a partir da inicial, através da resolução do problema do caixeiro viajante para o par (máquina, 
período) considerado. Como os custos e tempos de preparação são gerados tal que $c s_{\mathrm{ijk}} \neq \mathrm{cs}_{\mathrm{jik}}, \forall \mathrm{i}, \mathrm{j}$ e máquina $\mathrm{k}$, devem ser aplicados métodos para resolução do problema do caixeiro viajante assimétrico (Kanellakis e Papadimitriou, 1980 e Lysgaard, 1999). O procedimento de factibilização é aplicado à sequeência obtida no procedimento de préfactibilização, onde se tenta transferir produção de um determinado item i que está sendo produzido numa posição $p(i)$ no período $t$ e máquina $k$, para um período t" e máquina $k$ " numa posição p"(i). As transferências entre períodos e máquinas são executadas de maneira análoga às transferências descritas no Capítulo 4.

\subsubsection{Procedimento de Pré-factibilização}

O primeiro procedimento denominado pré-factibilização, consiste na resolução do problema do caixeiro viajante para cada máquina e período de maneira a determinar uma seqüência com menores tempos de preparação, caso a solução inicial seja infactível. Assim, com a resolução de TxK problemas de caixeiros viajantes, espera-se uma diminuição dos excessos da utilização da capacidade em cada máquina e período. Neste procedimento também é considerada a preparação das máquinas entre os períodos, por exemplo, se a máquina $\mathrm{k}$ estiver produzindo o item $\mathrm{i}$ no final do período $\mathrm{t}-\mathrm{l}$, e se esta máquina produzir o item i no início do período t, então o tempo (custo) de preparação para este item na máquina $\mathrm{k}$ e periodo t será nulo, uma vez que a máquina estava preparada para este item no final do período t-1. Convém observar aqui, que neste procedimento o objetivo é melhorar a seqüência inicial em relação à utilização da capacidade. Para isto, os TxK problemas de caixeiros viajantes são resolvidos considerando como custo, os tempos de preparação, que também são seqüuências dependentes.

\subsubsection{Procedimento de Factibilização}

Nesta seção é descrito um procedimento baseado em transferências de produção entre períodos e entre máquinas na tentativa de obter uma solução factivel. O procedimento é semelhante ao apresentado no Capítulo 4 , sendo também composto de dois passos principais: regressivo e progressivo no tempo. 
Seja $\Delta_{\mathrm{kt}}=\sum_{\mathrm{i}=1}^{\mathrm{N}}\left(\mathrm{b}_{\mathrm{ik}} \hat{\mathrm{X}}_{\mathrm{itk}}+\sum_{(\mathrm{i}, \mathrm{j}) \in \operatorname{seq}(\mathrm{t}, \mathrm{k})} \mathrm{ts}_{\mathrm{jitk}}\right)-\mathrm{CAP}_{\mathrm{tk}}$ a variável de folga da restrição de capacidade, para cada $(k, t)$ onde, seq $(k, t)$ é a seqüuência determinada no procedimento de préfactibilização. $O$ excedente de recursos utilizado na máquina $\mathrm{k}$ no período $\mathrm{t}$ é dado por $\operatorname{excesso}(k, t)=\max \left\{0, \Delta_{k 1}\right\}$. Para eliminar o excedente (excesso $(k, t)>0$ ), realiza-se a transferência de uma quantidade $q$ de algum item i produzido no par $(k, t)$ (máquina $k$, período t) para $\left(k^{\prime}, t^{\prime}\right)$ com $k \neq k^{\prime}$ ou $t \neq t^{\prime}$. A quantidade $q$ a ser transferida pode ser escolhida como apresentado anteriormente, ou seja:

$$
q=\min \left\{Z_{i t k}^{t^{\prime} k^{\prime}}, Q_{i t k}\right\},
$$

onde:

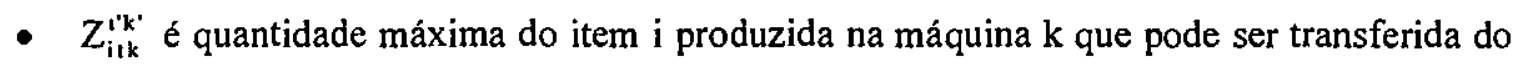
período $t(\operatorname{seq}(k, t))$ para o período t' e para máquina $k^{\prime}\left(\operatorname{seq}\left(k^{\prime}, t^{\prime}\right)\right)$ sem violar as restrições de balanço de estoque.

- $\mathrm{Q}_{\mathrm{itk}}=\frac{\text { excesso }(\mathrm{k}, \mathrm{t})}{\mathrm{b}_{\mathrm{ik}}}$ é quantidade exata do item $i$ que elimina o excesso da máquina $\mathrm{k}$ e período $\mathrm{t}$.

Os valores de $Z_{i+k}^{i k}$ nos passos progressivo e regressivo do procedimento de factibilização são determinados como no Capítulo 4 e, representados pelas expressões:

- Passo Regressivo no tempo

$$
Z_{i t k}^{t^{\prime} k^{\prime}}=\min \left\{X_{i t k}, \min _{\substack{j \in P_{i} \\ t^{\prime} \leq t \leq t-1}}\left\{\frac{I_{j z}}{a_{j i}}\right\}\right\} \text { para } t^{\prime}<t
$$

Se $\mathrm{t}=\mathrm{t}^{\prime}$, executa-se somente transferência entre máquinas, então $\mathrm{Z}_{\mathrm{i} \mathrm{ik}}^{\prime \mathbf{k}^{\prime}}=\mathrm{X}_{\mathrm{ilk}}$. Isto é válido também no passo progressivo.

- Passo Progressivo no tempo

$$
Z_{i t k}^{t k^{\prime}}=\min \left\{X_{i t k}, \min _{t \leq t \leq t^{\prime}-1}\left\{I_{i r}\right\}\right\} \text { para } t^{\prime}>t
$$




\section{Avaliação das transferências}

Para avaliar as quádruplas $\left(\mathrm{i}, \mathrm{q}, \mathrm{k}^{\prime}, \mathrm{t}^{\prime}\right)$ de possíveis transferências dos itens pertencentes a seq $(k, t)$ do par $(k, t)$ com violações de capacidade, utiliza-se o valor chamado de razão. Este valor é calculado baseado na alteração dos custos que a transferência causa e no excesso de utilização de recursos nos pares envolvidos. Assim, para cada par (k,t), a quádrupla (i,q,k',t') escolhida é aquela que minimiza a seguinte razão:

$$
\text { razão }=\frac{\Delta \text { custo }+ \text { FP.Penalidade }}{\Delta \text { redução }}
$$

Para um melhor entendimento de como é determinada a variação dos custos ( $\Delta$ custo), suponha que está sendo feita a avaliação da seguinte transferência do item i, que ocupa uma posição $p(i)$ na seq(k,t) para o par destino $\left(k^{\prime}, t^{\prime}\right)$, ocupando neste par, uma posição $p^{\prime}(i)$ da $\operatorname{seq}\left(k^{\prime}, t^{\prime}\right)$ :

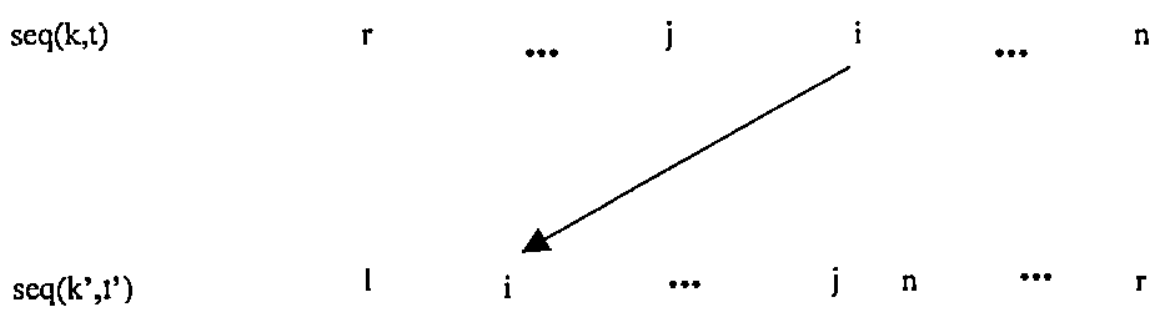

Observe que o item $\mathrm{i}$, candidato a ser transferido para o par $\left(\mathrm{k}^{\prime}, \mathrm{t}^{\prime}\right)$, pode ocupar $(\mathrm{N}-1)$ posições na seq $\left(k^{\prime}, t^{\prime}\right)$, caso não haja produção deste item no par $\left(k^{\prime}, t^{\prime}\right)$ destino. Como o objetivo deste procedimento é determinar uma solução factível, o item irá ocupar uma posição na $\operatorname{seq}\left(\mathrm{k}^{\prime}, \mathrm{t}^{\prime}\right)$ onde o tempo de preparação seja o mínimo possível. Assim, resolve-se o problema do caixeiro viajante considerando os itens na sequiência seq( $\left(k^{\prime}, t^{\prime}\right)$ e acrescentado o item i. Portanto, uma sequência é determinada com o menor tempo de preparação. Assim, o custo de preparação, do par $\left(\mathrm{k}^{\prime}, \mathrm{t}^{\prime}\right)$ destino, causado pela possível transferência do item i para a sequiência seq $\left(k^{\prime}, t^{\prime}\right)$ é dado pela diferença entre o custo desta nova sequiência (seq'(k', $\left.t^{\prime}\right)$ ) e o custo da sequiência atual sem o item $i\left(\operatorname{seq}\left(k^{\prime}, t^{\prime}\right)\right)$, então:

$\Delta$ csetup_destino $=\left\{\begin{array}{l}\text { custo de seq' }\left(k^{\prime}, t^{\prime}\right)-\text { custo de } \operatorname{seq}\left(k^{\prime}, t^{\prime}\right) \text {, caso não haja produção no par }\left(k^{\prime}, t^{\prime}\right) \text { do item } i \\ 0 \text { caso contrário }\end{array}\right.$ 
Agora, considere que está sendo feita uma tentativa de transferir toda a produção do item $\mathrm{i}$ do par origem $(\mathrm{k}, \mathrm{t})$ com violação de capacidade. $O$ custo de preparação no par $(\mathrm{k}, \mathrm{t})$ é dado pela diferença do custo de preparação da sequiência atual ( $\operatorname{seq}(k, t))$, e da sequiência obtida após a transferencia do item i $\left(\operatorname{seq}^{\prime}(k, t)\right)$. A sequuência seq' $(k, t)$ é obtida através da resolução do problema do caixeiro viajante para o par $(\mathrm{k}, \mathrm{t})$ retirado o item $\mathrm{i}$, e considerando os tempos de preparação. Então,

$\Delta$ csetup_origem $= \begin{cases}\text { custo de seq }(k, t)-\text { custo de } \operatorname{seq}^{\prime}(k, t), \\ \quad \text { (caso ocorra a transferência de toda a produção do item i do par }(k, t) \text { origem) } \\ 0, \quad \text { caso contrário }\end{cases}$

A variação do custo de preparação ( $\Delta$ csetup) ocorrido pela possivel transferência é dado por:

$\Delta$ csetup $=\Delta$ csetup_destino $+\Delta$ csetup_origem.

Assim, a variação dos custos ( $\Delta$ custo ) causada pela transferência da quantidade $q$ do item i da seq(k,t) para a seq(k',t') pode ser expressa como:

$\Delta$ custo $=\frac{q\left(\left(c_{i t^{\prime} k^{\prime}}-c_{i t k}\right)+\operatorname{passo} \sum_{\tau} \hat{\mathrm{h}}_{\mathrm{i \tau}}\right)+\Delta \mathrm{csetup}}{\text { custo da solução corrente }}$

onde,

- $\hat{\mathrm{h}}_{\mathrm{ir}}=\mathrm{h}_{\mathrm{i \tau}}-\sum_{\mathrm{r} \in \mathrm{P}(\mathrm{i})} \mathrm{a}_{\mathrm{ri}} \mathrm{h}_{\mathrm{rr}}$

- $\tau=\left\{\begin{array}{l}\mathrm{t}^{\prime}, \ldots, \mathrm{t}-1 \text { se passo regressivo no tempo } \\ \mathrm{t}, \ldots, \mathrm{t}^{\prime}-1 \text { se passo progressivo no tempo }\end{array}\right.$

- passo $=\left\{\begin{aligned}-1 & \text { se } \mathrm{t}^{\prime}>\mathrm{t} \text { (progressivo) } \\ 0 & \text { se } \mathrm{t}^{\prime}=\mathrm{t} \\ 1 & \text { se } \mathrm{t}^{\prime}<\mathrm{t} \text { (regressivo) }\end{aligned}\right.$

A penalidade em (6.1) é um termo não-negativo, que pode ser interpretado como um custo pelo excesso da produção da seq $(k, t)$ e da seq( $\left(k^{\prime}, t^{\prime}\right)$, dada:

$$
\text { Penalidade }=\frac{\text { excesso_depois }(k, t)}{\mathrm{CAP}_{k t}}+\frac{\text { excesso_depois }\left(k^{\prime}, t^{\prime}\right)-\operatorname{excesso\_ antes}\left(k^{\prime}, t^{\prime}\right)}{\operatorname{CAP}_{k^{\prime} t^{\prime}}}
$$

onde, 
excesso_depois $(k, t)=\left\{\begin{array}{l}\left\{\max \left\{0,\left(\sum_{r=1}^{N} b_{r k} X_{r t k}-b_{i k} q+\sum_{j, i \in s e q(k, t)} t s_{j i t k} Y_{j j t k}\right)-C A P_{t k}\right\}, \text { se } q \neq X_{i t k}\right. \\ \left\{\left\{\max \left\{0,\left(\sum_{\substack{r=1 \\ r \neq i}}^{N} b_{r k} X_{r t k}-b_{i k} q+\sum_{j, i \in s e q '(k, t)} t s_{j i t k} Y_{j i t k}\right)-C A P P_{t k}\right\}, \text { se } q=X_{i t k}\right.\right.\end{array}\right.$

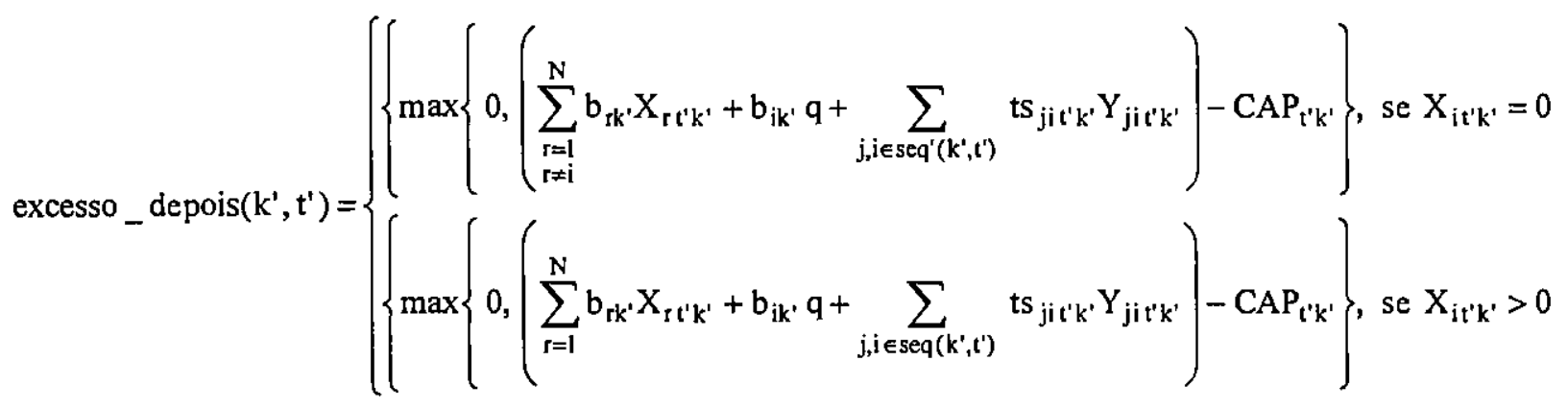

excesso_antes $\left(k^{\prime}, t^{\prime}\right)=\operatorname{excesso}\left(k^{\prime}, t^{\prime}\right)$

$\mathrm{O}$ fator FP em (6.1) representa um peso dado à penalidade, que pode ser aumentado de acordo com a dificuldade de obter uma solução factível. No primeiro passo regressivo e progressivo $\mathrm{FP}=1$, e $\mathrm{FP}=\mathrm{n}$ no n-ésimo passo.

A variação da redução ( $\Delta$ redução) representa a diferença entre 0 Excesso_depois $(k, t)$, ou seja, o excesso após executar a transferência de q unidades do item i e o excesso antes de executar a transferência, representado por Excesso_antes( $k, t)$. Assim, $\Delta$ redução $=\frac{\mathrm{qb}_{\mathrm{ik}}+\text { tsetup }}{\operatorname{cap}_{\mathrm{tk}}}$,

onde:

tsetup $=\left\{\begin{array}{l}\text { tempo de preparação da sequiência seq }(k, t) \text { - tempo de preparação da seqüência seq' }(k, t) \\ \text { (se houve transferência de toda produção do item i do } \operatorname{par}(k, t)) \\ 0, \quad \text { caso contrário. }\end{array}\right.$

Este método para a resolução do problema de dimensionamento e sequenciamento de lotes está sendo implementado e os resultados computacionais não serão apresentados por serem muito preliminares. Os parâmetros como geração da capacidade e geração dos custos e 
tempos de preparação obedecendo a desigualdade triangular também deverão ser feitos numa fase posterior.

Inicialmente um algoritmo desenvolvido por Glenn Dicus, Bart Jaworski e Joseph OuYang (Referência encontrada na Internet) para o problema do caixeiro viajante assimétrico (ATSP) está sendo utilizado. O procedimento para resolução do problema ATSP utiliza Simulated Annealing e o algoritmo 3-opt (ver Helsgaun, 2000).

Como continuação deste trabalho, também pretende-se determinar o modelo e resolvêlo utilizando o CPLEX 4.0 e, comparar as soluções obtidas com as soluções heurísticas. Provavelmente, esta comparação será feita para exemplos de pequenas dimensões. Ainda está em discussão qual será o parâmetro de comparação para as soluções dos exemplos de maior porte. Uma possibilidade seria comparar uma solução factível obtida pelo CPLEX depois de um número fixo de iteração ou mesmo, após um tempo determinado. Outra possibili dade seria comparar as soluções obtidas com um limitante fornecido pela relaxação linear, apesar deste ser pobre.

A seguir, no Capítulo 7, são apresentadas as conclusões e as propostas futuras para continuação dos procedimentos apresentados nesta tese. 


\section{CAPÍTULO 7}

\section{Conclusões e Perspectivas Futuras}

Nesta tese foram propostas heurísticas para resolver um problema de dimensionamento de lotes em ambiente multiestágio de produção, onde cada estágio é composto por máquinas paralelas com recursos limitados, e analisadas seus desempenhos computacionais. No modelo matemático foram incluídos custos e tempos de preparações, o que torna o problema extremamente complexo do ponto de vista computacional, justificando o emprego de heurísticas especializadas.

As heurísticas são variantes de um procedimento, o qual é uma extensão dos trabalhos de Berretta (1997) e Toledo (1998). No trabalho de Berretta (1997) foi considerado o problema de dimensionamento de lotes multiestágio, no entanto, não considera máquinas paralelas. Já no trabalho de Toledo (1997), foi desenvolvido uma heuristica para o problema de dimensionamento de lotes considerando máquinas paralelas, mas para o ambiente monoestágio. Assim, o problema estudado nesta tese difere desses dois trabalhos por considerar o problema multiestágio onde cada estágio é composto por máquinas paralelas.

Não foi encontrado trabalho na literatura que apresentasse um método de resolução para o problema aqui estudado, de modo que, as comparações foram feitas apenas com a solução ótima obtida pelo CPLEX 4.0 no grupo de problemas de dimensões pequenas. Para os problemas maiores, o tempo de execução do CPLEX 4.0 tornou-se insuportável e os valores obtidos pelas heurísticas foram comparados com limitantes inferiores obtidos através da 
aplicação de Relaxação Lagrangiana. Foi possível observar nos problemas menores, onde as soluções ótimas foram determinadas, que tal limitante era pobre, produzindo gaps bem maiores do que os reais (diferença entre a solução heurística e a ótima). Entretanto, há evidencias numéricas de que estas diferenças são melhores para exemplos maiores.

Os resultados obtidos permitiram concluir que a heurística mais indicada para a resolução do problema é a heurística HT2, pelos motivos discutidos no Capítulo 5 . Esta heurística foi capaz de obter soluções factíveis para $97.6 \%$ dos exemplos gerados com estruturas seriais e $83.9 \%$ dos exemplos com estruturas gerais (veja a Tabela 7.1). No entanto, a heurística HTl obteve também um bom desempenho da obtenção de soluções factíveis. A heurística $\mathrm{HO} 1$ teve o pior desempenho dentre todas as heurísticas, obtendo apenas $31.5 \%$ de soluções factíveis para os exemplos gerados com estruturas seriais e, $32.8 \%$ dos exemplos gerados com estruturas gerais.

Tabela 7.1. Porcentagens médias de FAC e GapL* para as heuristicas

\begin{tabular}{|c|c|c|c|c|}
\hline \multirow{2}{*}{ Heuristica } & \multicolumn{2}{|c|}{ Estruturas Seriais } & \multicolumn{2}{c|}{ Estruturas Gerais } \\
\cline { 2 - 5 } & FAC & GapL & FAC & GapL \\
\hline HO1 & 31.5 & 13.1 & 32.8 & 9.0 \\
\hline HT1 & 97.4 & 15.8 & 81.3 & 10.3 \\
\hline HO2 & 62.2 & 15.5 & 59.8 & 12.2 \\
\hline HT2 & 97.6 & 15.6 & 83.9 & 12.4 \\
\hline
\end{tabular}

*Calculados apenas para os exemplos onde todas heuristicas obtiveram uma solução factivel.

O objetivo inicial deste trabalho foi de desenvolver uma heuristica para encontrar soluções factíveis para os exemplos gerados com boa qualidade (HO1). Porém, o índice do fracasso na obtenção de soluções factíveis foi muito alto (veja Tabela 7.1), levando-nos a introduzir estratégias de Busca Tabu para evitar ciclos (HT1), o que permitiu encontrar um maior número de soluções factíveis, porém com a perda da qualidade (veja Tabela 5.61). Tendo em mente partir de uma solução inicial que considerasse algumas informações sobre a utilização dos recursos, foi introduzido o algoritmo WW-Paralelo Penalizado, surgindo assim, as heurísticas $\mathrm{HO} 2$ e HT2. Com este algoritmo foi possível melhorar as soluções em vários aspectos, tais como: diminuição no número de iterações para obtenção de soluções factíveis, conseqüentemente diminuição do tempo computacional, no entanto perdeu-se um pouco em qualidade (veja tabelas 5.55, 5.56 e 5.61). (Convém observar aqui que, os valores de GapL apresentados na Tabela 7.1, são os valores médios dos valores apresentados na Tabela 5.61.) 
Podemos observar também que o tempo computacional médio utilizado pelas melhores heurísticas (HT1 e HT2) para resolução dos exemplos de porte médio foi razoável, sendo que o tempo médio foi inferior a 20 segundos (veja Tabela 5.57). Convém observar também que, este é um resultado médio para 10, 17 e 40 itens, mas o tempo computacional máximo utilizado para as heurísticas HT1 e HT2 resolverem um exemplo foram de 103.81 segundos e 53.31 segundos, respectivamente.

Um dos passos na continuação deste trabalho, é o desenvolvimento de novas estratégias para melhorar a qualidade das soluções obtidas pelas heurf́sticas, principalmente em exemplos com custo alto de preparação. Estas estratégias devem ser adicionadas aos procedimentos P2, P3 e P4 do método heurístico. Assim, as principais propostas de pesquisas futuras são:

- Melhoria das heurísticas através da aplicação de meta-heurísticas, com o objetivo de reduzir os gaps, principalmente para os exemplos com custo alto de preparação. A aplicação da meta-heurística Busca Tabu foi baseada no uso da memória de curto prazo. A implementação da busca tabu melhorou o desempenho da heurística original na obtenção de soluções factíveis. Como proposta futura, poderiam ser implementadas estratégias baseadas no uso da memória de longo prazo, com o objetivo de diversificar e intensificar a busca realizada pela heurística. Uma outra meta-heurística que poderia ser investigada para o auxílio da heurística, seria o Simulated Annealing, ou o desenvolvimento de um procedimento híbrido que combinasse estas duas metaheurísticas (algo semelhante ao que foi feito em Berretta (1997)).

- Comparação da qualidade das soluções obtidas através das heuristicas com soluções factíveis obtidas utilizando o CPLEX 4.0. A idéia aqui é utilizar o CPLEX 4.0 para buscar uma solução factível utilizando parâmetros preestabelecidos. Os parâmetros poderiam ser o tempo de execução, o número de nós gerados, ou o número de iterações. Uma outra estratégia seria utilizar a solução obtida pela heurística com uma solução inicial de partida para o CPLEX e, assim, possibilitando a busca de soluções melhores.

- Heurísticas Lagrangianas: a cada $n$ iterações do método do subgradiente, aplicam-se as heurísticas HT1 e HT2 partindo-se das soluções infactíveis dos problemas Lagrangianos.

Também deve ser continuada a investigação de procedimentos de resolução para o problema inicialmente proposto no projeto de doutorado (3.1)-(3.8). Este modelo considera aspectos que até então não foram encontrados na literatura. 
Para o problema de dimensionamento de lotes e sequenciamento, deve continuar a implementação do procedimento proposto. Como foi visto na revisão bibliográfica, as pesquisas de métodos de resolução para este problema estão numa fase inicial, sendo assim muito promissora para investigações futuras. 


\section{Bibliografia}

Afentakis, P., Gavish, B. e Karmakar, U. (1984), "Computationally Efficient Optimal Solutions to the Lot-Sizing Problem in Multistage Assembly Systems", Management Science, 30 (2): 222-239.

Afentakis, P. e Gavish, B. (1986), "Optimal Lot-sizing Algorithms for Complex Product Structures", Operations Research, 34 (2): 237-249.

Afentakis, P. (1987), "A Parallel Heuristic Algorithm for Lot-Sizing in Multistage Production Systems", IIE Transactions, 19 (1): 34-42.

Akink, U. (1993), "A Practical Approach to Lot and Setup Scheduling at a Textile Firm", IIE Transactions, 25(2): 54-64.

Anthony, R. N. (1965), "Planning and Control Systems: A Framework for Analysis", Harvard University Press, Cambridge, Mass, apud em [Hö Candea, 1984].

Armentano, V. A. e Toledo, F. M. B. (1997), "Dynamic Programming Algorithms for the Parallel Machine Lot Sizing Problem", Pesquisa Operacional, 17:137-149.

Armentano, V. A., França, P. M. e Toledo, F. M. B. (1999), "A Network Flow Model for de Capacitated Lot-sizing Problem", Omega, 27: 275-284.

Bahl, H. C., Ritzman, L. P.e Gupta, J. N. D., (1987), “Determining Lot Sizes and Resource Requirements : A Review", Operations Research, 35 (3): 329-345.

Baker, K. R. (1993), "Requirements Planning", em "Graves, S.C., Rinnooy Kan, A. H. G e Zipkin, P. H. (1993), Logistic of Production and Inventory (Handbooks in Operations Research and Management Science, 4), Amsterdam, North Holland.

Berretta, R. E. (1997), "Heurísticas para Otimização do Planejamento da Produção em Sistemas MRP", Tese de Doutorado, FEEC-UNICAMP. 
Billington, P. J., McClain, J. O. e Thomas, L. J. (1983), "Mathematical Programming Approaches to Capacity MRP Systems: Review, Formulation and Problem Reduction," Management Science, 29 (10): 1126-1141.

Billington, P. J., McClain, J. O. e Thomas, L. J. (1986), "Heuristics for Multilevel Lot-Sizing with a Bottleneck ," Management Science, 32 (8): 989-1006.

Billington, P. J., Blackburn, J., Maes, J., Millen, R. e Wassenhove, L. N. V. (1995), "MultiItem Lotsizing Capacited Multi-Stage Serial Systems", IIE Transactions, 26 (2): 12-18.

Blackburn, J. D. e Millen, R. A (1982), "Improved Heuristics for Multi-Stage Requirements Planning Systems", Management Science, 28(1):44-56.

Blackburn, J. D. e Millen, R. A (1984), "Simultaneous Lot-Sizing and Capacity Planning in Multi-Stage Assembly Process", European Journal of Operational Research, 16:84-93.

Brüggemann, W. e Jahnke, H. (2000), "The Discrete Lot-Sizing and Scheduling Problem: Complexity and Modification for Batch Availability", European Journal of Operational Research, 124: 511-528.

Camarini, P. M., Fratta L. e Maffioli, F. (1975), "On Improving relation methods by modified Gradient Techniques", Mathematical Programming Study 3: 26-54.

Chen, W.H. e Thizy, J. M. (1990), " Analysis of Relaxations for the Multi-item Capacitated Lot-Sizing Problem", Annals of Operations Research, 26: 29-72.

Chiu, H. N e Lin, T. M (1989), "An Optimal Model and a Heuristic Technique for MultiStage Lot-Sizing Problems: Algorithms and Performance Tests", Engineering Costs and Production Economics, 16: 151-160.

Clark, A. J. e Scarf, H. (1960), "Optimal Policies for a Multi-Echelon Inventory Problem", Management Science, 6: 475-490.

Clark, A. R. (1990), "Problemas Multiestágios de Dimensionamento de Lotes com Tempo Não-Zero de Produção e Capacidade Finita", Tese de doutorado, Faculdade de Engenharia Elétrica, UNICAMP.

Clark, A. R. e Armentano, V. A. (1993), "Echelon Stock Formulation for Multi-Stage LotSizing With Component Lead Times", International Journal Of Systems Sciences, 24(9): 1759-1775.

Clark, A. R. e Armentano, V. A. (1995), "A Heuristic Resource-Capacitated Multi-Stage LotSizing Problem with Lead Times," Journal of the Operational Research Society, 46(10): 1208-1222.

Clark, A. R. e Clark, S. J. (2000), "Rolling- Horizon Lot-Sizing When Setup Times are Sequence-Dependent", International Journal of Production Research, 38(10): 22872307. 
Clark, A. R. (2000a), "A Local Search Approach to Lot Sequencing and Sizing", working paper.

Clark, A. R. (2000b), "Capacity Optimization in Master Production Scheduling", working paper.

Crowston, W. B. e Wagner, M. H. (1973), "Dynamic Lot Sizing Models for Multi-Stage Assembly Systems", Management Science, 20(1):14-21.

Dantzig, G. (1955), "Optimal Solution to a Dynamic Leontief Model with Substitution", Econométrica, 23: 295-302.

Deliarert, N. e Jeunet, J. (2000), "Solving Large Unconstrained Muitilevel Lot-sizing Problems Using a Hybrid Genetic Algorithm", International Journal of Production Research, 38(5):1083-1099.

Diaby, M. Bahl H., Karwan, M. H. e Ziont, S., (1992), "Capacitated Lot-Sizing and Scheduling by Lagrangean Relaxation ", European Journal Of Operational Research, 59: 444-458.

Dixon, P. e Silver, E. A. (1981), "A Heuristic Solution for the Multi-Item, Single-Level, Limited Capacity, Lot-Sizing Problem", Journal Of Operations Management, 2(1):23-39.

Drexфl A. e Kimms, A. (1997), "Lot sizing and Scheduling - Survey and Extension", European Journal of Operation Research, 99: 221-235.

Drexłl, A. e Haase, K. (1995), "Proportional Lotsizing and Scheduling", International Journal Of Production Economics, 40: 73-87.

Dumas, Y., Desrosiers, J., Gelinas, E. e Salomon, M. M. (1995), "An Optimal Algorithm for the Travelling Salesman Problem with Time Windows", Operations Research, 43(2), $367-371$.

Eppen, G. D. e Martin, R. K. (1987), "Solving Multi-item Capacitated Lot-Sizing Problems Using Variable Redefinition", Operations Research, 35(6):832-848.

Evans, James R. (1985), "An Efficient Implementation of the Wagner-Whitin Algorithm for Dynamic Lot-Sizing", Journal Of Operations Management, 5(2): 229-235.

Ferdergruen, A. e Tzur M. (1991), "A Simple Forward Algorithm to Solve General Dynamic Lot Sizing Models with $n$ Periods in $\mathrm{O}(\mathrm{n} \operatorname{logn})$ or $\mathrm{O}(\mathrm{n})$ time", Management Science, 37: 909-925.

Fernandes, F. C. F. (1991), "Concepção de um Sistema de Controle da Produção para uma Manufatura Celular", (Tese de Doutorado - EESC/USP).

Fleischmann, B. (1990), "The Discrete Lot-Sizing and Scheduling Problem", European Journal Of Operational Research, 44: 337-348. 
Fleischmann, B. (1994), "The Discrete Lot-Sizing and Scheduling Problem with SequenceDependent Setup Costs", European Journal Of Operational Research, 75: 395-404.

Fleischmann, B. e Meyr, H. (1997), "The General Lotsizing and Scheduling Problem", $O R$ Spektrum, 19: 11-21.

Florian, M., Lenstra, J. K. e Rinnoy Kan, A. H. G. (1980), "Deterministic Production Planning Algorithms and Complexity," Management Science, 26 (7): 669-679.

França, P. M., Armentano, V. A., Berretta, R. E. e Clark, A. R (1997), "A Heuristic Method for Lot-Sizing in Multi-Stage Systems", Computers \& Operations Research, 24 (9): 861874.

Glover, F. (1989), Tabu Search - Part I, Orsa Journal on Computing, 1 (3): 190-206.

Glover, F. (1990), Tabu Search - Part II, Orsa Journal on Computing, 2 (1): 4-32.

Graves, S. C. (1981), "A Review of Production Scheduling", Operations Research, 29(4): 646-675.

Haase, K. (1998), "Capacitated Lot-Sizing with Linked Production Quantities of Adjacent Periods, in: Drexl, A.,Kimms, A. (Hrsg.), Beyond Manufacturing Resource Planning (MRP II) - Advanced Models and Methods for Production Planning, Springer, Berlin, S. 127-146

Haase, K. e Kimms, A. (2000), " Lot Sizing and Scheduling with Sequence Dependent Setup Costs and Times and Efficient Rescheduling Opportunities", International Journal of Production Economics, 66: 159-169.

Harris, F. W. (1913), "How Many Parts to Make at Once", Factory, The Magazine of Management, 10(2):135-136, 152.

Harris, F. W., (1990), "How Many parts to make at once", Operations Research 38: 947-950

(reprint from Factory, The Magazine of Management, 10(2):135-136, 152)

Held, M., Wolfe, P., e Croweder, H.. (1974), "Validation of Subgradient Optimization", Mathematical Programming, 6: 62-68.

Helsgaun, K. (2000), “An Effective Implementation of the Lin-Kernighan Traveling Salesman Heuristic", European Journal of Operational Research 126: 106-130.

Hox, A. C. e Candea, D. (1984), Production and Inventory Management, Prentice-Hall, Inc.

Johnson, L. A. e Montgomery, D. C. (1974), "Operations Research in Production Planning, Scheduling and Inventory Control", New York: John Wiley \& Sons.

Kanellakis, Paris"C. e Papadimitriou, C. H. (1980), "Local Search for the Asymmetric Traveling Salesman Problem", Operations Research, 28(5): 1086-1099.

Kang, S., Malik, K. e Thomas, L. J. (1999), "LotSizing and Scheduling on Parallel Machines with Sequence-Dependent Setup Costs", Management Science, 45(2): 273-289. 
Katok, E., Lewis, S. H. e Harrison, T. P. (1998), "Lot-Sizing in General Assembly Systems with Setup Costs, Setup Times and Multiple Constrained Resources", Management Science, 44 (6):859-877.

Kimms, A. (1996a), “Competitive Methods for Multi-Level Lot Sizing and Scheduling: Tabu Search and Randomized Regrets", Int. J. Prod. Res., 34 (8): 2279-2298.

Kimms, A. (1996b), "Multi-level, Single Machine Lot Sizing and Scheduling (with Initial Inventory)", European Journal of Operational Research, 89: 86-99.

Kimms, A. (1997), "Demand Shuffle- A Method for Multilevel Proportional Lot Sizing and Scheduling", Naval Research Logistics, 44: 319-340.

Kimms, A. e Drexel, A. (1998a), "Proportional Lot Sizing and Scheduling: Some Extensions", Networks 32: 85-101.

Kimms, A. e Drexel, A. (1998b), "Some Insights into Proportional Lot Sizing and Scheduling", Journal of the Operational Research Society, 49: 1196-1205.

Kuik, R., Salomon, M. (1990), "Multi-level Lot-sizing Problem: Evalution of a Simulatedannealing Heuristic", European Journal of Operational Research, 45: 25-37.

Kuik, R., Salomom, M., Van Wassenhose, L. N. e Maes, J. (1993), "Linear Programming, Simulated Annealing and Tabu Search Heuristics for Lotsizing in Bottleneck Assembly Systems", IIE Transactions, 25(1): 62-72.

Kuik, R., Salomon, M. e Van Wassenhove, L. N. (1994), "Batching Decisions: Structure and Models", European Journal of Operational Research, 75: 243-263.

Laguna, M. (1995), "Tabu Search Tuturial”, II Escuela de Verano Latino-Americana de Investigation Operativa, Rio de Janeiro, 1995.

Laguna, M. (1999), "A Heuristic for Production Scheduling and Inventory Control in the Presence of Sequence-Dependent Setup Times", IIE Transactions 31: 125-134.

Lasdon, L. S. e Terjung, R. C. (1971), "An Efficient Algorithm for Multi-Item Scheduling”, Operations Research, 19: 946-969.

Lozano, S., Larraneta, J. e Onieva, L. (1991), "Primal-dual Approach to the Single Level Capacitated Lot-Sizing Problem", European Journal of Operational Research 51: 354366.

Luenberger, D. G. (1984), "Introduction to Linear and Non-Linear Programming", Second Edition, Addison-Wesley, Reading, Mass.

Lysgaard, J. (1999), "Cluster Based Branching for the Asymmetric Traveling Salesman Problem", European Journal of Operational Research, 119: 314-325. 
Maes, J., McClain, J. O. e Van Wassenhove, L. N. (1991), "Multilevel Capacitated LotSizing Complexity and LP based Heuristics," European Journal of Operational Research, 53: 131-148.

Maes, J. e Van Wassenhove, L. N. (1991), "Capacitated Dynamic Lotsizing Heuristics for Serial Systems", International Journal of Production Research, 29(6): 1235-1249.

McClain, J. O., Thomas, L. J. e Weiss, R. N. (1989), Efficient Solutions to a Linear Programming Model for Production Scheduling With Capacity Constraints and No Initial Stock, IIE Transactions, 21(2): 144-152.

Meyr, H. (2000), "Simultaneous Lotsizing and Scheduling by Combining Local Search with Dual Reoptimization", European Journal of Operational Research, 120:311-326.

Resende, M. O. e Sacomano, J. B. (1997), "Princípios dos Sistemas de Planejamento e Controle da Produção", Escola de Engenharia de São Carlos, USP (Editora da USP).

Roll, Y. e Karni, R. (1991), "Multi-item, Multi-level Lot Sizing With an Aggregate Capacity Constraint", European Journal Of Operation Research, 51:73-87.

Sabbag, Z. (1993), "Planejamento da Produção em Máquinas Paralelas Sob Restrições de Capacidade", Dissertação de Mestrado, FEE-UNICAMP.

Salomon, M., Salomon, M. M., Van Wassenhove, L. N., Dumas Y. e Dauzere-Peres, S. (1997), "Solving the Discrete Lotsizing and Scheduling Problem with Sequence Dependent Set-up Costs and Set-up Times Using the Travelling Salesman Problem with Time Windows", European Journal Of Operational Research, 100: 494-513.

Shapiro, J. F. (1993), "Mathematical Programming Models and Methods for Production Planning and Scheduling", em "Graves, S.C., Rinnooy Kan, A. H. G e Zipkin, P. H. (1993), Logistic of Production and Inventory (Handbooks in Operations Research and Management Science, 4), Amsterdam North Holland.

Sikora, R., Chhajed, D. e Shaw, M.J. (1996), "Integranting the Lot-Sizing and Sequencing Decisions for Scheduling a Capacitated Flow Line", Computers Ind. Engng, 4(30): 659679.

Stadler, H. (1996), "Mixed Integer Programming Model Formulations for Dynamic MultiItem Multi-Level Capacitated Lotsizing", European Journal of Operational Research, $94: 561-581$.

Tempelmeier, H. and Derstroff, M. (1996), "A Lagrangean-based Heuristic for Dynamic Multilevel Multiitem Constrained Lotsizing with Setup Times", Management Science, 42(5): 738-757. 
Tempelmeier, H. e Helber, S. (1994), “A Heuristic for Dynamic Multi-item Multi-level Constrained Lotsizing for General Product Structures", European Journal of Operation Research, 75: 296:311.

Tempelmeier, H. (1997), " Resource-Constrained Material Requirements Planning - MRP rc", Production Planning \& Control, 8(5): 451-461.

Toledo, F. M. B. (1998), "Dimensionamento de Lotes em Máquinas Paralelas", Tese de Doutorado, FEEC-UNICAMP.

Trigeiro, W. W., Thomas, L. J. e McClain, J. O. (1989),"Capacitated Lot Sizing With Setup Times", Management Science, 35(3), 353-366.

Veinott Jr., A F. (1969), "Minimum Concave-cost Solution of Leontief Substitution Models of Multi-facility Inventory Systems", Operations Research, 17: 262-291.

Wagelmans, A , Van Hoesel, S. e Kolen, A. (1992), "Economic Lot Sizing: na O(nlog n) Algorithm that Runs in Linear Time in the Wagner-Whitin Case", Operations Research, 40: $145-156$.

Wagner, H. M. e Whitin, T. M. (1958), "Dynamic Version of the Economic Lot Size Model," Management Science, 5 (1): 89-96.

Wolsey, L. A., (1995), "Progress with Single-Item lot-Sizing", European Journal of Operational Research, 86: 395-401.

Zangwill, W. I. (1969),"A Backlogging Model and a Multiechelon Model of a Dynamic Economic Lot Size Production System - a Network Approach", Management Science, 15(9):506-527. 


\section{APÊNDICE A}

\section{Notação Matricial e Formulações Equivalentes do Problema de Dimensionamento de Lotes Multiestágio: Estoque Convencional versus Estoque de Escalão}

\section{Introdução}

Neste apêndice é considerado o problema de dimensionamento de lotes formulado em termos de estoque convencional e em termos de estoque de escalão. $O$ estoque de escalão, a despeito de sua interpretação econômica, é interpretado como uma mudança de variável, definida por uma transformação linear. Este ponto de vista, permite mostrar mais facilmente a equivalência entre as formulações. Relembrando que a estrutura do processo de produção multiestágio pode ser representada por um grafo orientado $G(V, E)$, onde os nós em $V$ representam o conjunto de itens $e$, os arcos em $E$ representam as relações entre eles. $O$ arco $(i, j)$ existe somente se o item $\mathbf{j}$ depende da produção do item $\mathrm{i}$, ou seja, $\mathrm{j}$ é um sucessor imediato do item i e, $\mathrm{i}>\mathrm{j}$ (na estrutura do produto os itens são numerados de 1 até $\mathrm{N}$, dos itens finais às matérias primas). Existem várias representações possíveis para um grafo. Uma representação, considerada neste trabalho, usa o conjunto $\mathrm{S}(\mathrm{i}), \forall \mathrm{i} \in \mathrm{V}$, como o conjunto de sucessores imediatos do item $\mathrm{i} e, \mathrm{o}$ conjunto $\mathrm{P}(\mathrm{i}), \forall \mathrm{i} \in \mathrm{V}$, o conjunto dos itens predecessores imediatos do item i (Afentakis e Gavish, 1986). 


\section{Notação Matricial para o Problema de Dimensionamento de Lotes}

A formulação matemática do problema de dimensionamento de lotes aqui apresentada é uma abreviação, por simplicidade de notação, do modelo descrito no Capítulo 3, mas suficientemente geral para nossos propósitos de introduzir uma notação matricial.

Modelo Matemático do Problema de dimensionamento de lotes multiestágio:

$$
z=\min \sum_{i=1}^{N} \sum_{t=1}^{T}\left(c_{i t} X_{i t}+h_{i t} I_{i t}+\operatorname{cs}_{i t} Y_{i t}\right)
$$

Sujeito a:

$$
\begin{array}{ll}
I_{i(t-1)}+X_{i t}-I_{i t}-\sum_{j \in S(i)} a_{i j} X_{j t}=d_{i t}, & i=1, \ldots, N, t=1, \ldots, T, \\
\sum_{i=1}^{N}\left(b_{i k} X_{i t}+t_{i k} Y_{i t}\right) \leq C A P_{t k}, & k=1, \ldots, K, \quad t=1, \ldots, T, \\
X_{i t}-M Y_{i t} \leq 0, & i=1, \ldots, N, \quad t=1, \ldots, T, \\
Y_{i t} \in\{0,1\}, X_{1 t} \geq 0, \quad I_{i t} \geq 0 . & i=1, \ldots, N, t=1, \ldots, T .
\end{array}
$$

Com a finalidade de introduzir uma notação matricial para o problema (Al)-(A5), considere a seguinte notação:

\section{Dados:}

$\mathbf{b}^{\mathbf{k}}=\left[\begin{array}{llll}\mathrm{b}_{1 \mathrm{k}} & \mathrm{b}_{2 \mathrm{k}} & \cdots & \mathrm{b}_{\mathrm{Nk}}\end{array}\right]$ é o vetor-linha das necessidades de recursos para cada máquina $\mathrm{k}$;

$\mathbf{t s}^{\mathrm{k}}=\left[\begin{array}{llll}\mathrm{ts}_{\mathrm{Ik}} & \mathrm{ts}_{2 \mathrm{k}} & \cdots & \mathrm{ts}_{\mathrm{Nk}}\end{array}\right]$ vetor-linha dos tempos de preparação para cada máquina $\mathrm{k} ;$

$c^{\prime}=\left[\begin{array}{llll}c_{1 t} & c_{2 t} & \cdots & c_{N t}\end{array}\right]$ vetor-linha dos custos de produção para cada período t;

$\mathrm{cs}=\left[\begin{array}{llll}\mathrm{cs}_{1} & \mathrm{cs}_{2} & \cdots & \mathrm{cs}_{\mathrm{N}}\end{array}\right]$ vetor-linha dos custos de preparação;

$\mathbf{d}^{t}=\left[\begin{array}{llll}d_{1 t} & d_{2 t} & \cdots & d_{N t}\end{array}\right]$ vetor-coluna das demandas para cada período $t ;$

$\mathbf{h}^{t}=\left[\begin{array}{llll}h_{1 t} & h_{2 t} & \cdots & h_{N t}\end{array}\right]$ vetor dos custos de estoque convencional para cada periodo $t ;$

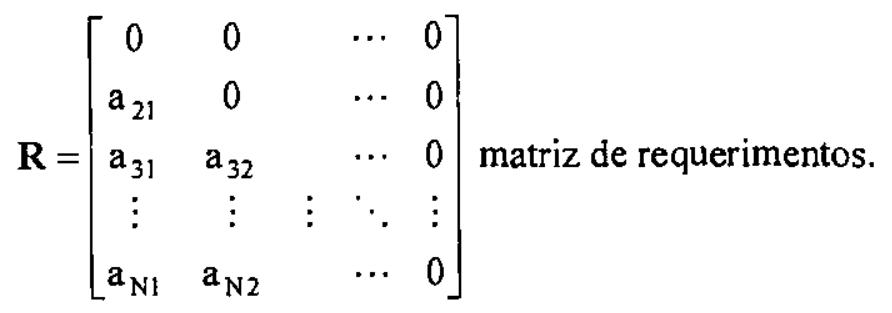


Obs. A matriz $\mathbf{R}$ tem um valor simbólico na apresentação do modelo, devendo ser armazenada na ordem de grandeza de $G=(V, E)$, uma vez que $a_{i j} \neq 0$ se e somente se $(i, j) \in E$, isto $\hat{e}, a_{i j}$ é um peso associado a cada arco $(i, j)$ (ou, analogamente, se $\mathrm{j} \in \mathrm{S}(\mathrm{i})$ ).

\section{Variáveis:}

$I^{t}=\left[\begin{array}{llll}I_{1 t} & I_{2 t} & \cdots & I_{N t}\end{array}\right]^{\prime}$ vetor-coluna dos estoques convencionais para cada $t$;

$E^{t}=\left[E_{1 t} E_{2 t} \cdots E_{N t}\right]^{\gamma}$ vetor-coluna dos estoques de escalão para cada t;

$\mathbf{X}^{t}=\left[\begin{array}{llll}X_{11} & X_{21} & \cdots & X_{N 1}\end{array}\right]^{\prime}$ vetor-coluna das produções em cada $t ;$

$\mathbf{Y}^{\mathbf{t}}=\{0,1\}^{\mathrm{N}}$ vetor-coluna que indica se houve preparação para o item $\mathrm{i}$ em $\mathrm{t}$.

Com esta notação o modelo (A1)-(A5) pode ser rescrito como:

$$
\operatorname{Minimize} \sum_{t=1}^{T}\left(c^{t} X^{t}+h^{\prime} I^{\prime}+\operatorname{cs} X^{t}\right)
$$

Sujeito a:

$$
\begin{array}{ll}
(I-R) X^{t}+I^{(t-1)}-I^{\prime}=d^{t} & t=1, \ldots T, \\
\mathbf{b}^{k} X^{t}+t^{k} \mathbf{Y}^{\prime} \leq \mathrm{CAP}_{\mathrm{tk}} & \mathrm{t}=1, \ldots \mathrm{T}, \mathrm{k}=1, \cdots, \mathrm{K}, \\
\mathbf{X}^{\mathrm{t}}-\mathbf{q} \mathbf{Y}^{\mathrm{t}} \leq \mathbf{0} & \mathrm{t}=1, \ldots \mathrm{T}, \\
\mathbf{X}^{\mathrm{t}} \geq 0, \mathbf{I}^{\mathrm{t}} \geq \mathbf{0}, \quad \mathbf{Y}^{\mathrm{t}}=\{0,1\}^{N} & \mathrm{t}=\mathrm{l}, \ldots \mathrm{T} .
\end{array}
$$

Note que a matriz ( $I-R)$, que definirá adiante a mudança de variável entre o estoque convencional e o estoque de escalão, é uma matriz inversivel (note que: $\operatorname{det}(\mathbf{I}-\mathbf{R})=1$ ):

$$
(I-R)=\left[\begin{array}{ccccc}
1 & 0 & & \cdots & 0 \\
-a_{21} & 1 & & \cdots & 0 \\
-a_{31} & -a_{32} & 1 & \cdots & 0 \\
\vdots & \vdots & \vdots & \ddots & \vdots \\
-a_{N 1} & -a_{N 2} & & \cdots & 1
\end{array}\right]
$$

Observe que os elementos não nulos em cada linha i de $\mathrm{R}$, representam a quantidade de requerimentos necessários do item $i$ para produção dos itens sucessores $\left(a_{i j} \neq 0\right.$, se 
$\mathrm{j} \in \mathrm{S}(\mathrm{i})$ ). E, cada coluna $\mathrm{j}$ de $\mathrm{R}$ representa a quantidade de requerimentos necessários para a produção do item $j\left(a_{i j} \neq 0\right.$, se $\left.i \in P(j)\right)$.

Assim, $\sum_{i \in P(j)} a_{i j} y_{i}$ é o j-ésimo elemento do vetor-linha $\mathbf{y R}$, ondey $=\left(y_{1}, y_{2}, \cdots, y_{N}\right)$ é um vetor-linha qualquer, enquanto que, $\sum_{\mathbf{j} \in \mathbf{S}(\mathrm{i})} \mathrm{a}_{\mathrm{ij}} z_{\mathrm{j}}$ é o i-ésimo elemento do vetor-coluna $\mathbf{R z}$, onde $z=\left(z_{1}, z_{2}, \cdots, z_{N}\right)$ é um vetor-coluna qualquer.

Uma linha $\mathbf{j}$ de $\mathbf{R}$ será nula se o item $\mathrm{j}$ é um item final, pois não possui itens sucessores e uma coluna será nula se o item não possuir itens predecessores. Pela numeração dos itens na estrutura de produto, as primeiras linhas da matriz $\mathbf{R}$ serão sempre nulas, dependendo naturalmente, da quantidade de itens finais.

Multiplicando a matriz $(\mathrm{I}-\mathrm{R})^{-1}$ a esquerda em ambos lados da equação (A7), segue:

$$
\mathbf{X}^{\prime}+(\mathbf{I}-\mathbf{R})^{-1} \mathbf{I}^{(t-1)}-(\mathbf{I}-\mathbf{R})^{-1} I^{\prime}=(\mathbf{I}-\mathbf{R})^{-1} \mathbf{d}^{\prime} \quad t=1, \ldots T
$$

Definindo-se uma nova variável por:

$$
\mathbf{E}^{\mathrm{t}}=(\mathbf{I}-\mathbf{R})^{-1} \mathbf{I}^{\mathrm{t}}, \quad \mathrm{t}=1, \ldots \mathrm{T}
$$

e um novo vetor de demanda como:

$$
D^{t}=(I-R)^{-1} d^{t} \quad t=1, \ldots T,
$$

a equação de balanceamento de estoque (A7) é equivalentemente escrita por:

$$
X^{t}+E^{t-1}-E^{t}=D^{t} \quad t=1, \ldots T .
$$

A equação (A13) é também equivalente a:

$$
\mathbf{I}^{\mathrm{t}}=(\mathbf{I}-\mathbf{R}) \mathbf{E}^{\mathrm{t}}, \quad \mathrm{t}=1, \ldots \mathrm{T},
$$

isto é,

$$
\begin{aligned}
& {\left[\begin{array}{l}
I_{1 t} \\
I_{2 t} \\
I_{3 t} \\
\vdots \\
I_{N t}
\end{array}\right]=\left(\left[\begin{array}{ccccc}
1 & 0 & 0 & \cdots & 0 \\
0 & 1 & 0 & \cdots & 0 \\
0 & 0 & 1 & \cdots & 0 \\
\vdots & \vdots & \vdots & \ddots & \vdots \\
0 & 0 & 0 & \cdots & 1
\end{array}\right]-\left[\begin{array}{ccccc}
0 & 0 & 0 & \cdots & 0 \\
a_{21} & 0 & 0 & \cdots & 0 \\
a_{31} & a_{32} & 0 & \cdots & 0 \\
\vdots & \vdots & \vdots & \ddots & \vdots \\
a_{n 1} & a_{n 2} & a_{n 3} & \cdots & 0
\end{array}\right]\right)\left[\begin{array}{c}
E_{1 t} \\
E_{2 t} \\
E_{3 t} \\
\vdots \\
E_{N t}
\end{array}\right]} \\
& \underbrace{v_{(I-R)}}_{I^{t}} \underbrace{\underbrace{t}}_{E^{t}}
\end{aligned}
$$

de onde segue que, $\mathrm{I}_{\mathrm{it}}=\mathrm{E}_{\mathrm{it}}$ para todos itens finais (uma vez que as primeiras linhas são linhas da matriz identidade) e, 


$$
I_{i t}=E_{i t}-\sum_{j \in S(i)} a_{i j} E_{i j} \quad i=1, \ldots, N, t=1, \ldots, T
$$

ou,

$$
E_{i t}=I_{i t}+\sum_{j \in S(i)} a_{i j} E_{i j} \quad i=1, \ldots, N, t=1, \ldots, T
$$

o que coincide com a definição de estoque de escalão dada no Capítulo 4, e representa o total de itens do tipo i em estoque no sistema no período t. Note também que os mesmos passos, usando (A14), leva à definição de demanda de escalão, conforme o Capítulo 4:

$$
D_{i t}=d_{i t}+\sum_{j \in S(i)} a_{i j} D_{j t} \quad i=1, \ldots, N, t=1, \ldots, T \text {. }
$$

Note que as novas variáveis de escalâo $E_{i t}$ e a demanda de escalão surgiram naturalmente aqui, a partir de uma manipulação algébrica com as equações de conservação de estoque, que embora simples não seria trivial, não fosse a notação matricial introduzida.

Embora sejam equivalentes a formulações, tanto em estoque convencional $\mathrm{I}_{\mathrm{it}}$ como em

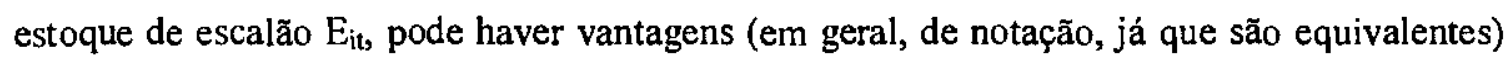
de se trabalhar com uma ou outra formulação. Um atrativo que o estoque de escalão oferece é que as restrições de balanceamento de estoque (A7) passa a ser decomponível por item no estoque de escalão (A15), como se fosse vários problemas monoestágios.

Para escrever um problema equivalente a (A6)-(A10), em termos do estoque de escalão, é necessário ainda analisar a alterações na função objetivo, quando escrita em termos das variáveis $\mathbf{E}^{\mathbf{t}}$. Isto é facilmente obtido, substituindo-se (A16) em (A6). Assim,

$$
\sum_{t=1}^{T}\left(c^{t} X^{t}+h^{t} I^{t}+\operatorname{cs} Y^{t}\right)=\sum_{t=1}^{T}\left(c^{t} X^{t}+h^{t}(I-R) E^{t}+\operatorname{cs} Y^{t}\right)
$$

e definindo-se $\hat{\mathbf{h}}^{\mathrm{t}}=\left[\begin{array}{llll}\hat{\mathrm{h}}_{1 \mathrm{t}} & \hat{\mathrm{h}}_{2 \mathrm{t}} & \cdots & \hat{\mathrm{h}}_{\mathrm{Nt}}\end{array} \mid\right.$, vetor dos custos de estoque de escalão em cada período $t$, segue que

$$
\hat{\mathbf{h}}^{\mathrm{t}}=\mathbf{h}^{\mathrm{t}}(\mathbf{I}-\mathbf{R})
$$

Uma vez mais, desenvolvendo o produto em (A20), a equação que define os custos na formulação em estoque de escalão coincide com a apresentada no Capítulo 4:

$$
\hat{h}_{j t}=h_{j t}-\sum_{i \in P(j)} a_{i j} h_{i t} \quad i=1, \ldots, N, t=1, \ldots, T,
$$


cuja dedução, como encontrada na literatura, requer demasiadas manipulações algébricas.

Além disso, a restrição de não-negatividade de $\mathbf{I}^{\mathbf{t}}$, com (A16) produz:

$$
(\mathbf{I}-\mathbf{R}) \mathbf{E}^{\mathfrak{l}} \geq \mathbf{0} \quad \mathrm{t}=1, \ldots, \mathrm{T} .
$$

A restrição (A21) devolve a interdependência que havia entre as variáveis de produção $\mathrm{X}_{\mathrm{it}}$ em (A7), agora nas variáveis de estoque $\mathrm{E}_{\mathrm{it}}$. $\mathrm{A}$ seguir, o modelo (A6)-(A10) é equivalentemente rescrito em termos do estoque de escalão.

\section{O MODELO REFORMULADO EM TERMOS DE ESTOQUE DE ESCALÃO}

$$
\operatorname{Minimize} \sum_{\mathbf{t}=1}^{T}\left(\mathbf{c}^{\mathbf{t}} \mathbf{X}^{\mathbf{t}}+\hat{\mathbf{h}}^{\mathbf{t}} \mathbf{E}^{\mathrm{t}}+\mathbf{c s} \mathbf{Y}^{\mathbf{t}}\right)
$$

Sujeito a:

$$
\begin{array}{ll}
\mathbf{X}^{\mathrm{t}}+\mathbf{E}^{(\mathrm{t}-1)}-\mathbf{E}^{\prime}=\mathbf{D}^{\mathrm{t}} & \mathrm{t}=1, \ldots \mathrm{T} \\
(\mathbf{I}-\mathbf{R}) \mathbf{E}^{\mathrm{t}} \geq \mathbf{0} & \mathrm{t}=1, \ldots \mathrm{T} \\
\mathbf{b}^{\mathrm{k}} \mathbf{X}^{\mathrm{t}}+\mathbf{t s}^{\mathrm{k}} \mathbf{Y}^{\prime} \leq \mathbf{C A P _ { \mathrm { tk } }} & \mathrm{t}=1, \ldots \mathrm{T}, \mathrm{k}=1, \cdots, \mathrm{K} \\
\mathbf{X}^{\mathrm{t}}-\mathrm{q} \mathbf{Y}^{\mathrm{t}} \leq \mathbf{0} & \mathrm{t}=1, \ldots \mathrm{T} \\
\mathbf{X}^{\mathrm{t}} \geq \mathbf{0}, \mathbf{E}^{\mathrm{t}} \geq \mathbf{0}, \quad \mathbf{Y}^{\mathrm{t}}=\{0,1\}^{\mathrm{N}} & \mathrm{t}=1, \ldots \mathrm{T} .
\end{array}
$$

\section{REFORMULAÇÃO SEM AS VARIÁVEIS DE ESTOQUE}

Tempelmeier e Derstroff (1996) rescreveram o modelo (A6)-(A10), eliminando as variáveis de estoque para aplicar a relaxação Lagrangiana, que será objeto de estudo do Apêndice $B$, onde será mostrada a equivalência com uma abordagem alternativa, baseada na formulação de estoque de escalão.

Por simplicidade de exposição, considere $\mathrm{T}=2$ e $\mathrm{K}=1$ no modelo (A6)-(A10), o qual pode ser escrito da seguinte forma (a extensão para o caso geral é direta):

$$
\text { Minimize } c^{1} \mathbf{X}^{1}+\mathbf{c}^{2} \mathbf{X}^{2}+\mathbf{h}^{1} \mathbf{I}^{1}+\mathbf{h}^{2} \mathbf{I}^{2}+\mathbf{c s} \mathbf{Y}^{1}+\mathbf{c s} \mathbf{Y}^{2}
$$

Sujeito a: 


$$
\begin{aligned}
& {\left[\begin{array}{cc}
(I-R) & 0 \\
0 & (I-R)
\end{array}\right]\left[\begin{array}{l}
X^{1} \\
X^{2}
\end{array}\right]-\left[\begin{array}{cc}
I & 0 \\
-I & I
\end{array}\right]\left[\begin{array}{l}
I^{1} \\
I^{2}
\end{array}\right]=\left[\begin{array}{l}
d^{1} \\
d^{2}
\end{array}\right]} \\
& b^{1} X^{1}+t^{1} Y^{1} \leq C A P_{11} \\
& b^{1} X^{2}+t^{1} Y^{2} \leq C A P_{21} \\
& X^{1}-q Y^{1} \leq 0 \\
& X^{2}-q Y^{2} \leq 0 \\
& X^{1} \geq 0, \quad X^{2} \geq 0, Y^{1}=\{0,1\}^{N}, Y^{2}=\{0,1\}^{N} \\
& I^{1} \geq 0, I^{2} \geq 0 .
\end{aligned}
$$

Note que a matriz coeficiente das variáveis de estoque tem inversa dada por:

$$
\left[\begin{array}{cc}
I & 0 \\
-I & I
\end{array}\right]^{-1}=\left[\begin{array}{ll}
I & 0 \\
I & I
\end{array}\right]
$$

Multiplicando ambos os termos da equação (A29) por esta inversa, segue:

$$
\left[\begin{array}{ll}
I & 0 \\
I & I
\end{array}\right]\left[\begin{array}{cc}
(I-R) & 0 \\
0 & (I-R)
\end{array}\right]\left[\begin{array}{l}
X^{1} \\
X^{2}
\end{array}\right]-\left[\begin{array}{l}
I^{1} \\
I^{2}
\end{array}\right]=\left[\begin{array}{ll}
I & 0 \\
I & I
\end{array}\right]\left[\begin{array}{l}
d^{1} \\
d^{2}
\end{array}\right]
$$

ou,

$$
\left[\begin{array}{l}
I^{1} \\
I^{2}
\end{array}\right]=\left[\begin{array}{cc}
(I-R) & 0 \\
(I-R) & (I-R)
\end{array}\right]\left[\begin{array}{l}
X^{1} \\
X^{2}
\end{array}\right]-\left[\begin{array}{l}
d^{1} \\
d^{1}+d^{2}
\end{array}\right]
$$

Devido a não-negatividade das variáveis de estoque $\mathbf{I}^{\mathbf{t}} \geq \mathbf{0},(\mathrm{A} 36)$ é equivalente a:

$(\mathrm{I}-\mathrm{R}) \mathrm{X}^{1} \geq \mathrm{d}^{1}$

$(I-R) X^{1}+(I-R) X^{2} \geq d^{1}+d^{2}$.

Além disso, as variáveis $\mathrm{I}^{\mathrm{t}}$ podem ser eliminadas da função objetivo, substituindo-se (A36) em (A28):

$$
c^{1} X^{1}+c^{2} X^{2}+h^{1}\left((I-R) X^{1}-d^{1}\right)+h^{2}\left((I-R) X^{1}+(I-R) X^{2}-d^{1}-d^{2}\right)+\operatorname{cs} Y^{1}+\operatorname{cs} Y^{2} .
$$

Desta forma, o modelo (A28)-(A35) é equivalentemente rescrito por:

$\operatorname{Min}\left(c^{1}+\left(h^{1}+h^{2}\right)(I-R)\right) X^{1}+\left(c^{2}+h^{2}(I-R)\right) X^{2}-\left(h^{1}+h^{2}\right) d^{1}-h^{2} d^{2}+c s Y^{1}+c s Y^{2}$ 
Sujeito a:

$$
\begin{aligned}
& (I-R) X^{1} \geq d^{1} \\
& (I-R)\left(X^{1}+X^{2}\right) \geq d^{1}+d^{2} \\
& b^{1} X^{1}+t^{1} Y^{1} \leq C A P_{11} \\
& b^{1} X^{2}+t^{1} Y^{2} \leq C A P \\
& 21 \\
& X^{1}-q Y^{1} \leq 0 \\
& X^{2}-q Y^{2} \leq 0 \\
& X^{1} \geq 0, \quad X^{2} \geq 0, \quad Y^{1}=\{0,1\}^{N}, Y^{2}=\{0,1\}^{N} .
\end{aligned}
$$

Observe que as restrições (A35) e (A36) são equivalentes a (A38) e (A39). Entretanto, (A38) e (A39) não são equivalentes a (veja (A14)):

$$
\begin{aligned}
& \mathbf{X}^{1} \geq(I-R)^{-1} d^{1}=D^{1} \\
& X^{1}+X^{2} \geq(I-R)^{-1}\left(d^{1}+d^{2}\right)=D^{1}+D^{2},
\end{aligned}
$$

uma vez que a propriedade de não-negatividade das variáveis de estoque não é recíproca, isto é, apesar da não-negatividade do estoque convencional levar à não-negatividade do estoque de escalão, a recíproca não é válida. As restrições (A45) e (A46) poderiam ser deduzidas erroneamente a partir de (A36), da seguinte maneira: multiplicando-se cada equação em (A36) por (I-R) ${ }^{-1}$ e usando (A13), segue:

$$
\begin{aligned}
& \mathbf{E}^{1}=(I-R)^{-1} I^{1}=X^{1}-(I-R)^{-1} d^{1} \\
& E^{2}=(I-R)^{-1} I^{1}=X^{1}+X^{2}-(I-R)^{-1}\left(d^{1}+d^{2}\right),
\end{aligned}
$$

Agora, pressupondo erroneamente que $E^{\mathfrak{l}} \geq 0$ se e somente se $I^{t} \geq 0$, então (A45) e (A46) seriam equivalentes a (A38) e (A39). De outra forma, (A45) e (A46) garantem que $\mathbf{E}^{\mathfrak{t} \geq 0}$ (definido por (A47) e (A48)), porém, $I^{\mathbf{t} \geq 0}$ não necessariamente será satisfeita.

O exemplo seguinte ilustra a afirmaçāo acima. Considere um problema com $\mathrm{N}=3$ itens e estrutura de produtos serial, $a_{i j}=1$, e o horizonte de planejamento $\mathrm{T}=2$ períodos :

Tabela A1. Demandas por período.

\begin{tabular}{|c|c|c|}
\hline Item & $\mathbf{t}=\mathbf{1}$ & $\mathbf{t}=\mathbf{2}$ \\
\hline 1 & 10 & 10 \\
\hline 2 & 10 & 10 \\
\hline 3 & 10 & 10 \\
\hline
\end{tabular}

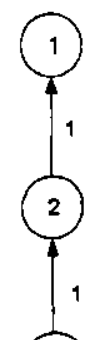

182 
Tabela A2. Demandas de escalão por período.

\begin{tabular}{|l|l|l|}
\hline Item & $t=1$ & $t=2$ \\
\hline 1 & 10 & 10 \\
\hline 2 & 20 & 20 \\
\hline 3 & 30 & 30 \\
\hline
\end{tabular}

Observe que o plano de produção dado na Tabela A3 satisfaz as restrições (A45) e (A46). Entretanto, ao considerar as restrições de balanço nos estoques convencionais, por exemplo: $X_{21}+I_{20}=d_{21}+X_{11}+I_{21},\left(I_{20}=0\right)$ do que segue: $I_{21}=-10$. Portanto, as restrições (A45) e (A46) garantem somente que o estoque de escalão seja não-negativo, mas os níveis de estoques convencionais podem ser negativos. De outra forma,

$$
\mathbf{E}^{1}=\mathbf{X}^{1}-\mathbf{D}^{1}=\left(\begin{array}{l}
20 \\
20 \\
30
\end{array}\right)-\left(\begin{array}{c}
10 \\
20 \\
30
\end{array}\right)=\left(\begin{array}{l}
10 \\
0 \\
0
\end{array}\right),
$$

logo:

$$
I^{1}=(I-R) E^{1}=\left(\begin{array}{ccc}
1 & 0 & 0 \\
-1 & 1 & 0 \\
0 & -1 & 1
\end{array}\right)\left(\begin{array}{l}
10 \\
0 \\
0
\end{array}\right)=\left(\begin{array}{c}
10 \\
-10 \\
0
\end{array}\right) \text { e, portanto, } I_{21}=-10
$$

A3.Tabela com uma solução do exemplo $\left(\mathrm{X}_{\mathrm{t1}}\right)$.

\begin{tabular}{|l|l|l|}
\hline Item & $\mathbf{t = 1}$ & $\mathbf{t = 2}$ \\
\hline 1 & 20 & 0 \\
\hline 2 & 20 & 20 \\
\hline 3 & 30 & 30 \\
\hline
\end{tabular}

Por outro lado, considere $E_{i t}=I_{i t}+\sum_{j \in S(i)} a_{i j} E_{j t}$ e $I_{i t} \geq 0, i=1, \ldots, N, t=1, \cdots, T$. Se o item i é um item final, então $E_{i t}=I_{i t}$, pois $S(i)=\varnothing$. Assim, $E_{i t} \geq 0$, para todo item final. Suponha agora que $E_{j t} \geq 0$, para todo $j$ pertencente aos níveis $0,1, \ldots, L-1$ de uma estrutura de produtos e que $E_{i t}$ esteja no nível L. Assim, $E_{i t}=I_{i t}+\sum_{j \in S(i)} a_{i j} E_{j t}$ é uma soma de termos 
não-negativos, uma vez que $E_{j t}$ está num nível menor que $L$. Consequentemente $E_{i t} \geq 0$. Isto mostra a seguinte propriedade.

Propriedade. Sejam $\mathbf{I}^{\mathrm{t}}$ e $\mathbf{E}^{\mathrm{t}}$ relacionados por (A13) e (A16). Então, se $\mathrm{I}^{\mathrm{t}} \geq 0$ segue que $\mathbf{E}^{\mathbf{t}} \geq \mathbf{0}$. No entanto, $\mathbf{E}^{\mathbf{t}} \geq \mathbf{0}$ não garante que $\mathbf{I}^{\mathbf{t}} \geq \mathbf{0}$. 


\title{
APÊNDICE B
}

\author{
Abordagens Equivalentes: Relaxação Lagrangiana \\ Baseada na Formulação em Termos de Estoque \\ Convencional versus Relaxação Lagrangiana Baseada na \\ Formulação em Termos de Estoques de Escalão
}

\section{Introdução}

Utilizando a notação e as relações entre as formulações do problema de dimensionamento de lotes apresentadas no Apêndice A, é mostrado, neste apêndice, a equivalência da relaxação Lagrangiana do modelo formulado em termos de estoque convencional e de escalão.

Primeiramente será feita a relaxação do modelo usando a formulação equivalente sem as variáveis de estoque (A37)-(A44), conforme Tempelmeier e Derstroff (1996) e, em seguida, a relaxação usando a formulação equivalente em termos do estoque de escalão. Por fim, será mostrada a equivalência das duas abordagens.

\section{Relaxação do Modelo Reformulado sem as variáveis de Estoque}

Considere a reformulação equivalente do problema de dimensionamento de lotes sem as variáveis de estoque $((\mathrm{A}(37)-(\mathrm{A} 44))$ : 
$\operatorname{Min}\left(c^{1}+\left(h^{1}+h^{2}\right)(I-R)\right) X^{1}+\left(c^{2}+h^{2}(I-R)\right) X^{2}-\left(h^{1}+h^{2}\right) d^{1}-h^{2} d^{2}+c s Y^{1}+c s X^{2}$

Sujeito a:

$$
\begin{aligned}
& (I-R) X^{1} \geq d^{1} \\
& (I-R)\left(X^{1}+X^{2}\right) \geq d^{1}+d^{2} \\
& b^{1} X^{1}+\mathbf{t s}^{1} Y^{1} \leq \mathrm{CAP}_{11} \\
& \mathbf{b}^{1} \mathbf{X}^{2}+\mathbf{t s}^{1} \mathbf{X}^{2} \leq \mathrm{CAP}_{21} \\
& \mathbf{X}^{1}-q \mathbf{Y}^{1} \leq \mathbf{0} \\
& \mathbf{X}^{2}-q \mathbf{Y}^{2} \leq \mathbf{0} \\
& \mathbf{X}^{1} \geq \mathbf{0}, \quad \mathbf{X}^{2} \geq \mathbf{0} \quad \mathbf{Y}^{1}=\{0,1\}^{\mathrm{N}}, \mathbf{Y}^{2}=\{0,1\}^{\mathrm{N}}
\end{aligned}
$$

Considere $v^{1} \geq 0$ e $v^{2} \geq 0$, os vetores multiplicadores de Lagrange associados às restrições (B2) e (B3). Considere também $\mu_{11} \geq 0$ e $\mu_{21} \geq 0$, os vetores multiplicadores associados às restriçōes (B4) e (B5). O problema Lagrangiano é então definido por:

$$
\begin{aligned}
& \operatorname{Min}\left(c^{1}+\left(\mathbf{h}^{1}+\mathbf{h}^{2}\right)(I-R)\right) \mathbf{X}^{1}+\left(\mathbf{c}^{2}+\mathbf{h}^{2}(\mathbf{I}-\mathbf{R})\right) \mathbf{X}^{2}-\left(\mathbf{h}^{1}+\mathbf{h}^{2}\right) \mathbf{d}^{1}-\mathbf{h}^{2} \mathbf{d}^{2}+\mathbf{c s} \mathbf{Y}^{1}+\mathbf{c s} \mathbf{Y}^{2}+ \\
& -v^{1}\left((\mathbf{I}-\mathbf{R}) \mathbf{X}^{1}-\mathbf{d}^{1}\right)-v^{2}\left((\mathbf{I}-\mathbf{R}) \mathbf{X}^{1}+(\mathbf{I}-\mathbf{R}) \mathbf{X}^{2}-\mathbf{d}^{1}-\mathbf{d}^{2}\right)+\mu_{11}\left(\mathbf{b}^{1} \mathbf{X}^{1}+\mathbf{t s}^{1} \mathbf{Y}^{1}-\mathrm{CAP}_{11}\right)+ \\
& +\mu_{21}\left(\mathbf{b}^{1} \mathbf{X}^{2}+\mathrm{ts}^{1} \mathbf{Y}^{2}-\mathrm{CAP}_{21}\right)
\end{aligned}
$$

Sujeito a:

$$
\begin{aligned}
& \mathbf{X}^{1}-q \mathbf{Y}^{1} \leq 0 \\
& \mathbf{X}^{2}-q \mathbf{Y}^{2} \leq 0 \\
& \mathbf{X}^{1} \geq \mathbf{0}, \mathbf{X}^{2} \geq 0, \quad \mathbf{Y}^{1}=\{0,1\}^{\mathrm{N}}, \mathbf{Y}^{2}=\{0,1\}^{\mathrm{N}}
\end{aligned}
$$

Tempelmeier e Derstroff (1996) consideraram este problema demasiadamente relaxado para produzir bons limitantes e incluíram as restrições (B11) e (B12) com o objetivo de garantir estoques não-negativos, já que as condições de não-negatividade das variáveis de estoque foram relaxadas (restrições (B2) e (B3)). No entanto, como demonstrado no Apêndice $A$, as restrições (B11) e (Bl2) garantem somente a não-negatividade dos estoques de escalão, 
o que não implica que os estoques convencionais sejam não-negativos. Estas observações não invalidam o referido trabalho, pois para toda solução factível tem-se que $I^{\mathbf{t}} \geq \mathbf{0}$, o que implica $\mathbf{E}^{\mathbf{t}} \geq \mathbf{0}$, de modo que as restrições adicionadas não excluem qualquer solução factível. A rigor, para se ter a não-negatividade das variáveis de estoque convencionais, isto é: $I^{\mathfrak{t}} \geq \mathbf{0}$, dever-seia ser incluído a restrição: (I-R) $\mathbf{E}^{\dagger} \geq 0$ (veja (A16)). Porém, esta restrição introduziria dificuldades na resolução do problema Lagrangiano abaixo.

$$
\begin{aligned}
\operatorname{Min} & \left(\mathbf{c}^{1}+\left(\mathbf{h}^{1}+\mathbf{h}^{2}\right)(\mathbf{I}-\mathbf{R})-\left(\mathbf{v}^{1}+\mathbf{v}^{2}\right)(\mathbf{I}-\mathbf{R})+\mu_{11} \mathbf{b}^{1}\right) \mathbf{X}^{1}+ \\
& \left(\mathbf{c}^{2}+\mathbf{b}^{2}(\mathbf{I}-\mathbf{R})-v^{2}(\mathbf{I}-\mathbf{R})+\mu_{21} \mathbf{b}^{1}\right) \mathbf{X}^{2}+\left(\mathbf{c s}+\mu_{11} \mathbf{t s}^{1}\right) \mathbf{Y}^{1}+\left(\mathbf{c s}+\mu_{21} \mathbf{t s}^{2}\right) \mathbf{Y}^{2}+ \\
& -\left(\mathbf{h}^{1}+\mathbf{h}^{2}\right) \mathbf{d}^{1}-\mathbf{h}^{2} \mathbf{d}^{2}+\left(\mathbf{v}^{1}+v^{2}\right) \mathbf{d}^{1}+\mathbf{v}^{2} \mathbf{d}^{2}-\mu_{11} \mathrm{CAP}_{11}-\mu_{21} \mathrm{CAP}_{21}
\end{aligned}
$$

Sujeito a:

$$
\begin{aligned}
& X^{1} \geq(I-R)^{-1} d^{1} \\
& X^{1}+X^{2} \geq(I-R)^{-1}\left(d^{1}+d^{2}\right) \\
& X^{1}-q Y^{1} \leq 0 \\
& X^{2}-q Y^{2} \leq 0 \\
& X^{1} \geq 0, \quad X^{2} \geq 0 \quad Y^{1}=\{0,1\}^{N}, Y^{2}=\{0,1\}^{N}
\end{aligned}
$$

Observe que este problema pode ser decomposto em $\mathrm{N}$ subproblemas com um único item, os quais podem ser resolvidos otimamente pelo algoritmo de Wagner e Whitin (Wagner e Whitin, 1958). Em outras palavras, os autores lançaram mão do estoque de escalão para desacoplar as variáveis de produção. Além disso, utilizam o método do subgradiente para maximização da função dual (dada pelo valor ótimo de (B10)), onde os subgradientes são determinados da seguinte maneira:

- Componentes do subgradiente relacionadas às restrições de balanço de estoques.

$$
\left(\begin{array}{l}
(I-R) X^{1}-d^{1} \\
(I-R) X^{1}+(I-R) X^{2}-d^{1}-d^{2}
\end{array}\right) \text {, que, por (A36), é igual a }\left(\begin{array}{l}
I^{1} \\
I^{2}
\end{array}\right)
$$

- Componentes do subgradiente relacionadas às restrições de capacidades.

$$
\left(\begin{array}{l}
B^{1} X^{1}+t s^{1} Y^{1}-C_{A P} \\
B^{1} X^{2}+t s^{1} Y^{2}-C^{2}
\end{array}\right)
$$




\section{Relaxação do Modelo Reformulado em Termos de Estoque de Escalão}

Considere o modelo (A22)-(A27) e, por simplicidade de exposição, $T=2$ e $K=1$. Considere também o vetor $\lambda^{t} \geq \mathbf{0}$, o vetor multiplicador de Lagrange associado às restrições (A24) e $\mu_{t} \geq 0$ o vetor multiplicador de Lagrange associado às restrições (A25).

O problema Lagrangiano é dado abaixo:

$\operatorname{Min} c^{1} \mathbf{X}^{1}+\mathbf{c}^{2} \mathbf{X}^{2}+\hat{\mathbf{h}}^{\mathrm{l}} \mathbf{E}^{1}+\hat{\mathbf{h}}^{2} \mathbf{E}^{2}+\mathrm{cs} \mathbf{Y}^{1}+\mathrm{cs} \mathbf{Y}^{2}-\lambda^{1}(\mathbf{I}-\mathbf{R}) \mathbf{E}^{1}-\lambda^{2}(\mathbf{I}-\mathbf{R}) \mathbf{E}^{2}+$

$$
\mu_{1}\left(\mathbf{b}^{1} \mathbf{X}^{1}+\mathbf{t s}^{1} \mathbf{Y}^{1}-\mathrm{CAP}_{11}\right)+\mu_{2}\left(\mathbf{b}^{1} \mathbf{X}^{2}+\mathbf{t s}^{1} \mathbf{Y}^{2}-\mathrm{CAP}_{2 \mathrm{I}}\right)
$$

Sujeito a:

$$
\begin{aligned}
& \mathbf{X}^{1}-\mathbf{E}^{1}=\mathbf{D}^{1}\left(=(I-R)^{-1} \mathbf{d}^{1}\right) \\
& \mathbf{X}^{2}+\mathbf{E}^{1}-\mathbf{E}^{2}=\mathbf{D}^{2} \quad\left(=(I-R)^{-1} \mathbf{d}^{2}\right) \\
& \mathbf{X}^{1}-q \mathbf{Y}^{1} \leq \mathbf{0} \\
& \mathbf{X}^{2}-q \mathbf{Y}^{2} \leq \mathbf{0} \\
& \mathbf{X}^{1} \geq \mathbf{0}, \quad \mathbf{X}^{2} \geq \mathbf{0} \quad \mathbf{Y}^{1}=\{0,1\}^{N}, \mathbf{Y}^{2}=\{0,1\}^{\mathrm{N}} \\
& \mathbf{E}^{1} \geq 0, \mathbf{E}^{2} \geq 0 .
\end{aligned}
$$

Considerando novamente as restrições (B19) e (B20), porém adicionando-se (B19) a (B20), obtém-se:

$$
\begin{aligned}
& \mathbf{X}^{1}-\mathbf{E}^{1}=\mathbf{D}^{1} \\
& \mathbf{X}^{1}+\mathbf{X}^{2}-\mathbf{E}^{2}=\mathbf{D}^{1}+\mathbf{D}^{2} .
\end{aligned}
$$

De (B24), segue:

$$
\begin{aligned}
& \mathbf{X}^{1} \geq \mathbf{D}^{1} \\
& \mathbf{X}^{1}+\mathbf{X}^{2} \geq \mathbf{D}^{1}+\mathbf{D}^{2},
\end{aligned}
$$

que são equivalentes às restrições $(\mathrm{B} 11)$ e $(\mathrm{B}(12)$, que foram introduzidas por Tempelmeier $\mathrm{e}$ Derstroff (1996) com o objetivo de garantir a não-negatividade dos estoques. Considerando os termos relacionados às variáveis de estoque e produção na função objetivo (B18) e, substituindo-se as expressões $\mathbf{E}^{\mathrm{t}}=(\mathbf{I}-\mathbf{R})^{-1} \mathbf{I}^{\mathrm{t}}$ e $\hat{\mathbf{h}}^{\mathrm{t}}=\mathbf{h}^{\mathrm{t}}(\mathbf{I}-\mathbf{R})$, na função objetivo, segue: 


$$
\begin{aligned}
\mathbf{c}^{1} \mathbf{X}^{1}+ & \mathbf{c}^{2} \mathbf{X}^{2}+\hat{\mathbf{h}}^{1}(\mathbf{I}-\mathbf{R})^{-1} \mathbf{I}^{1}+\hat{\mathbf{h}}^{2}(\mathbf{I}-\mathbf{R})^{-1} \mathbf{I}^{2}-\lambda^{1}(\mathbf{I}-\mathbf{R})(\mathbf{I}-\mathbf{R})^{-1} \mathbf{I}^{1} \\
& -\lambda^{2}(\mathbf{I}-\mathbf{R})(\mathbf{I}-\mathbf{R})^{-1} I^{2} \\
& =c^{1} \mathbf{X}^{1}+c^{2} \mathbf{X}^{2}+\mathbf{h}^{1} I^{1}+\mathbf{h}^{2} \mathbf{I}^{2}-\lambda^{1} I^{1}-\lambda^{2} \mathbf{I}^{2}
\end{aligned}
$$

Substituindo-se ainda a relação (A36) para eliminar as variáveis de estoque, tem-se:

$$
\begin{aligned}
c^{1} X^{1}+c^{2} X^{2}+h^{1}((I-R) & \left.X^{1}-d^{1}\right)+h^{2}\left((I-R)\left(X^{1}+X^{2}\right)-d^{1}-d^{2}\right)+ \\
& -\lambda^{1}\left((I-R) X^{1}-d^{1}\right)-\lambda^{2}\left((I-R)\left(X^{1}+X^{2}\right)-d^{1}-d^{2}\right)
\end{aligned}
$$

Reorganizando-se os termos da função objetivo acima, que o problema Lagrangiano (B18)-(B24) é equivalente a:

$$
\begin{gathered}
\operatorname{Min}\left(\mathbf{c}^{1}+\left(\mathbf{h}^{1}+\mathbf{h}^{2}\right)(\mathbf{I}-\mathbf{R})-\left(\lambda^{1}+\lambda^{2}\right)(\mathbf{I}-\mathbf{R})+\mu_{11} \mathbf{b}^{1}\right) \mathbf{X}^{1}+ \\
\left(\mathbf{c}^{2}+\mathbf{h}^{2}(\mathbf{I}-\mathbf{R})-\lambda^{2}(\mathbf{I}-\mathbf{R})+\mu_{21} \mathbf{b}^{1}\right) \mathbf{X}^{2}+\left(\mathbf{c s}+\mu_{11} \mathbf{t s}^{1}\right) \mathbf{Y}^{1}+\left(\mathbf{c s}+\mu_{21} \mathbf{t s}^{2}\right) \mathbf{Y}^{2}+\ldots \\
\quad-\left(\mathbf{h}^{1}+\mathbf{h}^{2}\right) \mathbf{d}^{1}-\mathbf{h}^{2} \mathbf{d}^{2}+\left(\lambda^{1}+\lambda^{2}\right) \mathbf{d}^{1}+\lambda^{2} \mathbf{d}^{2}-\mu_{11} \mathrm{CAP}_{11}-\mu_{21} \mathrm{CAP}_{21}
\end{gathered}
$$

Sujeito a:

$$
\begin{aligned}
& \mathbf{X}^{1} \geq \mathrm{D}^{1} \\
& \mathbf{X}^{1}+\mathbf{X}^{2} \geq \mathrm{D}^{1}+\mathrm{D}^{2} \\
& \mathbf{X}^{\mathbf{1}}-q \mathbf{Y}^{1} \leq \mathbf{0} \\
& \mathbf{X}^{2}-q \mathbf{Y}^{2} \leq \mathbf{0} \\
& \mathbf{X}^{1} \geq \mathbf{0}, \quad \mathbf{X}^{2} \geq \mathbf{0} \quad \mathbf{Y}^{1}=\{0,1\}^{N}, \mathbf{Y}^{2}=\{0,1\}^{N}
\end{aligned}
$$

Observe também que este problema pode ser decomposto em $N$ subproblemas com um único item e resolvido otimamente pelo algoritmo de Wagner e Whitin. Também, os subgradientes são determinados da seguinte maneira:

- Componentes do subgradiente relacionados às restrições de balanço de estoques:

$$
\left(\begin{array}{l}
(\mathbf{I}-\mathbf{R}) \mathrm{E}^{1} \\
(\mathrm{I}-\mathbf{R}) \mathrm{E}^{2}
\end{array}\right) \text { que, por (A16), é igual a: }\left(\begin{array}{l}
\mathbf{I}^{1} \\
\mathrm{I}^{2}
\end{array}\right)
$$




$$
\because \text { :Cr's MATr. }
$$

- Componentes do subgradiente relaumadus ds . . ind es de capacidades.

$$
\left(\begin{array}{l}
B^{1} X^{1}+t s^{1} Y^{1}-C A P_{11} \\
B^{1} X^{2}+t s^{1} Y^{2}-C A P_{21}
\end{array}\right)
$$

De onde pode-se concluir que o subgradiente dado por (B32) e (B33), obtido a partir da formulação do problema em termos de estoque de escalão, é idêntico ao subgradiente (B25) e (B26), obtido para o problema formulado sem as variáveis de estoque. As funções objetivos também são iguais, pois os multiplicadores duais são atualizados da mesma maneira. Portanto, pode-se concluir que os limitantes fornecidos por ambas relaxações são os mesmos, ou as abordagens são equivalentes.

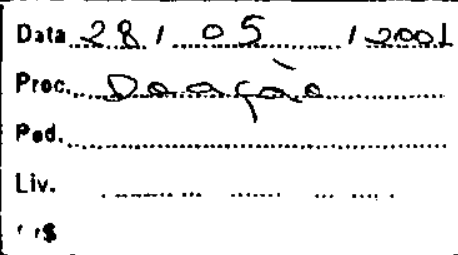

